\title{
Physical and chemical properties of clastic sediments from two caves in the northern karst region of Puerto Rico
}

\author{
Autum R. Downey \\ West Virginia University, ardowney@mix.wvu.edu
}

Follow this and additional works at: https://researchrepository.wvu.edu/etd

Part of the Geochemistry Commons, Geology Commons, and the Sedimentology Commons

\section{Recommended Citation}

Downey, Autum R., "Physical and chemical properties of clastic sediments from two caves in the northern karst region of Puerto Rico" (2020). Graduate Theses, Dissertations, and Problem Reports. 7716.

https://researchrepository.wvu.edu/etd/7716

This Thesis is protected by copyright and/or related rights. It has been brought to you by the The Research Repository @ WVU with permission from the rights-holder(s). You are free to use this Thesis in any way that is permitted by the copyright and related rights legislation that applies to your use. For other uses you must obtain permission from the rights-holder(s) directly, unless additional rights are indicated by a Creative Commons license in the record and/ or on the work itself. This Thesis has been accepted for inclusion in WVU Graduate Theses, Dissertations, and Problem Reports collection by an authorized administrator of The Research Repository @ WVU. For more information, please contact researchrepository@mail.wvu.edu. 
Physical and chemical properties of clastic sediments from two caves in the northern karst region of Puerto Rico

\author{
Autum Rae Downey \\ Thesis submitted \\ to the Eberly College of Arts and Sciences \\ at West Virginia University \\ in partial fulfillment of the requirements for the degree of \\ Master of Science in \\ Geology
}

\author{
Dorothy Vesper, Ph. D., Chair \\ Kathleen Benison, Ph. D. \\ Louis McDonald, Ph. D. \\ Department of Geology and Geography
}

Morgantown, West Virginia

2020

Keywords: cave sediment, Puerto Rico, karst, geochemistry, X-ray fluorescence, fluorescence spectroscopy, PARAFAC, EEM, organic matter, trace elements Copyright 2020 Autum Downey 


\title{
ABSTRACT \\ Physical and chemical properties of clastic sediments from two caves in the northern karst region of Puerto Rico
}

\begin{abstract}
Autum Rae Downey
Geochemical properties and organic characteristics are essential to understanding the general depositional dynamics of a cave. Most work on clastic cave sediments focuses on physical properties of sediments. Little work has been done on bulk organic matter and geochemical properties.

This project reports physical and geochemical characterization of cave sediments from two caves in the northern karst region of Puerto Rico: El Tallonal Cave and Cueva Clara. Core and grab samples were collected and analyzed for particle size, total organic carbon, total nitrogen, organic matter characteristics using fluorescence spectroscopy, and major and minor elements using X-ray fluorescence (XRF). The sediments were poorly to extremely poorly sorted despite being seemingly homogeneous. Sand- and silt-sized grains composed most of the sediments from both locations. Within El Tallonal Cave, differences in organic chemical properties between saturated and unsaturated sediments were observed. The maximum value of total organic carbon, total nitrogen, and organic $\mathrm{C} / \mathrm{N}$ ratios were higher, and the range was greater in saturated sediments. A three-component parallel factor analysis (PARAFAC) model was created using collected excitation-emission matrices on organic matter extracted from the sediments. All three modeled components were humic acid-like. Proportions of the modeled components differ between saturated and unsaturated sediments. Elemental concentrations collected using XRF on El Tallonal Cave sediments revealed that Al and Si are negatively correlated, suggesting that clay minerals and quartz occur together resulting in Si dominating in those sediments. Trace elements $(\mathrm{Cr}, \mathrm{Mn}, \mathrm{Co}, \mathrm{Ni}, \mathrm{As}, \mathrm{Rb}$, and $\mathrm{Nb}$ ) correlated positively with $\mathrm{Ti}$, implying these elements are sourced from the same parent material. Correlations between Fe, Al, and Mn with P, Co, and As suggest that sorption or co-precipitation with Fe, Al, and Mn oxides is a possible retention mechanism within El Tallonal Cave sediments. No relationship between grain size and geochemical properties was observed. Preliminary comparison with soil and bedrock from the Luqillo Mountains located within the central highlands of Puerto Ricop show similar concentrations of Ti and Zr within El Tallonal Cave sediments suggesting these elements are conservative during transport.

Results of this thesis show that sediment deposition and chemistry in individual caves are complex natural systems. Heterogeneity among cores within single caves was observed. Future studies are needed to better understand the differences observed in saturated and unsaturated sediments, as well as to further explore the mechanisms controlling the geochemical trends observed in cave sediments.
\end{abstract}




\section{Acknowledgements}

This project was supported by the The Puerto Rico Testsite for Exploring Contamination Threats (PROTECT) Program (award number P42ES017198), a project funded by the National Institute of Environmental Health Sciences' Superfund Research Program. Additional support was provided by the WVU department of Geology and Geography and the Geological Society of America. I'd like to offer an extended thank you to the University of Puerto Rico and associated researchers Dr. Ingrid Padilla and Ángel A. Acosta-Colón for their field support and logistical planning. Additional thanks to Dr. Ellen Herman, Dr. Brian Smith, Omar Rodriguez, Tatiana Rosado, Laura Rodriguez, and Jill Riddell for their field assistance. An extended thank you to Abel Vale, the Ciudadanos Del Karso (the Citizens of Karst), and the National Parks Company of the Commonwealth of Puerto Rico for cave access. Several people were involved in the lab work completed for this project. Thanks to Annie Simpson, Jill Riddell, and Matt Bell for lab assistance. Extra support was provided by Evan Kipnis and Dr. Brenda Bowen at the University of Utah for XRF instrument time and calibrations. I would also like to thank Dr. Kathleen Benison and Dr. Louis McDonald for their input and guidance during this project. Special gratitude is extended to my advisor and mentor Dr. Dorothy Vesper whose guidance through both my undergraduate and graduate degree has kept me ever curious. Her counsel has - and will continue to - shape me as a researcher. Additionally, I'd like to thank Jill Riddell and Matt Bell for our mobile office work sessions and valuable scientific insight. Finally, I'd like to thank C + $\mathrm{C}$ and my family for their constant support. 


\section{Table of Contents}

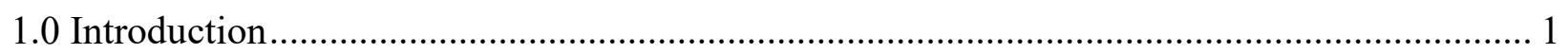

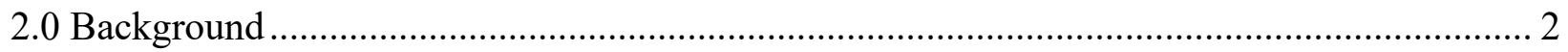

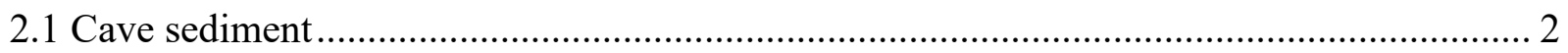

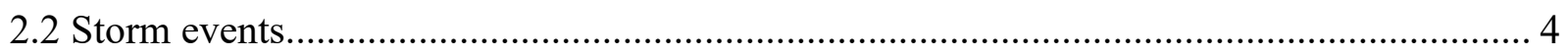

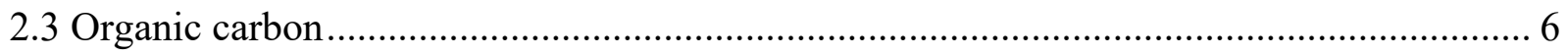

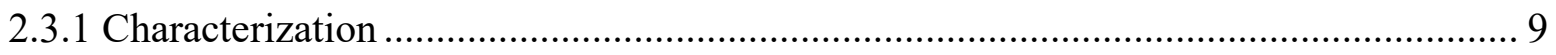

2.3.2 Organic carbon in cave systems.......................................................................... 10

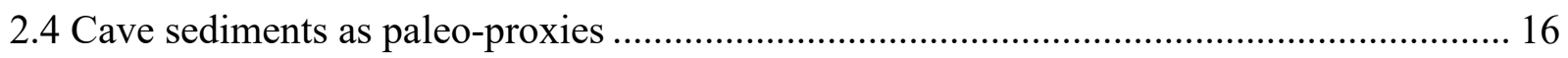

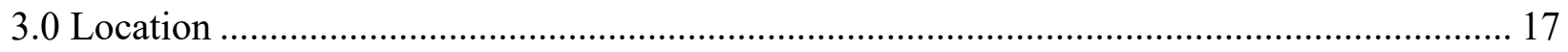

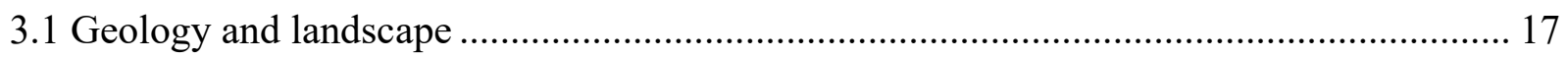

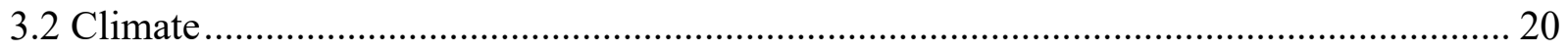

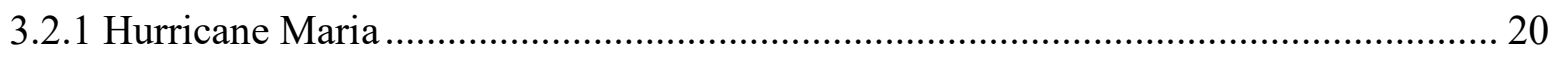

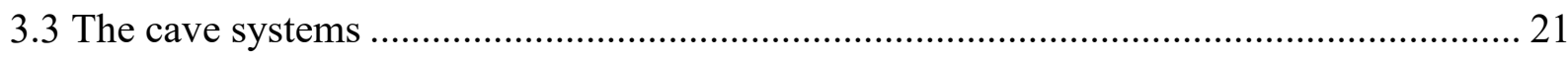

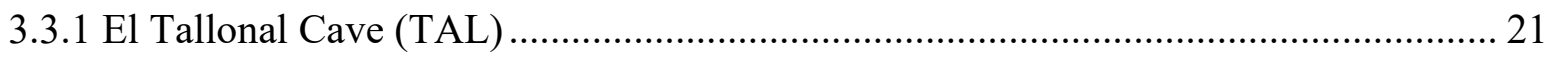

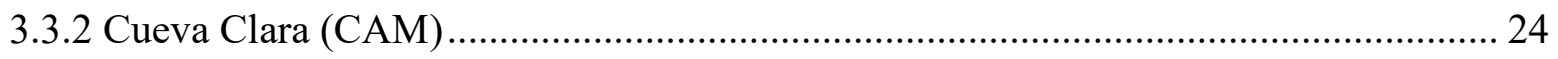

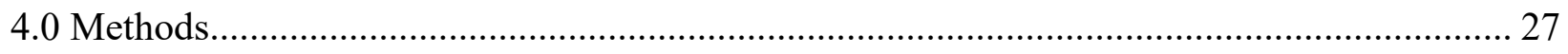

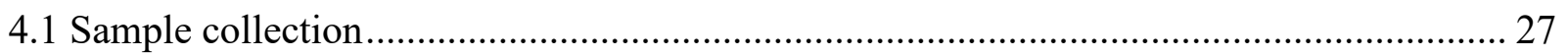

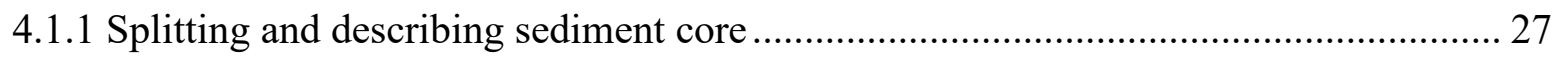

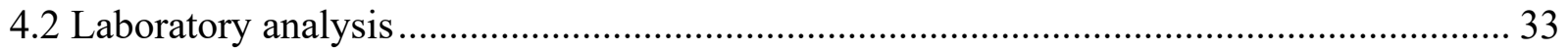

4.2.1 Particle size analysis ............................................................................................ 33

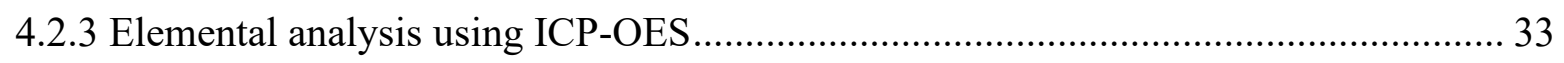

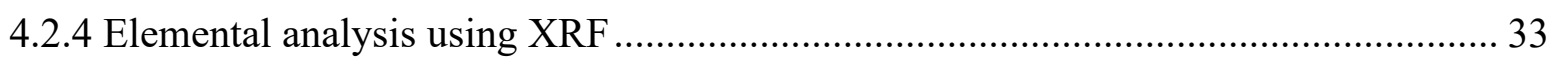

4.2.5 Total carbon, total organic carbon, total inorganic carbon, and total nitrogen............. 36

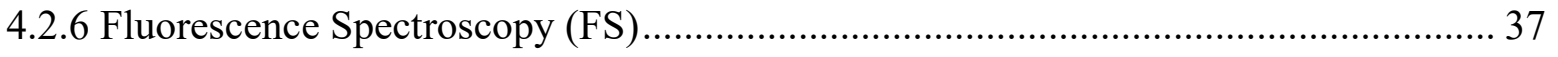




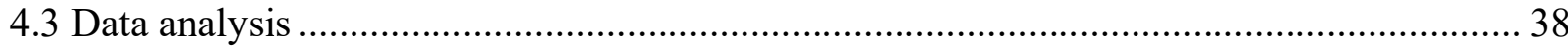

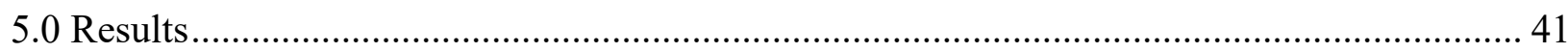

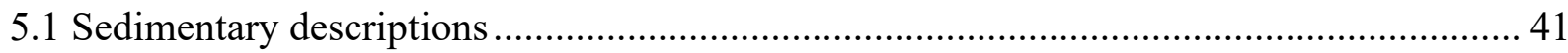

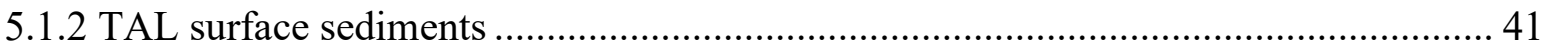

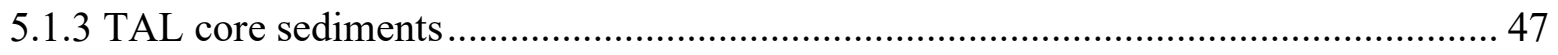

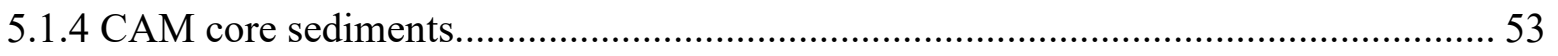

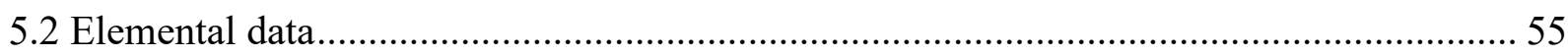

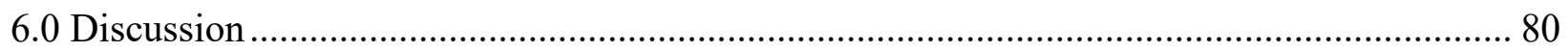

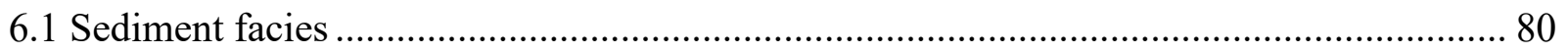

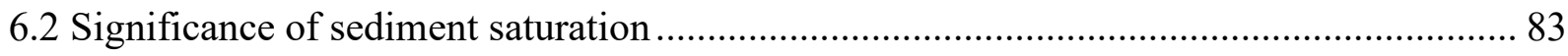

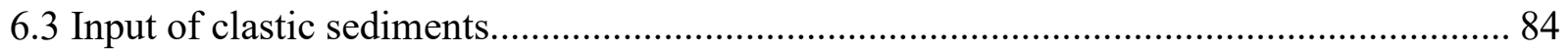

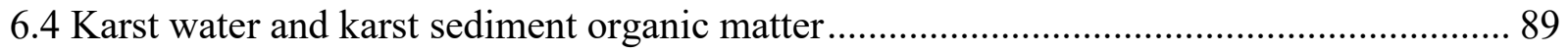

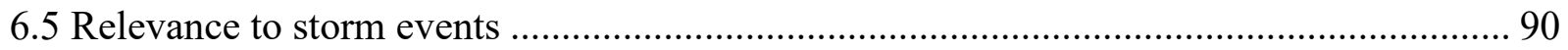

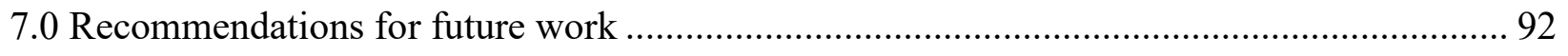

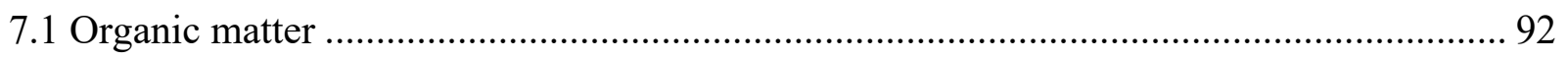

7.2 Post-depositional diagenesis and metal cycling ................................................................. 93

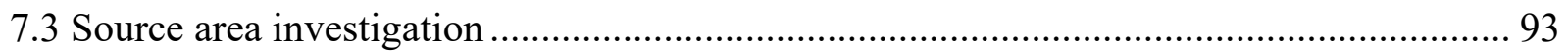

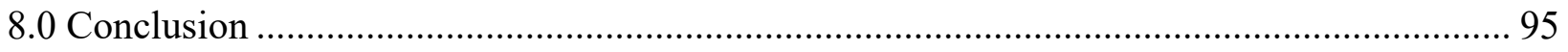

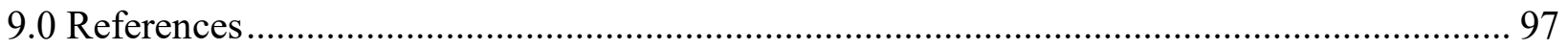




\section{List of Figures}

Figure 1: (A) Conceptual illustration of allogenic and autogenic clastic sediment as categorized relative to a conduit. (B) Possible sources of clastic sediment input into a conduit. Sediment sources may contribute both allogenic and autogenic sediment, as indicated by the gradient filled boxes. The conduit system is commonly dominated by allogenic sediment input, indicated by the dominantly allogenic color gradient fill (modified from Bosch and White, 2007)

Figure 2: Case study example of allogenic input into a conduit system after an extreme storm. Tres Pueblos Sinkhole (A) one week after Hurricane Maria, (B) one month after Hurricane Maria; and (C) one year after Hurricane Maria. .................................................................... 7

Figure 3: The various components of sediment organic matter. Recalcitrant organic matter are materials that are persistent in nature and resist further decomposition. Liable organic matter will undergo many stages of decomposition before entering the recalcitrant organic matter pool. Time is represented on the left-hand side. 8

Figure 4: Peaks and regions indicated spatially within the excitation emission space. Peaks labeled as described by Coble (1996) and regions labeled as described by Chen et al. (2003)... 13

Figure 5: Conceptual model of parallel factor analysis (PARAFAC). PARAFAC decomposes an emission excitation data set, here from i to I into distinct components illustrated on the righthand side of the figure

Figure 6: Generalized cross section from the central highlands to the northern coast of Puerto Rico. Surface topography is controlled by the underlying carbonate unit (modified from Monroe 1976).

Figure 7: The island of Puerto Rico with karst regions highlighted. The two cave systems in this project and the path of Hurricane Maria (from southeast to northwest) are indicated. Karst data source: USGS. Hurricane Maria data source: NOAA.

Figure 8: (A) Aerial imagery and surface contours of the regional topography surrounding El Tallonal Cave (TAL); Distinct magote peaks are present within the surround area. (B) Aerial imagery and surface contours of the regional topography surrounding Cueva Clara (CAM). Magote karst is absent in this region as the Río Camuy system is contained within a different carbonate rock unit. Sinkholes in this region are karst windows to the Río Camuy River. TAL cave map modified from Lace (2006). CAM cave map modified from Acosta-Colon (2016). ... 22

Figure 9: Map of El Tallonal Cave with sampling locations categorized by sampling round. The compartmentalized cave sections are indicated by the dashed boxes. Cave map modified from

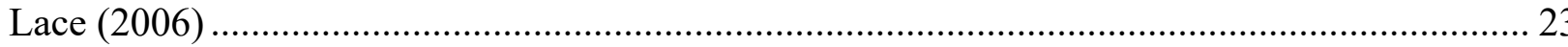

Figure 10: Map of Cueva Clara with sample locations labeled. The toured cave entrance and overlook to the Emplame Sinkhole are also labeled. Cave map modified from Nieves-Rivera (2003) and Acosta-Colon (2016). 
Figure 11: Generalized cross section of the middle of El Tallonal Cave with sample locations included. Point locations represent grab samples. Sample locations with a length represent sediment cores. Observed water level (dark blue) and dammed water level (light blue) are indicated. Samples were given a depth relative to the datum illustrated in this figure.

Figure 12: The spatial distribution of sample locations TAL-16 and TAL-17. Sample locations TAL-16 and TAL-17 were collected in a diagonal transect along a sediment bank in the middle of the cave. Dammed water level is depicted. A) sample transect location in the middle of the cave. B) location of collected core samples along the transect..................................................... 30

Figure 13: Flow chart illustrating subsampling and laboratory analysis..................................... 32

Figure 14: A) Particle size distribution of a sample collected from El Tallonal Cave as a function of volume percent with geometric mean, sorting, and skewness as reported in the GRADISTAT program. B) Grain size, sorting, and skewness divisions in the GRADISTAT program. Modified

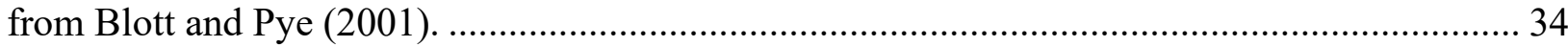

Figure 15: A) Photo showing the XRF core scanner located at the University of Utah's RED lab. B) The XRF core scanner with a sediment core loaded and ready for scanning. 35

Figure 16: Aqueous phase excitation emission matrix of tryptophan, tyrosine, and humic acid. Regions one through five are indicated. Region classification from Chen et al. (2003).............. 40

Figure 17: Grain size distribution in El Tallonal Cave (TAL) and Cueva Clara (CAM). Sand, silt,

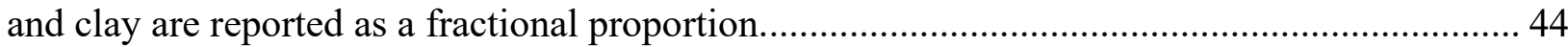

Figure 18: A) Sediment from the sediment bank surface were collected one, two, and three meters away from the cave stream at locations TAL-A through TAL-E. Spatial variation in B) grain size and C) sorting of sediment surface samples from El Tallonal Cave (TAL). Dashed lines represent poorly sorted (sorting value 2-4) and extremely poorly sorted (sorting value $>4$ ). Sorting values are unitless. Spatial variation in grain size and sorting of sediment surface samples from El Tallonal Cave (TAL). Sediment from the sediment bank surface were collected one, two, and three meters away from the cave stream at locations TAL-A through TAL-E. Dashed lines represent poorly sorted (sorting value 2-4) and extremely poorly sorting (sorting value $>4)$. Sorting values are unitless.

Figure 19: Relationship between percent silt and sorting from surface sediments collected one, two, and three meters away from the stream at locations TAL-A through TAL-E...................... 46

Figure 20: Core photographs and proportion of sand from location TAL-14 and TAL-15 ........ 49

Figure 21: Core photographs and proportion of sand from TAL-16-01, TAL-16-02, TAL-16-03, and TAL-16-04. Cores are not displayed in stratigraphic order................................................. 52

Figure 22: Core photographs and proportion of sand from TAL-16-05, TAL-16-06, TAL-16-07, and TAL-16-08. Cores are not displayed in stratigraphic order............................................... 54 
Figure 23: Core photographs and proportion of sand from CAM-01-01, CAM-05-01, CAM-0701, and CAM-10-01. Cores are not displayed in stratigraphic order.

Figure 24: Relationship between total carbon (TC), total organic carbon (TOC), total inorganic carbon (TIC), and total organic carbon from El Tallonal Cave sediments (TAL). 59

Figure 25: Relationship between total nitrogen (TN), organic $\mathrm{C} / \mathrm{N}$ ratio, and total organic carbon (TOC; \%) from El Tallonal Cave sediments (TAL).

Figure 26: A) Sediment from the sediment bank surface were collected one, two, and three meters away from the cave stream at locations TAL-A through TAL-E. Spatial distribution of B) fraction of organic carbon (FOC); C) total inorganic carbon (TIC); and D) organic $\mathrm{C} / \mathrm{N}$ ratios of all surface sediments collected from El Tallonal Cave (TAL).

Figure 27: Total organic carbon (TOC; \%) collected from the top of each core collected from TAL-16 ordered by depth relative to the datum. Dammed water level is $118 \mathrm{~cm}$ below datum.. 62

Figure 28: Variability in organic $\mathrm{C} / \mathrm{N}$ ratios, total nitrogen $(\mathrm{TN})$, and total organic carbon (TOC; $\%$ ) between saturated and unsaturated sediments. Dammed water level is $118 \mathrm{~cm}$ below datum.

Figure 29: Excitation-emission matrix (EEM) data collected on the alkaline extraction from TAL-16 sample location subsamples. $1^{\text {st }}$ and $2^{\text {nd }}$ order Rayleigh scattering has been removed. The EEMs have been normalized to the max intensity of each scan. EEMs were collected from $\lambda$ ex: $240-400 \mathrm{~nm}$ and $\lambda \mathrm{em}: 280-540 \mathrm{~nm}$.

Figure 30: Relationship between fluorescence index (FI) and biological index (BIX) and total organic carbon (TOC; \%). Saturated and unsaturated subsamples are indicated. FI values $<1.40$ indicate organic matter of terrestrial origin (dashed line). BIX values $>1$ indicate fresh autotrophic organic matter (dashed line).

Figure 31: Excitation-emission matrices (EEM) of the three-component parallel factor analysis (PARAFAC) model. Regions one through five are labeled. All modeled components fall within region five (humic acid-like).

Figure 32: Proportion of the modeled parallel factor analysis (PARAFAC) components one, two, and three in the sample set categorized by core. Dammed water level is indicated.

Figure 33: Ternary diagram with the three modeled parallel factor analysis (PARAFAC) components. Components are reported as a fractional proportion.

Figure 34: Total organic carbon (TOC; \%) as a function of the contribution of each component. Saturated and unsaturated samples are indicated.

Figure 35: Elemental concentrations plotted in molar units from highest to lowest average value of A) the entire dataset; B) major elements; and C) trace elements. Symbols are averages; error bars are a total of one standard deviation 
Figure 36: Eigenvalues of principle components 1-7 and scatter plot of the principle component analysis (PCA). Dashed line represents the three groups of elemental concentrations present

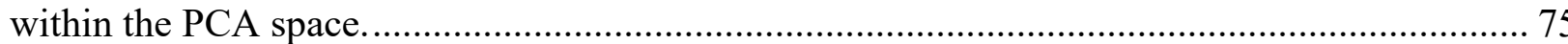

Figure 37: Pearson correlation matrix of elemental concentrations quantified using XRF. Matrix was created using the "Hmisc" package in R. Grey shaded values represent p-values $<0.05$. Boxed values indicate an $R$ value $>0.6$ (blue shaded) and $<-0.6$ (orange shaded).

Figure 38: Zirconium vs $\mathrm{Ti}, \mathrm{Pb}$, and As separated by core. Two distinct groups are observed due to variation in concentrations from different core locations. Solid blue ellipse represent TAL-16 cores and orange dashed ellipse represents TAL-14 cores.

Figure 39: Photos of the Emplame Sinkhole during the February 2019 sampling. The Río Camuy River is approximately 20 meters below the "bath ring" A) The sinkhole photographed from the back of CAM. The overlook photographed is a popular attraction during the cave tour through CAM. B) Photograph of Emplame Sinkhole from another perspective emphasizing the "bath ring" created by the Río Camuy River backflooding resulting from the Hurricane Maria flooding.

Figure 40: Elemental composition of A) bedrock and B) overlying $0.2 \mathrm{~m}$ of soil collected from the two dominant lithologies in the Luquillo Critical Zone Observatory. C) Average elemental concentrations of El Tallonal Cave (TAL) sediments plotted against the soil elemental concentrations of the two lithologies. Error bars represent one standard deviation total. The Luquillo Critical Zone Observatory data are from White et al. (1998) and Buss et al. (2017).... 87 


\section{List of Tables}

Table 1: Cave sediment facies and their descriptions........................................................... 5

Table 2: Fluorescent peaks and indices used to characterize an EEM. ..................................... 11

Table 3: Samples collected organized by sampling round and type of samples collected. ......... 28

Table 4: Analysis completed on collected subsamples................................................. 31

Table 5: Surface sediment sample locations and associated tracking IDs............................... 43

Table 6: Cores collected from sample location TAL-16 and position relative to the dammed

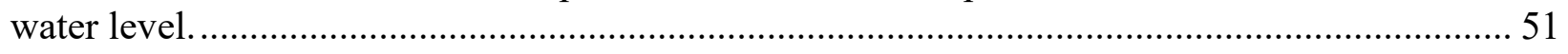

Table 7: Summary table of all collected carbon and nitrogen concentrations from sample location

TAL-16. Surface samples are not included in the un-saturated sample set. ............................. 58

Table 8: Results of the six parallel factor analysis (PARAFAC) models. The model with the minimum number of emission, excitation, and sample out lairs and minimum absolute value of intensity in the residuals is desired. The PARAFAC model with three components was chosen.67

Table 9: Mineral assemblages and proportions of the quartz diorite bedrock and soil and the volcaniclastic bedrock and soil from the Luquillo Mountains................................................ 86 


\section{List of Appendices}

Appendix I: Naming convention for samples collected from El Tallonal Cave and Cueva Clara, PR 105

Appendix II: Organic matter extraction method comparison ............................................. 106

Appendix III: Solid phase FS summary ...................................................................... 110

Appendix IV: All collected subsamples with tracking ID and analysis completed.................. 112

Appendix V: Core photographs and particle size data collected from the remaining core not

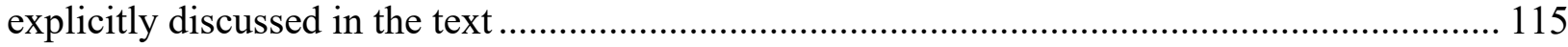

Appendix VI: Summary table of all collected particle size data from a Beckman Coulter single wavelength LS13-320 particle size analyzer ...................................................................... 118

Appendix VII: Summary table of all collected TC, TOC, and TN data ................................ 122

Appendix VIII: Summary table of all quantified XRF data. ............................................ 123

Appendix IX: All quantified XRF data displayed relative to depth of the collected cores from TAL-16-01.

Appendix X: All quantified XRF data displayed relative to depth of the collected cores from TAL-16-02.

Appendix XI: All quantified XRF data displayed relative to depth of the collected cores from TAL-16-03.

Appendix XII: All quantified XRF data displayed relative to depth of the collected cores from TAL-16-04

Appendix XIII: README for the GitHub repository dedicated to all coding scripts used for this project 


\section{List of Abbreviations and Acronyms}

BIX - biological index

CAM - Cueva Clara (part of the Camuy Cave system)

cps - counts per second

DI - deionized water

DOC - dissolved organic matter

EEM - excitation-emission matrix

FI - fluorescent index

FS - fluorescence spectroscopy

ICP - OES - inductively coupled plasma - optical emission spectroscopy

PARAFAC - parallel factor analysis

PCA - principle component analysis

PCR - polymerase chain reaction

POC - particulate organic matter

$\mathrm{SI}_{\mathrm{C}}-$ saturation index with respect to calcite

TAL - El Tallonal Cave

$\mathrm{TC}$ - total carbon

TDS - total dissolved solids

TIC - total inorganic carbon

$\mathrm{TN}$ - total nitrogen

TOC - total organic carbon

XRF - X-ray fluorescence 


\subsection{Introduction}

This study provides initial sedimentary descriptions and geochemical and organic properties of cave sediments from the northern karst region of Puerto Rico. Geochemical properties and organic characteristics are essential to understanding the general depositional dynamics of a cave. The range and variability of these parameters in clastic cave deposits are a first step in our ability to use these deposits for paleoclimate reconstruction, specifically meteoric precipitation events such as hurricanes. This study illustrates the variability in clastic sediments (laterally and with depth) from two cave systems. The data presented here demonstrates the complexity in these clastic deposits.

Clastic cave sediments are a promising means to evaluate hydrological models, examine anthropogenic changes, and to provide insight into regional climate change (van Hengstum et al., 2010). Cave sedimentation is a function of local climate variability, and thus many more data are needed to make broader regional - or even global - paleoclimate reconstructions (White, 2007). A detailed examination of the physical and chemical components of clastic cave deposits in individual caves affected recently by a hurricane is an important first step in understanding how storms affect cave sedimentation.

Assessing the physical and chemical properties of clastic cave sediments from the northern karst region of Puerto Rico was done through four major objectives: (1) Explore physical characteristics of clastic cave sediments both laterally through a cave and with depth; (2) Assess the range and variability of total organic carbon, organic $\mathrm{C} / \mathrm{N}$ ratios, total nitrogen of clastic cave sediment; (3) Evaluate the fluorescence properties of organic matter extracted from clastic cave sediments; (4) Quantify bulk elemental makeup of clastic cave sediments. These four objectives will allow data from the two caves to be compared to each other, as well as to results from caves elsewhere to better document the range of physical and sedimentary processes on caves 


\subsection{Background}

\subsection{Cave sediment}

Caves contain both chemical and clastic sediments. Chemical sediments defined as materials precipitating in-situ within a cave encompass a broad range of minerals due to the environmental conditions present in a cave. Chemical sediments occur dominantly through supersaturation with respect to a certain mineral. Chemical precipitation of minerals in a cave results in crystals typically composed of carbonates, but may also include sulfates, chlorides, and silica. Clastic sediments include all materials not precipitated in-situ and fall into two broad categories: allogenic and autogenic. Physical and chemical weathering within the cave system releases clasts of the host rock, including abundant carbonate clasts, as well as quartz, chert, clay minerals, and organics and are referred to as autogenic (White, 1988). Sediments sourced from the surface, referred to as allogenic sediments, encompass a variety of material (Figure 1A). Allogenic sediments enter a conduit via two pathways: (1) vertical infiltration via fracture - and - smaller sized pathways; or (2) lateral transport from a direct surface connection (e.g. sinkholes, swallets, vertical shafts) (Figure 1B). The latter dominates volumetrically (Bosch and White, 2007).

Surface derived transport is dependent on the efficiency of surface - to - ground water transfer. For example, surface connections via sinking streams flowing directly into the conduit ceiling will transport a higher sediment load than a surface connection via diffuse infiltration. Once surface water enters the groundwater system, transport of the sediment load must follow groundwater flow. The ability for sediment to remain suspended through the groundwater flow path will control the clastic material entering the conduit. Cave systems commonly contain unknown passages or undiscovered portions that create complex and convoluted groundwater flow. For these reasons, cave sediments are quite complex. Interior cave deposits are subject to remobilization and reworking. The extent to which sediments are remobilized and deposited during high flow events is variable and location-specific. Tracing sediment transport through cave systems based solely on physical sediment characteristics is problematic. Within conduits, drastic variations occur in sedimentary sequences that are only a few meters apart. Attempts to stratigraphically correlate sedimentary sequences laterally through a conduit system has been unsuccessful. 


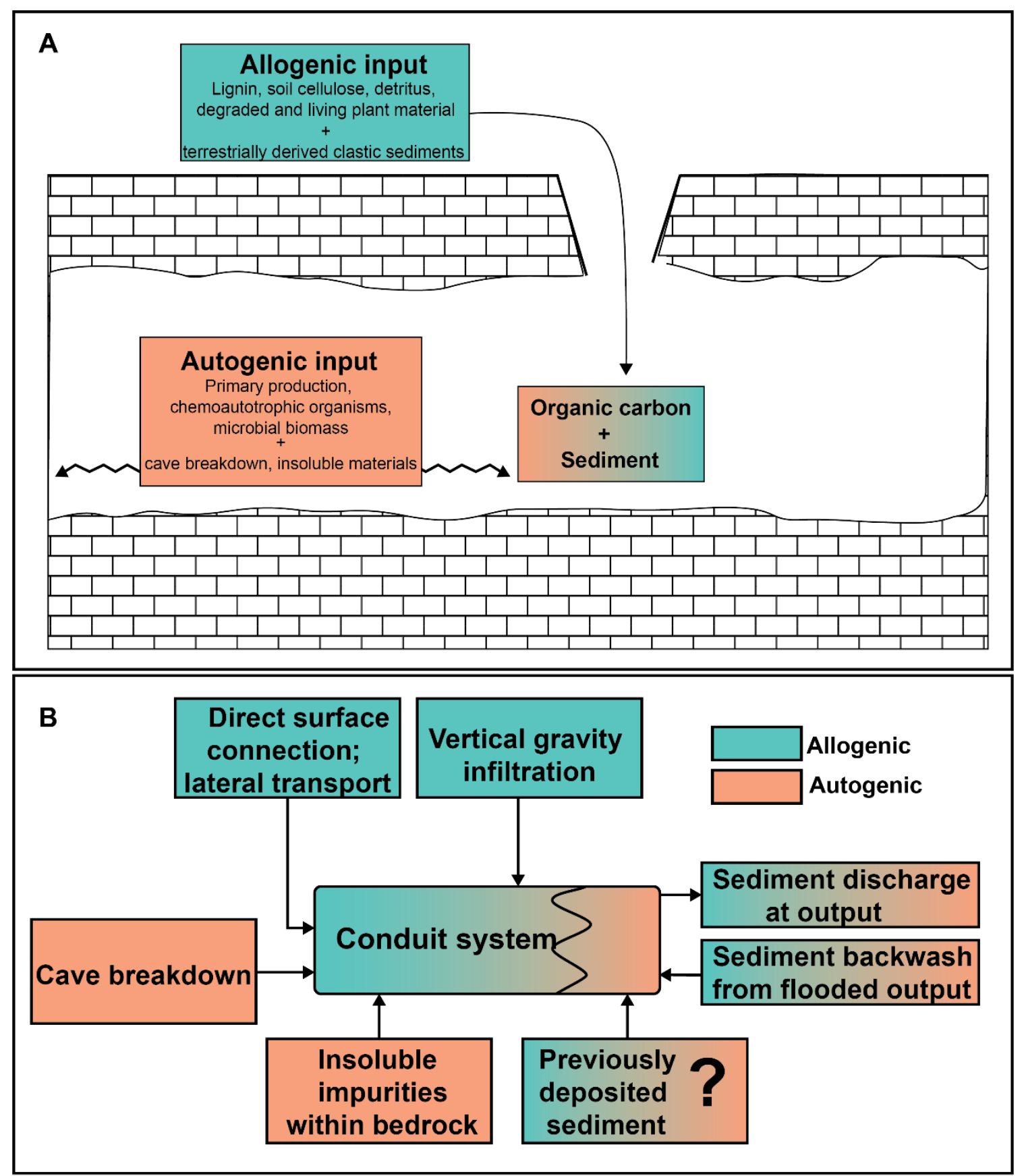

Figure 1: (A) Conceptual illustration of allogenic and autogenic clastic sediment as categorized relative to a conduit. (B) Possible sources of clastic sediment input into a conduit. Sediment sources may contribute both allogenic and autogenic sediment, as indicated by the gradient filled boxes. The conduit system is commonly dominated by allogenic sediment input, indicated by the dominantly allogenic color gradient fill (modified from Bosch and White, 2007). 
Cave sediments have been studied and classified based on grain size, shape, and composition to understand the hydrological conditions under which they were deposited. Five facies were first described by Gillieson (1986) and modified by Bosch and White (2007) (Table 1). This classification scheme was described based on Appalachian cave systems. It is important to note that the hydrologic conditions, structural controls, and sediment source areas of Appalachian karst and Puerto Rico vary. Puerto Rico's karst is eogenetic with higher porosity and permeability, lower flow variability, longer lag time in response to an input signal, and lower overall response in discharge than telogenetic karst (Florea and Vacher, 2006). Fornos et al. (2009) introduced a sediment classification based on an eogenetic system (Table 1). These descriptions provide a more accurate reference for describing cave sedimentation in this study.

Cave formation, or speleogenesis, initiates as carbonate rock containing a series of joints, fractures, and bedding planes provide a less resistant pathway for infiltrating groundwater. As groundwater flows through these pathways, a feedback mechanism of dissolution and pathway widening initiates (White, 1988). Widening facilitates the onset of turbulent flow allowing a conduit to carry suspended load. Cave sedimentation and speleogenesis are intimately linked. Sedimentation in a conduit begins as soon as speleogenesis widens a conduit to allow turbulent flow (Farrant and Smart, 2011). This connection is complex and codependent as conduit development is non-linear. A cave may undergo periods of vertical abandonment, clogging, or collapse. In addition to this, a cave system will undergo multiple cycles of sediment accumulation and erosion in response to external forcing due to climatic events or, on a larger scale, glacial and inter-glacial cycles.

\subsection{Storm events}

The onset of sediment mobility within a conduit is marked by a threshold and strongly non-linear (Herman et al., 2008). This non-linear nature makes deposition an episodic phenomenon. Flooding events drive huge pulses of surface-derived sediment and associated organic carbon into the system. This has recently been illustrated by the effect of Category 5 Hurricane Maria on the northern karst region of Puerto Rico (Figure 2). The extent of surfacederived input is dependent on the intensity of the storm and the flashiness of the system (Herman et al., 2006). 
Table 1: Cave sediment facies and their descriptions.

\begin{tabular}{|c|c|c|}
\hline $\begin{array}{l}\text { Lithofacies } \\
\text { name }\end{array}$ & Sediment characteristics & Hydrologic condition \\
\hline $\begin{array}{l}\text { Channel } \\
\text { facies }^{a}\end{array}$ & Well-sorted within a given bed & $\begin{array}{l}\text { Deposited in active cave } \\
\text { streams; mainly bedload }\end{array}$ \\
\hline $\begin{array}{l}\text { Thalweg } \\
\text { facies }^{a}\end{array}$ & $\begin{array}{l}\text { Well sorted, gravel, cobble, and } \\
\text { boulder size }\end{array}$ & $\begin{array}{l}\text { Cave stream cut through } \\
\text { previously deposited } \\
\text { channel facies; all finer } \\
\text { grained material has been } \\
\text { winnowed out }\end{array}$ \\
\hline $\begin{array}{l}\text { Slackwater } \\
\text { facies }^{a}\end{array}$ & $\begin{array}{l}\text { Well sorted fine-grained clay and } \\
\text { silts }\end{array}$ & $\begin{array}{l}\text { Deposited after a flooding } \\
\text { event; initially suspended } \\
\text { load }\end{array}$ \\
\hline $\begin{array}{l}\text { Diamicton } \\
\text { facies }^{a}\end{array}$ & $\begin{array}{l}\text { Unsorted, unbedded sediment } \\
\text { deposits consisting of all particle } \\
\text { sizes }\end{array}$ & $\begin{array}{l}\text { Catastrophic mass wasting } \\
\text { event; high relief drainage } \\
\text { basin required; not } \\
\text { deposited in modern }\end{array}$ \\
\hline $\begin{array}{l}\text { Waterlain } \\
\text { clastic fine- } \\
\text { grained }^{b}\end{array}$ & $\begin{array}{l}\text { Well-moderately sorted fine-grained } \\
\text { deposition; can be finely laminated } \\
\text { or unstratified; mostly quartz }\end{array}$ & $\begin{array}{l}\text { Deposited after high flow } \\
\text { events }\end{array}$ \\
\hline Carbonate $^{b}$ & $\begin{array}{l}\text { Fine grained carbonate grains to } \\
\text { large angular cave breakdown } \\
\text { deposits }\end{array}$ & $\begin{array}{l}\text { Breakdown triggered by a } \\
\text { permanent change in the } \\
\text { water table influencing the } \\
\text { stability of the cave system }\end{array}$ \\
\hline Mixed $^{b}$ & $\begin{array}{l}\text { Includes both siliciclastic and } \\
\text { carbonate material resulting in a } \\
\text { variety of characteristics }\end{array}$ & No hydrologic restriction \\
\hline Relict $^{b}$ & $\begin{array}{l}\text { Older deposits of fine grained red- } \\
\text { black silts, mm scale laminations, } \\
\text { more clay present than waterlain } \\
\text { clastic fine-grained facies }\end{array}$ & $\begin{array}{l}\text { Deposited in ponded areas } \\
\text { of the cave system that do } \\
\text { not fill with storm water on a } \\
\text { regular basis }\end{array}$ \\
\hline
\end{tabular}


Doehring and Vierbuchen (1971) described sediment deposition in Cave Springs Cave, Virginia as a result of Hurricane Camille in 1969, reporting a newly deposited terrace up to 1.5 $\mathrm{m}$ tall which caused permanent changes in the cave's stream flow and sediment load. Trends between modern cave sediment deposition in response to rainfall events have been found using core scanning $\mu$-XRF on sediment cores from a saturated cave in the Yucatan Peninsula (McNeill-Jewer et al., 2019). Conversely, another saturated cave system in the Yucatan Peninsula did not experience increased sediment deposition in response to Category 1 Hurricane Ingrid, despite a $0.7 \mathrm{~m}$ rise in the water table. The difference in sedimentation in response to a major storm demonstrates the extreme variability and heterogeneity observed in karst aquifers.

Attempts to quantify sedimentation rates or sediment budgets with a cave system, although informative, are indirect (Collins et al., 2015b; Hart and Schurger, 2005). During lowflow conditions, cave streams commonly lack suspended load and appear completely clear. It is at this condition when a cave is studied by observers. Due to the inability to directly study cave systems during high flow, the exact mechanism, rate, and sediment distribution during high flow events within a cave system remains unknown (White, 1988).

\subsection{Organic carbon}

Organic carbon in sediment includes living biomass as well as plant and animal tissue at all stages of decomposition (Figure 3). Decomposition of a sediment's organic matter results from decay of large macromolecules to small monomers and the ultimate transformation back to $\mathrm{CO}_{2}$. This process takes time. Some molecules decompose more efficiently than others. This

leads to recalcitrant pools of organic carbon. Recalcitrant organic matter has essentially shed all liable portions of the material resulting in a stable molecule resistant to further weathering through a process referred to as humification.

Natural organic matter is incredibly complexity. There is currently no way to directly measure the structure and composition of these molecules (Insam, 1996). This makes understanding organic matter cycling complicated. The idea that recalcitrance, stabilization, and carbon age are correlated to one another is debatable (Kleber et al., 2011). The exact structure of humic substances are not known and is thought to vary drastically depending on the source. Due to this complexity, general bulk characterization of organic carbon is used in place of detailed molecular analysis. 
A
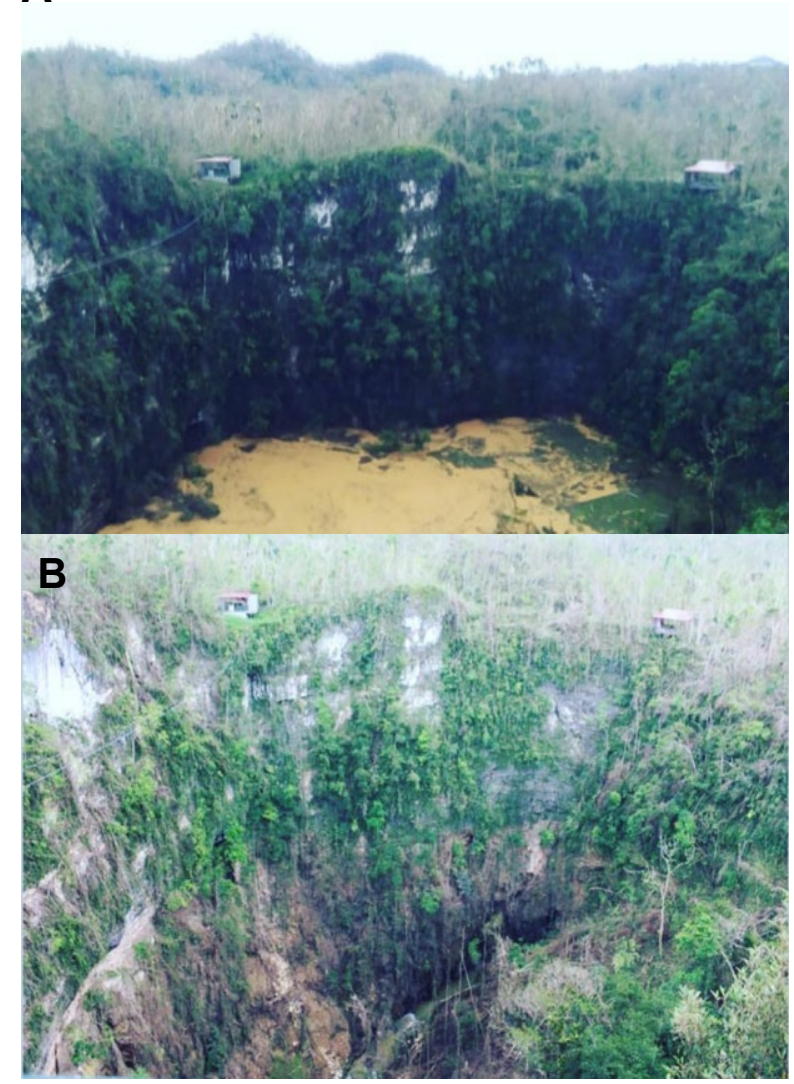

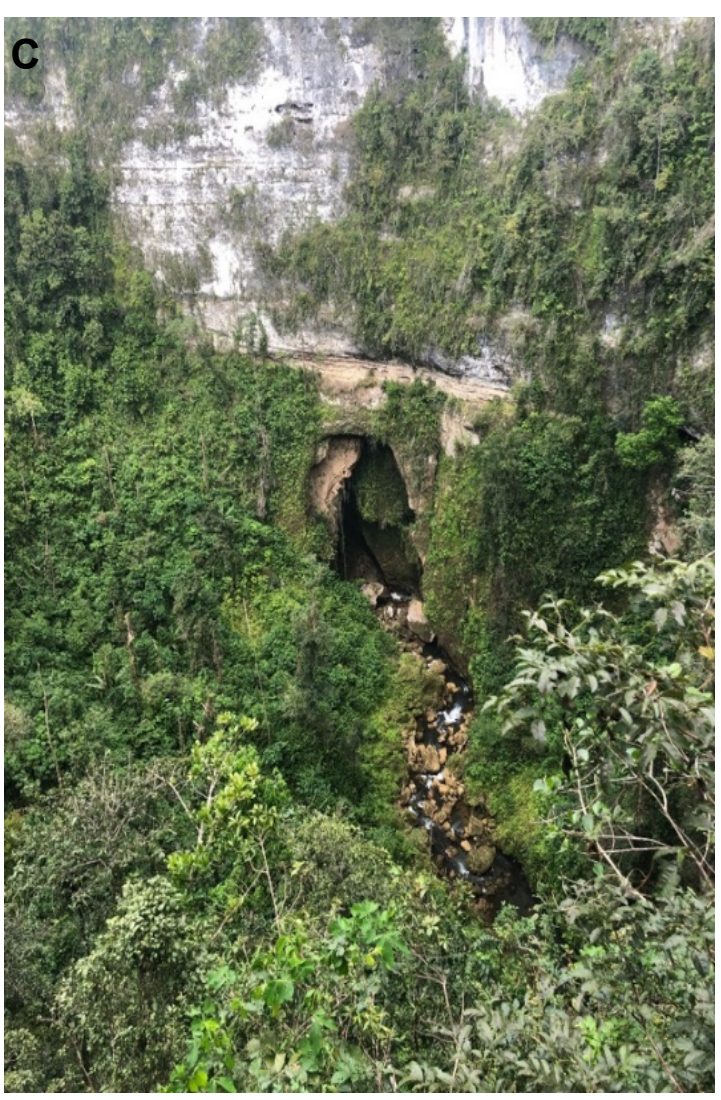

Figure 2: Case study example of allogenic input into a conduit system after an extreme storm. Tres Pueblos Sinkhole (A) one week after Hurricane Maria, (B) one month after Hurricane Maria; and (C) one year after Hurricane Maria. 


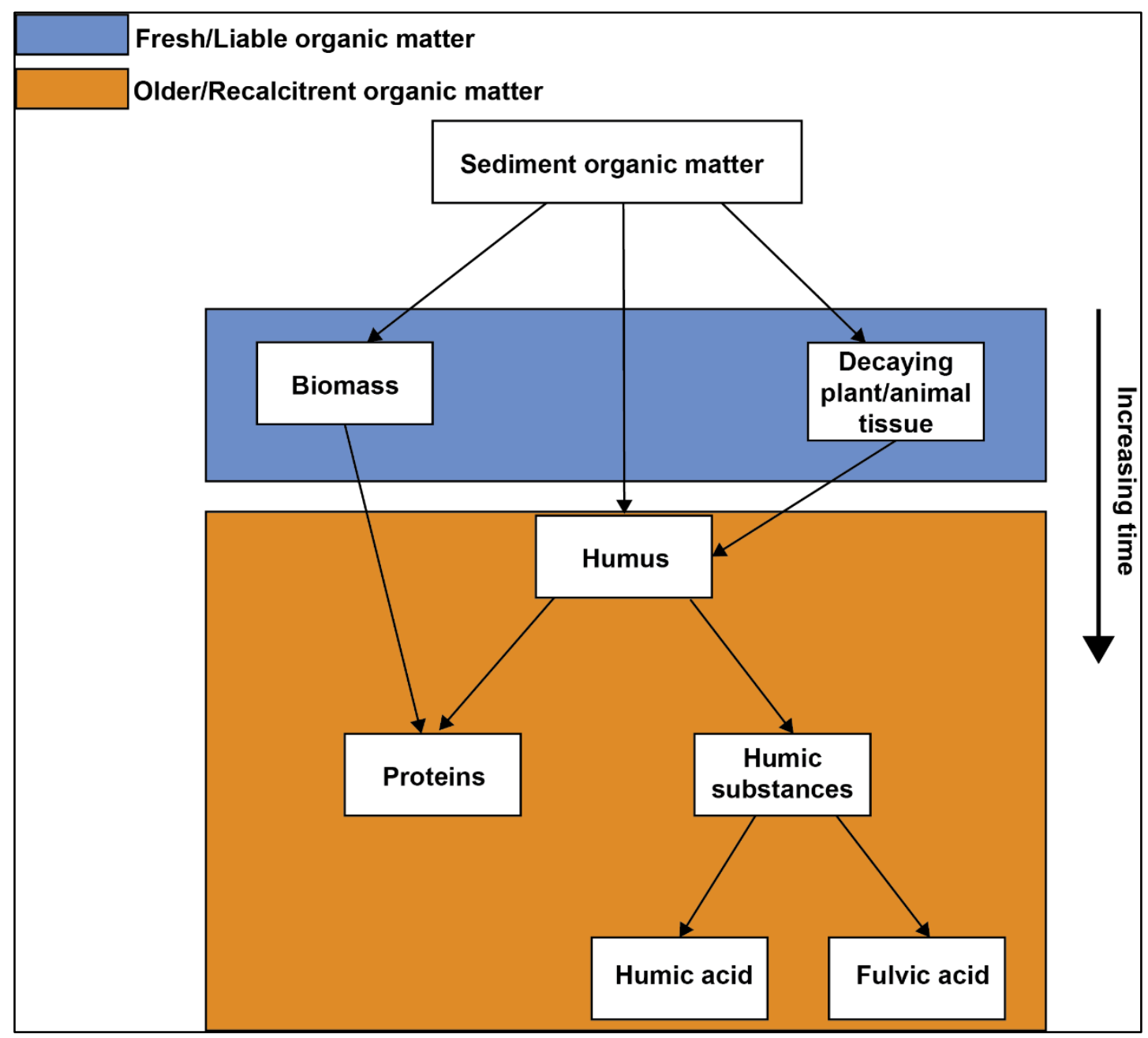

Figure 3: The various components of sediment organic matter. Recalcitrant organic matter are materials that are persistent in nature and resist further decomposition. Liable organic matter will undergo many stages of decomposition before entering the recalcitrant organic matter pool. Time is represented on the left-hand side. 


\subsubsection{Characterization}

Fluorescence spectroscopy is a technique used to characterize DOC. The wavelength at which a molecule fluoresces depends on its structure and size. Molecules capable of fluorescing when excited by lower wavelengths (ultraviolet through visible) are referred to as fluorophores. There are two major categories of fluorophores in natural systems: humic-like (terrestrial derived) and protein-like (microbial derived) (Gabor et al., 2014).

An emission-excitation matrix (EEM) is an assembly of fluorescence data with excitation, emission, and intensity on the $\mathrm{X}, \mathrm{Y}$, and $\mathrm{Z}$ axis, respectively. EEM's are characterized using several parameters (Table 2). Peaks designated A, C, and M refer to humic-like material while peaks B and $\mathrm{T}$ describe tyrosine-like and tryptophan-like material (protein-like), respectively (Figure 4). There are five general regions in an EEM space (Chen et al., 2003). Regions one and two represent aromatic protein, region three is fulvic acid-like, region four is microbial by-product-like, and region five is humic acid-like (Figure 4). Fluorescent indices are also used to characterize an EEM. Humification index quantifies the degree of humification. High values indicate lower $\mathrm{H} / \mathrm{C}$ ratios and thus a greater degree of humification. Fluorescence index (FI) is used to differentiate between terrestrial-and microbial-derived organic carbon. Fluorescence index values of 1.4 or less indicate DOM of terrestrial origin and values of 1.9 or higher correspond to microbially-derived material. An inverse relationship exists between FI and DOM aromaticity (Gabor et al., 2014). Biological index, like FI, is a measure of terrestrial vs. microbial components (Coble, 1996). Values of BIX between 0.8 and 1.0 correspond to freshly produced DOM of biological or microbial origin, whereas values below 0.6 are considered to contain little autochthonous organic matter (Birdwell and Engel, 2010).

While the peaks and indices described above were developed to quantify the fluorescent characteristics of DOC, they only utilize the intensity of a few discrete points within a data matrix, a matrix containing potentially thousands of data points. Moreover, sediment organic matter exhibits high fluorescence variability that may not be present within the range of these predetermined fluorescence peaks (Shirshova et al., 2009). To get a more complete understanding of an EEM, chemometrics are often used. Parallel factor analysis is a statistical method, like principle component analysis but applied to three dimensions (sample $\times$ emission $\times$ excitation). This method mathematically separates spectra of overlapping fluorescent components. This type of exploratory analysis takes large, complex EEM files and 
reduces them into individual components (Bro, 1997). Parallel factor analysis is particularly valuable due to its ability to make direct chemical interpretations from the model.

Parallel factor analysis of a 3-way dataset decomposes the data signal into a set of trilinear terms and a residual array (eq. 1).

$$
x_{i j k}=\sum_{f=1}^{F} a_{i f} b_{j f} c_{k f}+e_{i j k}
$$

$x_{i j k}$ is the intensity of the $i^{\text {th }}$ sample at the $j^{\text {th }}$ emission value and at the $k^{\text {th }}$ excitation value (Figure 5). Each $f$ corresponds to a PARAFAC component. Each component has $I a$-values (scores), one for each sample. Each component also has $J b$-values, one for each emission wavelength as well as $K c$ values, one for each excitation wavelength. Parameter $a_{i f}$ is directly-proportional to the concentration of the $f^{\text {th }}$ analyte of sample $I . b_{j f}$ is a scaled estimate of the emission spectrum of the $f^{\text {th }}$ analyte and $c_{k f}$ is linearly proportional to the specific absorption coefficient of the $f^{\text {th }}$ analyte. Finally, $e_{i j k}$ is the residual representing the variability not accounted for by the model (Murphy et al., 2014).

The PARAFAC model has three assumptions: (1) individual chemical components have distinctly different excitation and emission spectra; (2) fluorescence intensity relates linearly with concentration and spectra are consistent across all wavelengths; and (3) fluorescence intensity is an amalgamation of a fixed number of components (Bro, 1997).

\subsubsection{Organic carbon in cave systems}

Input of allogenic dissolved organic carbon (DOC) and particulate organic carbon (POC) may arrive via two different pathways: infiltration through the epikarst zone or rapid injection through a direct surface connection. In most karst systems DOC represents a larger flux than POC, and as a result, is studied at greater lengths (Gillieson, 1986). It is thought that negligible organic carbon is generated within the cave itself due to the darkness limiting primary productivity (van Hengstum et al., 2010). While the lack of light obviously eliminates phototropic microbial activity, it is possible that chemoautotrophic metabolism can flourish. The thought that organic matter generation is negligible could be limiting our understanding of organic carbon cycling in these systems. 
Table 2: Fluorescent peaks and indices used to characterize an EEM.

\begin{tabular}{|c|c|c|}
\hline Measurement & Calculation & Interpretation \\
\hline $\begin{array}{l}\text { BIX (biological } \\
\text { index) }\end{array}$ & $\begin{array}{l}\text { Emission intensity at } 380 \\
\text { divided by emission intensity at } \\
430 \mathrm{~nm} \text { at excitation } 310 \mathrm{~nm}\end{array}$ & $\begin{array}{l}>1 \text { recently produced } \mathrm{OM}^{a} \text { via } \\
\text { autotrophic productivity }\end{array}$ \\
\hline $\begin{array}{l}\text { FI (fluorescence } \\
\text { index) }\end{array}$ & $\begin{array}{l}\text { Emission intensity at } 470 \\
\text { divided by emission intensity at } \\
520 \mathrm{~nm} \text { at excitation } 370 \mathrm{~nm}\end{array}$ & $\begin{array}{l}<1.4 \mathrm{OM}^{a} \text { of terrestrial origin } \\
>1.9 \mathrm{OM}^{a} \text { of microbial origin }\end{array}$ \\
\hline $\begin{array}{l}\mathrm{HI} \text { (humification } \\
\text { index) }\end{array}$ & $\begin{array}{l}\text { Area under the emission } \\
\text { spectra from } 435-480 \text { divided } \\
\text { by the area under the emission } \\
\text { spectra from } 300-345 \mathrm{~nm}+ \\
435-480 \mathrm{~nm} \text {, at excitation } 254\end{array}$ & $\begin{array}{l}\text { Higher values indicate increasing } \\
\text { degree of humification; low }=<5 \\
\text { and increases with decomposition; } \\
\text { high values indicate lower H/C } \\
\text { ratios }\end{array}$ \\
\hline Peak A & $\begin{array}{l}\text { Maximum intensity at } 260 \mathrm{~nm} \\
\text { excitation and } 380-460 \mathrm{~nm} \\
\text { emission }\end{array}$ & Humic acid-like \\
\hline Peak B & $\begin{array}{l}\text { Maximum intensity at } 275 \mathrm{~nm} \\
\text { excitation and } 310 \mathrm{~nm} \\
\text { emission }\end{array}$ & Tyrosine-like, protein-like \\
\hline Peak C & $\begin{array}{l}\text { Maximum intensity at } 350 \mathrm{~nm} \\
\text { excitation and } 420-480 \mathrm{~nm} \\
\text { emission }\end{array}$ & Humic acid-like \\
\hline Peak M & $\begin{array}{l}\text { Maximum intensity at } 312 \mathrm{~nm} \\
\text { excitation and } 380-420 \mathrm{~nm} \\
\text { emission }\end{array}$ & Marine/non-marine humic acid-like \\
\hline Peak T & $\begin{array}{l}\text { Maximum intensity at } 275 \mathrm{~nm} \\
\text { excitation and } 340 \mathrm{~nm} \\
\text { emission }\end{array}$ & Tryptophan-like, protein-like \\
\hline Region 1 & $\begin{array}{l}\text { Excitation }<250 \mathrm{~nm}<335 \mathrm{~nm} \\
\text { emission }\end{array}$ & Aromatic protein \\
\hline Region 2 & $\begin{array}{l}\text { Excitation }<250 \mathrm{~nm} \text { and } \\
\text { emission between } 380 \text { and } \\
335 \mathrm{~nm}\end{array}$ & Aromatic protein \\
\hline Region 3 & $\begin{array}{l}\text { Excitation }<250 \mathrm{~nm} \text { and } \\
\text { emission }>350 \mathrm{~nm}\end{array}$ & Fulvic acid-like \\
\hline Region 4 & $\begin{array}{l}\text { Excitation between } 250-280 \\
\mathrm{~nm} \text { emission }<380 \mathrm{~nm}\end{array}$ & microbial by-product-like \\
\hline Region 5 & $\begin{array}{l}\text { Excitation }>280 \mathrm{~nm} \text { and } \\
\text { emission }>380 \mathrm{~nm}\end{array}$ & Humic acid-like \\
\hline
\end{tabular}


Table 2: Fluorescent peaks and indices used to characterize an EEM (continued).

\begin{tabular}{lll}
\hline \hline Measurement & \multicolumn{1}{c}{ Calculation } & \multicolumn{1}{c}{ Interpretation } \\
\hline C:A & $\begin{array}{l}\text { Peak C intensity: Peak A } \\
\text { intensity ratio }\end{array}$ & $\begin{array}{l}\text { High values }=\text { humic acid-like } \\
\text { Low values }=\text { fulvic acid-like }\end{array}$ \\
C:T & $\begin{array}{l}\text { Peak C intensity: peak } \mathrm{T} \\
\text { intensity ratio }\end{array}$ & $\begin{array}{l}\text { High values }=\text { humic/recalcitrant } \\
\mathrm{OM}^{a} \\
\text { Low values }=\text { fresh/liable OM } \mathrm{OM}^{a}\end{array}$ \\
\hline a Organic matter & & \\
\hline
\end{tabular}




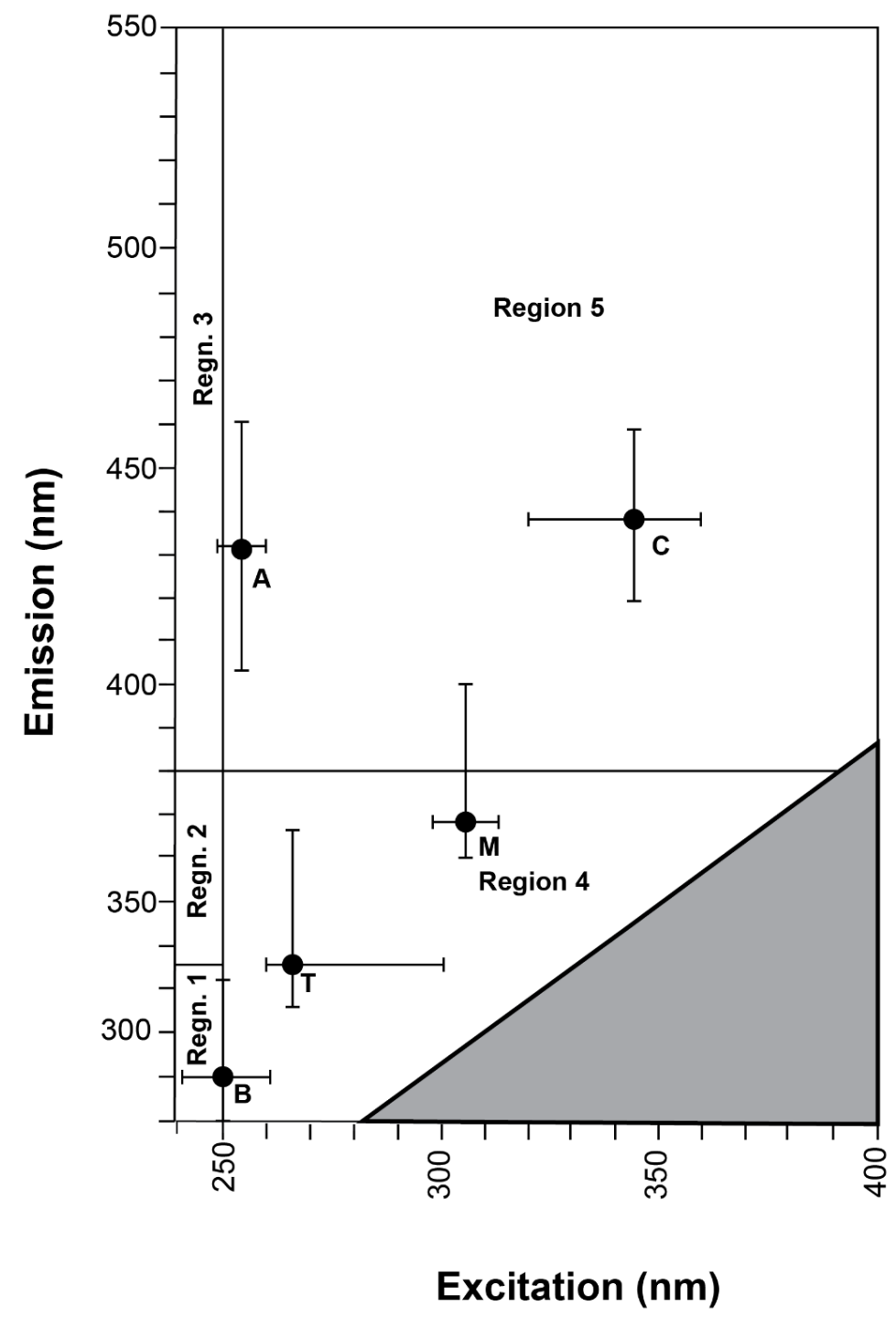

Figure 4: Peaks and regions indicated spatially within the excitation emission space. Peaks labeled as described by Coble (1996) and regions labeled as described by Chen et al. (2003). 


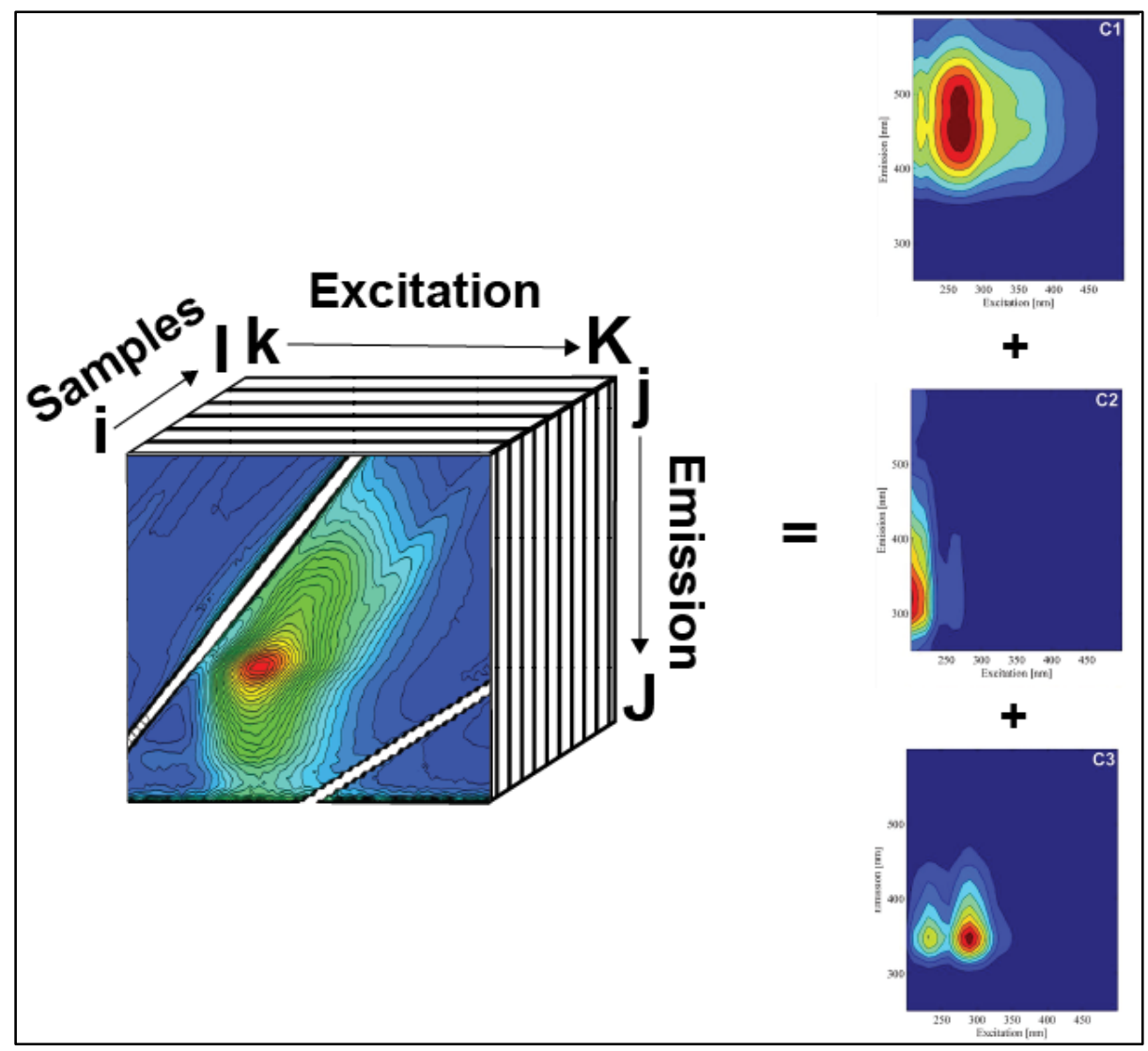

Figure 5: Conceptual model of parallel factor analysis (PARAFAC). PARAFAC decomposes an emission excitation data set, here from $i$ to I into distinct components illustrated on the righthand side of the figure. 
It has been observed that DOC concentrations in the water column and DOC associated with suspended sediment decreases from input to output (Blott and Pye, 2001; Husic et al., 2017; Simon et al., 2007). This suggests that DOC is retained in the system via some metabolic pathway, sorption, or physical entrapment. Concentrations of DOC are variable between input type and hydrologic condition. Sinking streams have been found to contain higher DOC concentrations but had little variation during changing flow conditions. Epikarst waters contained lower DOC concentration but exhibited variability consistent with the onset of changing flow conditions (Pipan and Culver, 2013).

To better understand how organic carbon is transported and retained within a cave, Simon et al. (2010) characterized DOC from major inputs and outputs using PARAFAC analysis. Significant variation in DOC characteristics between input and output were observed and is likely a reflection of the organic carbon source. Component one (humic-like, high molecular weight) was most-strongly represented in the cave stream, component two (humic-like, low molecular weight) was represented in the soil DOC from the karstic surface, and component three (protein-like) was represented in cave drip water. A similar study done by Pipan and Culver (2013) in a different system found that cave drip water contained a lower percent of aromatic compounds than both the sink and resurgence point. Aromatic compounds are highly stable. They are generally more resistant to decomposition and persist in natural systems. DOC with higher aromaticity is considered recalcitrant and thus older than less aromatic DOC. Less aromatic DOC in drip waters indicates the presence of freshly produced DOC, likely a result of microbial activity in the epikarst zone.

Birdwell and Engel (2010) reported fluorescence index (FI) and humification index (HIX) values for groundwater from a confined portion of the Edwards aquifer to be 1.51-2.65 and 0.17-9.03, respectively. Suggesting that there exists a significant microbial component (protein-like) and an overall lack of terrestrial input into this groundwater system. This signature is consistent during recharge periods, indicating that the influx of nutrient-rich surface material stimulated, rather than inhibited, microbial activity. The dominating microbial signature of the DOC in this study is likely a function of the confined nature of the sampled aquifer. Mudarra et al. (2011) measured the fluorescence properties of multiple spring waters from an unconfined system and found the dominant organic matter was fluvic acid-like. 
Within a conduit, sediment organic carbon is retained and stored for an extended period relative to water residence time (Husic et al., 2017). Within the hyporheic zone, total biomass is closely correlated with POC concentration rather than DOC concentration. In marine sediments, molecular weight decreases with depth and age (Lukawska-Matuszewska et al., 2018). These studies support the idea that freshly produced organic matter are large molecules that undergo post depositional humification towards a recalcitrant product (Sobczak et al., 1998).

\subsection{Cave sediments as paleo-proxies}

Historically paleoclimate studies have focused on speleothems due to their fine resolution and cyclical precipitation banding. Only recently have cave sediments been recognized as a valuable source of information regarding past climatic conditions (White, 2007). The onset of sediment accumulation occurs simultaneously with the formation of the conduit whereas speleothem growth initiates after conduit formation. Because of this, dating clastic sediments reveal a minimum age of the conduit and is likely to be more accurate than dates revealed using speleothems.

There has been a surge of research attempting to reconstruct paleoclimate and paleostorm records through clastic cave sediments in the past two decades. Most reconstruction attempts have focused on organic carbon characterization and dating using both radiocarbon and magnetic polarity techniques (Hearty et al., 2004; Panno et al., 2004; Polk et al., 2013; Polk et al., 2007; van Hengstum et al., 2010). These studies suggest that when a single core is studied carbon dates reveal little to no age reversals and are generally stratigraphically-continuous. Organic matter has been found to decrease with increasing depth and age as a result of progressive microbial degradation under aerobic conditions creating $\mathrm{CO}_{2}$ and a loss of easily-oxidized organic carbon. Tamalavage et al. (2018) successfully identified sediment organic carbon sources to a sinkhole through time. Periods of increased primary productivity and changes in sediment source areas were quantified using an isotope mixing model. This study most importantly demonstrates that organic carbon variation is present in the depositional record on the karstic surface. 


\subsection{Location}

This study was conducted on two cave systems located in the northern karst region of Puerto Rico, El Tallonal Cave (TAL) and Cueva Clara (CAM). Location TAL was chosen because this cave's water quality and sediment chemistry has been monitored since August 2016.

Datalogger data collected from TAL show that a spike in turbidity in the cave stream coincides with the onset of a rain event (pers. comm. Pantoja-Agred, 2016). The spike in turbidity suggests that this cave system experiences regular allogenic input from the surface. The second location, CAM, was included in this study because sediment accumulation as a result of Hurricane Maria was directly observed (Miller, 2018). Though both locations were flooded as a result of Hurricane Maria, the "normal" conditions are very different between the two systems. El Tallonal cave is a wet cave with a continuously-flowing cave stream whereas CAM is a completely dry cave. Inclusion of TAL and CAM provide a comparison between the physical and chemical sediment characteristics present in these two different systems.

\subsection{Geology and landscape}

Puerto Rico is part of a volcanic island arc, consisting of mountainous central highlands with steep slopes and large incised valleys, surrounded by a flat lying coastal plain (Figure 6). It is the easternmost island of the Greater Antilles located near the North American-Caribbean

plate subduction zone (Cox, 1985; Jolly et al., 2001). Igneous terrain makes up 52 percent of the island surface. These volcanics are concentrated in the central highlands and are basaltic with high compositional variation from silica rich to K-rich calc-alkaline basalts (Jolly et al., 2001). The volcanic central highlands and are surrounded by coastal sedimentary rocks from the late Jurassic to early Eocene (Murphy et al., 2012). Coastal limestone covers about one-fifth of the land area. There are two major karst regions, located on the northern and southern coast of the island (Giusti, 1978) (Figure 7). The sediment studied in this project are transported from two major sources: (1) the volcanic central highlands; and (2) the carbonates.

The Puerto Rican karst is eogenetic, undergoing little to no post-depositional deformation. Carbonates were deposited in shallow, clear water with open circulation, ranging in age from Oligocene to Miocene (Giusti, 1978). 


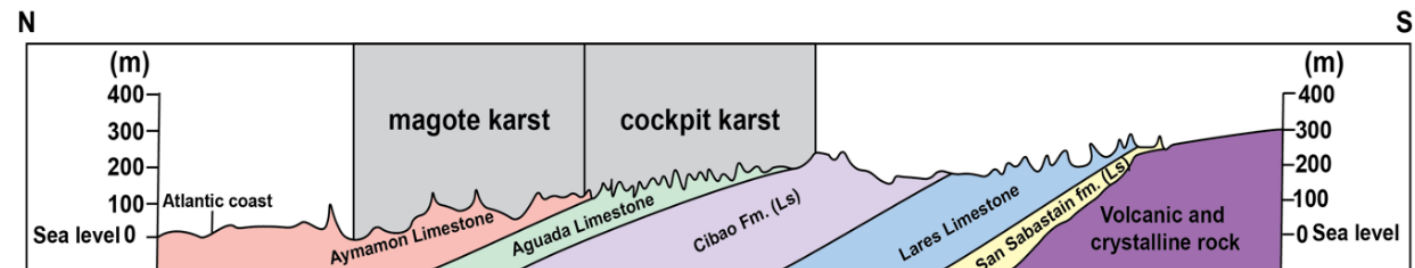

Figure 6: Generalized cross section from the central highlands to the northern coast of Puerto Rico. Surface topography is controlled by the underlying carbonate unit (modified from Monroe 1976). 


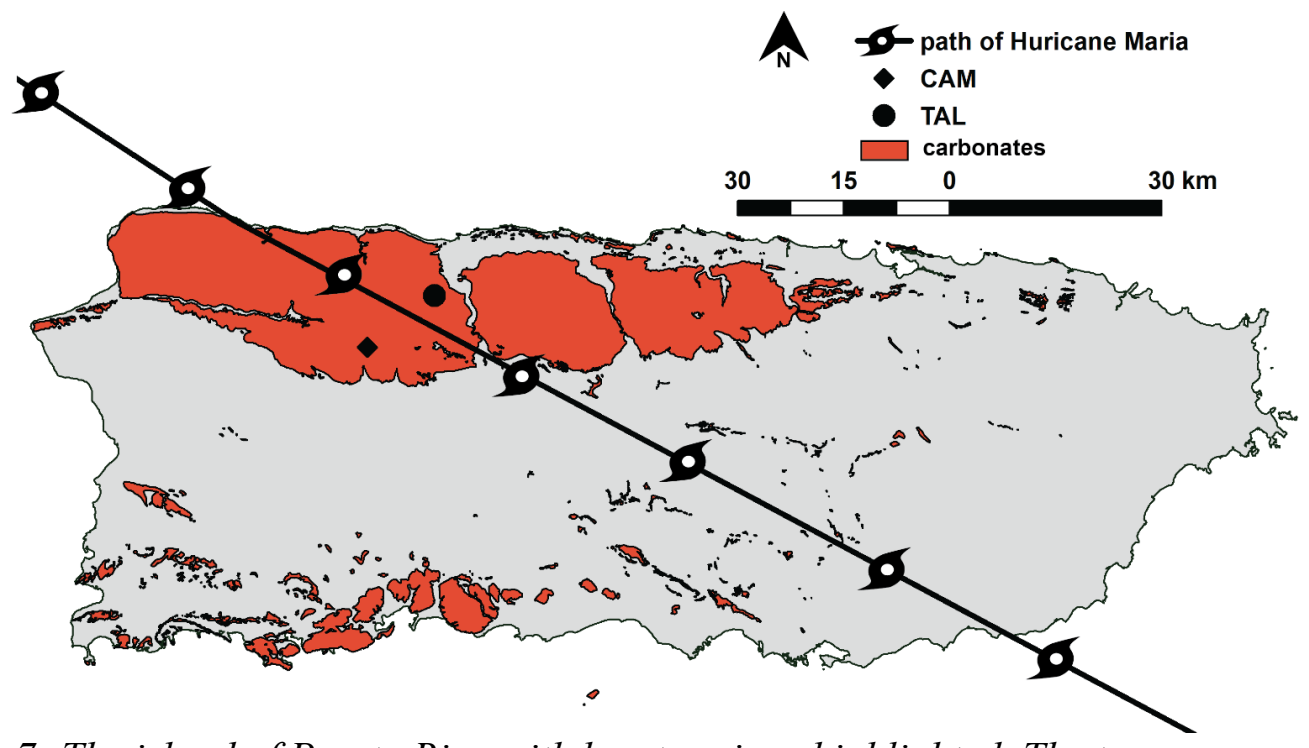

Figure 7: The island of Puerto Rico with karst regions highlighted. The two cave systems in this project and the path of Hurricane Maria (from southeast to northwest) are indicated. Karst data source: USGS. Hurricane Maria data source: NOAA. 
The Puerto Rican karst is eogenetic, undergoing little to no post-depositional deformation. Carbonates were deposited in shallow, clear water with open circulation, ranging in age from Oligocene to Miocene (Giusti, 1978).

The island of PR consists of five major limestone formations (Figure 6). The Aymammon and Aguada limestones have the highest permeability $(1-0.02 \mathrm{~cm} / \mathrm{S})$ and are the most productive aquifers on the island. Water budget calculations yield a discharge (Q) of $0.11 \mathrm{~m}^{3} / \mathrm{s}$ and 0.02 $\mathrm{m}^{3} / \mathrm{s}$ for the two formations, respectively (Giusti, 1978). These formations on average are 85 percent $\mathrm{CaCO}_{3}, 4.8$ percent $\mathrm{MgCO}_{3}, 6$ percent $\mathrm{SiO}_{4}$, and 9 percent insoluble material (Monroe. 1976). Karstification is most intense in the Aymammon limestone and decreases seaward (Giusti, 1978). The tropical climate and eogenetic nature of the Aymammon limestone unit results in a karst topography referred to as magotes (Figure 8). These are rounded mounds with a hardened shell surrounding a softer, eroded interior. The induration and reprecipitation of the uppermost portion of the exposed carbonate produces a "clogging" of the primary porosity and provides important structural integrity (Ford and Williams, 2007). Magotes are asymmetrical, exhibiting a shallow east side in response to the easterly rain typical of the tropical high-pressure systems that pass through the island.

\subsection{Climate}

Along the northern coast of PR, trade winds trend from the northeast. The annual air temperature mean is $25^{\circ} \mathrm{C}$ with little yearly variation. Mean annual rainfall for the northern coast of the island is $1550 \mathrm{~mm} / \mathrm{yr}$ (Morelock et al., 2016)

Major rainfall events are produced during the passage of a cold front or an easterly wave over the region. The frequency of these weather fronts determine whether the island experiences relatively wet or dry conditions (Gomez-Gomez et al., 2014).

\subsubsection{Hurricane Maria}

On September 20th, 2017 Hurricane Maria made landfall on the southeastern side of PR just under a Category 5 hurricane. The eyewall crossed the island from the southeast to northwest (Figure 7). The storm surge combined with the tides on the northern coast producing a maximum surge of $1.5 \mathrm{~m}$. Rainfall on the island reached upwards of $97 \mathrm{~cm}$ in just over 32 hours (Pasch et al., 2017). River discharge in many places reached at or near record levels and in many cases 
disabled or destroyed the water level monitoring stations. Severe flooding and mudslides affected much of the island (Pasch et al., 2017). Large volumes of newly-deposited sediment were documented in many caves throughout PR after Hurricane Maria (Miller, 2018).

\subsection{The cave systems}

\subsubsection{El Tallonal Cave (TAL)}

El Tallonal Cave is located on private land, protected and preserved by the Citizens of Karst (Cidadanos del Karso) and used for private water supply. It is dammed at the portal and has been instrumented with an Aquatroll@ 600 datalogger since 2016 (pers. comm. Padilla, 2019). The cave has one main sinusoid passage with no branching side passages and no known upper or lower levels (Figure 9). Water flows upwards into the sump and discharges from the base of a magote at the cave entrance (Figure 8). The cave is approximately 60 meters long and varies from 1.5 meters to just over 6 meters wide.

Water quality at TAL has been monitored by researchers at the University of Puerto Rico, Mayaguez since August of 2016 as part of a long-term study to better characterize groundwater flow in the region. The groundwater flowpath is relatively short, entering and exiting on either side of a magote, however, dye traces have been unsuccessful (pers. comm. Padilla, 2019) Groundwater response to a rain event is variable depending on the time of year. In the warmer months of the year (August-November) a rain event is marked by an increase in groundwater temperature. In the cooler months (January-May) a rain event is marked by a decrease in groundwater temperature. A spike in turbidity in response to rain event is temporally-consistent indicating that allogenic input coincides with these rain events.

Aqueous systems experiencing the dissolution or precipitation of calcite is determined by the $\mathrm{SI}_{c}$. An SI value above zero (indicating equilibrium) is supersaturated thus precipitating calcite. $\mathrm{A} \mathrm{SI}_{\mathrm{c}}$ value less than zero is undersaturated, indicating the water can dissolve calcite. The SIc values were calculated using $\mathrm{Ca}$ and alkalinity concentrations and $\mathrm{pH}$ from the data provided by the University of Puerto Rico, Mayaguez. All SI $I_{C}$ values from TAL are at or above 0 (maximum $\left.\mathrm{SI}_{\mathrm{c}}=0.45\right)$. Phosphate and TDS $(\mathrm{mg} / \mathrm{L})$ experience a sharp increase in October of 2017 and could be a response to the massive flooding that occurred within the system during Hurricane Maria. 
A

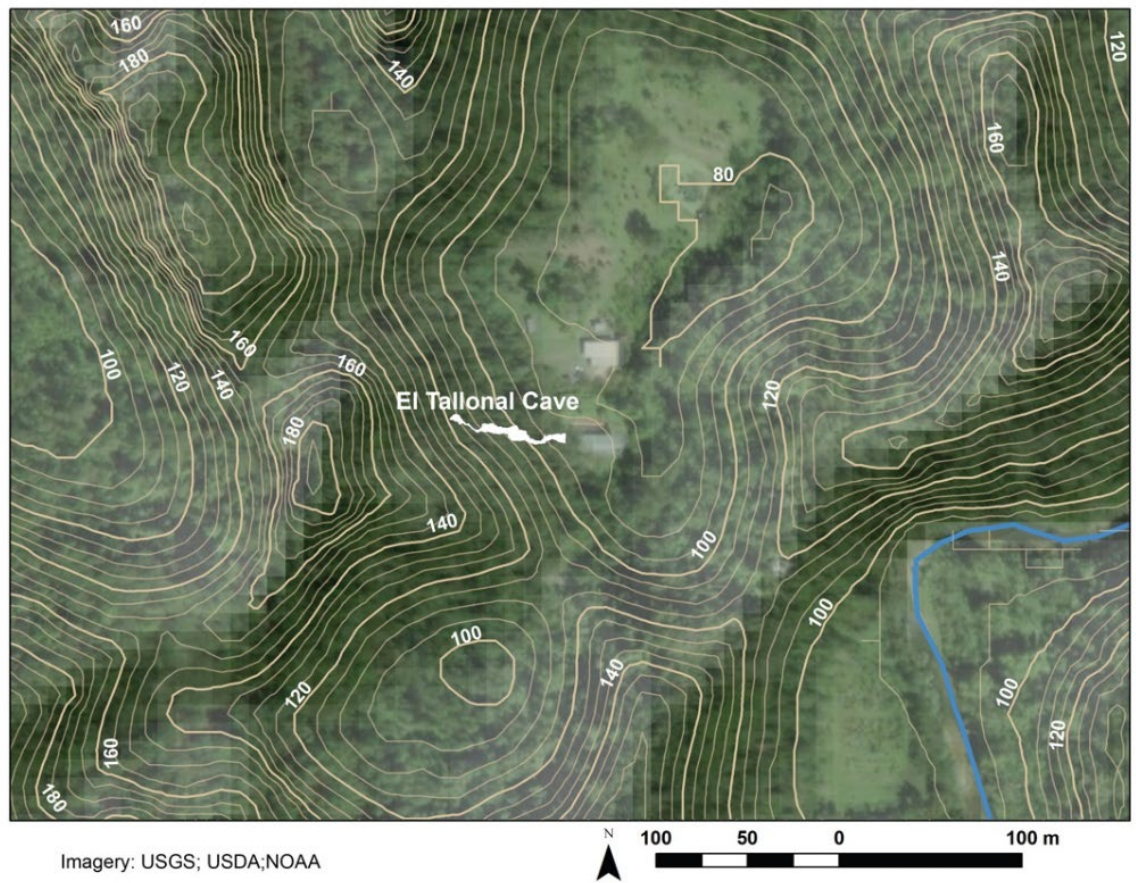

B

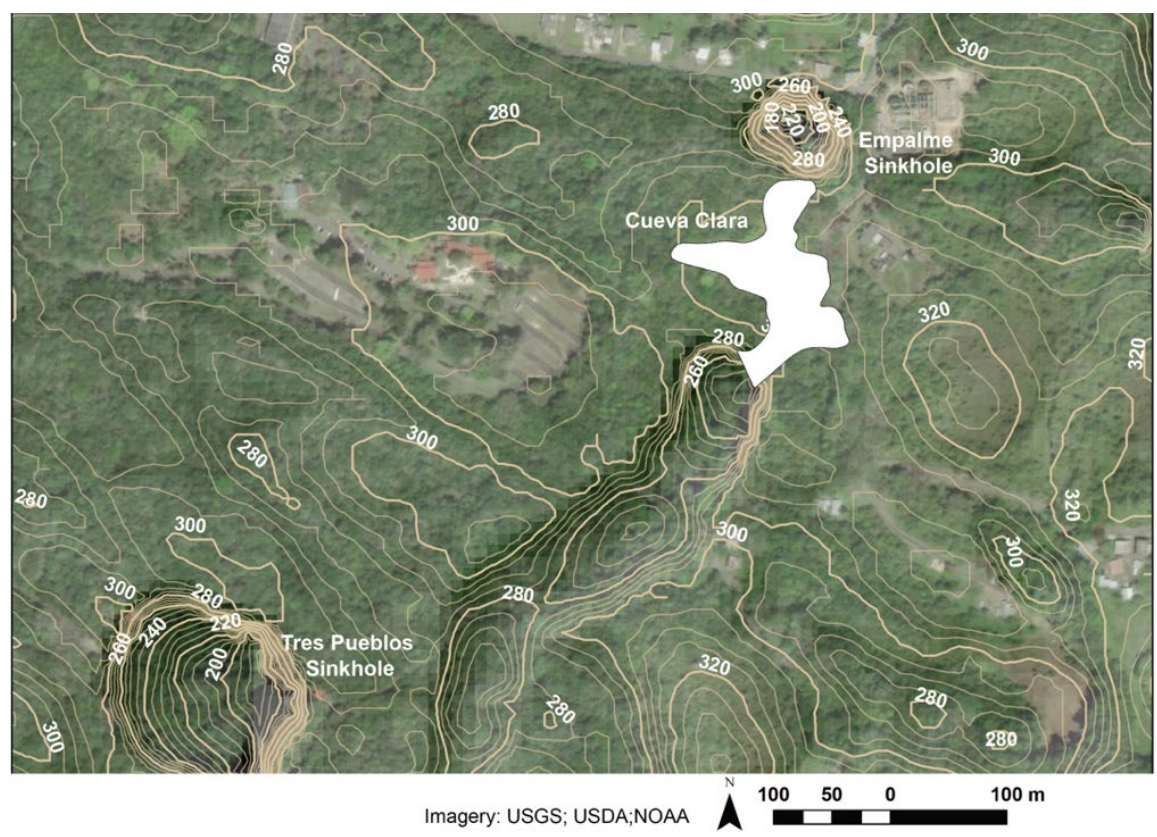

Figure 8: (A) Aerial imagery and surface contours of the regional topography surrounding El Tallonal Cave (TAL); Distinct magote peaks are present within the surround area. (B) Aerial imagery and surface contours of the regional topography surrounding Cueva Clara (CAM). Magote karst is absent in this region as the Rio Camuy system is contained within a different carbonate rock unit. Sinkholes in this region are karst windows to the Rio Camuy River. TAL cave map modified from Lace (2006). CAM cave map modified from Acosta-Colon (2016). 


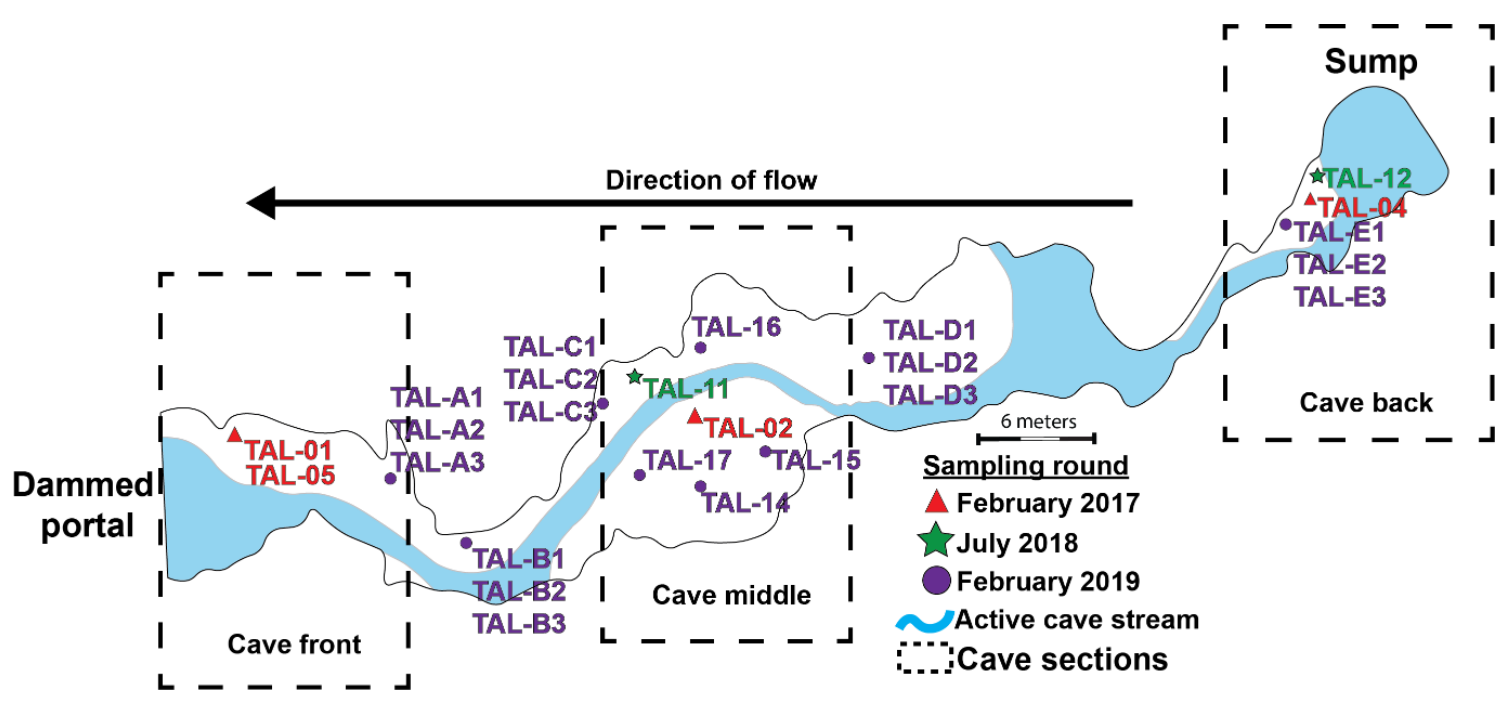

Figure 9: Map of El Tallonal Cave with sampling locations categorized by sampling round. The compartmentalized cave sections are indicated by the dashed boxes. Cave map modified from Lace (2006) 
The cave has three main compartments: the front, the middle, and the back (Figure 9). These divisions are based on cave morphology and major sediment bank locations.

\section{The front}

The dammed portal inhibits the amount of terrestrial input at the entrance (e.g. windblown plant material, biota, dust). The front is approximately 1.2 meters tall x 3 meters wide. An Aquatroll® 600 datalogger is located approximately two meters into the cave from the dammed entrance. Multiple blue crabs and cave scorpions are in the crevasses of the cave ceiling and clastic sediment banks in this portion of the cave.

Connecting the front and middle of the cave is a narrow passageway, approximately 1meter x 1.5 meters and contains soda straws and stalagmites.

\section{The middle}

The middle compartment is approximately seven meters wide by two meters tall and is the largest room in the cave. The sediment banks in this region of the cave are the largest and most accessible. Clastic material within the stream channel contain well-rounded, dominantly pebble and cobble sized grains suggesting that the stream has winnowed out smaller grained material over time. An erosional terrace was observed in the sediment bank on the northern side of the cave stream. This terrace marks the water level when the dam is closed and was present before Hurricane Maria and therefore is not attributed to the flooding caused by the hurricane.

Connecting the middle and back of the cave is a narrow passageway with small (approximately $5 \mathrm{~cm}$ long) soda straws on the cave ceiling.

\section{The back}

The back compartment of the cave is approximately 1.2 meters wide by one meter tall. It contains a clastic bank that hugs the northern side of the cave wall immediately adjacent to a pool marking the end of the accessible passage.

\subsubsection{Cueva Clara (CAM)}

Cueva Clara is part of the National Parks Company of the Commonwealth of Puerto Rico natural protected area and is located in the Río Camuy cave system (Figure 8). It is the main 
toured portion of the Río Camuy system and has direct vehicle and walkway access to the entrence. The interior of the cave has paved walkways for tourism. The National Parks Company owns and maintains the cave, however, as of 02/16/2019 the park has remained closed to the public as a result of the damage from Hurricane Maria.

This system has been carved by the Río Camuy River, the third largest subterranean river in the world (Nieves-Rivera, 2003). The Río Camuy cave system contains multiple levels above the existing stream level as a result of the Río Camuy River diverting underground as baseflow lowered. Cave sediments from the upper most levels of the system, dated using cosmogenic isotopes ( ${ }^{10} \mathrm{Be}$ and ${ }^{26} \mathrm{Al}$ ), are up to $4.5 \mathrm{MA}$ (Miller, 2018). Cueva Clara is a dry cave due to the vertical abandonment of the Río Camuy River. It contains two main portals, both at the base of large sinkholes (Figure 10). The Río Camuy River is at the base of the Emplane Sinkhole making the back portion of Cueva Clara a karst window overlooking the bottom level of the Río Camuy system.

The Río Camuy River level rose as result of Hurricane Maria so that it reached the entrance of Cueva Clara via the Emplame Sinkhole, completely flooding it. Once the river levels returned to baseflow after the storm, approximately 0.4 meters of sediment was deposited throughout the cave as determined by the height of sediment accumulation on the paved walkways after the flooding subsided. Cueva Clara also contained a large bat population, all of which were decimated due to the flooding from the hurricane. 

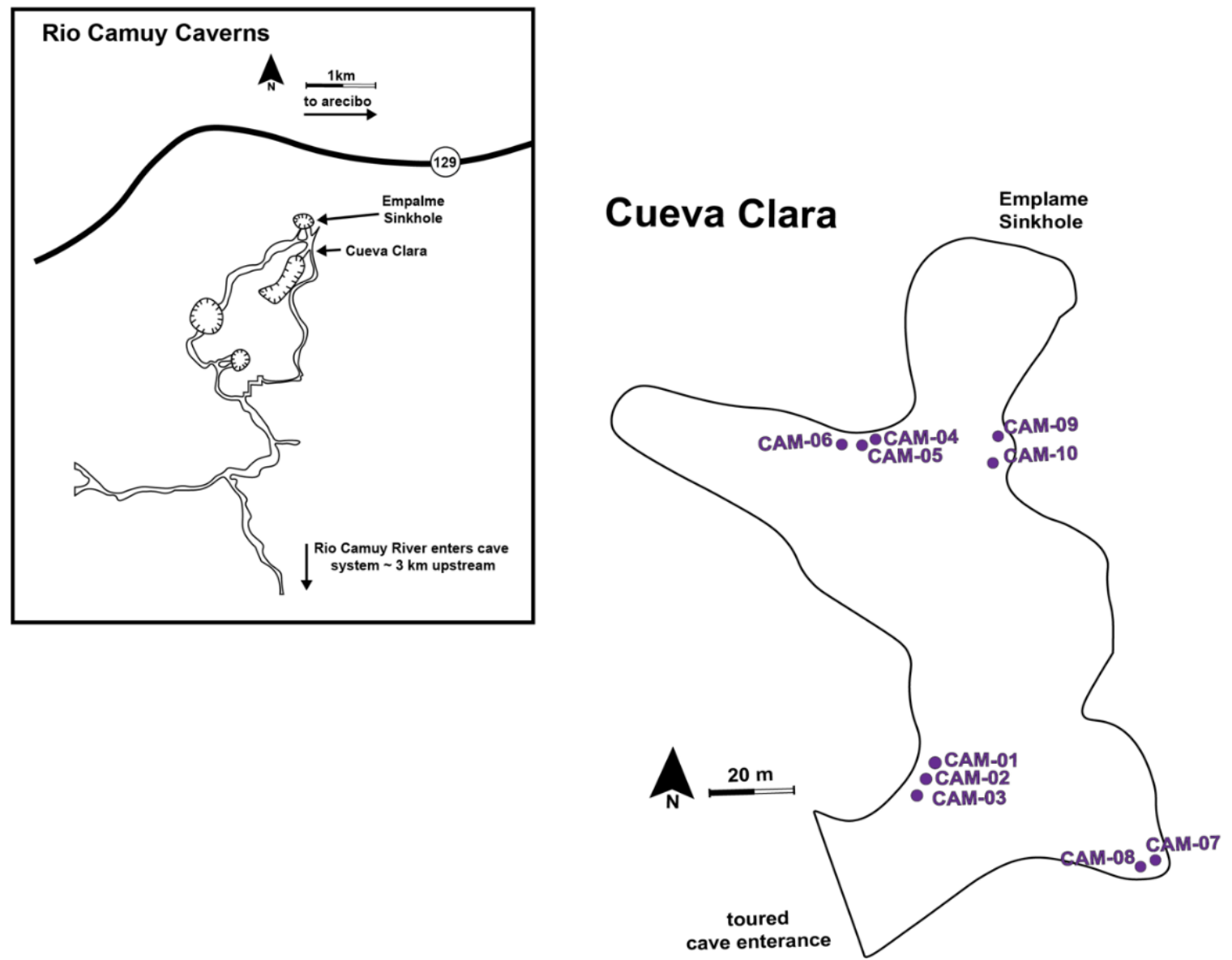

Figure 10: Map of Cueva Clara with sample locations labeled. The toured cave entrance and overlook to the Emplame Sinkhole are also labeled. Cave map modified from Nieves-Rivera (2003) and Acosta-Colon (2016). 


\subsection{Methods}

\subsection{Sample collection}

Three sampling rounds were conducted, and both grab samples and sediment core were collected (Table 3). Core samples were collected using 5 x $30.5 \mathrm{~cm}$ polyethylene core sleeves. Cores collected from TAL were sampled using hand force to slide the polyethylene core sleeve into the sediment. Core samples from CAM were collected using an AMS soil corer with a slide hammer attachment.

After collection all samples were refrigerated and kept from direct light until further analysis. A detailed list of all samples and analysis completed on each sample is found in Appendix IV.

Samples collected from the front portion of TAL have been excluded in this study. Sample locations TAL-16 and TAL-17 were collected along a diagonal transect through the sediment bank on either side of the stream in the middle portion of the cave (Figure 11). Sediment collected from the middle portion of TAL are the focus of this study (Figure 12).

Core samples from Cueva Clara were collected from various locations throughout the cave (Figure 10). This sediment, deposited by Hurricane Maria, had since dried and hardened. Desiccation cracks were observed on the sediment surface.

\subsubsection{Splitting and describing sediment core}

The cores were split in half lengthwise in order to subsample for specific analysis (Table 4). The core sleeve was split using an AMS safety liner splitter and straight edge blade. Once the core was split, both halves photographed.

Once described, one half of the core was subsampled for analysis (Figure 13). Subsamples were collected from depths in which visible change had occurred (e.g. color change, grain size change, and textural change). Each subsample had a thickness of $1 \pm 0.5 \mathrm{~cm}$. If a given subsampled section was thinner than one $\mathrm{cm}$ the subsample was collected from only the desired section. The depth relative to the top of the core was incorporated into the sample tracking ID (Appendix IV). Samples were later converted to a depth relative to a datum within the cave. The depth relative to the datum of each subsample is found in Appendix IV.

The unsampled half was stored and later analyzed using XRF. After splitting and subsampling the core, it was wrapped in aluminum foil, labeled, and refrigerated. 
Table 3: Samples collected organized by sampling round and type of samples collected.

\begin{tabular}{lccl}
\hline \hline Sampling round & $\begin{array}{c}\text { Sampling } \\
\text { locations }\end{array}$ & Method & Number of samples \\
\hline (1) Feb 2017 & TAL $^{a}$ & Grab samples & 4 Grab samples \\
(2) July 2018 & TAL $^{a}$ & Grab samples & 11 Grab samples \\
(3) Feb 2019 & TAL $^{a}$ & $\begin{array}{l}\text { Grab and core } \\
\text { samples }\end{array}$ & 20 Grab samples \\
& & Core samples & 18 Core samples \\
(3) Feb 2019 & CAM $^{b}$ & & \\
\hline $\begin{array}{l}{ }^{a} \text { El Tallonal Cave } \\
{ }^{b} \text { Cueva Clara }\end{array}$ & & &
\end{tabular}




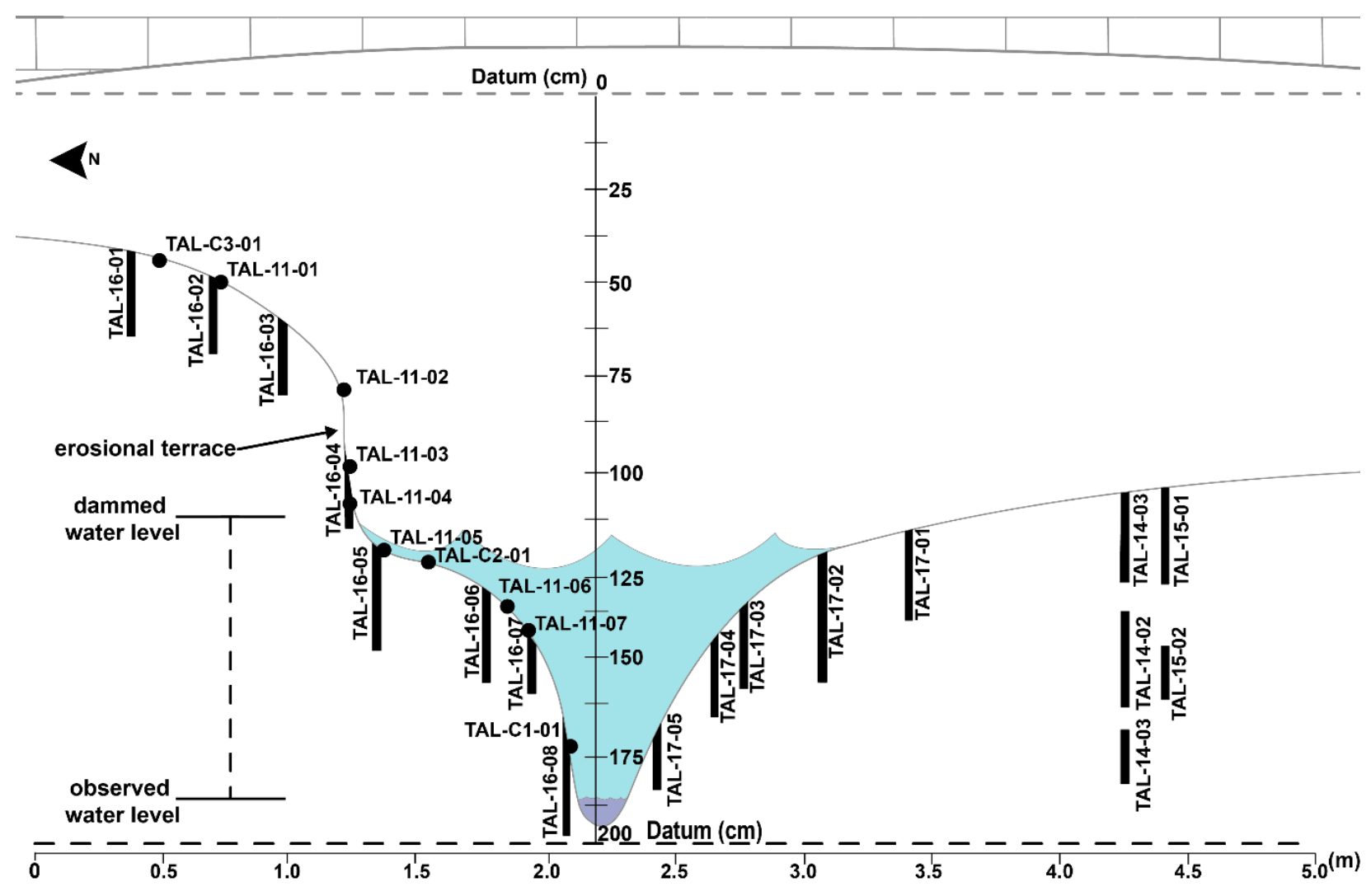

Figure 11: Generalized cross section of the middle of El Tallonal Cave with sample locations included. Point locations represent grab samples. Sample locations with a length represent sediment cores. Observed water level (dark blue) and dammed water level (light blue) are indicated. Samples were given a depth relative to the datum illustrated in this figure. 


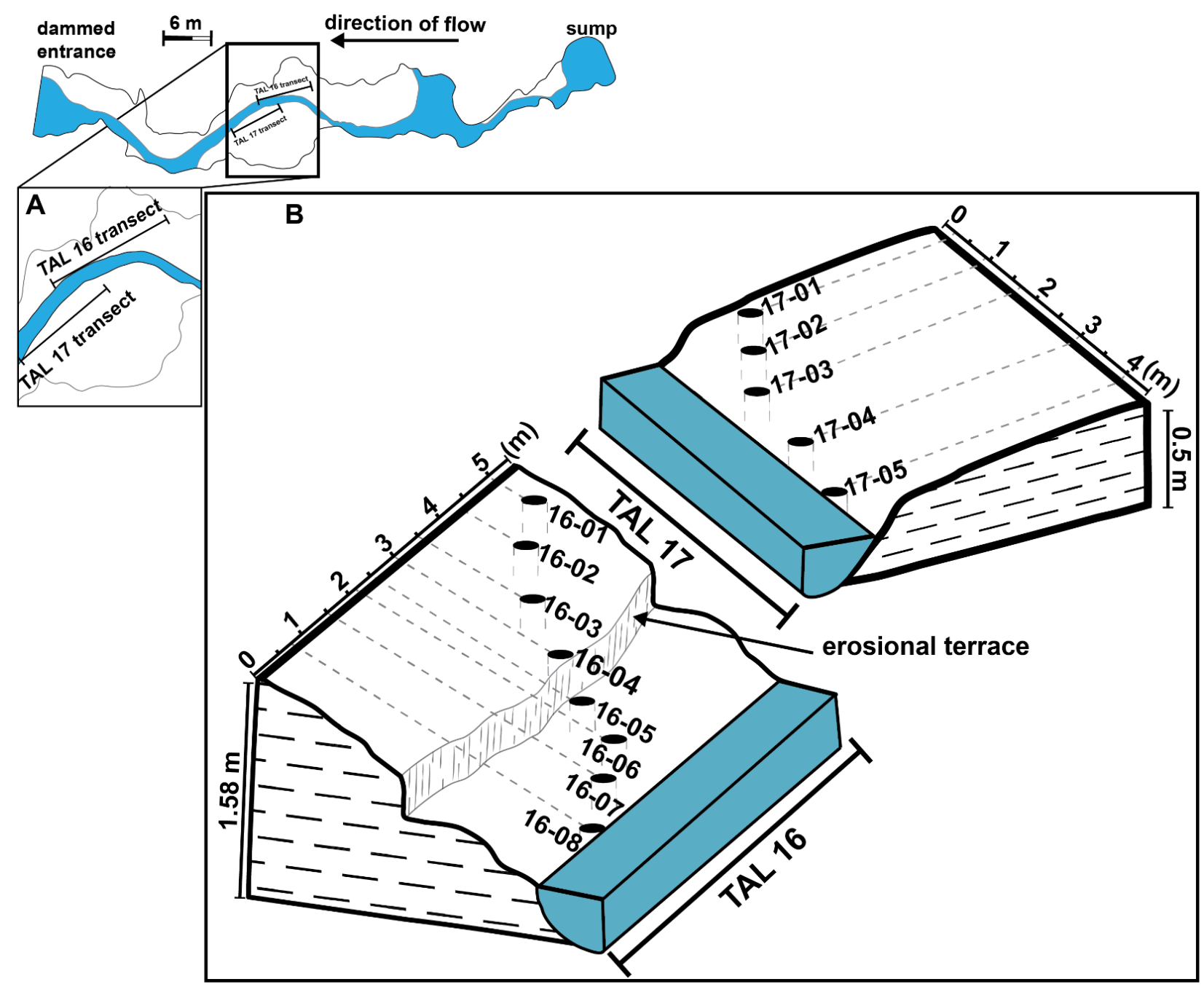

Figure 12: The spatial distribution of sample locations TAL-16 and TAL-17. Sample locations TAL-16 and TAL-17 were collected in a diagonal transect along a sediment bank in the middle of the cave. Dammed water level is depicted. A) sample transect location in the middle of the cave. B) location of collected core samples along the transect. 
Table 4: Analysis completed on collected subsamples.

\begin{tabular}{|c|c|c|c|}
\hline Analysis & $\begin{array}{l}\text { Mass needed } \\
(\mathrm{g})\end{array}$ & Storage container & Sample preparation \\
\hline $\mathrm{TOC}^{a}$ and $\mathrm{TN}^{b}$ & $1-2$ & Plastic petri dish & $\begin{array}{l}\text { Air-dried, oven-dried at } \\
60^{\circ} \mathrm{C} \text { and lightly ground }\end{array}$ \\
\hline Particle size & $2-3$ & $50 \mathrm{~mL}$ centrifuge tube & $\begin{array}{l}\text { Sediment, Calgon powder, } \\
\text { and DIc slurry }\end{array}$ \\
\hline $\mathrm{FS}^{\mathrm{e}}$ & 3 & Aluminum foil & Alkaline $\mathrm{OM}^{d}$ extraction \\
\hline $\mathrm{XRF}^{f}$ & $\mathrm{~N} / \mathrm{A}$ & $\begin{array}{l}\text { Split plastic core sleeve } \\
\text { wrapped in aluminum foil } \\
\text { and plastic wrap }\end{array}$ & Air-dried \\
\hline \multicolumn{4}{|c|}{$\begin{array}{l}a \text { Total organic carbon } \\
b \text { Total nitrogen } \\
{ }^{c} \text { Deionized water } \\
d \text { Organic matter } \\
\text { e Fluorescence spectroscopy } \\
{ }^{f} \text { X-ray fluorescence } \\
\end{array}$} \\
\hline
\end{tabular}




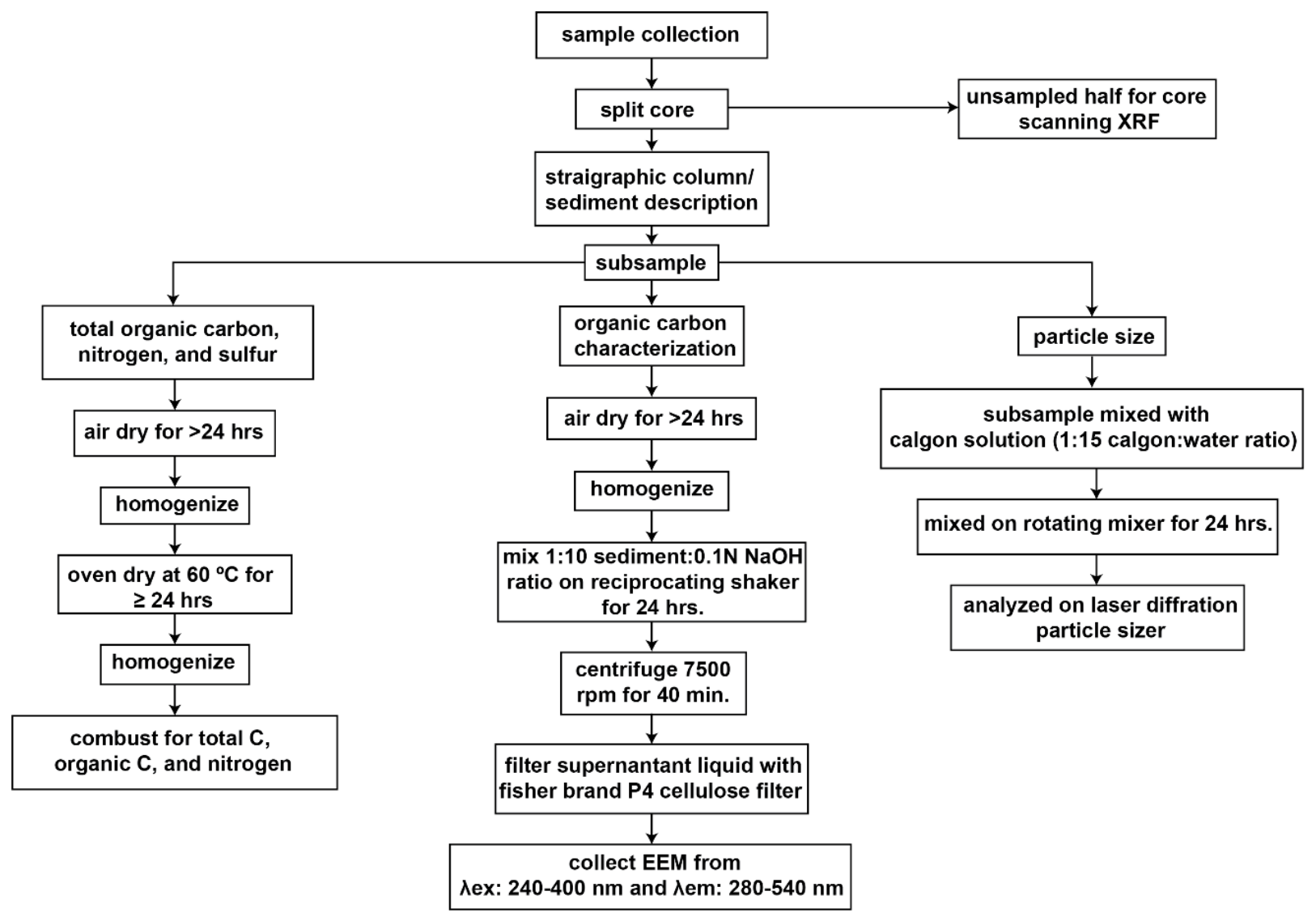

Figure 13: Flow chart illustrating subsampling and laboratory analysis. 


\subsection{Laboratory analysis}

\subsubsection{Particle size analysis}

Subsamples for particle size analysis were prepped using a 1:1.5 (v/v) sediment to five percent Calgon solution ratio. The sediment slurry was placed on a rotary shaker at $70 \mathrm{rpm}$ overnight. Sediment slurries were analyzed using a Beckman Coulter single wavelength LS13320 particle size analyzer that measures sizes between $0.4 \mu \mathrm{m}$ and 2,000 $\mu \mathrm{m}$ based on Fraunhofer diffraction theory. Particle size is reported as a function of volume percent.

Raw data files from the instrument were organized in $\mathrm{R}$ and processed through the GRADISTAT program (Blott and Pye, 2001). This program computes grain size, sorting and skewness, as modified from Folk and Ward (1957) (Figure 14).

\subsubsection{Elemental analysis using ICP-OES}

Inductively coupled plasma - optical emission spectroscopy (ICP-OES) was used to measure major and trace elemental concentrations of selected reference samples (16 in total) following a lithium borate fusion method. This fusion method involves melting the sample matrix with lithium tetraborate and subsequently dissolving the mixture in nitric acid. Lithium borate fusion facilitates a complete dissolution of the resulting mixture. The fusion and ICP-OES analyses were completed by Activation Laboratories, Inc. of Anacaster Ontario following their lithogeochemsitry method - code 4Litho.

\subsubsection{Elemental analysis using $X R F$}

Sediment samples were analyzed for elemental concentrations using XRF. Both the loose sediments and the core samples were measured using a low energy scan (for major elements, plus $\mathrm{Ba}, \mathrm{V}$ and $\mathrm{Cr}$ ) and high energy (for trace elements) conditions using a Bruker AXS TRACER III-V ED-XRF equipped with a Rh X-ray tube. Low-energy analysis was completed at $15 \mathrm{kV}$ and $34.4 \mu \mathrm{A}$, with helium, and a count time of $60 \mathrm{~s}$. High-energy analysis was completed at $40 \mathrm{kV}$ and $25 \mu \mathrm{A}$, with an $\mathrm{Al}-\mathrm{Ti}-\mathrm{Cu}$ filter, and a count time of $60 \mathrm{~s}$ (Rowe et al., 2012). Core scans were completed in $2.0 \mathrm{~mm}$ intervals using an automated core scanner apparatus that houses the handheld XRF described above (Figure 15). All XRF scans were completed at the University of Utah's Records of Environment and Disturbance (RED) lab. 
A

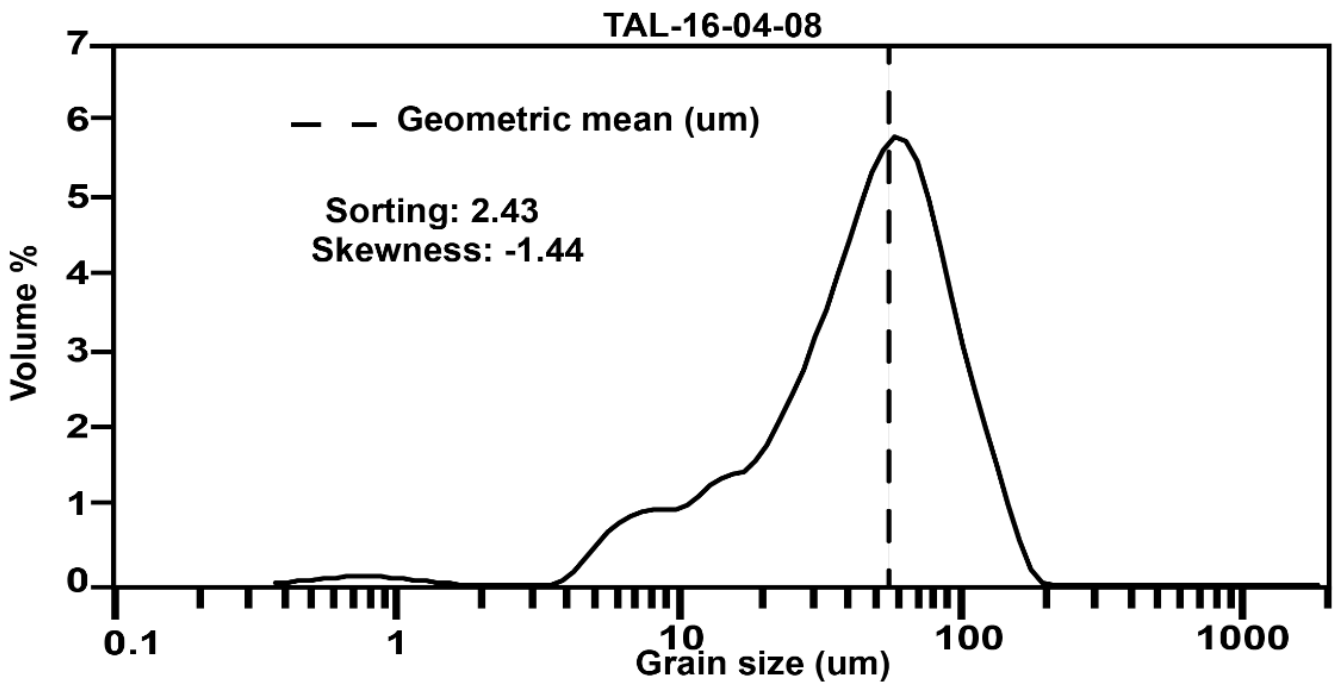

B
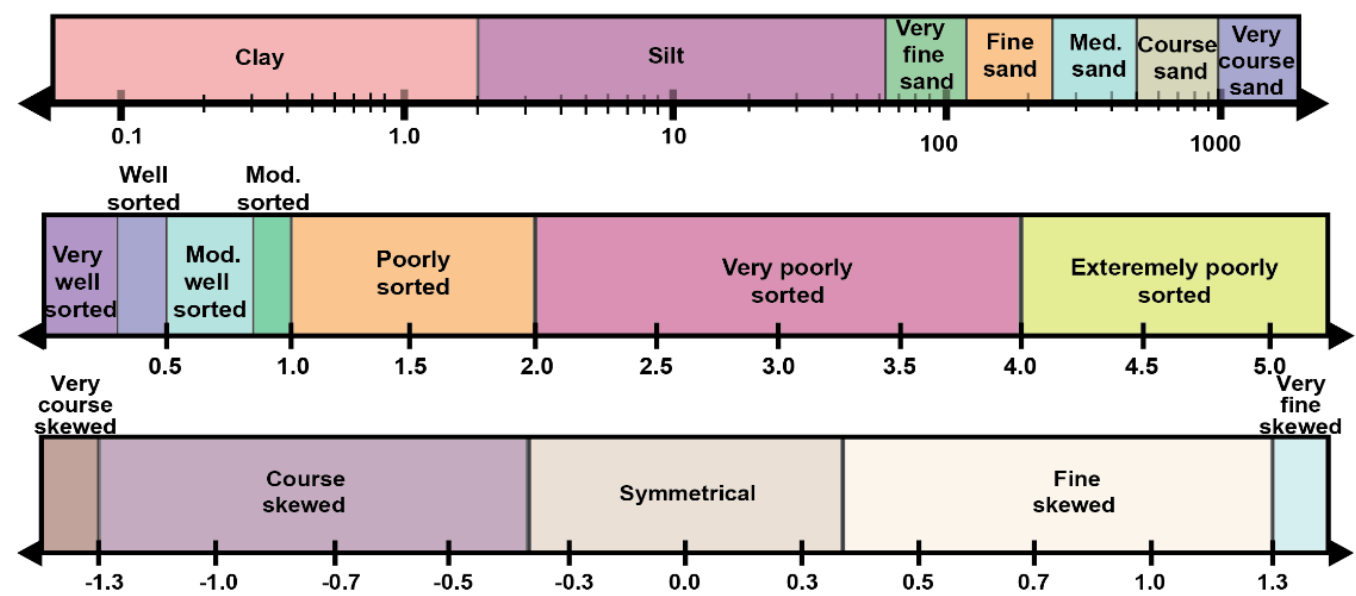

Figure 14: A) Particle size distribution of a sample collected from El Tallonal Cave as a function of volume percent with geometric mean, sorting, and skewness as reported in the GRADISTAT program. B) Grain size, sorting, and skewness divisions in the GRADISTAT program. Modified from Blott and Pye (2001). 

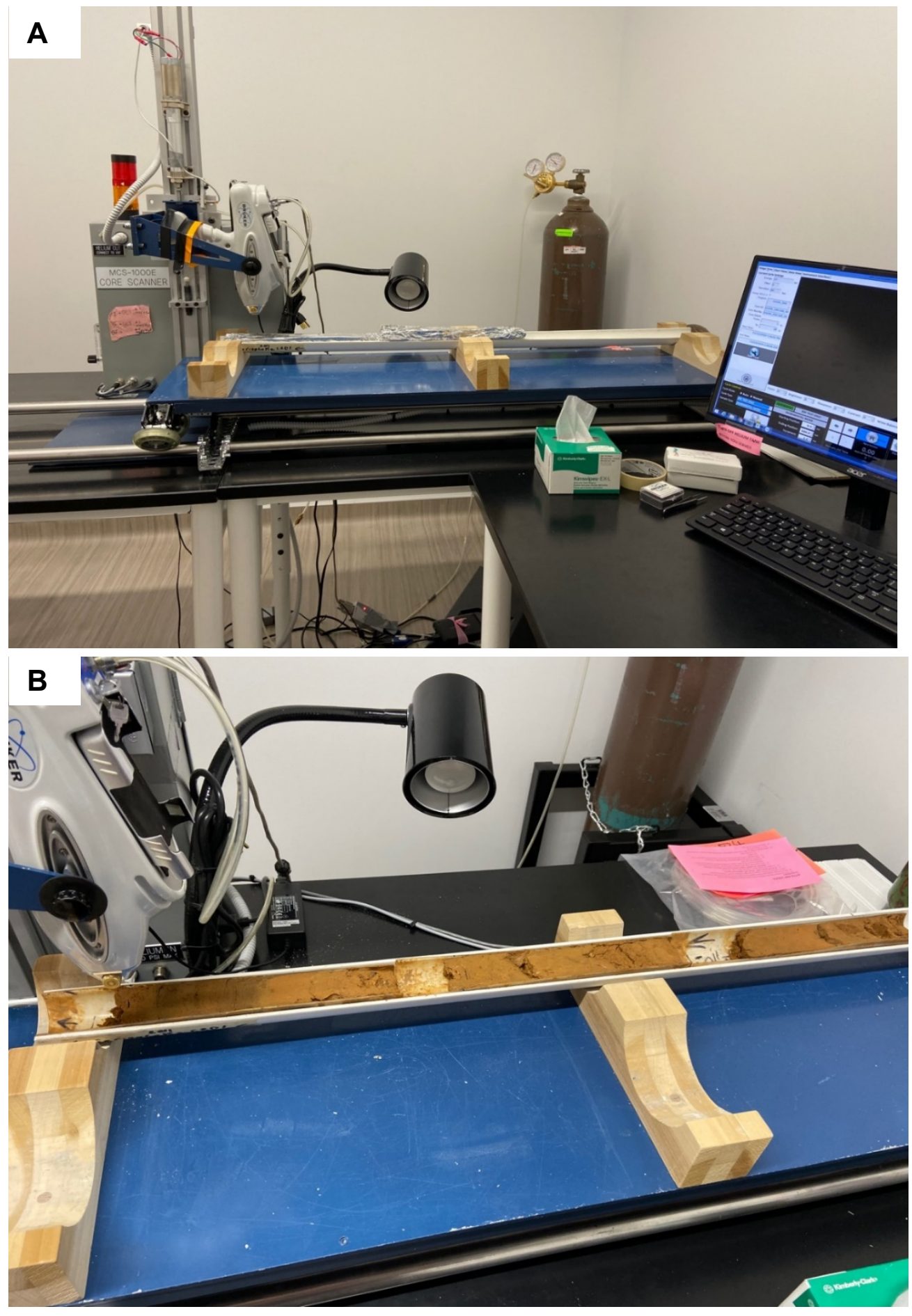

Figure 15: A) Photo showing the XRF core scanner located at the University of Utah's RED lab. $B)$ The XRF core scanner with a sediment core loaded and ready for scanning. 
Collected XRF data were quantified using a modified version of the mudrock calibration created by Rowe et al. (2012). Selected reference samples were air dried, pulverized to $<74 \mu \mathrm{m}$, placed in an X-ray translucent plastic container in order to protect the instrument sensor, and subsequently analyzed using the same X-ray conditions as previously described. These reference spectra were loaded into proprietary Bruker AXS calibration software (S1CalProcess).

Reference concentrations of each element collected from ICP-OES as described in section 4.2.1 were evaluated against the raw photon counts from each element calculated by inter-element slope and baseline corrected peak heights. Because the software used to create this calibration is proprietary, a full disclosure and discussion of the calibration routines is currently not available. Calibration was created by collaborators from the University of Utah following methods outlined in Kipnis et al. (2019)

Core sample preparation involved storage just above freezing $\left(\sim 0.5^{\circ} \mathrm{C}\right)$ to facilitate drying. For analysis, cores must have water content $<40$ percent (MacLachlan et al., 2015). Once dried, the core was placed on the automated core scanner and covered in an X-ray translucent plastic wrap in order to protect the instrument sensor and analyzed using the same X-ray conditions as previously described.

After data collection, significant post-processing and data manipulation was performed. Spectra collected from the core were filtered through to pick out any compromised scans. This included scans in which the total photon counts were $<3000$ cps or where argon photon counts were $>1000$ cps. Compromised scans occured due to three major reasons; (1) there existed too large of a gap between the instrument sensor and the core; (2) a gap in the core itself; or (3) a gap between the end of one core and the beginning of another. Given that the scan interval was 2.0 $\mathrm{mm}$, excluding compromised scans did not necessarily affect the data trends through the core.

The custom calibration was applied to the filtered raw spectra using proprietary software from Bruker. Once applied, raw photon counts were converted to concentrations and the fully processed data was exported into excel.

\subsubsection{Total carbon, total organic carbon, total inorganic carbon, and total nitrogen}

Approximately three grams of sediment were placed into a plastic petri dish and left to air dry for two days. Once the sample was air dried it was homogenized and oven dried at $60^{\circ} \mathrm{C}$ for 24 hours. After oven drying, the sample was homogenized a second time. After preparation, the 
samples were sent to the University of Florida's Stable Isotope Mass Spectrometry Lab for analysis.

\subsubsection{TC and TN}

Samples were analyzed using Carlo Erba NA1500 CNHS elemental analyzer. After flash combustion the sample gas was passed through a hot reduction column $\left(650^{\circ} \mathrm{C}\right)$ consisting of reduced elemental copper to remove oxygen and a chemical (magnesium perchlorate) trap to remove water, finally reaching a gas chromatography column at $125^{\circ} \mathrm{C}$ that separates the $\mathrm{N}_{2}$ and $\mathrm{CO}_{2}$ gases.

\subsubsection{TIC and TOC}

Total inorganic carbon (TIC) was measured coulometrically using a UIC (Coulometrics) $5017 \mathrm{CO}_{2}$ coulometer. The sediment samples were placed into vials topped with septa. A double needle assembly was used to purge the sample vial of atmospheric gas using $\mathrm{CO}_{2}$-free nitrogen carrier gas. Acid was then injected into the sample vial and evolved $\mathrm{CO}_{2}$ was carried to the coulometer where total carbon as $\mathrm{CO}_{2}$ was measured.

Total organic carbon (TOC) was obtained by taking the difference between total carbon (TC) and TIC.

\subsubsection{Fluorescence Spectroscopy (FS)}

Characterization of sediment organic carbon was performed using a Horiba Scientific FluoroLog-3 spectrofluorometer system. This system is configured with 450-Watt light source, single grated emission monochromator, and a single grated excitation monochromator. Excitation-emission matrices (EEM) were collected from $\lambda \mathrm{ex}$ : 240-400 nm and $\lambda \mathrm{em}$ : 280-540 $\mathrm{nm}$ and a slit width of one $\mathrm{nm}$ for both the excitation source and emission detector. $1^{\text {st }}$ and $2^{\text {nd }}$ order Rayleigh scattering were removed before and after each scan.

Aqueous tryptophan, tyrosine, and humic acid were used as a standard reference for the EEM scans (Figure 16). Tryptophan and tyrosine are both amino acids and are used as a reference for the characteristic peak T ( $\lambda$ ex: $275 \mathrm{~nm}$; $\lambda \mathrm{em}$ : $340 \mathrm{~nm}$ ) and peak B ( $\lambda$ ex: $275 \mathrm{~nm}$; $\lambda \mathrm{em}: 310 \mathrm{~nm}$ ) in Coble (1996), respectively. Humic acid is a more complicated material and therefore does not have a distinct fluorescence peak but rather a region $(\lambda \mathrm{ex}: 250-400 \mathrm{~nm}$; $\lambda$ em: 
375-550). Specifications of the fluorometer used in this study restricted the possibility of measuring fluorescence response of raw sediments (Appendix III)

Organic matter was extracted into an aqueous form. There many ways to extract organic matter from a solid medium with results dependent on the method. Comparisons between two extraction methods were performed: (1) $0.1 \mathrm{M}$ sodium hydroxide and; (2) $0.1 \mathrm{M}$ sodium pyrophosphate $\left(\mathrm{Na}_{4} \mathrm{P}_{2} \mathrm{O}_{7}\right)$ (Chen and Hur, 2015; Greenfield et al., 2018) (Appendix II). Results from this comparison concluded that using $0.1 \mathrm{NaOH}$ as the extraction solution yielded a higher florescence response and thus all extractions were performed using $\mathrm{NaOH}$ as the extraction solution. All extractions were completed by following a modified version of the method outlined in Hur et al (2014).

Air-dried sediment measured between three and four grams was mixed with $0.1 \mathrm{M} \mathrm{NaOH}$ solution in a 1:10 sediment:solution $(\mathrm{m} / \mathrm{m})$ ratio and placed overnight on a reciprocating shaker. The sediment-alkaline slurry was then centrifuged at $7500 \mathrm{rpm}$ for 40 minutes. The supernatant liquid was then filtered through a Fisher brand P4 cellulose filter and collected for analysis on the fluorometer following the parameters previously outlined. All organic extractions were diluted by 50 percent when ran for analysis on the fluorometer.

Once an EEM was collected, it was exported to a CSV file. The data were then manipulated in R (Appendix XIII). Raw data collected from the fluorometer was manipulated in $\mathrm{R}$ using the "eemR" package (Massicotte, 2019). This package removed first and second order

Rayleigh scattering from a $15 \mathrm{~nm}$ range and interpolated intensity over the Rayleigh scattering range (Figure 29). All EEMs were normalized to a percent of the maximum intensity for each scan. This was done to normalize the data across all samples for PARAFAC modeling Indices BIX and FI were calculated using formulas contained in the "eemR" package. Parallel factor analysis was performed using the "staRdom" R package (Pucher et al., 2020). Model results from the PARAFAC analysis are reported in section 5.2. Details on the PARAFAC modeling code are found in Appendix XIII.

\subsection{Data analysis}

Stratigraphic columns and core photographs were created and modified in Adobe Photoshop and Illustrator. Figures were created using a combination of Grapher by Golden Software, R, and Microsoft Excel and edited using Adobe Illustrator and Microsoft Excel. 
Post processing was completed in R. All R scripts used in this project can be found in the git repository dedicated to this project (https://github.com/ardowney/Masters thesis). 


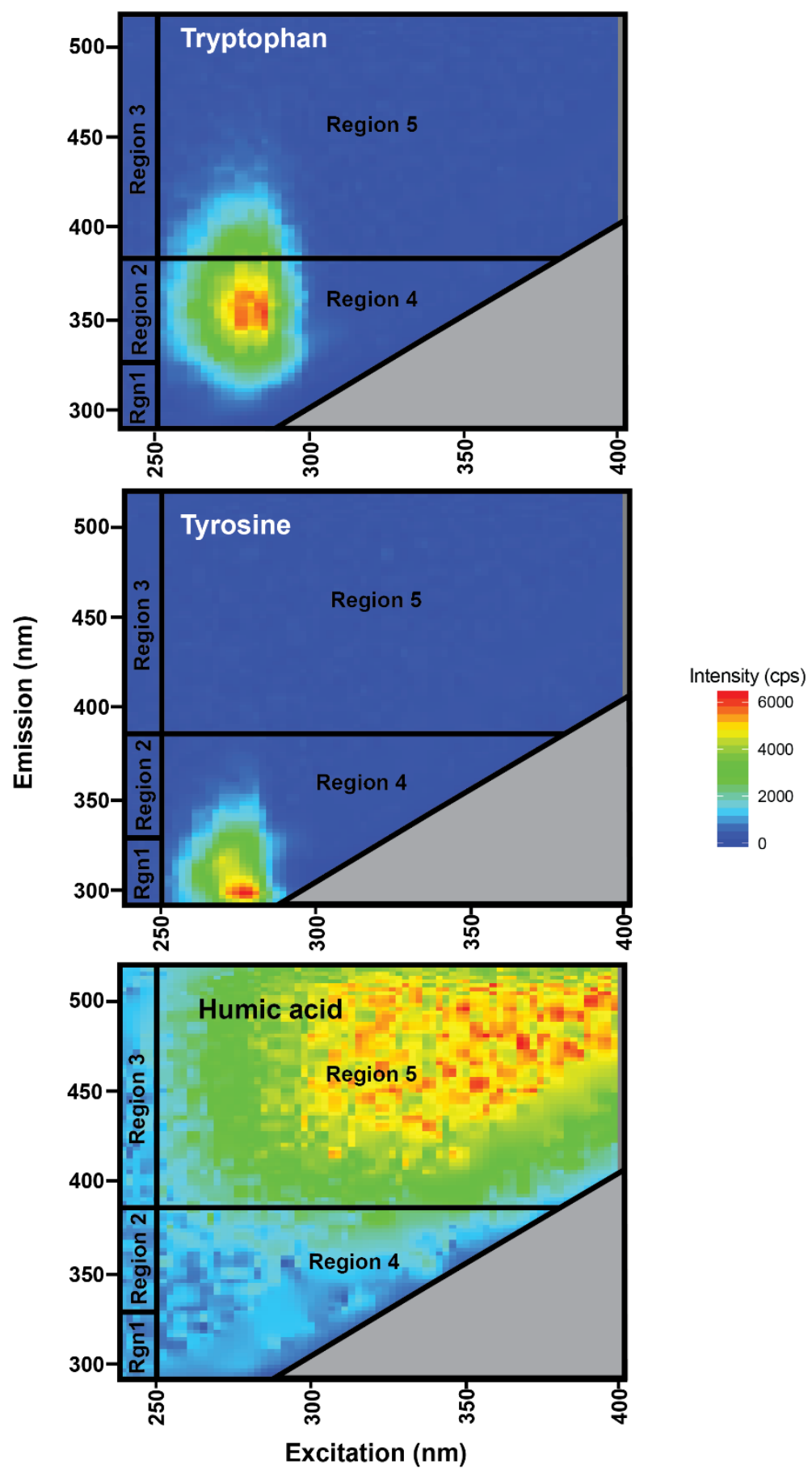

Figure 16: Aqueous phase excitation emission matrix of tryptophan, tyrosine, and humic acid. Regions one through five are indicated. Region classification from Chen et al. (2003). 


\subsection{Results}

\subsection{Sedimentary descriptions}

\subsubsection{Bulk grain size characteristics}

Particle size data were collected on subsamples from TAL $(\mathrm{n}=156)$ and CAM $(\mathrm{n}=58)$

(Figure 17). Sand- and silt-sized grains composed most of the sediments from both locations. The samples from TAL contained a slightly higher proportion of clay than those from CAM. Proportion of sand and silt ranged from 0 percent to 95 percent. Clay proportions are less variable, ranging from 0 percent to 20 percent.

Medium sand was the dominant sand-sized fraction in all subsamples collected from TAL. Coarse silt was the dominant grain size in the mud-sized fraction (silt and clay) in all subsamples collected from TAL. Fine sand was the dominant sand sized fraction in all CAM subsamples. Coarse and medium silt was the dominant mud sized fraction in all CAM subsamples.

All sediments collected from TAL and CAM are categorized as poor to extremely poorly sorted (>2.0). Inspection in the lab with a magnifying glass showed that many of the more "clay$y$ " layers contained small amounts of fine to medium sand. It is likely that the presence of these sand grains resulted in the poorly sorted classification. Another factor potentially controlling the poorly sorted classification are the cohesiveness of clay particles resulting in clumping of smaller clay particles into larger grains and skewing the results collected on the particle analyzer. Though precautions were taken to avoid clumping (section 4.2.1) completely eliminating clumping of clay particles is effectively impossible.

Due to the cohesiveness present in the TAL sediments, a high proportion of clay was expected from the particle size analysis. This was not the case, suggesting that only a small proportion of clay is needed in order create a cohesive sediment. Additional cohesiveness could be a result of microcrystalline $\mathrm{Fe}, \mathrm{Al}$, and $\mathrm{Mn}$ oxide coatings on the sediment grains.

\subsubsection{TAL surface sediments}

Surface sediments were collected from one, two and three meters away from the stream throughout the cave (Table 5). Mean grain size was largest $(140 \mu \mathrm{m})$ in the back of the cave, 2 meters from the stream (TAL-E2-01-00). This sample contained 68 percent sand and had mean grain size larger than the surrounding sediment (Figure 18). This sample also had the poorest 
sorting (7.1; extremely poorly sorted). Sediment with the lowest mean grain size $(12 \mu \mathrm{m})$ is also located in the back of the cave, one meter away from the stream. This sample contained 99 percent fine-grained materials (silt and clay). In the middle of the cave (TAL-C), mean grain size one, two, and three meters away from the stream had little variation but sediment furthest away from the stream were the least sorted (Figure 18).

Sorting values on all surface sediments are $>2.0$, categorizing them as very poorextremely poorly sorted (Appendix VI). Lower sorting values indicate better sorting. There is a negative correlation between percent silt and sorting (Figure 19). The correlation between sorting and percent clay is not statistically-significant $\left(\mathrm{R}^{2}=0.12 p\right.$ value $\left.>0.05\right)$. Within the fine-grained material (silt and clay) course silt is the dominant size. Within the sand sized fraction, medium sand is the dominant grain size. There is no apparent trend in grain size or sorting spatially from the back to the front of the cave (Figure 18).

Sediments collected from one, two and three meters from the stream also had no apparent trend between location with either grain size or sorting. This is likely a function of the complex geomorphology of the cave passage. Groundwater flow before the stream enters the conduit in the back portion of the cave (labeled sump in figure 9) limits the material able to enter the cave. This controls grain size transport. Fluvial flood deposits include larger grains than those within TAL. While mostly composed of sub-sand sized grains, the poorly sorted nature of surface sediments in TAL indicates allogeneic input and rapid deposition during flood waters. This is further evidenced by the onset of turbidity accompanied by a rain event in the cave stream (pers. comm. Pantoja-Agred, 2016). Very coarse to coarse sand in the front of the cave suggests that high flow events supply enough energy to transport larger grains from the sump to the dammed portal.

It is important to note that well-rounded, pebble-sized clasts were present in the stream channel throughout the cave. This suggests that the cave stream has winnowed out the sediment, presumed to have previously filled TAL, leaving behind only the larger clasts in the stream channel. 
Table 5: Surface sediment sample locations and associated tracking IDs.

\begin{tabular}{lccc}
\hline \hline $\begin{array}{l}\text { Relative } \\
\text { location } \\
\text { within cave }\end{array}$ & Sample location & $\begin{array}{c}\text { Distance from } \\
\text { cave stream } \\
(\mathrm{m})\end{array}$ & Tracking ID \\
\hline Front & TAL-A & 1 & TAL-A1-01-00 \\
& & 3 & TAL-A2-01-00 \\
\hline $\begin{array}{l}\text { Passage } \\
\text { between front } \\
\text { and middle }\end{array}$ & TAL-B & 1 & TAL-A3-01-00 \\
& & 2 & TAL-B1-01-00 \\
\hline Middle & TAL-C & 3 & TAL-B3-01-00 \\
& & 2 & TAL-C1-01-00 \\
& & 3 & TAL-C2-01-00 \\
\hline $\begin{array}{l}\text { Passage } \\
\text { between } \\
\text { middle and } \\
\text { back }\end{array}$ & TAL-D & 1 & TAL-C3-01-00 \\
\hline Back & & 2 & TAL-D2-01-00 \\
& & 3 & TAL-D3-01-00 \\
& & 1 & TAL-E1-01-00 \\
& & 2 & TAL-E2-01-00 \\
\hline
\end{tabular}




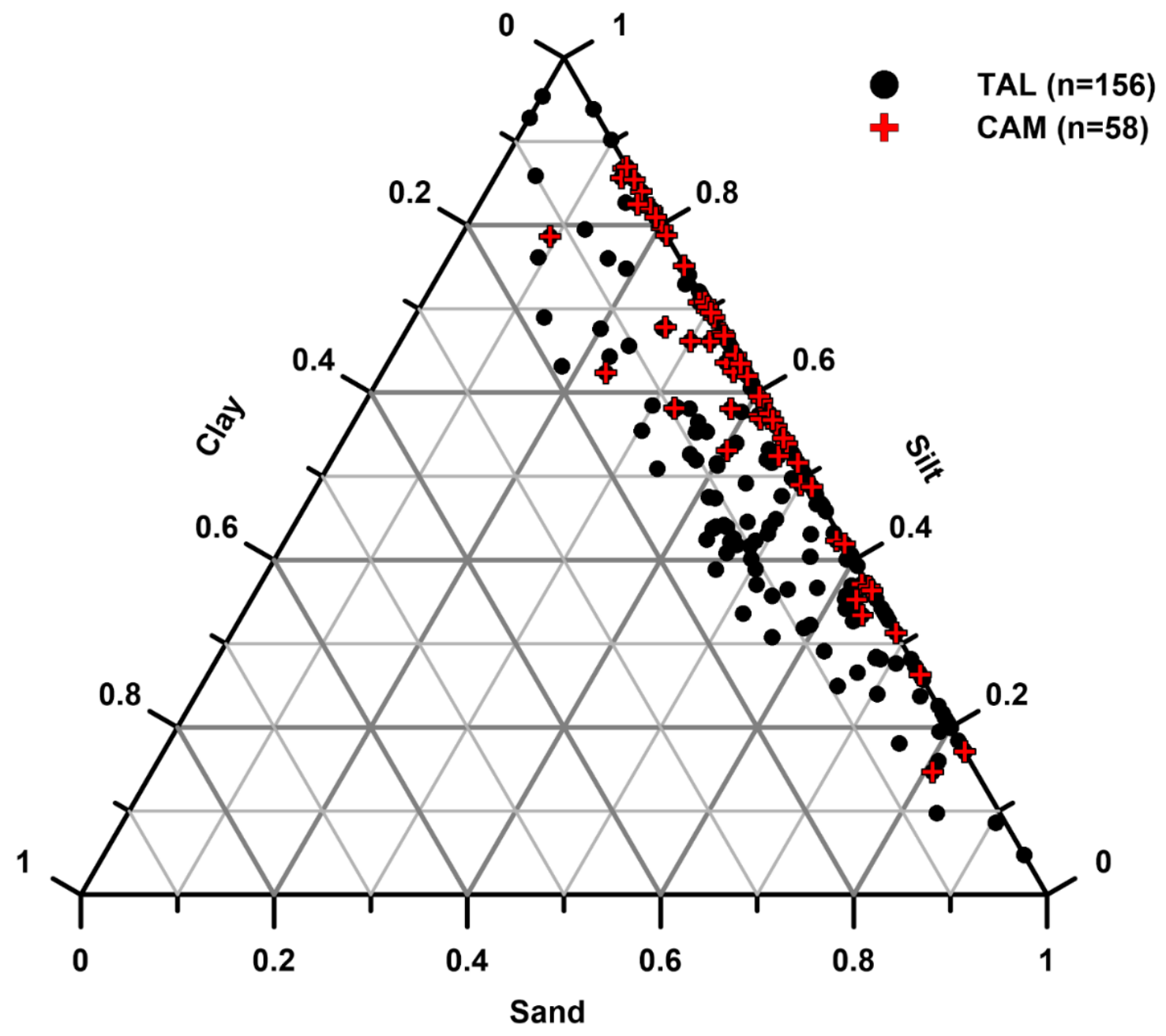

Figure 17: Grain size distribution in El Tallonal Cave (TAL) and Cueva Clara (CAM). Sand, silt, and clay are reported as a fractional proportion. 

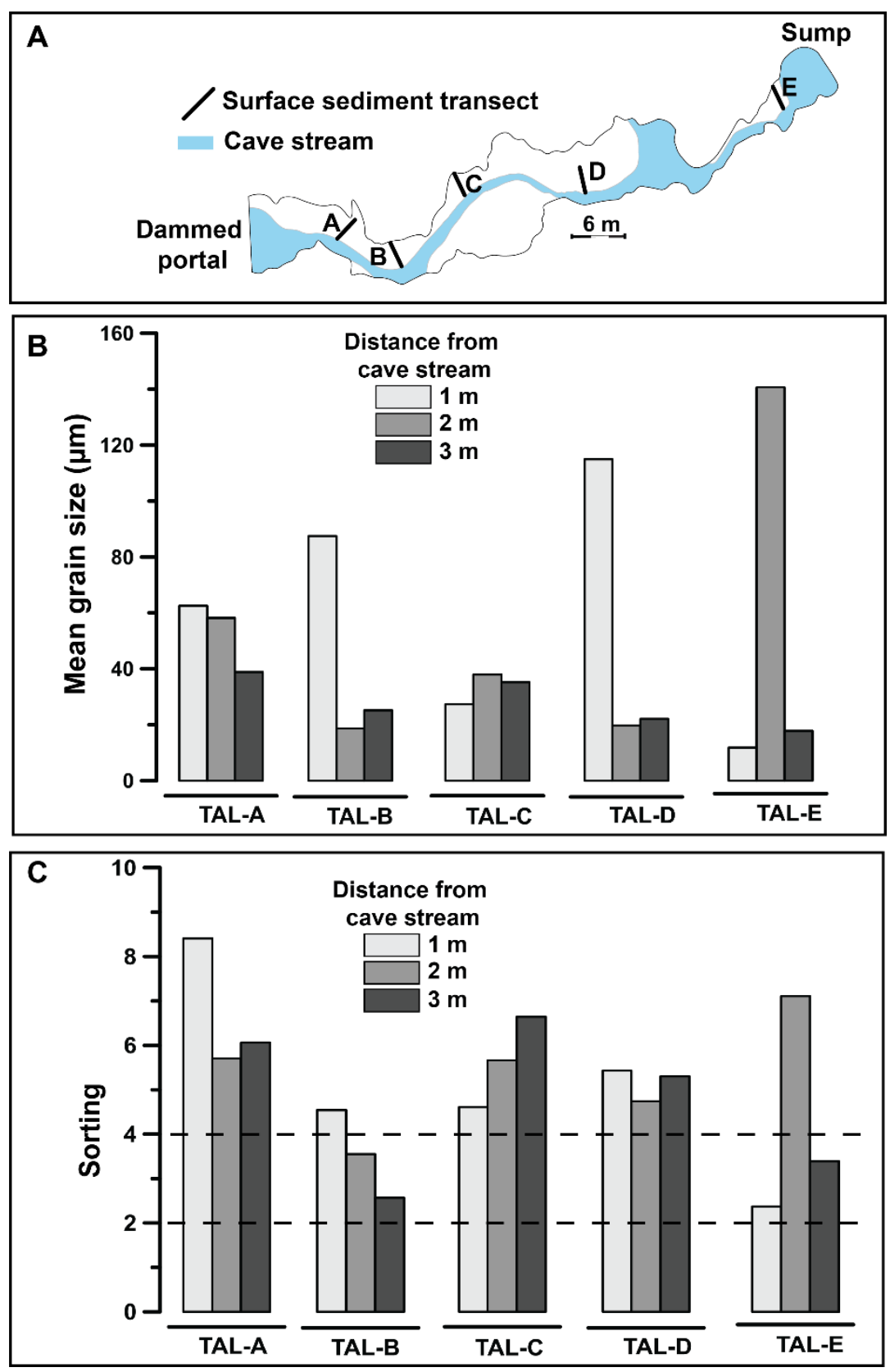

Figure 18: A) Sediment from the sediment bank surface were collected one, two, and three meters away from the cave stream at locations TAL-A through TAL-E. Spatial variation in B) grain size and $C$ ) sorting of sediment surface samples from El Tallonal Cave (TAL). Dashed lines represent poorly sorted (sorting value 2-4) and extremely poorly sorted (sorting value $>4$ ). Sorting values are unitless. Spatial variation in grain size and sorting of sediment surface samples from El Tallonal Cave (TAL). Sediment from the sediment bank surface were collected one, two, and three meters away from the cave stream at locations TAL-A through TAL-E. Dashed lines represent poorly sorted (sorting value 2-4) and extremely poorly sorting (sorting value $>4)$. Sorting values are unitless. 


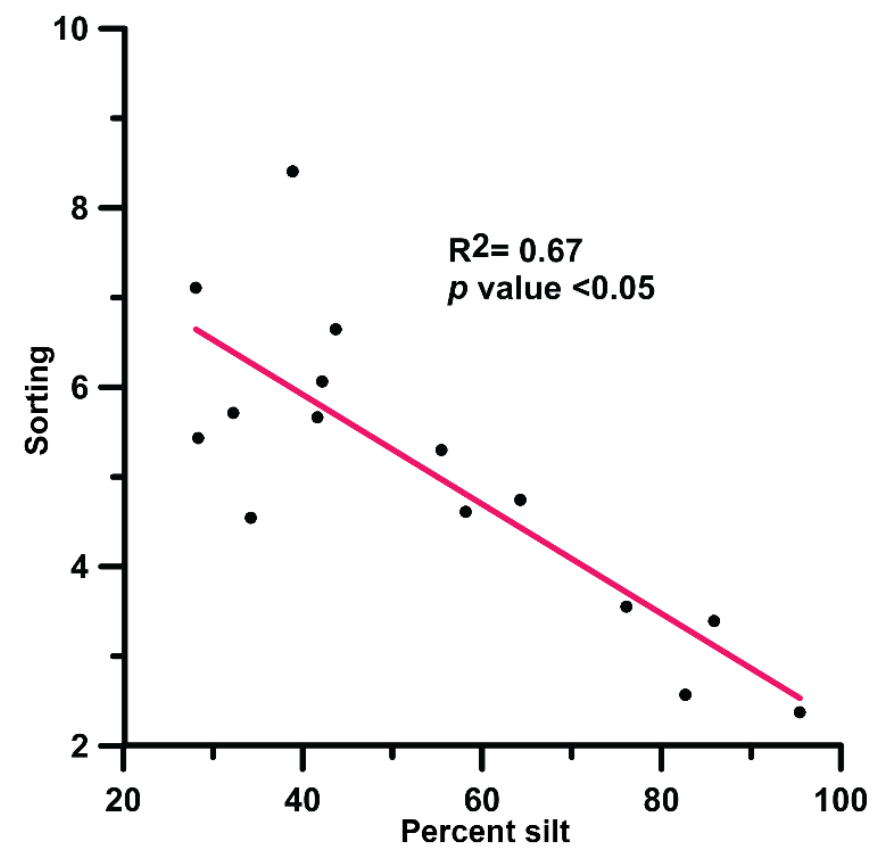

Figure 19: Relationship between percent silt and sorting from surface sediments collected one, two, and three meters away from the stream at locations TAL-A through TAL-E. 


\subsubsection{TAL core sediments}

The dammed portal raises the water level in the cave and lowers the natural flow velocity. Since the dam must be released for researchers to enter the cave, the exact water level when the dam is operational is not exactly known but can be inferred based on the geomorphology of the sediment banks in the middle of the cave. The cave stream flows through the middle room of the cave, resulting in deposition of sediment banks on either side of the stream. The northern sediment bank contains an erosional "terrace" (Figure 12). The sediment bank on the southern side of the cave stream is lower in height and inferred to be the erosional terrace on that side of the cave stream based on the meander bend at that location (Figure 9). Water level when the dam is closed submerges most of the sediment bank on the southern side of the stream and reaches the bank terrace level on the northern side of the stream. Sediments from TAL are deemed saturated or unsaturated based on the location relative to the erosional terrace. The erosional terrace was present prior to the flooding resulting from Hurricane Maria and therefore not caused by the hurricane.

Course silt is the dominant fine-grained material and medium sand is the dominant sand sized material, consistent with trends observed in the surface sediments. Contrary to the surface sediments there is no significant correlation between sorting and percent silt, or sand was observed $\left(\mathrm{R}^{2}=0.09 p\right.$ value $\left.>0.05\right)$.

Redox zonation results from variation in oxygen availability in a natural environment. Speciation, precipitation, or complexation may occur based on the redox conditions of the surrounding environment. The type of redox zonation is controlled by the thermodynamic availability of electron acceptors in an environment (Pinti, 2011). Redox zonation within a sedimentary environment is often observed as color changes resulting from speciation or mineral precipitations. Cores collected from TAL exhibit little "true" stratification. Most layering in the cores are due to variation in cohesiveness, color change, or redox zonation. Cohesive layering below a loose sediment layer separated by a sharp boundary is common.

\subsubsection{TAL-14}

Three cores were collected at TAL-14 sample location. These cores were collected consecutively with depth. Gaps between core segments are due to incomplete recovery. Grain size in these three cores are $50 \pm 10$ percent sand sized (Figure 20). Proportion of sand decreases 
to between 9 and 6 percent from 55 to $60 \mathrm{~cm}$ depth. There is a pebble sized clast of limestone was observed at $44 \mathrm{~cm}$ depth at a boundary between sand and silt layer (Figure 20). A dominantly sand layer from 43 to $52 \mathrm{~cm}$ depth contained small $(1 \pm 0.5 \mathrm{~cm})$ clay "chunks" presumed to be rip up clasts.

\subsubsection{TAL-15}

Two consecutive cores with depth were collected at TAL-15 sample location (Figure 20). Gaps between core segments are a result of incomplete recovery. A cohesive layer from 6-12 cm contained a broken piece of a speleothem (soda straw; $2 \mathrm{~cm}$ in length). Below this cohesive layer is black material that continues through the rest of the core. This black material is angular and brittle. The top of the second core at TAL-15 sample location marks a drastic change in composition and sedimentary characteristics. Layers of the black material are separated by thin layers $(0.5 \mathrm{~cm})$ of cohesive finer grained material. Multiple larger clasts (pebble sized) of this black grained material were observed. These larger clasts were sand-sized grains cemented together. The cause of this cementation is unknown. These cemented grains were individually stratified with sequences of brown/reddish brown and black banding within the larger cemented grains. In total, three sequences of this black material followed by a thin clay layer are present. A sandy layer containing well-rounded pebble sized quartz grains. These grains are likely the same material as those observed in the active stream channel. A total of five pebble sized quartz grains were observed in a "pocket" within a thin $(1 \mathrm{~cm})$ sandy layer. At approximately $45 \mathrm{~cm}$ depth a pristine crystal of calcite is present.

Manganese oxides precipitate preferentially on quartz (Ford and Williams, 2007). While no quantified data were collected on the elemental composition of any of the black material in this core, unquantified XRF scans were. Raw XRF spectra collected from this black material shows higher cps in the energy range associated with Mn florescence. Based on this it likely that the black material is indeed manganese oxide.

Core locations TAL-14 and TAL-15 are located 1.5 m apart. Despite being collected proximal from the same bank, these two core locations have little similarity. No sediment layering or stratification similar enough to be correlated between the two core locations are present. 

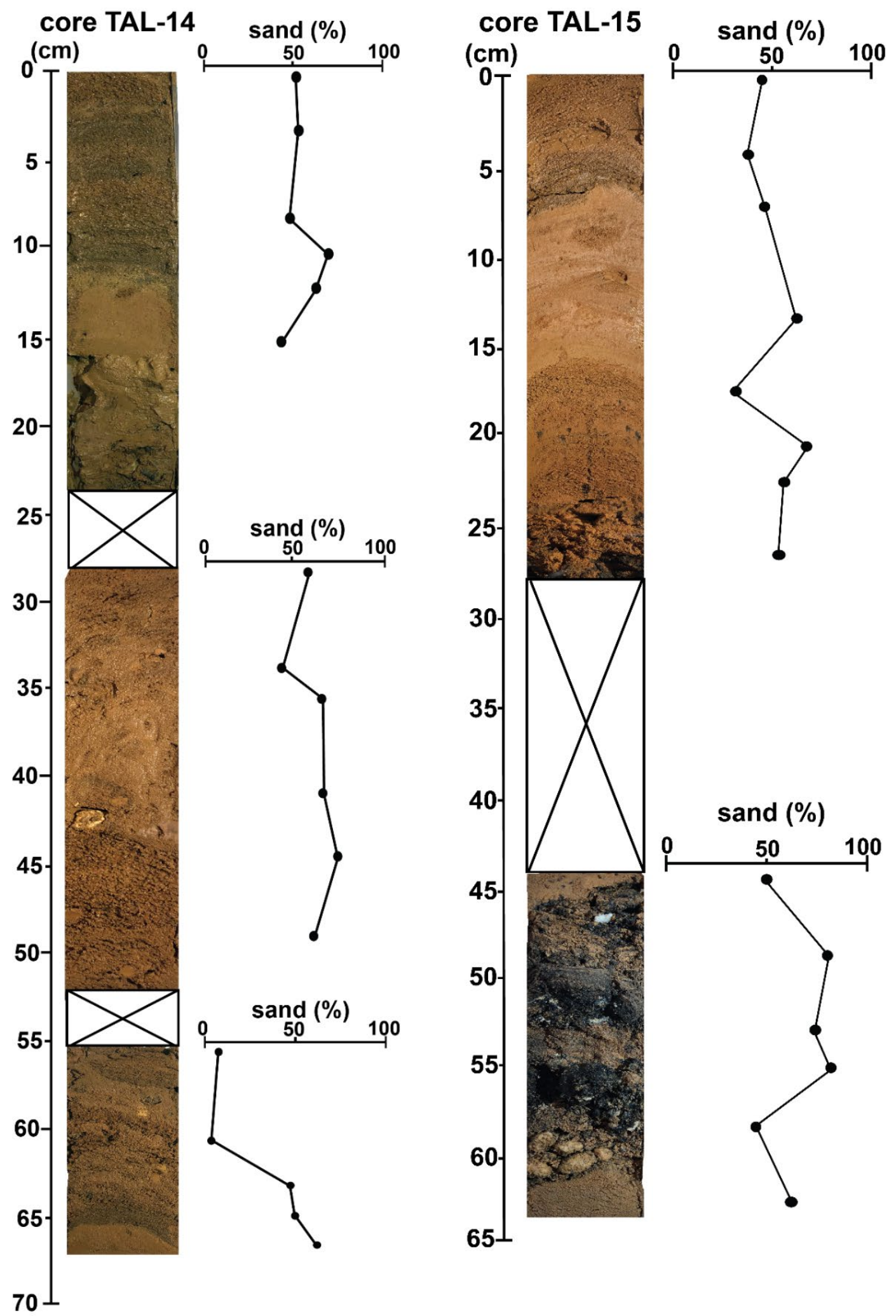

Figure 20: Core photographs and proportion of sand from location TAL-14 and TAL-15. 
Cores TAL-14 and TAL-15 sampled locations were the only core location in which consecutive cores were collected with depth. The lack of stratigraphic correlation between these two locations suggests that correlation of the remaining core sample locations is implausible. There is too much spatial variation between the cores to make correlative interpretations. This is also illustrated by the high variability observed in the sediment characteristics of the previously described surface sediments (Figure 18).

\subsubsection{TAL-16}

Sample location TAL-16 consists of eight sediment cores collected along a diagonal transect along the northern sediment bank in the middle of the cave (Figure 12). Each core is treated separately. This is because the cores are not consecutive in depth and do not contain continuous, correlatable layers.

Four cores were collected from the bank above the erosional terrace and four were collected below the terrace (Table 6; Figure 12). Core TAL-16-01 is dominantly sand (60 percent) and contains no stratification. At $16 \mathrm{~cm}$ depth is a thin layer $(1 \mathrm{~cm})$ of approximately 100 percent fine-grained material (Figure 21). The transition from this fine-grained layer to the sandier layer above is marked by a sharp boundary in sedimentary texture and no color change. Notable sedimentary textures include a small piece $(0.5 \mathrm{~cm})$ of black material and a larger $(1 \mathrm{~cm})$ chunk of clay, likely a rip-up clast.

Core TAL-16-02 contained little to no variation in grain size and lacked any stratigraphic layering or color change. The entire $24 \mathrm{~cm}$ of core is $50 \pm 5$ percent sand (Figure 21). Core TAL16-03 is 50 percent sandy material. The first $13 \mathrm{~cm}$ of core is more cohesive and less sandy than the bottom $7 \mathrm{~cm}$, however, based on the particle size data the proportion of sand similar in both layers. A small piece $(0.2 \mathrm{~cm})$ of black material was observed at nine $\mathrm{cm}$ depth (Figure 21).

Core TAL-16-04 is the last core on the upper terrace. It is closest to the water table when the dam is closed. This sample is extremely cohesive. Hand force was not enough to slide the core sleeve into the sediment. A "chunk" of this approximately $20 \mathrm{~cm}$ section of the bank was sampled instead of collecting a true core. It is dominantly fine-grained (60-90 percent mud-sized) and has little variation in sedimentary texture. There are "hair-like" strands of black material that transitions into distinct banding (Figure 21). It is likely that the banding observed in this core is redox zoning resulting from changes in oxygen availability due to fluctuations in water level. 
Table 6: Cores collected from sample location TAL-16 and position relative to the dammed water level.

\begin{tabular}{ll}
\hline Core & \multicolumn{1}{c}{ Saturated/Unsaturated } \\
\hline TAL-16-01 & Unsaturated \\
TAL-16-02 & Unsaturated \\
TAL-16-03 & Unsaturated \\
TAL-16-04 & $\begin{array}{l}\text { Unsaturated/saturated } \\
\text { depending on water level }\end{array}$ \\
TAL-16-05 & Saturated \\
TAL-16-06 & Saturated \\
TAL-16-07 & Saturated \\
TAL-16-08 & Saturated \\
\hline
\end{tabular}




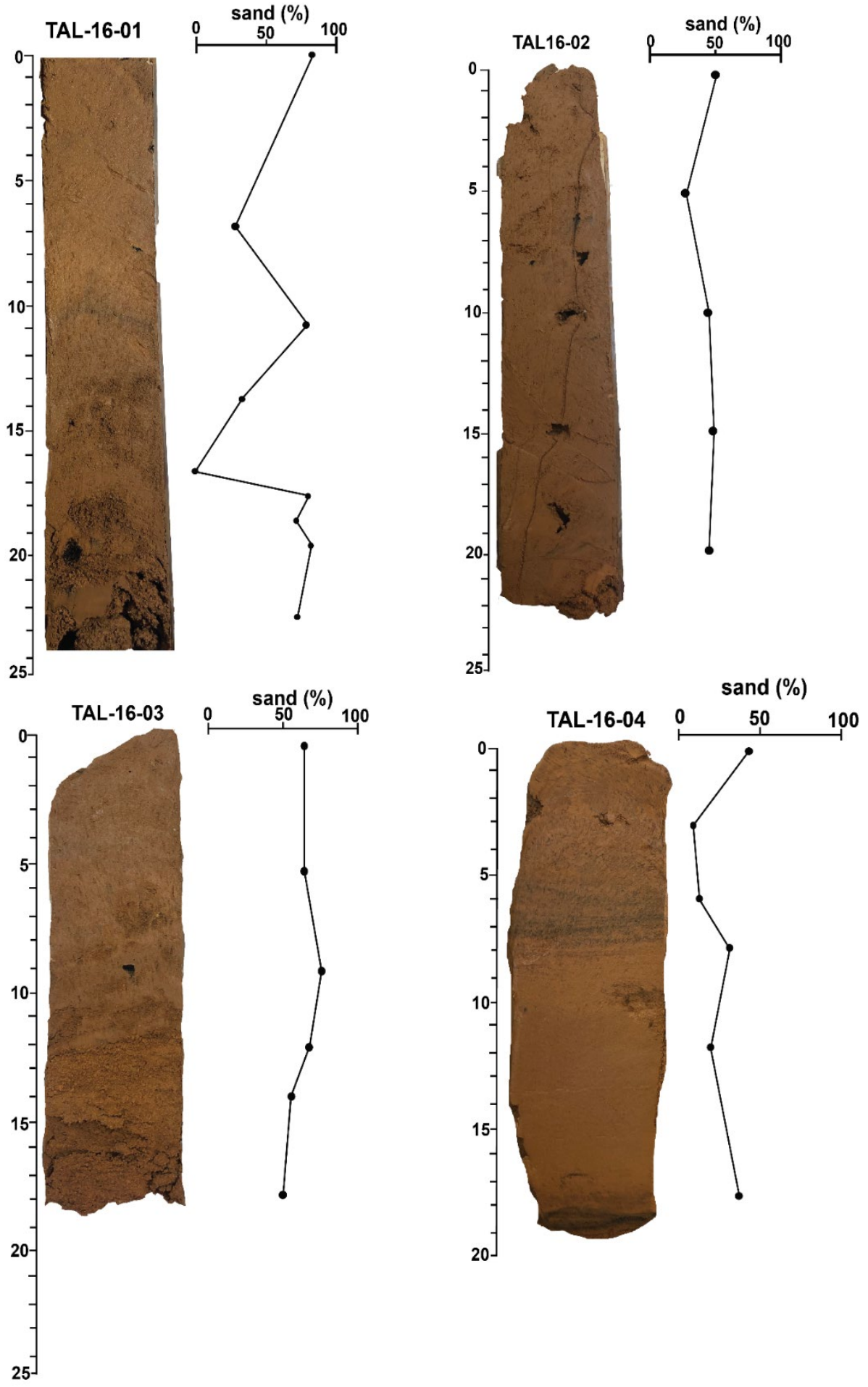

Figure 21: Core photographs and proportion of sand from TAL-16-01, TAL-16-02, TAL-16-03, and TAL-16-04. Cores are not displayed in stratigraphic order. 
The next four core are subaqueous when the dam is closed. Core TAL-16-05 varies from 40-50 percent sand and contains no sedimentary layering. Proportion of sand decreases with depth (Figure 22). Color changes were observed as horizontal redox banding. The top two and bottom two $\mathrm{cm}$ of core TAL-16-06 were dominantly fine-grained (80 percent) (Figure 22). No sedimentary layering is present. Core TAL-16-07 is dominantly sand (50-60 percent). Redox

zones rather than sharp banding were observed in core TAL16-07 (Figure 22). A small piece (0.5 $\mathrm{cm}$ ) of black material was observed at $5 \mathrm{~cm}$ depth, possibly a manganese oxide coating. Core TAL-16-08 is $50 \pm 10$ percent sandy material. Just as the three other subaqueous core, no sedimentary layering was observed. Redox banding separated by a gradational boundary was observed as well (Figure 22).

Redox banding present in the four subaqueous core varies between two distinct colors: greenish (Munsell color: $5 \mathrm{Y} 5 / 3$ ) and black (Munsell color: $2.5 \mathrm{Y} 4 / 1$ ). The boundary between the redox bands are variable in shape and clarity, some boundaries are sharp while others are gradational.

\subsubsection{CAM core sediments}

Cores were collected from various locations through CAM (Figure 10). In general, all CAM sediments contained slightly-higher proportions of sand than sediment from TAL (Figure 17). Core from CAM contained more distinct sedimentary layering than those collected from TAL. The redox banding observed in TAL sediments are absent in CAM sediments likely because the sediments in CAM were recently deposited in a dry cave and have not undergone repeated wet/dry cycles like the TAL sediments.

Large desiccation cracks covered the sediment surface throughout the entire CAM location. Again, the top $30.5 \mathrm{~cm}$ of sediment were cored at various locations throughout the cave. This sediment was likely deposited by back flooding of the Río Camuy River as a result of the flooding caused by Hurricane Maria. The flooding entered the cave from the Emplame sinkhole in the northeast portion of the cave (Figure 10). The water remained in the cave until the water levels in the Río Camuy River returned after the floodwaters receded. The core collected throughout the cave is variable spatially and no obvious stratigraphic correlation was observed between the cores. 

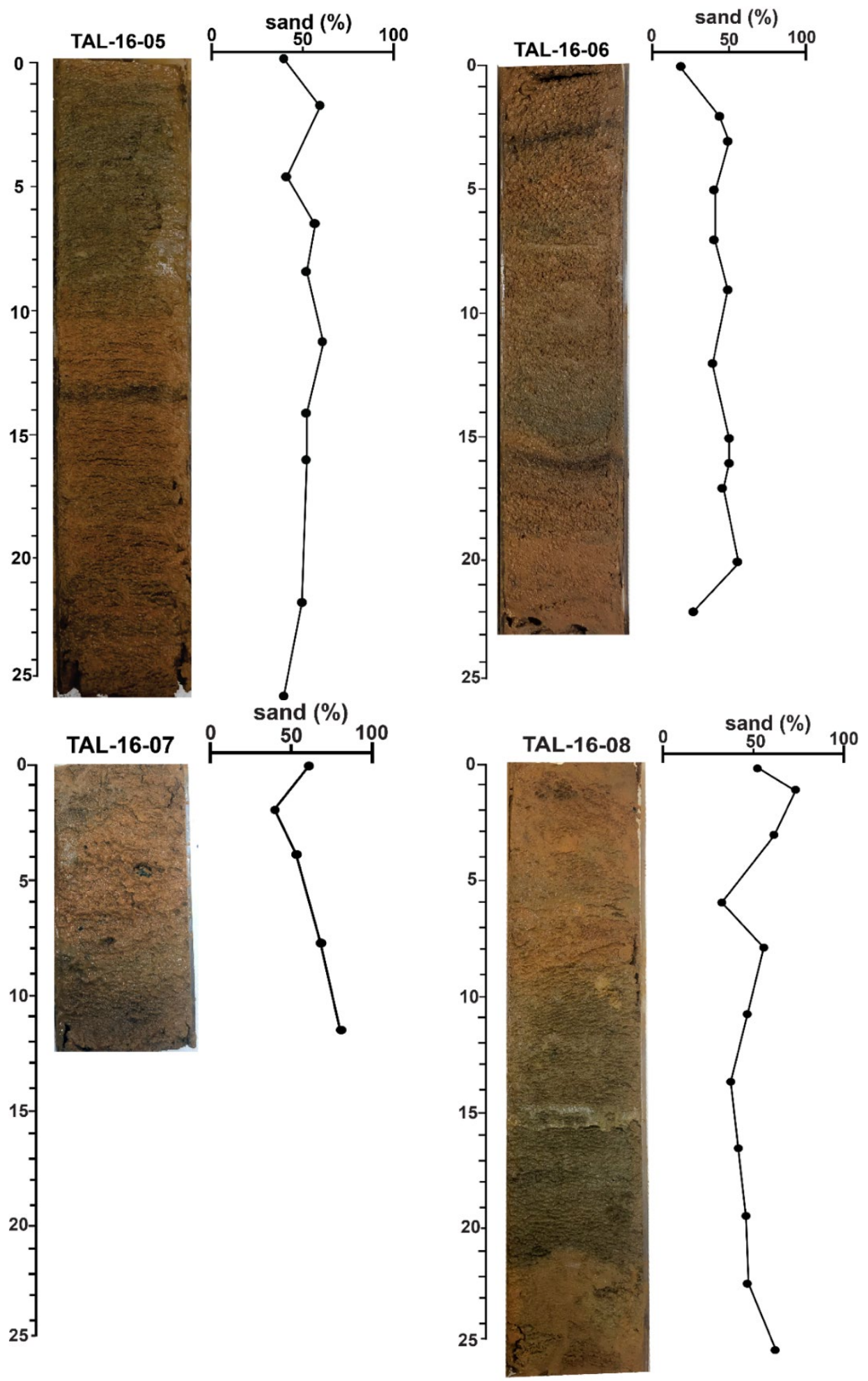

Figure 22: Core photographs and proportion of sand from TAL-16-05, TAL-16-06, TAL-16-07, and TAL-16-08. Cores are not displayed in stratigraphic order. 
Core CAM-05-01 is composed almost entirely of sand while CAM-07-01 collected $50 \mathrm{~cm}$ away is dominantly mud (Figure 23). Core CAM-07-01 contains blocky clay chunks that are likely rip up clasts. This same texture was observed in core CAM-01-01 to a lesser degree. Core CAM-01-01 contained the most obvious stratigraphic layering. Angular pebble-sized carbonate clasts were observed in the top $10 \mathrm{~cm}$ of CAM-10-01 (Figure 23). It is unknown where these clasts originated but are likely sourced from the lower levels of the Río Camuy cave system or the region surrounding the Emplame sinkhole. Carbonate clasts were not observed in any of the other core collected from this cave.

Black material was observed within core CAM-01-01 and CAM-07-01 (Figure 23). The black material, possibly organic, is contained in the bottom $10 \mathrm{~cm}$ of both cores. This material was inferred to be organic rather than a manganese oxide due to the charcoal like texture and brittle nature of the material. Manganese oxide in TAL sediments was amorphous and microcrystalline, contrary to the black material in this core. Remaining core from this location lack this black material.

All particle size data collected as part of this project are found in Appendix VI.

\subsection{Elemental data}

\subsubsection{Carbon and nitrogen}

All surface sediments from TAL (Table 6) and core samples from location TAL-16 were analyzed for TOC, TIC, and TN (Appendix VII). Concentrations of TOC range from 0.01 to 0.2 $\mathrm{mol} / \mathrm{kg}$. These concentrations converted to percent of organic carbon range from 0.13 percent to 2.4 percent. Concentrations of TN range from $2.9 \times 10^{-3}$ to $1.7 \times 10^{-2} \mathrm{~mol} / \mathrm{kg}$. Concentrations of TIC range from 0 to $4.25 \times 10^{-2} \mathrm{~mol} / \mathrm{kg}$, or 0 to 0.5 percent. Molar ratios of organic $\mathrm{C}$ : $\mathrm{N}$ range from 3.90 to 12.2 (Table 7). There exists a strong positive correlation between TC (mol/kg) and TOC $(\mathrm{mol} / \mathrm{kg})\left(\mathrm{R}^{2}=0.97 p\right.$ value $\left.<0.05\right)$ (Figure 24$)$. The $\mathrm{R}^{2}$ value of the TC vs TIC relationship is lower but still significant $\left(\mathrm{R}^{2}=0.52 p\right.$ value $\left.<0.05\right)$ (Figure 24). On a log-linear scale, percent organic carbon and organic $\mathrm{C} / \mathrm{N}$ are positively correlated $\left(\mathrm{R}^{2}=0.88 p\right.$ value $<0.05$ (Figure 25 ). There is a strong positive relationship between percent organic carbon and $\mathrm{TN}\left(\mathrm{R}^{2}=0.94, p\right.$ value $<0.05)$. Location TAL-C1-01-00 collected from the middle of the cave contained the highest percent organic carbon value (1.58 percent) out of all surface sediment samples (Figure 26). 

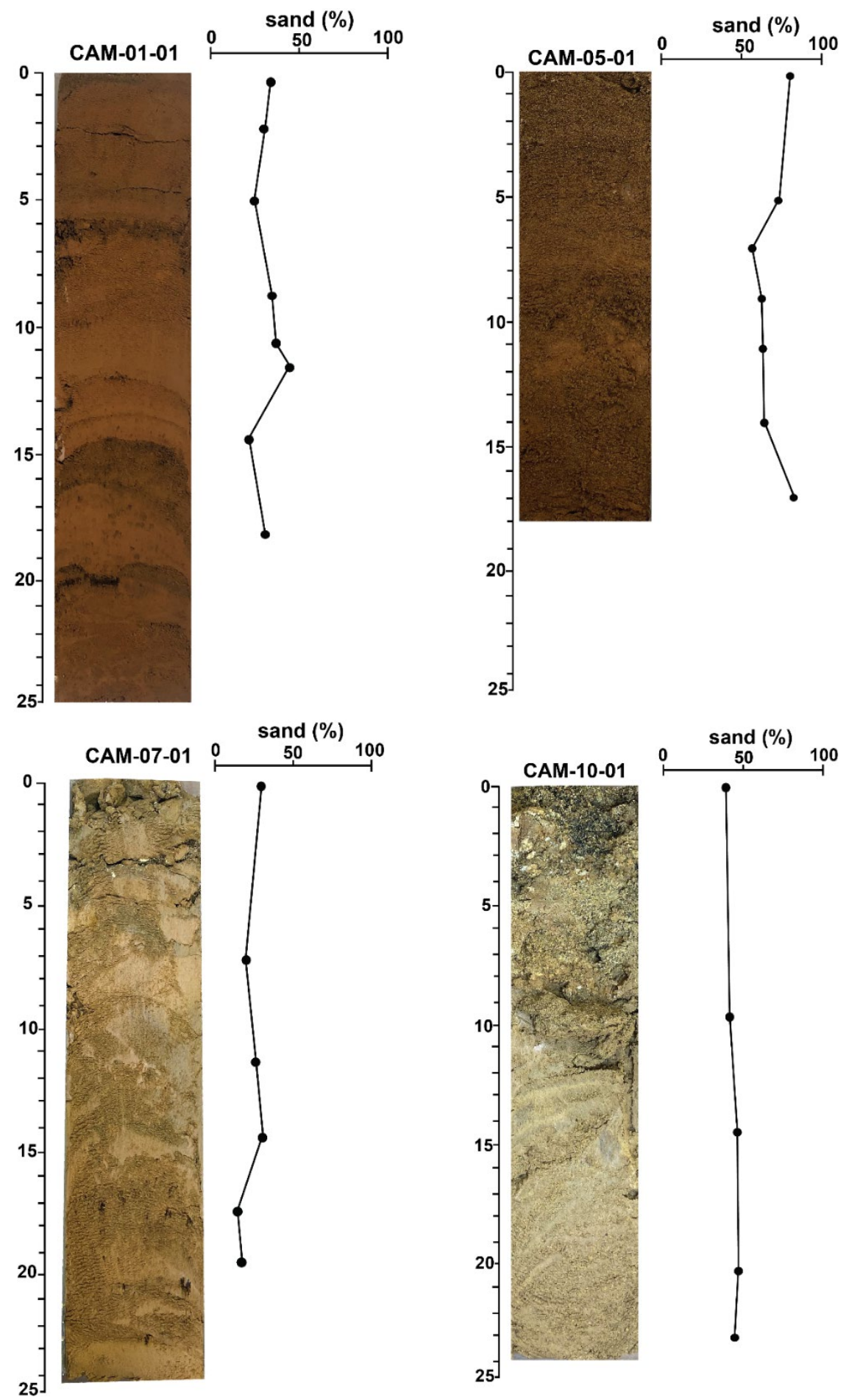

Figure 23: Core photographs and proportion of sand from CAM-01-01, CAM-05-01, CAM-0701, and CAM-10-01. Cores are not displayed in stratigraphic order. 
At sample locations TAL-A, TAL-B, and TAL-C percent organic carbon was highest one meter away from the stream and decreased with increasing distance from the stream (Figure 26). At sample location TAL-E, the trend is opposite, organic carbon values increase with increasing distance from the stream. Sample location TAL-D contained the highest percent organic carbon value two meters away from the stream. Surface sediments from the front of the cave contains the highest TIC concentrations relative to the other collected surface sediments. Surface sediments collected from the back of the cave contained the lowest TIC values relative to the other collected surface sediments (Figure 26). Surface sediments contained higher TN values than either the core samples.

Sample location TAL-16 consisted of eight cores collected in a diagonal transect across the sediment bank (Figure 12). TAL-16-01 through TAL-16-04 are not saturated when the dam is closed. The bottom four core samples are saturated (Table 6). The top $1 \mathrm{~cm}$ of sediment collected from the first four core have a consistent decrease in organic carbon with depth. Sediment collected from the top $1 \mathrm{~cm}$ of each saturated core contain higher organic carbon values than the unsaturated sediment core (Figure 27).

Sediments collected from the portion of the bank that are saturated contain higher concentrations and a larger range of organic carbon and TN (Figure 28). Organic $\mathrm{C} / \mathrm{N}$ values are generally higher in saturated samples except for two unsaturated samples with higher organic $\mathrm{C} / \mathrm{N}$ values (Figure 28). The ranges of organic $\mathrm{C} / \mathrm{N}$ in both the saturated and unsaturated sediments is comparable, although the saturated samples contained slightly-higher organic $\mathrm{C} / \mathrm{N}$ values.

\subsubsection{Fluorescence spectroscopy}

Fluorescence data were collected on organic matter extracted from solid sediment using an alkaline extraction solution of the subsamples collected from TAL-16-01 through TAL-16-05 (Figure 29). Cores TAL-16-01 through TAL-16-05 includes all unsaturated sediment cores and one saturated sediment core (Table 6). The number of saturated samples analyzed by fluorescence spectroscopy FS ( $\mathrm{n}=5$ ) differs from the saturated samples analyzed for TOC, TC, TIC, and TN ( $\mathrm{n}=38)$. Due to the limited number of saturated sediment extractions analyzed, the FS data collected provides a preliminary comparison. 
Table 7: Summary table of all collected carbon and nitrogen concentrations from sample location TAL-16. Surface samples are not included in the un-saturated sample set.

\begin{tabular}{|c|c|c|c|c|c|c|}
\hline & & $\begin{array}{c}\text { TOCa }^{\circ} \\
(\mathrm{mol} / \mathrm{kg})\end{array}$ & $\begin{array}{c}\mathrm{TIC}^{b} \\
(\mathrm{~mol} / \mathrm{kg})\end{array}$ & $\begin{array}{c}\mathrm{TC}^{c} \\
(\mathrm{~mol} / \mathrm{kg})\end{array}$ & $\begin{array}{c}\mathrm{TN}^{d} \\
(\mathrm{~mol} / \mathrm{kg})\end{array}$ & $\begin{array}{c}\text { Organic } \\
\mathrm{C} / \mathrm{N}^{e}\end{array}$ \\
\hline \multirow{4}{*}{$\begin{array}{l}\text { Surface } \\
(n=15)\end{array}$} & Minimum & $4.91 \times 10^{-2}$ & $1.67 \times 10^{-3}$ & $5.99 \times 10^{-2}$ & $6.43 \times 10^{-3}$ & 7.63 \\
\hline & Maximum & $1.32 \times 10^{-1}$ & $3.33 \times 10^{-2}$ & $1.48 \times 10^{-1}$ & $1.36 \times 10^{-2}$ & 1.22 \\
\hline & Average & $8.42 \times 10^{-2}$ & $1.35 \times 10^{-2}$ & $9.77 \times 10^{-2}$ & $9.09 \times 10^{-3}$ & 9.20 \\
\hline & $\begin{array}{l}\text { Standard } \\
\text { deviation }\end{array}$ & $2.44 \times 10^{-2}$ & $9.42 \times 10^{-3}$ & $2.50 \times 10^{-2}$ & $2.06 \times 10^{-3}$ & 1.35 \\
\hline \multirow{4}{*}{$\begin{array}{l}\text { Un- } \\
\text { saturated } \\
(n=24)\end{array}$} & Minimum & $1.08 \times 10^{-2}$ & $<\mathrm{MDL}^{f}$ & $1.08 \times 10^{-2}$ & $2.86 \times 10^{-3}$ & 3.50 \\
\hline & Maximum & $6.08 \times 10^{-2}$ & $2.00 \times 10^{-2}$ & $7.99 \times 10^{-2}$ & $8.57 \times 10^{-3}$ & 9.10 \\
\hline & Average & $2.71 \times 10^{-2}$ & $3.68 \times 10^{-3}$ & $3.07 \times 10^{-2}$ & $5.32 \times 10^{-3}$ & 5.00 \\
\hline & $\begin{array}{l}\text { Standard } \\
\text { deviation }\end{array}$ & $1.11 \times 10^{-2}$ & $5.37 \times 10^{-3}$ & $1.59 \times 10^{-2}$ & $1.17 \times 10^{-3}$ & 1.36 \\
\hline \multirow{4}{*}{$\begin{array}{l}\text { Saturated } \\
(n=38)\end{array}$} & Minimum & $1.63 \times 10^{-2}$ & $<\mathrm{MDL}^{f}$ & $1.08 \times 10^{-2}$ & $2.86 \times 10^{-3}$ & 3.50 \\
\hline & Maximum & $1.96 \times 10^{-1}$ & $4.25 \times 10^{-2}$ & $2.29 \times 10^{-1}$ & $1.71 \times 10^{-2}$ & 1.20 \\
\hline & Average & $6.49 \times 10^{-2}$ & $1.41 \times 10^{-2}$ & $7.90 \times 10^{-2}$ & $7.96 \times 10^{-3}$ & 7.29 \\
\hline & $\begin{array}{l}\text { Standard } \\
\text { deviation }\end{array}$ & $4.75 \times 10^{-2}$ & $1.21 \times 10^{-2}$ & $5.62 \times 10^{-2}$ & $3.42 \times 10^{-3}$ & 2.45 \\
\hline $\begin{array}{l}a \text { Total org } \\
b \text { Total inor } \\
{ }^{c} \text { Total carl } \\
{ }^{d} \text { Total nitr } \\
{ }^{e} \text { Organic } \\
{ }^{f} \text { Less thar }\end{array}$ & $\begin{array}{l}\text { ic carbon } \\
\text { nic carbon } \\
\text { en } \\
\text { bon:nitrog } \\
\text { pethod dete }\end{array}$ & $\begin{array}{l}\text { ratio } \\
\text { tion limit }\end{array}$ & & & & \\
\hline
\end{tabular}



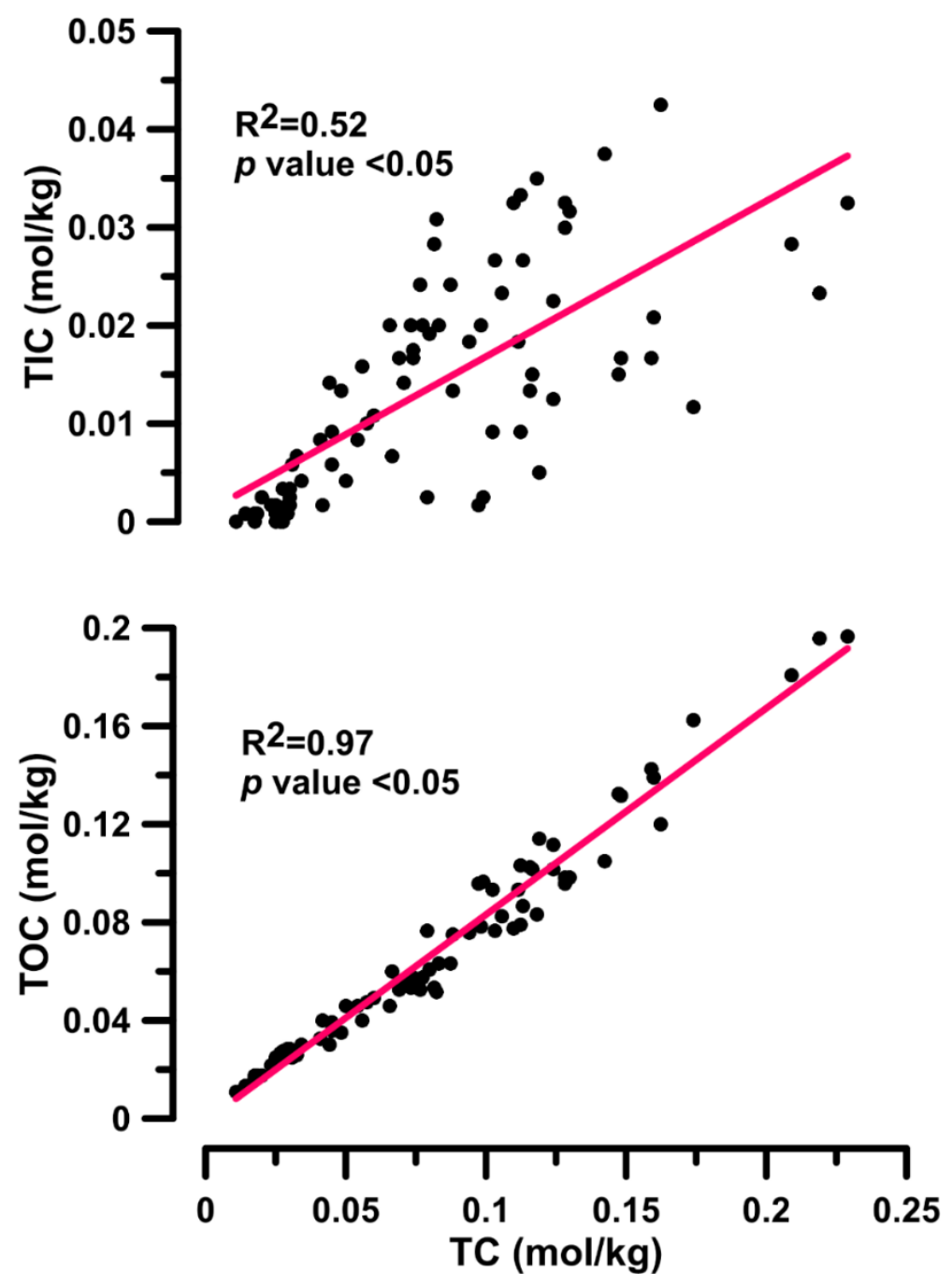

Figure 24: Relationship between total carbon (TC), total organic carbon (TOC), total inorganic carbon (TIC), and total organic carbon from El Tallonal Cave sediments (TAL). 

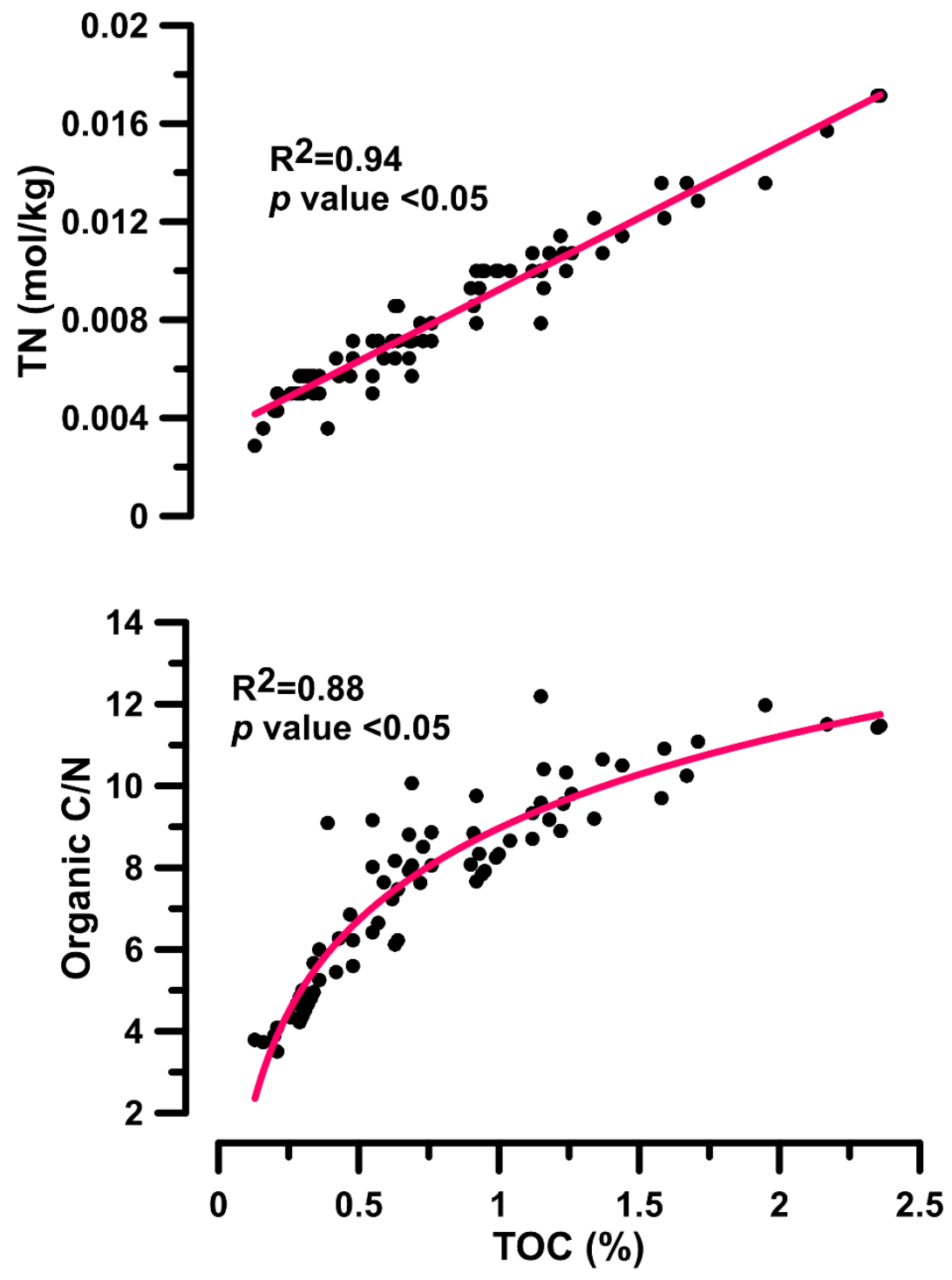

Figure 25: Relationship between total nitrogen (TN), organic $C / N$ ratio, and total organic carbon (TOC; \%) from El Tallonal Cave sediments (TAL). 

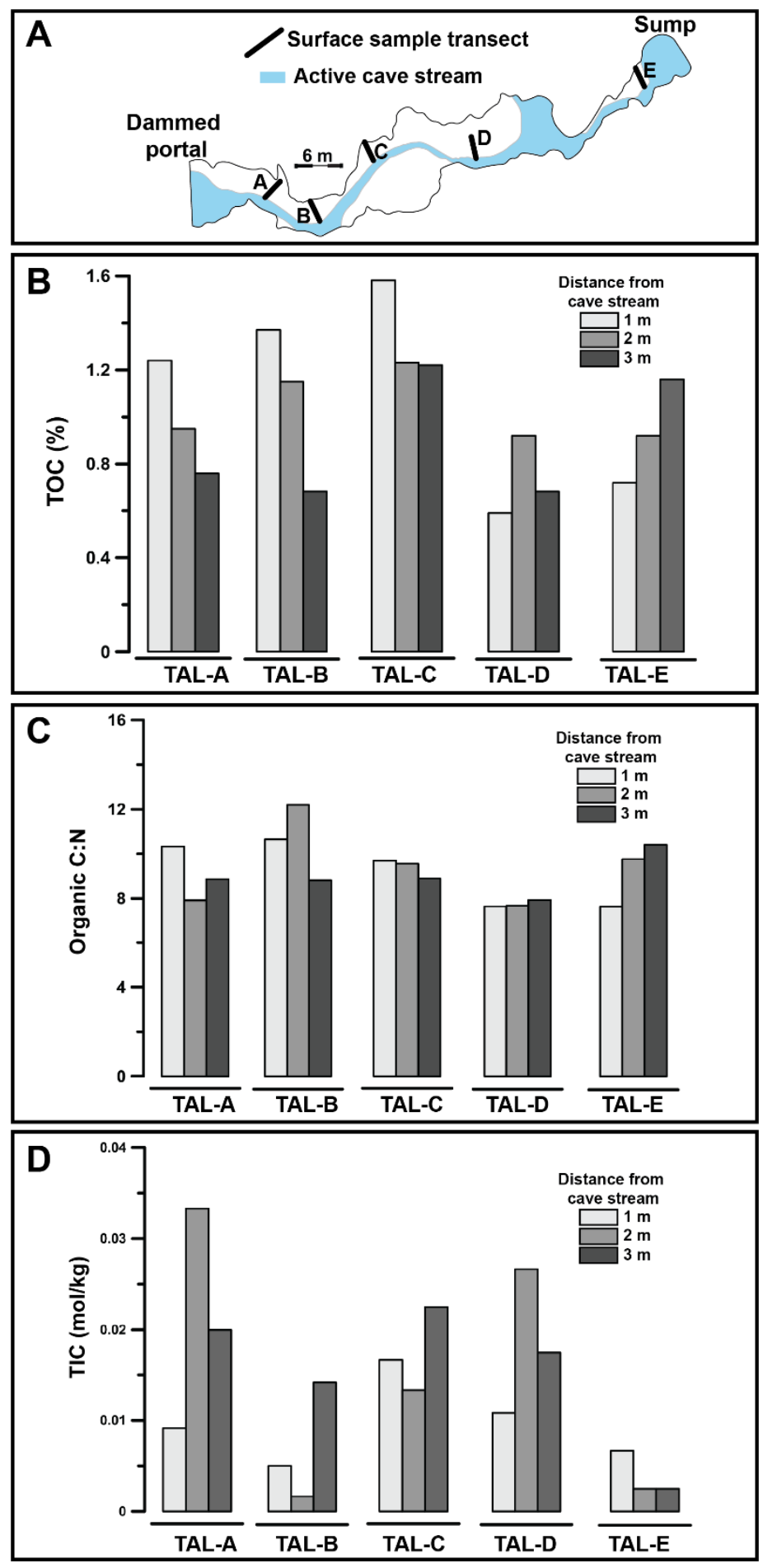

Figure 26: A) Sediment from the sediment bank surface were collected one, two, and three meters away from the cave stream at locations TAL-A through TAL-E. Spatial distribution of B) fraction of organic carbon (FOC); $C$ ) total inorganic carbon (TIC); and D) organic $C / N$ ratios of all surface sediments collected from El Tallonal Cave (TAL). 


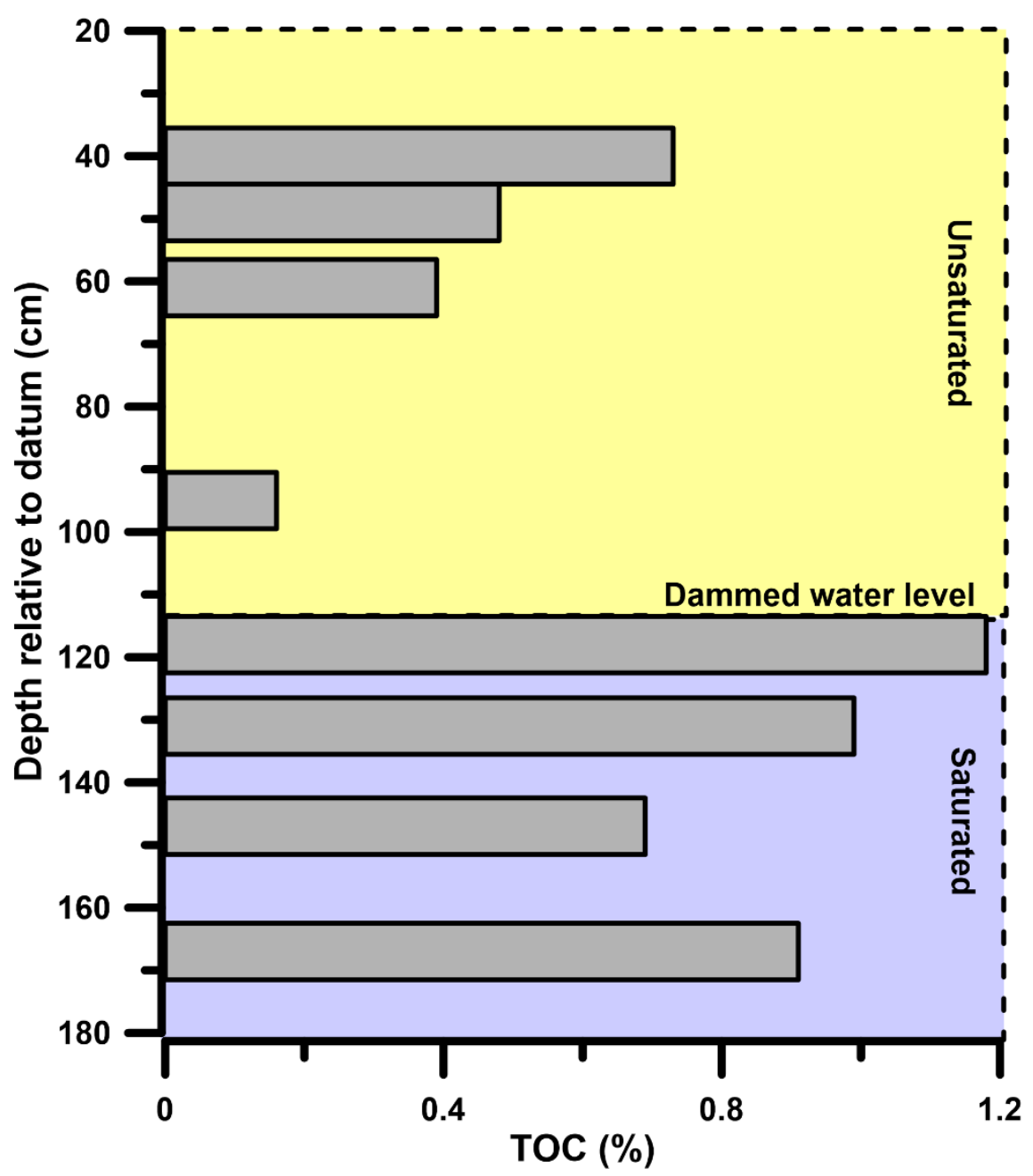

Figure 27: Total organic carbon (TOC; \%) collected from the top of each core collected from TAL-16 ordered by depth relative to the datum. Dammed water level is $118 \mathrm{~cm}$ below datum. 


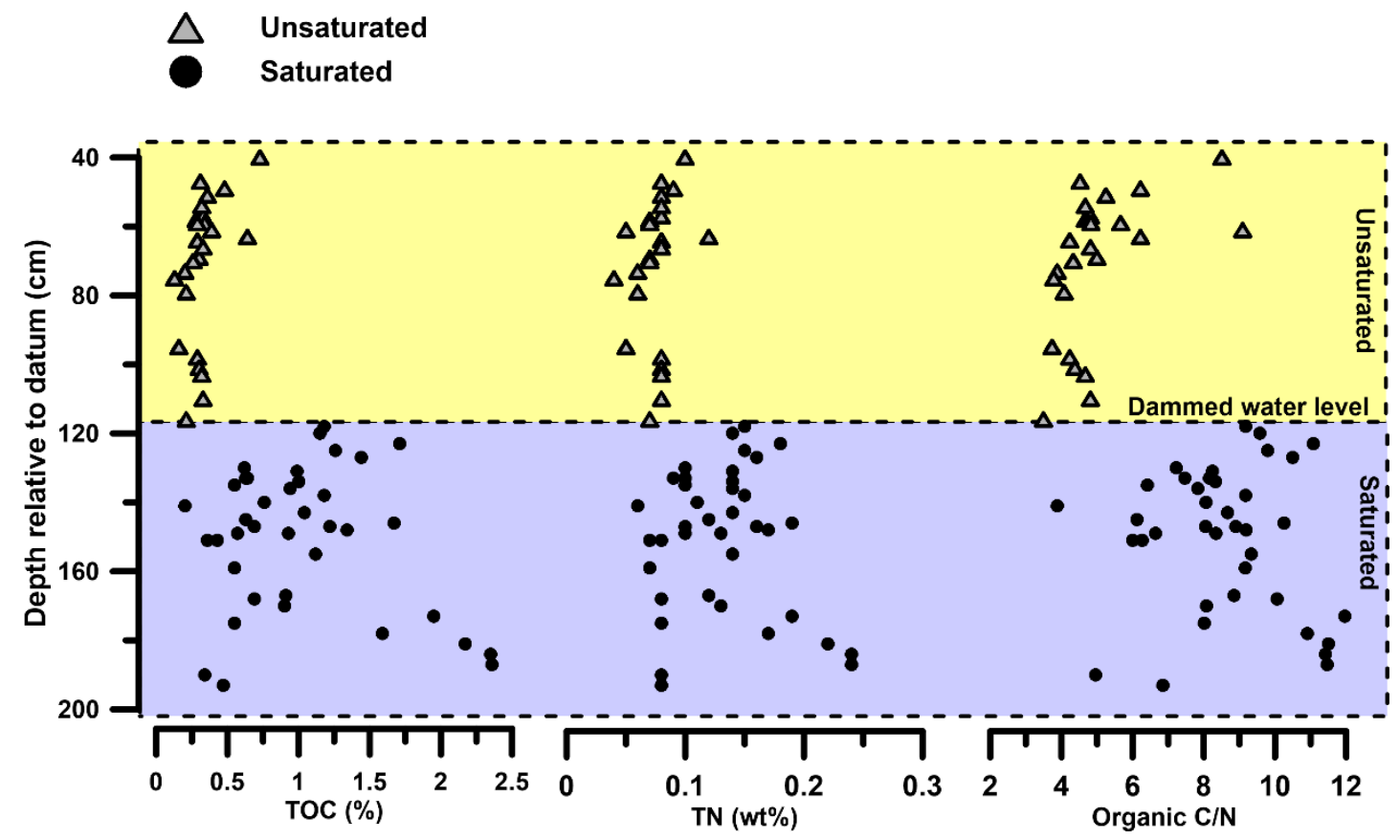

Figure 28: Variability in organic C/N ratios, total nitrogen (TN), and total organic carbon (TOC; \%) between saturated and unsaturated sediments. Dammed water level is $118 \mathrm{~cm}$ below datum. 


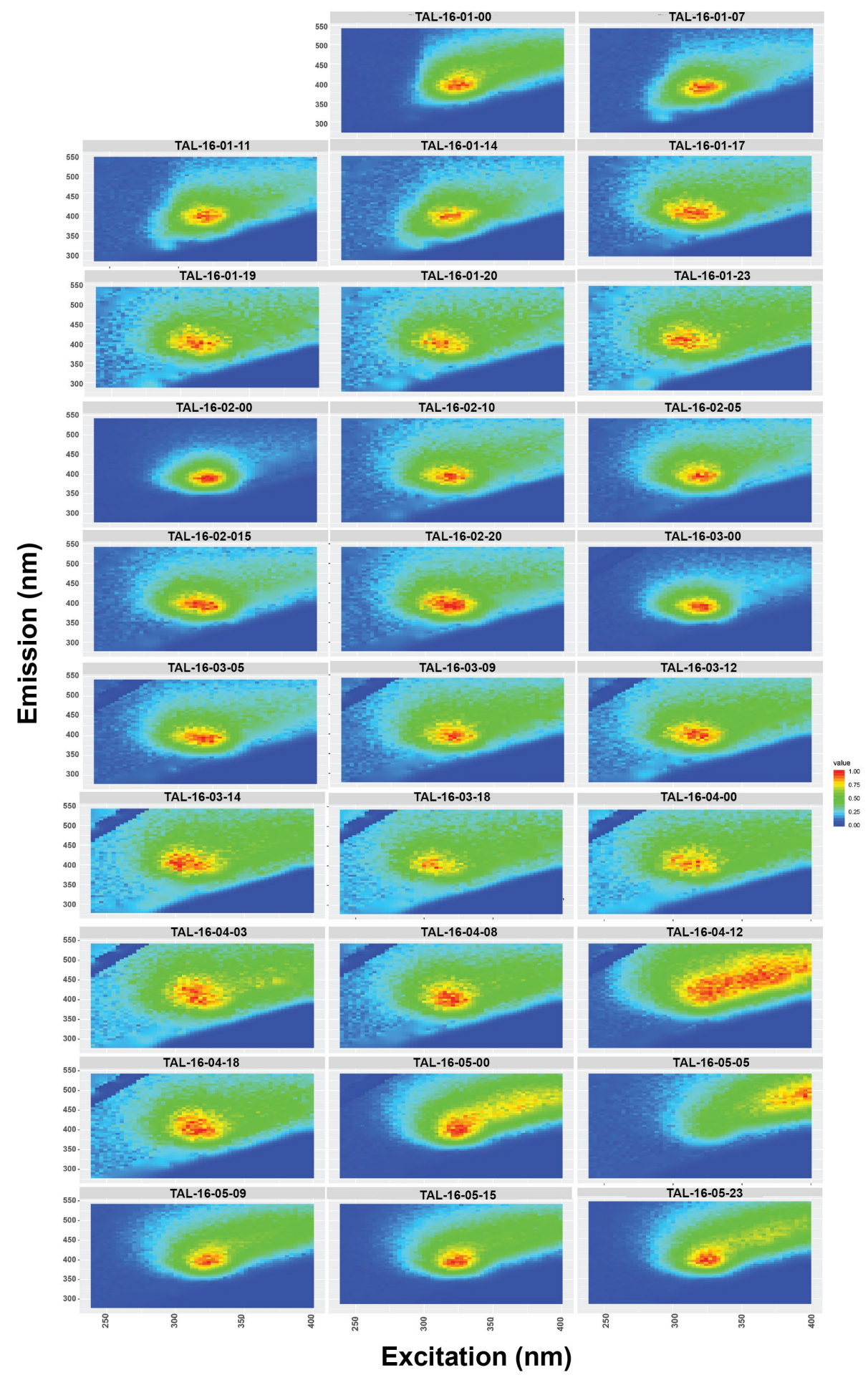

Figure 29: Excitation-emission matrix (EEM) data collected on the alkaline extraction from TAL-16 sample location subsamples. $1^{\text {st }}$ and $2^{\text {nd }}$ order Rayleigh scattering has been removed. The EEMs have been normalized to the max intensity of each scan. EEMs were collected from

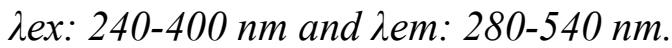


The FS data collected from these sediments had BIX values from 0.68 to 1.87 and FI values from 0.89 to 1.54 (Figure 30). The highest BIX value was obtained from $12 \mathrm{~cm}$ below the top of the sediment bank surface. Lower BIX and FI values were found in samples with the highest organic carbon values (Figure 30). Samples with a BIX value $>1$ are composed of fresh autotrophic organic matter. All saturated samples have BIX values $>1$. Unsaturated samples with BIX values $>1$ are also present. There is no clear connection between proximity to the cave stream and BIX values $>1$. Samples with organic matter containing FI values $>1.90$ are considered to originate from a microbial origin. There were no sediments in this sample set containing FI values $>1.90$. The maximum FI value (1.50) was found in core TAL-16-04. This is the closest unsaturated core to the cave stream and is likely to experiences partial submergence with fluctuating water level. Unsaturated samples generally had lower organic $\mathrm{C} / \mathrm{N}$ and a large range of BIX and FI values.

Corrected EEM's with $1^{\text {st }}$ and $2^{\text {nd }}$ order Rayleigh scattering removed were used to create a PARAFAC model. The model was created using a combination of the "eemR" and the “staRdom" packages in R (Massicotte, 2019; Pucher et al., 2020). The model creates an output of six possible models ranging from two to seven components. There is no clear rule to choosing the appropriate number of components (Murphy et al., 2013). Models without distinct peaks in the residual terms are desired however, it is unlikely that a given model will completely describe an entire dataset. The chosen model must minimize the number of leverage outliers and the maximum absolute value of the intensity in the residuals. The absolute values of the maximum intensity are used as a PARAFAC model can result in negative residual intensities as well.

A PARAFAC model with three components was chosen as the model with the lowest number of outliers and a relatively low maximum absolute value intensity (Table 8). All three modeled components are contained in region five of the EEM space (humic acid-like) (Figure 31). The proportion of each component was normalized to the total contribution of each sample (Figure 32). Component two dominates and component one is the most variable between the samples (Figure 33). The proportion of component one is highest on saturated samples, independent of organic carbon concentration (Figure 34). The opposite is true for component three. It is lowest in the saturated samples. The sample with the largest proportion of component one also contains the highest organic $\mathrm{C} / \mathrm{N}$ ratio (Figure 34). Unsaturated samples generally contain a lower proportion of component one and lower org $\mathrm{C} / \mathrm{N}$ ratios. 

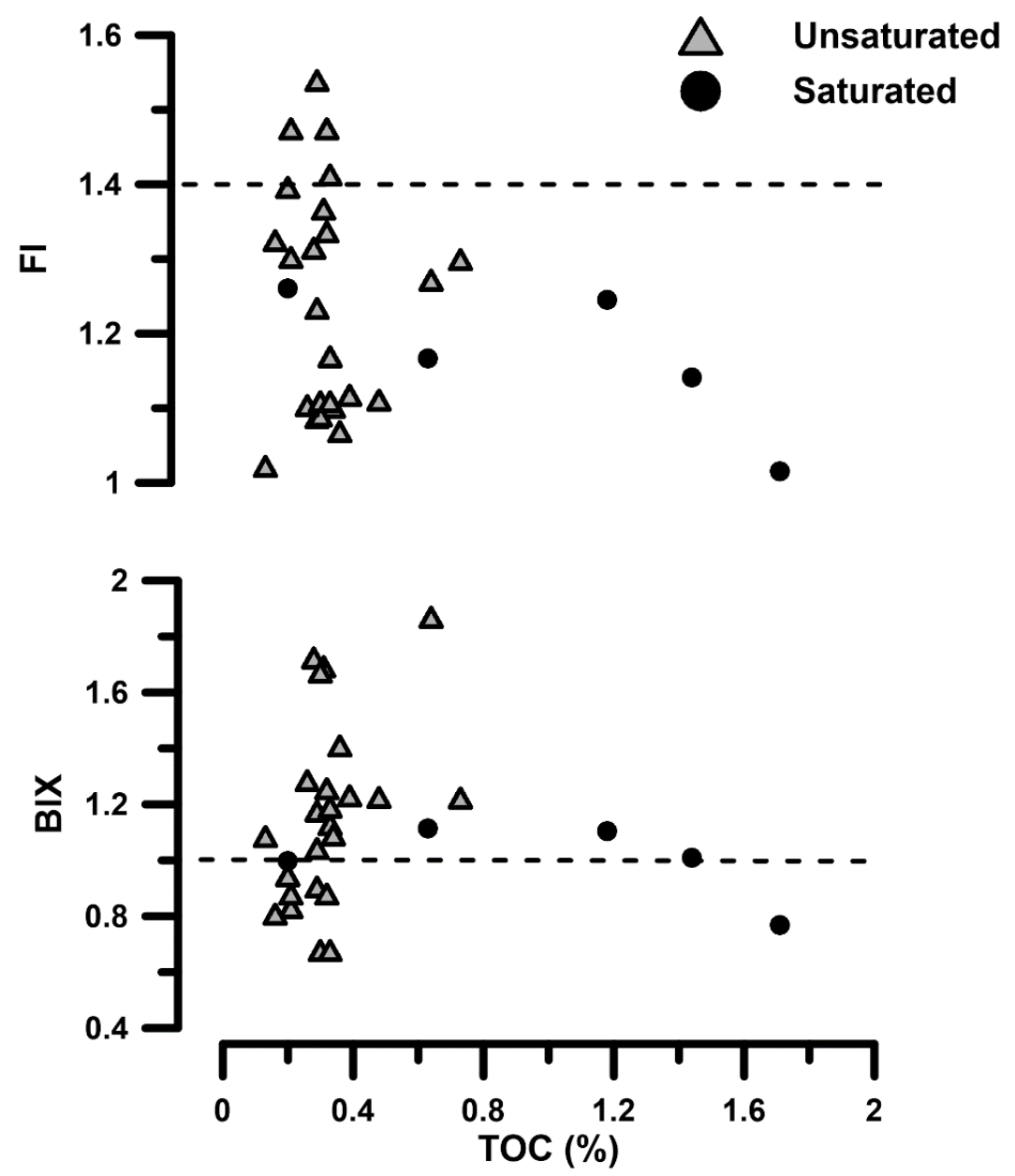

Figure 30: Relationship between fluorescence index (FI) and biological index (BIX) and total organic carbon (TOC; \%). Saturated and unsaturated subsamples are indicated. FI values $<1.40$ indicate organic matter of terrestrial origin (dashed line). BIX values $>1$ indicate fresh autotrophic organic matter (dashed line). 
Table 8: Results of the six parallel factor analysis (PARAFAC) models. The model with the minimum number of emission, excitation, and sample out lairs and minimum absolute value of intensity in the residuals is desired. The PARAFAC model with three components was chosen.

\begin{tabular}{lcccc}
\hline \hline Model ${ }^{a}$ & $\begin{array}{c}\text { Number of } \\
\text { emission } \\
\text { out liars }\end{array}$ & $\begin{array}{c}\text { Number of } \\
\text { excitation } \\
\text { out liars }\end{array}$ & $\begin{array}{c}\text { Number of } \\
\text { sample out } \\
\text { liars }\end{array}$ & $\begin{array}{c}\text { Max residual } \\
\text { intensity } \\
\text { (absolute value) }\end{array}$ \\
\hline 2 Components & 5 & 5 & 4 & 0.44 \\
3 Components ${ }^{b}$ & $5^{b}$ & $5^{b}$ & $4^{b}$ & $0.25^{b}$ \\
4 Components & 5 & 6 & 4 & 0.33 \\
5 Components & 5 & 6 & 4 & 0.20 \\
6 Components & 5 & 6 & 4 & 0.25 \\
7 Components & 5 & 6 & 4 & 0.25 \\
\hline${ }^{a}$ n=35 samples & & & & \\
${ }^{b}$ Chosen model & & & & \\
\hline
\end{tabular}



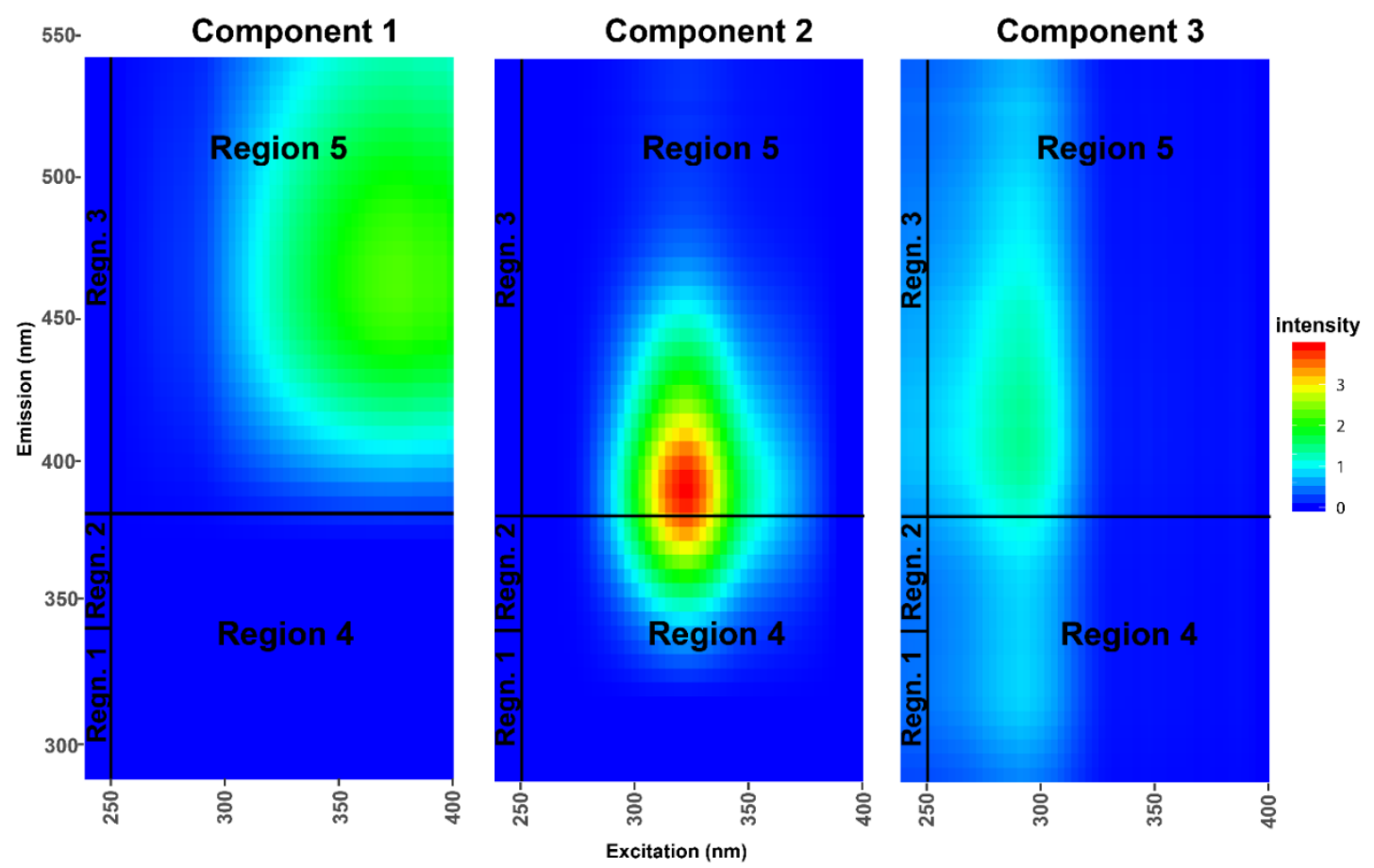

Figure 31: Excitation-emission matrices (EEM) of the three-component parallel factor analysis (PARAFAC) model. Regions one through five are labeled. All modeled components fall within region five (humic acid-like). 


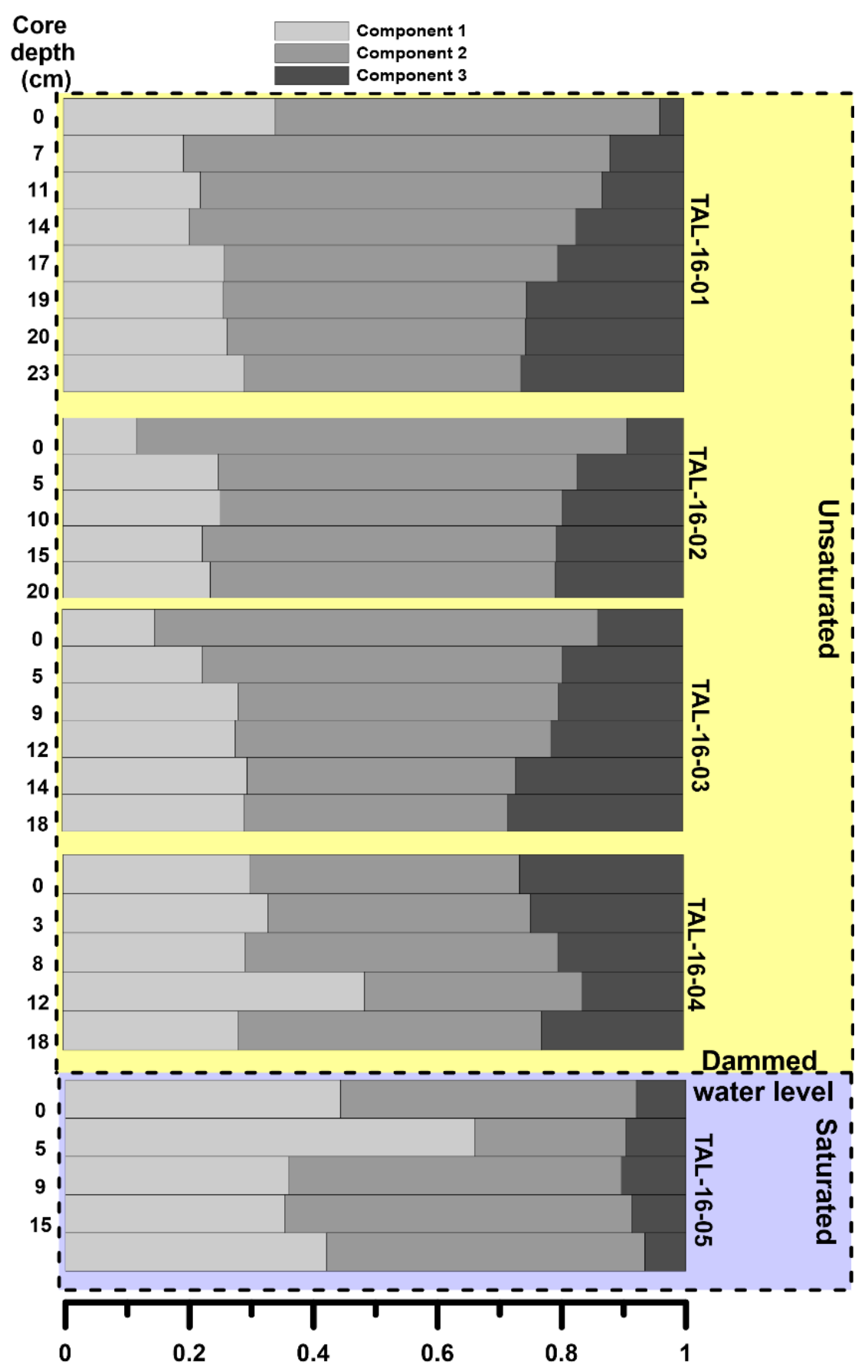

Figure 32: Proportion of the modeled parallel factor analysis (PARAFAC) components one, two, and three in the sample set categorized by core. Dammed water level is indicated. 


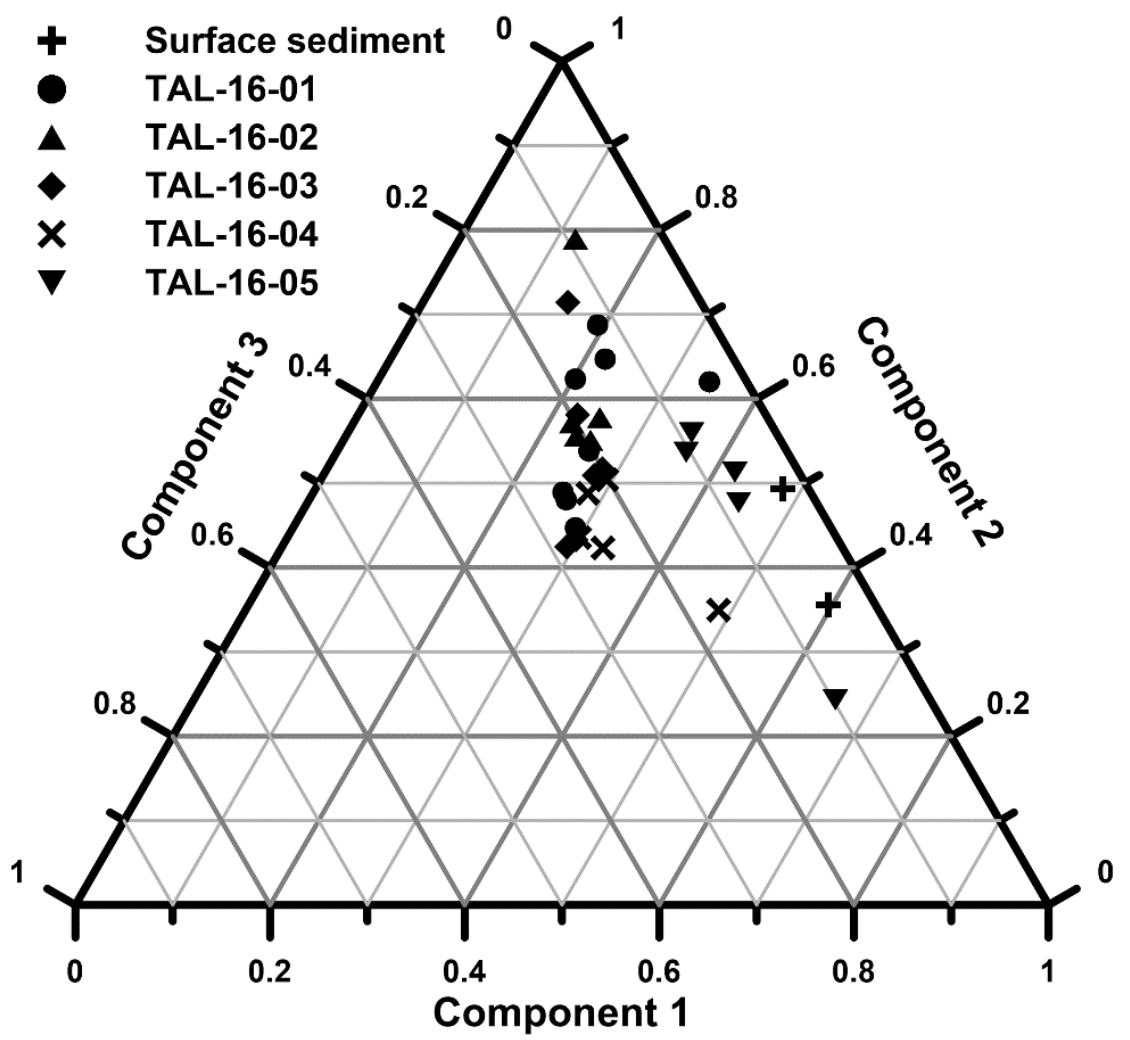

Figure 33: Ternary diagram with the three modeled parallel factor analysis (PARAFAC) components. Components are reported as a fractional proportion. 

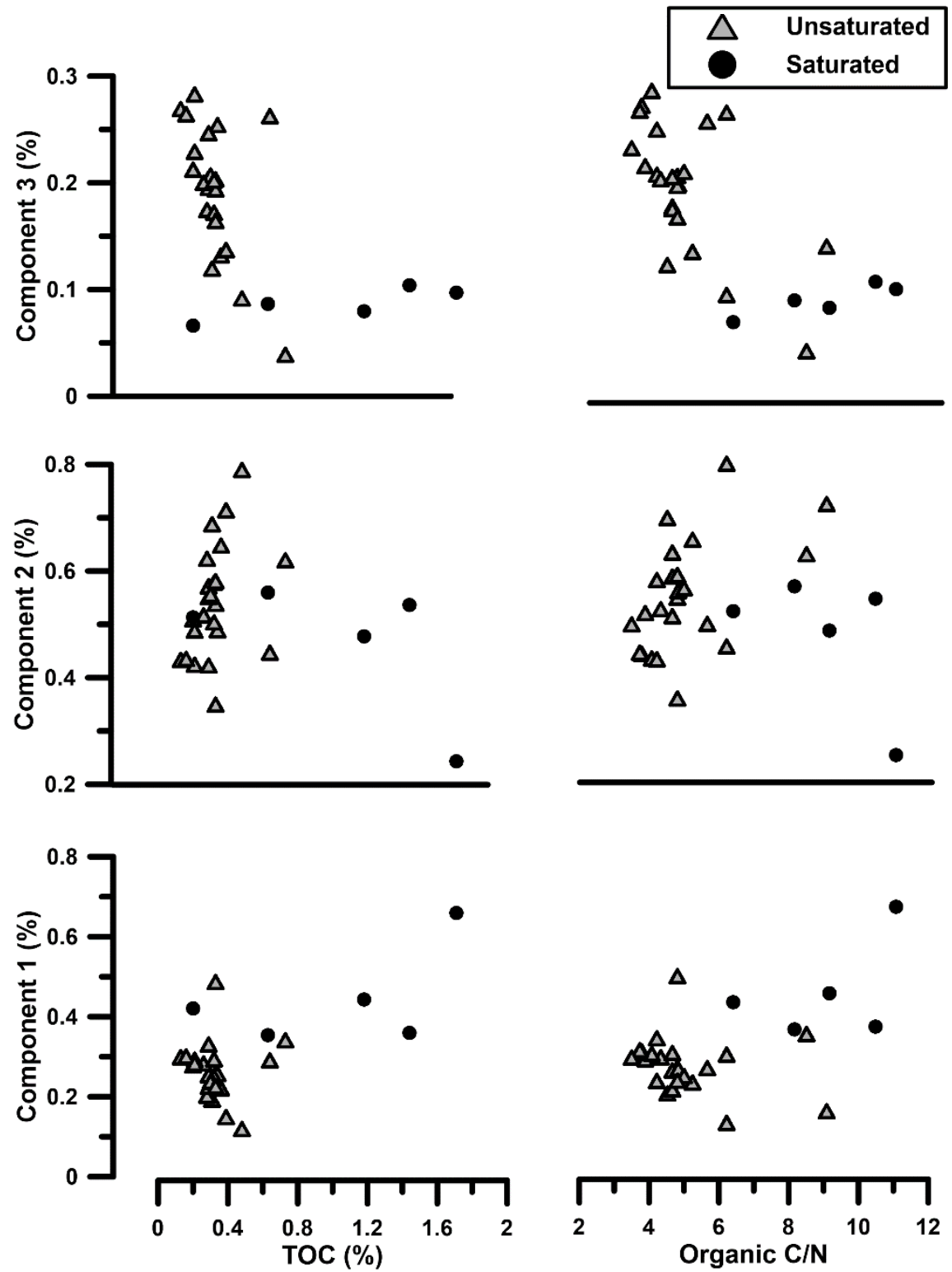

Figure 34: Total organic carbon (TOC; \%) as a function of the contribution of each component. Saturated and unsaturated samples are indicated. 
Saturated sediments contained lower proportions of PARAFAC component three. Proportion of component three varied with depth in unsaturated sediments as well. The top of each unsaturated core had the highest proportion of component three and decreased with depth. This pattern was consistent in all unsaturated cores at location TAL-16 (Figure 32).

\subsubsection{Elemental concentrations}

Data collected from XRF analysis were quantified using a custom calibration for the four unsaturated core samples from location TAL-16 (Table 6) and the core collected from location TAL-14. Major elements (Na, Al, Si, K, P, Ca, Ti, and Fe) are reported in weight percent and

minor elements ( $\mathrm{Ba}, \mathrm{Cr}, \mathrm{Cu}, \mathrm{Co}, \mathrm{Mn}, \mathrm{Ni}, \mathrm{Zn}, \mathrm{Rb}, \mathrm{Nb}, \mathrm{Mo}$, and $\mathrm{Y}$ ) are reported as ppm (Appendix VIII). Concentrations reported as 0 weight percent are present at low (below calibration detection) concentrations. Quantified data were then converted to $\mathrm{mol} / \mathrm{kg}$.

The most abundant element by an order-of-magnitude is Si (Figure 35). Aluminum is the second most abundant element and Fe is next. Principle component analysis (PCA) was performed using major and minor elements (Figure 36). Principle component analysis is a mathematical algorithm that reduces the dimensionality while simultaneously maintaining most of the variation in a dataset (Ringnér, 2008). In most cases, a dataset is reduced to two or three principle components. The selected principle components are uncorrelated and therefore, explain most of the variability in a dataset. Variables plotting close together, far from the origin, exhibit similar variation in a dataset (Bro and Smilde, 2014). Elemental concentrations plot in all four quadrants of the PCA biplot (Figure 36). Silicon and Al plot almost directly across from one another. Aluminum and Si have a negative relationship. These elements, along with the associated elemental concentrations plotting near them in the PCA space, compose group one and group two elements within this dataset (Figure 36). Groups one and two contain elements composing most mineral assemblages (i.e. silica tetrahedra and aluminum octahedra) and therefore likely represent the overall lithology. Group three, containing all other elemental concentrations plot between quadrant one and three of the PCA biplot. These elements are clustered around an $\mathrm{x}$ value of -1 (absolute minimum) and a y-value of zero, representing a heavy weight on component one. This reveals that most of the variation in group three elements is described by principle component one. The opposite is true for groups one and two. 
A Pearson Correlation Matrix was created using the "Hmisc" (Harrell and Dupont, 2020) package in R to explore correlations between pairs of elements (Appendix XIII). These two major elements, $\mathrm{Al}$ and $\mathrm{Si}$, were found to be strongly negatively-correlated $(\mathrm{R}=-0.86 p$ value $<0.05$ ) (Figure 37). As such, these relationships provide information about the lithology of these sediments. Composed of alternating layers of aluminum octahedra and silica tetrahedra, phyllosilicate minerals result in some positive correlation in $\mathrm{Al}$ and Si concentrations (Essington, 2015). The strong negative correlation between $\mathrm{Al}$ and $\mathrm{Si}$ suggests that quartz and clay minerals occur together, resulting in high Si concentrations and low Al concentrations. Molar concentrations of $\mathrm{Na}$ and $\mathrm{K}$ are associated with $\mathrm{Al}$ and $\mathrm{Si}$, respectively (Figure 37). Correlation between $\mathrm{Si}$ and $\mathrm{K}(\mathrm{R}=0.71 p$ value $<0.05)$ is not as strong as $\mathrm{Al}$ and $\mathrm{Na}(\mathrm{R}=0.99 p$ value $<0.05)$. This lower $\mathrm{R}$ value is due to the presence of outliers with unexpectedly-high $\mathrm{Si}$ concentrations. Potassium is the only elements strongly correlated with $\mathrm{Si}$. Aluminum is positively correlated with $\mathrm{P}$ and $\mathrm{Cu}$ (Figure 37). Copper is the only trace element associated with $\mathrm{Al}(\mathrm{R}=0.66 p$ value $<0.05$ ). Organic phosphorus accounts for 20-70 percent of the total P pool in a sedimentary environment (Essington, 2015). Within these sediments, phosphorus is negatively correlated with TOC ( $\mathrm{R}=-0.71 p$ value $<0.05)$. Sorption of $\mathrm{P}$ is known to have a strong and almost irreversible affinity for sorption to $\mathrm{Al}$ and $\mathrm{Fe}$ oxyhydroxides (Von Wandruszka, 2006). The positive correlation between $\mathrm{Al}$ and $\mathrm{P}$ suggests that most of the $\mathrm{P}$ pool in these sediments could be sorbed to aluminum oxide. Within a cave environment, $\mathrm{P}$ can be supplied by bat guano. While CAM was known to have a large bat population (before Hurricane Maria), it is unknown if TAL contains a bat population. No bats were observed during field work in TAL.

Dissolution of the carbonate rock matrix supplies most of the $\mathrm{Ca}$ to these cave sediments and therefore is not well correlated with other elemental concentrations (Figure 37). While $\mathrm{Ca}$ can be supplied by allogenic materials (e.g. silicate and phyllosilicates), Ca supplied by carbonate dissolution can be expected to outweigh Ca supplied by other sources (Essington, 2015). Water samples collected by the University of Puerto Rico, Mayaguez reveal that the water in TAL is supersaturated with respect to calcite (average $\mathrm{SIc}=0.29, \mathrm{n}=9$ ) (pers. comm. PantojaAgred, 2016). Kinetic thresholds on the precipitation of calcite suggest that at low supersaturation values, calcite $\left(\mathrm{SI}_{\mathrm{c}}<1\right)$ will not actually precipitate the predicted value at equilibrium (White, 1988). This kinetic threshold results in more $\mathrm{Ca}$ in solution than is expected of which can be retained in the clastic sediments within the cave. 

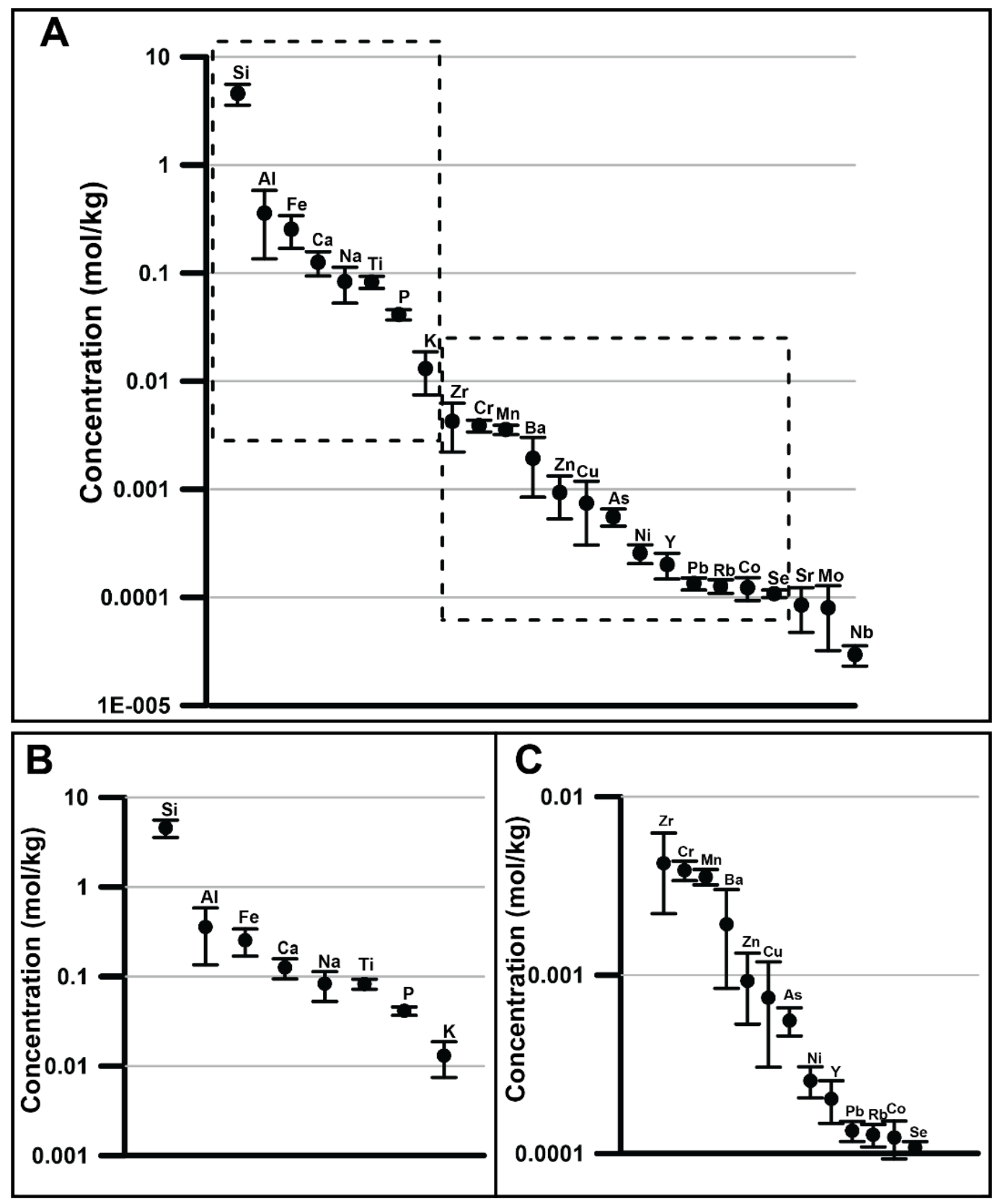

Figure 35: Elemental concentrations plotted in molar units from highest to lowest average value of A) the entire dataset; B) major elements; and C) trace elements. Symbols are averages; error bars are a total of one standard deviation. 

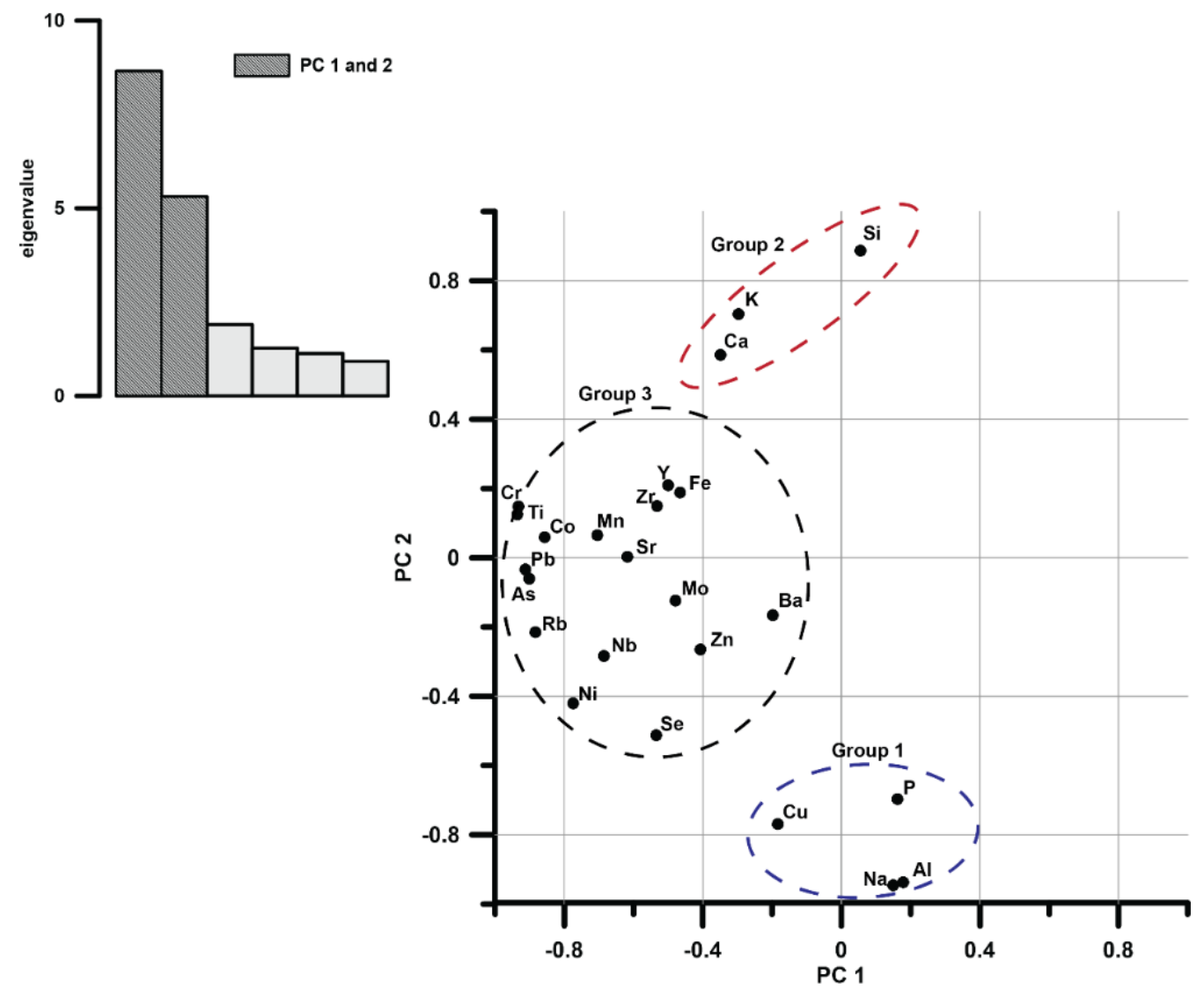

Figure 36: Eigenvalues of principle components 1-7 and scatter plot of the principle component analysis (PCA). Dashed line represents the three groups of elemental concentrations present within the PCA space. 
Trace elements in this project refer to any element with concentrations at or below 0.01 $\mathrm{mol} / \mathrm{kg}$ (Figure 35C). Titanium is likely present in nature as the stable oxide, rutile. Due to the stability of rutile, Ti tends to accumulate in sediments and is often used as an indication to the degree of weathering. Titanium is positively correlated with several trace elements, most notably $\mathrm{Cr}, \mathrm{As}$, and $\mathrm{Mn}$ (Figure 37). Chromium and Ti are very strongly correlated ( $\mathrm{R}=0.99 p$ value $<0.05)$. In addition to $\mathrm{Ti}$, As is positively correlated with $\mathrm{Rb}(\mathrm{R}=0.85 p$ value $<0.05), \mathrm{Nb}$ $(\mathrm{R}=0.64 p$ value $<0.05), \mathrm{Ni}(\mathrm{R}=0.75 p$ value $<0.05)$, and $\mathrm{Co}(\mathrm{R}=0.72 p$ value $<0.05)$ in these sediments (Figure 37$)$. The only strong positive correlation with $\mathrm{Fe}$ is $\mathrm{Co}(\mathrm{R}=0.79 p$ value $<0.05)$.

Manganese rapidly precipitates as microcrystalline oxides when environments transition from suboxic to oxic (Dixon et al., 1990). As a result, Mn oxide precipitation is a good indication of changing water level. Precipitation of microcrystalline Mn oxide was observed in core TAL16-04 resulting from fluctuating water level (Figure 21). Manganese is positively correlated with $\mathrm{Ti}$ and $\mathrm{Cr}(\mathrm{R}=0.69 p$ value $<0.05)$ in these sediments.

Retention of trace elements $\mathrm{Pb}, \mathrm{As}, \mathrm{Cr}, \mathrm{Co}$, and $\mathrm{Ni}$ in a sedimentary environment occur through sorption to Al, Fe, and Mn oxides (Cerqueira et al., 2011; Dixon et al., 1990; Ma and Hooda, 2010; McKenzie, 1980). The strong positive correlation between $\mathrm{Mn}$ and $\mathrm{Pb}$ could indicate $\mathrm{Pb}$ sorption to $\mathrm{Mn}$ oxide.

Sorption and co-precipitation are a dominant retention mechanism for trace elements in a sedimentary environment. However, correlation does not imply sorption as a definite retention mechanism. This project did not focus on understanding why these correlations are present. As such, implying sorption or co-precipitation are meant as a potential cause for these correlative relationships.

The correlation matrix reveals several cases where the correlation coefficient is exceedingly-low, but still significant (e.g. Fe vs. Si) (Figure 37). Low $p$ values (below $\alpha=0.05$ ) implies that a change in the predictor variable is associated with a change in the response values. This is possible even with noisy and highly-variable data. While $p$ values are a widely used statistical parameter, caution when using this parameter in large datasets is advised (Lin et al., 2013). A $p$ value measures the distance between the data and the null hypothesis, typically using the standard deviation of the predictor values (i.e. the standard error) (Biau et al., 2010). 
$\mathrm{Na}$

\begin{tabular}{|c|c|c|c|c|c|c|c|c|c|c|c|c|c|c|c|c|c|c|c|c|c|c|c|}
\hline Al & 0.99 & Al & & & & & & & & & & & & & & & & & & & & & \\
\hline $\mathrm{Si}$ & -0.84 & -0.86 & Si & & & & & & & & & & & & & & & & & & & & \\
\hline $\mathbf{P}$ & 0.72 & 0.70 & -0.46 & $\bar{P}$ & & & & & & & & & & & & & & & & & & & \\
\hline $\mathrm{K}$ & -0.73 & -0.69 & 0.71 & -0.45 & $\mathrm{~K}$ & & & & & & & & & & & & & & & & & & \\
\hline $\mathrm{Ca}$ & -0.50 & -0.52 & 0.51 & -0.36 & 0.49 & $\mathrm{Ca}$ & & & & & & & & & & & & & & & & & \\
\hline $\mathrm{Ba}$ & 0.13 & 0.15 & -0.10 & 0.04 & 0.06 & 0.16 & $\mathrm{Ba}$ & & & & & & & & & & & & & & & & \\
\hline$\pi$ & -0.30 & -0.27 & 0.03 & -0.18 & 0.34 & 0.33 & 0.11 & $\mathrm{Ti}$ & & & & & & & & & & & & & & & \\
\hline $\mathrm{Cr}$ & -0.31 & -0.28 & 0.05 & -0.19 & 0.35 & 0.37 & 0.13 & 0.99 & $\mathrm{Cr}$ & & & & & & & & & & & & & & \\
\hline$M n$ & -0.19 & -0.16 & 0.03 & -0.13 & 0.20 & 0.33 & 0.05 & \begin{tabular}{|l|l|}
0.69 \\
\end{tabular} & 0.69 & $\mathrm{Mn}$ & & & & & & & & & & & & & \\
\hline $\mathrm{Fe}$ & -0.16 & -0.18 & 0.09 & -0.26 & 0.21 & 0.27 & 0.12 & 0.37 & 0.36 & 0.15 & $\mathrm{Fe}$ & & & & & & & & & & & & \\
\hline Co & -0.16 & -0.15 & 0.01 & -0.22 & 0.26 & 0.32 & 0.21 & 0.76 & 0.76 & 0.54 & 0.79 & Co & & & & & & & & & & & \\
\hline $\mathrm{Ni}$ & 0.20 & 0.24 & -0.37 & 0.14 & 0.09 & 0.04 & 0.26 & 0.66 & 0.64 & 0.49 & 0.16 & 0.62 & $\mathrm{Ni}$ & & & & & & & & & & \\
\hline $\mathrm{Cu}$ & \begin{tabular}{|l|}
0.63 \\
\end{tabular} & 0.66 & -0.59 & 0.43 & -0.28 & -0.31 & 0.32 & 0.04 & 0.03 & 0.07 & -0.09 & 0.11 & 0.66 & $\mathrm{Cu}$ & & & & & & & & & \\
\hline $\mathrm{Zn}$ & 0.10 & 0.14 & -0.18 & 0.04 & 0.05 & 0.03 & 0.16 & 0.31 & 0.30 & 0.24 & 0.04 & 0.26 & 0.50 & 0.37 & $\mathrm{Zn}$ & & & & & & & & \\
\hline As & -0.14 & -0.11 & -0.10 & 0.02 & 0.21 & 0.19 & 0.11 & 0.89 & 0.89 & 0.57 & 0.32 & 0.72 & 0.75 & 0.18 & 0.35 & As & & & & & & & \\
\hline $\mathrm{Pb}$ & -0.16 & -0.13 & -0.08 & 0.04 & 0.25 & 0.23 & 0.11 & 0.90 & 0.90 & 0.66 & 0.31 & 0.72 & 0.75 & 0.17 & 0.34 & 0.96 & $\mathrm{~Pb}$ & & & & & & \\
\hline $\mathrm{Se}$ & 0.37 & 0.38 & -0.40 & 0.21 & -0.18 & 0.07 & 0.16 & 0.38 & 0.39 & 0.49 & 0.16 & 0.43 & 0.58 & 0.55 & 0.30 & 0.39 & 0.45 & $\mathrm{Se}$ & & & & & \\
\hline $\mathrm{Rb}$ & 0.02 & 0.05 & -0.23 & 0.03 & 0.14 & 0.11 & 0.14 & \begin{tabular}{|l|}
0.79 \\
\end{tabular} & 0.77 & 0.49 & 0.41 & 0.74 & 0.76 & 0.32 & 0.39 & 0.85 & 0.80 & 0.53 & $\mathbf{R b}$ & & & & \\
\hline $\mathrm{Sr}$ & -0.10 & -0.09 & 0.05 & -0.27 & 0.15 & 0.11 & 0.04 & 0.55 & 0.54 & 0.31 & 0.23 & 0.47 & 0.45 & 0.10 & 0.27 & 0.55 & 0.52 & 0.24 & 0.60 & Sr & & & \\
\hline $\mathrm{Y}$ & -0.29 & -0.26 & 0.13 & -0.15 & 0.30 & 0.29 & 0.04 & 0.46 & 0.47 & 0.46 & 0.04 & 0.33 & 0.32 & -0.10 & 0.12 & 0.40 & 0.45 & 0.15 & 0.35 & 0.18 & $Y$ & & \\
\hline $\mathrm{Zr}$ & -0.11 & -0.13 & 0.05 & -0.25 & 0.10 & 0.57 & 0.20 & 0.43 & 0.45 & 0.38 & 0.44 & 0.50 & 0.22 & 0.04 & 0.10 & 0.31 & 0.30 & 0.26 & 0.39 & 0.29 & 0.22 & $\mathrm{Zr}$ & \\
\hline $\mathrm{Nb}$ & 0.12 & 0.15 & -0.29 & 0.17 & 0.05 & 0.04 & 0.04 & 0.61 & 0.60 & 0.44 & 0.13 & 0.46 & 0.56 & 0.19 & 0.26 & 0.64 & 0.63 & 0.48 & 0.72 & 0.42 & 0.52 & 0.25 & $\mathrm{Nb}$ \\
\hline Mo & 0.12 & 0.11 & -0.18 & -0.14 & -0.07 & 0.21 & 0.22 & 0.36 & 0.37 & 0.22 & 0.42 & 0.49 & 0.30 & 0.12 & 0.18 & 0.27 & 0.26 & 0.33 & 0.41 & 0.36 & 0.05 & 0.62 & 0.28 \\
\hline
\end{tabular}

Figure 37: Pearson correlation matrix of elemental concentrations quantified using XRF. Matrix was created using the "Hmisc" package in R. Grey shaded values represent p-values $<0.05$. Boxed values indicate an $R$ value $>0.6$ (blue shaded) and $<-0.6$ (orange shaded). 
The standard error between any two parameters shrinks as sample size increases. Problems when interpreting $p$ values arise when the standard error between the parameters becomes so small that even small distances from the estimated values and the null hypothesis become statistically significant. This results in $p$ values that approach zero, not as a rejection of the null hypothesis but as an artifact of the large sample size (Lin et al., 2013). The computed correlation matrix contained many data points $(\mathrm{n}=669)$. Low $\mathrm{R}$ values and $p$ values may be an artifact of this large sample size. That is not to say that variables with high correlation coefficients are void. There still exists significant statistical power in those highly-correlated variables.

When Ti, Cr, and As are plotted against Zr two distinct groups are observed (Figure 38). $\mathrm{Pb}$ and $\mathrm{Ni}$ also exhibit this trend. When separated out by core, this bifurcation is due to variation in core locations (Figure 38). Core collected from location TAL-14 show higher Zr concentrations than core collected from location TAL-16. An additional population of sediment with higher $\mathrm{Ti}, \mathrm{Cr}$, and As values was observed and isolated to the TAL-16-04 core sediments (Figure 38). Sediment collected in this core was between the saturated and unsaturated zones. The saturated condition of the core varies depending on the water level and as a result, Mn oxides have precipitated throughout this core. Higher concentrations of $\mathrm{Ti}, \mathrm{Cr}$, and As may be a result of the fluctuating saturated and unsaturated conditions. Given that sample location TAL-14 is further from the inferred dammed water level and that sampling was collected consecutively with depth, it is unknown if these sediments were saturated (Figure 11).

Subsamples were collected from a range of $1 \pm 0.5 \mathrm{~cm}$ for particles size analysis. XRF data (collected every $2 \mathrm{~mm}$ ) was averaged from a one $\mathrm{cm}$ range corresponding to the collected subsample range for particle size analysis. No statistically-significant correlations between particle size and elemental concentrations were observed in the collected dataset from TAL. Subsamples collected for particle size and the XRF averaged data did not contain much overlap. The lack of trends between grain size and elemental concentrations may be due to the limited sample size. Additionally, discrepancies in exact sample depth between the averaged XRF data and the subsamples collected for particle size analysis are a potential issue effecting the lack of correlation. 

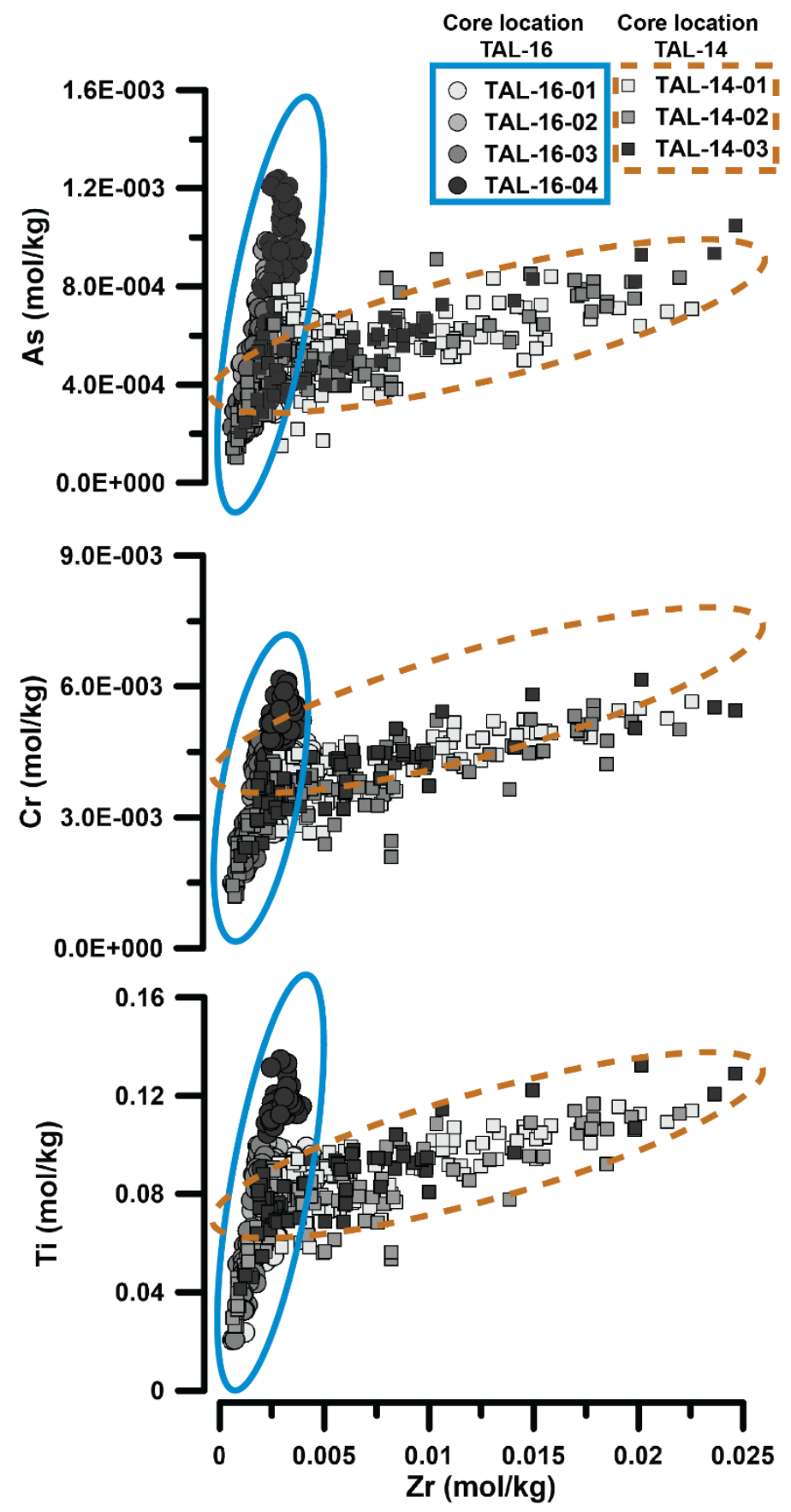

Figure 38: Zirconium vs Ti, Pb, and As separated by core. Two distinct groups are observed due to variation in concentrations from different core locations. Solid blue ellipse represent TAL-16 cores and orange dashed ellipse represents TAL-14 cores. 


\subsection{Discussion}

\subsection{Sediment facies}

Sediment facies classifications by Bosch and White (2007) are described through observations made in teleogenetic cave systems and based on physical sediment characteristics (Table 1). Grain sizes and sediment sorting are categorized relative to the system. Bosch and White (2007) state that the content in a cave system is dependent on the available source material and that most sedimentary deposits will not contain distinct facies. The purpose of this project was not to fully characterize the facies present in these caves. Additionally, applying these facies to sediments from TAL is somewhat difficult as the collected core showed little true "stratification" in grain size. This classification provides a loose framework for describing cave sediments. Considering bulk sedimentary characteristics, a minimum of two facies were observed in TAL: thalweg facies present in the active stream channel and channel facies present in the bank sediments (Table 1).

The thalweg facies is created when a secondary (younger) stream channel cuts through previously deposited channel facies, winnowing out smaller materials and leaving larger clasts behind (Table 1). Well-rounded cobbles and pebbles were observed in the active stream channel and similar well-rounded pebbles were found in core TAL-15-02 leading to this thalweg classification (Figure 20). Additionally, the cave stream is active in contrast to the sediment bank which have been in place for some time based on the presence of small $(1-2 \mathrm{~cm})$ stalactites on the top of the sediment bank in some locations. Bank sediments from TAL were poorly sorted and lacked gravel and pebble sized clasts (except for TAL-15-02). These sediments could be considered a channel facies though it is not possible to distinguish channel facies from slackwater facies here (Table 1). It is likely that these sediments were deposited through sequences of channel and slackwater facies conditions.

Sediments collected from CAM are likely to have been deposited by backflooding of the Río Camuy River resulting from flooding in response to Hurricane Maria. This interpretation is based on the flooding observed in Tres Pueblos Sinkhole located approximately $0.6 \mathrm{~km}$ from CAM (Figure 2). Additional evidence of this backflooding was the "bath ring" observed in the Emplame Sinkhole during sediment collection at CAM (Figure 39). For water to reach CAM, based on elevation difference, the Río Camuy River experienced a 20-meter rise in water level. This depositional condition is characteristic of the slackwater facies, however, CAM sediments 
are poorly sorted and contained what are interpreted as rip-up clasts (Table 1). Slackwater facies are reported as the first centimeters of clay capping the very top of a sedimentary deposit. Sediments from CAM do not contain any such clay cap. Sediment core from CAM contained no graded bedding or sorting indicating gradual suspended load settling via waning transport energy.

Facies developed by Fornos et al. (2009) describe sediments from an eogenetic cave system. Sediments described in this study were collected from a submerged cave system. Facies descriptions include both physical sediment characteristics and organic matter concentrations. Considering the differences in saturated and unsaturated sediments observed in this project, describing both organic and physical properties are necessary when studying sediments from a submerged cave system. Facies are grouped into waterflow coarse-grained deposits, waterlain clastic fine-grained deposits, carbonate deposits, and mixed facies (Table 1). Slackwater facies from Bosch and White (2007) roughly correlates to waterlain clastic fine-grained facies described by Fornos et al. (2009). Waterlain clastic fine-grained facies include thinly-laminated brown clays, silts, and fine sands. Mineralogy of these sediments is dominantly siliceous, and composition corresponds to soil material transported by rainwater. Thinly-laminated clays and silts were also described by Bull (1981) in cave sediments within a vadose system and concluded that neither grain size nor laminae thickness were related to current direction. Waterlain clastic fine-grained facies are deposited through surface derived input and periodic accumulation or organic matter as plant material is present. This waterlain clastic fine-grained facies can be applied to sediments from TAL, though differences in sediment characteristics are present. Sediments from TAL do not contain thinly-laminated clays and silts and lack obvious organic matter laminations.

Sediment data collected from both caves are inherently biased. Neither cave was fully mapped for the presence and types of sediments and therefore it is almost certain that other facies are present but were not captured in this study. The difficulty in applying facies classification to sediments collected in this project is due to the lack of a full map, variability within caves, the generalization of facies descriptions, and the geomorphological and groundwater controls on cave sedimentation. 

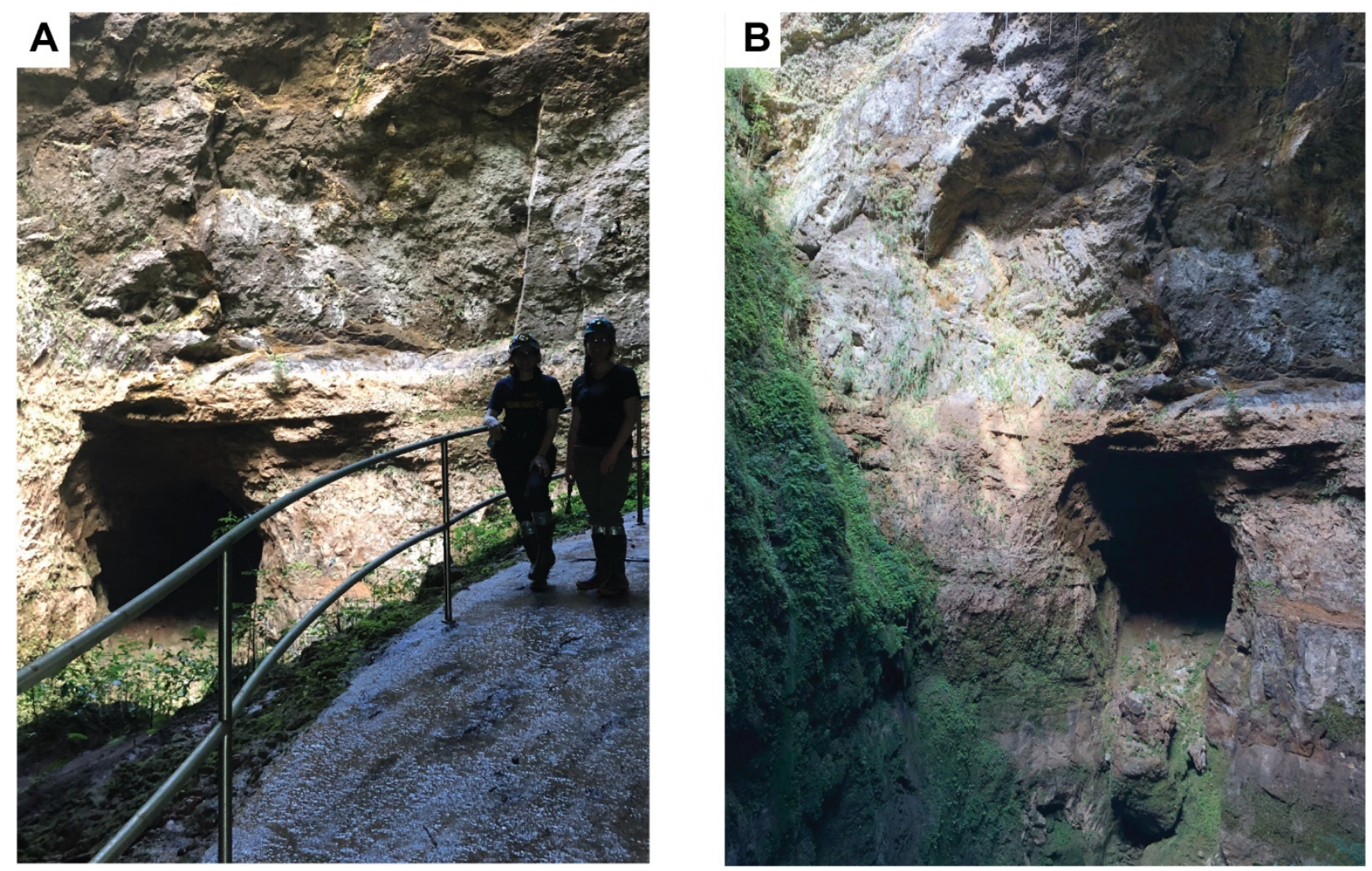

Figure 39: Photos of the Emplame Sinkhole during the February 2019 sampling. The Rio Camuy River is approximately 20 meters below the "bath ring" A) The sinkhole photographed from the back of CAM. The overlook photographed is a popular attraction during the cave tour through CAM. B) Photograph of Emplame Sinkhole from another perspective emphasizing the "bath ring" created by the Rio Camuy River backflooding resulting from the Hurricane Maria flooding. 


\subsection{Significance of sediment saturation}

The dynamic nature of the sediment solution makes it a complex environment.

Heterogeneity is a characteristic property of sediment environments. This includes the sediment solution as well. This heterogeneity facilitates the presence of microenvironments.

Microenvironments can occur as a result of the physical heterogeneity of the sediment or by a limiting nutrient (e.g. $\mathrm{O}_{2}$ ). There exist many microenvironments within a sedimentary environment. For example, $\mathrm{O}_{2}$ availability around a single sediment particle can vary from 21 percent to 0 percent in just two mm (Madigan et al., 2018).

A distinct difference in organic chemical properties between saturated and unsaturated sediments was observed. The range of TOC, TN and organic $\mathrm{C} / \mathrm{N}$ ratios were higher in saturated sediments. Saturated sediments also contained higher concentrations than unsaturated sediments. These saturated sediments, as the name suggests, contain more water within the pore space. This water and the elemental components within it are hereinafter referred to as the sediment solution. Chemical reactions such as hydration, hydrolysis, acid-base, oxidation-reduction and complexation occur largely within the sediment solution (Essington, 2015). These reactions control the fate and behavior of several geochemical species as well as retention via precipitation- dissolution and adsorption-desorption. In addition to facilitating chemical fate and behavior, the sediment solution is the principle mode of transport for materials into and out of these sediments. The presence of redox reactions and electromotive potential are correlated to pore water volume (Wanzek et al., 2018). The presence of extensive redox zonation in the saturated core collected from location TAL-16 illustrates this point.

Chess et al. (2010) described grain size trends and sediment facies from Butler Cave, VA. Sample selections were based on a "low and wet" and "high and dry" classification on the basis that sediment sourced from the lower portions of the cave were recently deposited in relation to sediments from higher portions of the cave. Color variation between these two sediments were quantified by collecting optical absorption spectra through diffuse reflectance spectroscopy and calculating color ratios. A distinct difference in color ratios were found between low and high sediment. This color variation is attributed to the varying degrees of hydration of iron oxides. The cause of color variation in the sediments collected from this project was not explored but may be due to variable degrees of hydration of iron oxides like those described in Chess et al. (2010) 
The physical differences between core TAL-14 and TAL-15 (1.5 m apart) could be attributed to the presence of microenvironments (Figure 20). The section of core TAL-15 containing Mn oxide contained larger sand grains, creating more pore space and potentially a larger volume of sediment solution facilitating the precipitation of Mn oxide. Differences between saturated and unsaturated sediments were less evident in the collected FS data and PARAFAC model. This is partially due to the low number of saturated samples analyzed as previously discussed in section 5.2.2. However, the saturated samples included in the PARAFAC model contained a lower proportion of component three (Figure 32). A PARAFAC model including additional saturated samples is recommended in order to more accurately evaluate these data. The large range of organic $\mathrm{C} / \mathrm{N}$ ratio in saturated sediments suggest that $\mathrm{C} / \mathrm{N}$ ratios may not be indicative of changing carbon sources. All saturated samples had a FI value $<1.40$ indicating DOM of terrestrial origin opposed to microbial origin. While this might be the case, it is important to remember that the indices calculated in this study were created for non-cave environments. The environmental conditions within a cave system may lead to incorrect interpretation of these data. While the calculated indices are still a valuable tool for evaluating organic matter properties, a re-evaluation may be necessary when characterizing organic matter in a cave environment.

Cave sediments contain an archive of potentially critically important paleoclimatic information. The data presented in this project suggest that paleoclimate reconstructions should be focused on unsaturated sediments or those that do not experience repeated wet-dry cycles in order to minimize the amount of post depositional diagenesis. Considering the dynamic nature of cave systems and complex connection between cave sedimentation, cave morphology, and speleogenesis, it remains difficult to eliminate the possibility of sediments being saturated in-situ at some point in a caves evolution.

\subsection{Input of clastic sediments}

Sediments from TAL and CAM indicate that there is likely a mixture of carbonate and igneous source materials. The onset of turbidity coinciding with a rain event at TAL is evidence that sedimentation is dominantly surface derived in TAL The source area for most sediments in this region of PR is the central volcanic highlands (section 3.1). The Luquillo Critical Zone Observatory located in the northeastern portion of the central highlands. Quartz diorite and 
volcaniclastics ranging from basaltic to andesitic are the two dominant lithologies in that region (Figure 40). Bedrock weathering rates in the Luquillo Mountain region of PR were found to experience the fastest chemical weathering rates of any granitoid rocks on earth's surface (Schulz and White, 1999). Weathering rates of the volcaniclastic lithologies were found to be several orders of magnitude higher than the quartz diorite (Buss et al., 2017). Some amount of clay minerals was present in soils above both lithologies though the quartz diorite soil contained a higher proportion (Table 9). Soils above the Luquillo Mountain lithologies provide information on the chemical weathering processes resulting in the alteration of primary igneous minerals into secondary clay minerals. Physical weathering processes also play an important role during transport from the central highlands into the karst system. The Luquillo Mountain region is not the exact source area of the sediments in TAL but still provide a useful preliminary comparison.

Sediments from TAL are depleted in $\mathrm{Si}, \mathrm{Al}, \mathrm{Fe}, \mathrm{K}, \mathrm{Sr}, \mathrm{Y}$, and $\mathrm{Nb}$ when compared to the Luquillo Mountain soils from both lithologies (Figure 40). Depletion in TAL sediments may suggest that these elements are not transported and sequenced within the cave system. While this could be the case it is important to consider how complexation and speciation may affect the mobility of these sediments both in the conduit, after deposition, and during transport from the source area. Similar concentrations of Ti and Zr in TAL sediments compared to the Luquillo Mountain soils could be an indication these elements are conservative during transport from volcanic highlands into the cave system (Figure 40). The increase in Ca concentrations between TAL sediments and the volcanic soils is possibly due to the additional supply of Ca into the system from carbonate dissolution. However other cave sediments within the northern karst of PR have not been analyzed and therefore no data exists to confirm the Ca source.

Major elements $\mathrm{Al}$ and $\mathrm{Si}$ are strongly negatively correlated in these sediments. The reason for this is unknown. The negative correlation may suggest a lack of clay minerals. However, chemical weathering of the central highlands has been found to produce secondary clay minerals quite rapidly (Table 9). It is more likely that clay minerals and quartz occur together resulting in Si dominating in those sediments. This is evidenced by the poorly sorted nature of TAL sediments. Sections of core with low Si concentrations and high Al concentrations could indicate a lack of quartz or a high proportion of Al oxides. X-ray diffraction was not included in this project; therefore, these interpretations cannot be validated. 
Table 9: Mineral assemblages and proportions of the quartz diorite bedrock and soil and the volcaniclastic bedrock and soil from the Luquillo Mountains.

\begin{tabular}{|c|c|c|c|c|c|c|c|}
\hline \multicolumn{4}{|c|}{ Quartz diorite $^{a}$} & \multicolumn{4}{|c|}{ Volcaniclastics $^{b}$} \\
\hline \multicolumn{2}{|c|}{ Bedrock } & \multicolumn{2}{|c|}{ Soil } & \multicolumn{2}{|c|}{ Bedrock } & \multicolumn{2}{|c|}{$\underline{\text { Soil }}$} \\
\hline$\%$ & Mineral & $\%$ & Mineral & $\%$ & Mineral & $\%$ & Mineral \\
\hline 56.4 & Plagioclase & 53.7 & Quartz & 36.0 & Plagioclase & 56.0 & Kaolinite \\
\hline 24.9 & Quartz & 27.1 & Kaolinite & 24.0 & Chlorite & 26.3 & Quartz \\
\hline 9.50 & Biotite & 15.7 & Biotite & 10.0 & Quartz & 11.3 & Illite \\
\hline 6.30 & Hornblend & 3.40 & Goethite & 9.40 & Pyroxene & 3.90 & Goethite \\
\hline 1.90 & Geothite & & & 8.00 & Epidote & 1.70 & Hematite \\
\hline \multirow[t]{3}{*}{1.80} & K-feldspar & & & 5.80 & K-feldspar & & \\
\hline & & & & 3.60 & Amphibole & & \\
\hline & & & & 0.40 & Kaolinite & & \\
\hline
\end{tabular}

${ }^{a}$ Bedrock and soil data from White et al. (1998)

${ }^{b}$ Bedrock and soil data from Buss et al. (2017) 
OQuartz diorite
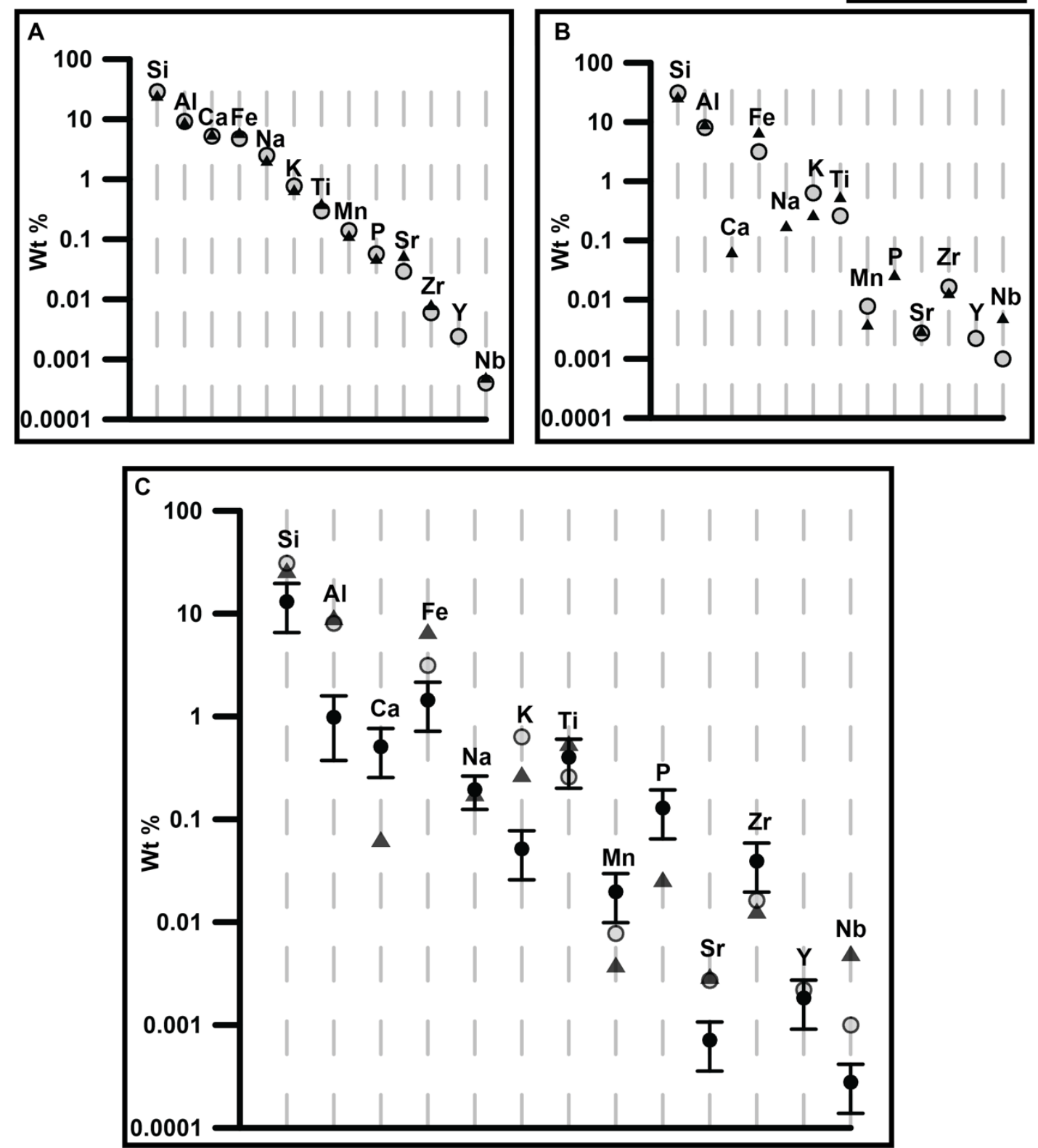

Figure 40: Elemental composition of A) bedrock and B) overlying $0.2 \mathrm{~m}$ of soil collected from the two dominant lithologies in the Luquillo Critical Zone Observatory. C) Average elemental concentrations of El Tallonal Cave (TAL) sediments plotted against the soil elemental concentrations of the two lithologies. Error bars represent one standard deviation total. The Luquillo Critical Zone Observatory data are from White et al. (1998) and Buss et al. (2017). 
Group three elements observed in the PCA analysis include almost all the trace elements in the dataset (Figure 36). Trace elements are rarely found in discrete mineral phases in a sedimentary environment. Rather, these elements exist as inclusions, incorporated into a mineral structure through isomorphic substitution, associated with a mineral structure (as well as organic matter), through sorption or co-precipitation (Essington, 2015). Because trace elements are not inherently connected to discrete mineral phases, concentrations tend to be highly variable depending on the environment. This property makes geochemical trends in trace metal concentrations potentially important in understanding cave sediment sources and transport.

Several trace elements correlate positively with Ti in these sediments (Figure 37). The exact mechanism controlling this is not known. One hypothesis is that $\mathrm{Ti}$ and those trace elements are supplied from the same volcanic source. Titanium is generally present in sediment as a highly stable oxide rutile and has historically been used as an indication of weathering. The concentration of $\mathrm{Cr}$ in lake sediments has been found to increase with decreasing grain size (Mwamburi, 2016). Chromium concentration in the central highlands as of this project has not been evaluated. Though $\mathrm{Cr}$ concentrations tend to be elevated in sediments sourced from maficultra mafic parent material (Essington, 2015). The strong correlation between $\mathrm{Cr}$ and Ti suggests that $\mathrm{Cr}$ could be used as an additional indication to the degree of weathering.

Organic matter from epikarst, terrestrial plants, and autotrophic metabolism has been successfully traced to a sinkhole through time using physical and chemical sediment properties, namely ${ }^{13} \mathrm{C}$ isotope analysis (Tamalavage et al., 2018). This work demonstrates that it is possible for sediment characteristics to vary depending on the source. An important distinction between sediments deposited at the base of a sinkhole and sediments within a cave system is that sediments deposited within a sinkhole have not yet entered the subsurface. This fact minimizes some complexity when tracing a sediment source. A groundwater flow path in a karst aquifer almost always contain some unknown or unexplored portion and therefore adds uncertainty exactly where allogenic sediments enter an aquifer. The lag time between a rain event and the onset of temperature change within TAL is effectively zero (pers. comm. Pantoja-Agred, 2016). This suggests that surface water is entering the cave system rapidly and potentially not far from the main input location in the back compartment of the cave (Figure 9). However, tracing groundwater flow at TAL has been unsuccessful (pers. comm. Padilla, 2019). Identifying sediment source areas to a sinkhole is a promising conclusion that suggests sediment sources to a 
cave system can more confidently be traced when the groundwater flow path has been well established.

\subsection{Karst water and karst sediment organic matter}

Dissolved organic carbon in karst aquifers and cave systems has been well studied (Birdwell and Engel, 2010; Brown and McKay, 2009; Hartland et al., 2012; Husic et al., 2017; Simon et al., 2007; Simon et al., 2010). Organic carbon within suspended sediment from a cave stream has been found to be retained and/or degraded through a caves flow path (Husic et al., 2017). Post-depositional sediment organic matter has not been explored to the same extent. Results from this project suggest significant post depositional diagenesis and organic matter transformations are important processes controlling the fate and behavior of chemical species. Organic matter characterization via FS has been a prominent area of research within soil, agriculture, and waste management studies and provides valuable information about the type of organic matter present in karst sediments.

Parallel factor analysis was done on cave water DOC by Simon et al. (2010). A threecomponent model best fit the variation in fluorescent characteristics. Component two from their model closely matched component two from the PARAFAC model in this project. Component two in Simon et al. (2010) was similar to humic-like compounds and was represented in soil above the epikarst zone. The Simon et al. (2010) sample set was small $(n=18)$ and as a result lowers the ability of the PARAFAC model to produce statistically significant results and potentially skews the effect size of the sample set. Additionally, DOC from the soil samples were extracted using deionized water (DI) and not an alkaline solution and therefore only water extractable organic matter was analyzed. These factors make it difficult to perform any quantifiable comparison to the EEM data collected in this project.

A dominantly-microbial signature was observed $(\mathrm{FI}>1.9)$ in groundwater DOC from a confined portion of the Edwards aquifer leading to the conclusion that surface input stimulates microbial activity (Birdwell and Engel, 2010). No FI values were higher than 1.9 in the analyzed organic matter extracts in this project. The extent of microbially-generated organic matter is unknown in TAL. Given the increase in total organic carbon in saturated sediments, it is likely that if organic matter production is occurring, it is generated within the saturated sediments. Though highest FI and BIX values were observed in unsaturated sediments. The lower values of 
FI in this project when compared to Birdwell and Engel (2010) suggest that applying these predefined indices to environmental conditions differing from those used to define them eliminate portions of EEM data that are potentially informative in understanding organic matter dynamics.

Panno et al. (2004) measured organic carbon and collected radiocarbon age dates of clastic cave sediments from Illinois and found that organic carbon concentrations decreased with increasing depth from the bank surface and were stratigraphically consistent with no age reversals. This finding is consistent with organic carbon concentrations measured in unsaturated sediments (Figure 27). Age dating was not done as part of the PR project and remains unknown if this decreasing organic carbon concentrations in unsaturated sediments are correlated to age.

\subsection{Relevance to storm events}

Fine-grained cohesive sediments present in a cave system has important implications for contaminant fate and transport in a karst aquifer. Clastic input into cave or conduit must first enter the subsurface, most often through groundwater flow. The presence of these cohesive sediments in a groundwater flow path with known organic contaminants may have a high potential for sorption onto the sediment particles. Cave sediments associated with contamination will cause retention of a contaminant in an aquifer. Sediments within a flowing water increase transport. Large storm events such as Hurricane Maria will mobilize previously deposited sediments and the associated sorbed contaminants, potentially entering public or private water supplies.

Sediment mobility is within a conduit is marked by a threshold (Herman et al., 2008).

The installed datalogger in TAL shows that turbidity coincides with even small rain events (pers. comm. Pantoja-Agred, 2016). In contrast, sediment input within CAM occurs only once the Río Camuy river reaches the cave level. Cueva Clara cave does not experience continuous groundwater input as it is an upper (older) level of the Río Camuy system and has since been abandoned by the Río Camuy river (Miller et al., 2017). The differences between these two systems show that a threshold marking the onset of sediment transport and surface derived input is highly variable and specific to a given system. Collins et al. (2015a) documented cave sedimentation from a submerged cave in Yucatan with Hurricane Ingrid (Category 1) and found no deposition associated with the $0.7 \mathrm{~m}$ rise in the water table. Considering the differences between the two caves included in this project puts this into context. The cave systems included 
in this project are drastically different when it comes to sediment deposition in response to a rain event. Deposition depends both on cave morphology, groundwater flow, and the magnitude of the rain event. These factors must first be considered when investigating sediment deposition in response to major storm events.

Identifying paleostorms within the sedimentary record is an area of increased research as frequency of global catastrophic weather events has increased as a result of climate change (McCloskey and Keller, 2009). It is important to uncover how past climate change has impacted the frequency and severity of extreme weather events to further understand how it will affect the occurrence of extreme weather events now and in the future. Donnelly (2005) reconstructed a record of storm surge deposits from a backbarrier salt-pond located in PR going back 2000 years. This reconstruction was done based on the presence of courser grained material within the sedimentary record of this salt-pond. Cave morphology can restrict the flow in such a way that grain size changes may not be indicative of floodwaters. The sediment collected from CAM were known to be deposited through floodwaters but contained only sub sand sized grains. Properties other than grain size (i.e. trace element, organic matter, isotopes) will provide more information when reconstructing paleostorms using cave sediments.

Caves act as a sediment sink. Clastic input is injected into a subsurface depositional environment, protecting it from the erosive processes occurring within subaerial systems (Gale, 1984). This makes cave sediments important archives of paleostorm data. Despite the complexity of cave sedimentation, it remains worthwhile to continue exploring these deposits as paleoclimate archives. While the storm record reconstructed by Donnelly (2005) is still significant finding, coastal sediments are continuously reworked and remobilized. This coupled with the direct influence of the ocean and inability to distinguish between tropical storms, hurricanes, or tsunamis places some uncertainty in the paleostorm record. Cave systems located inland eliminates the influence of tsunamis or other localized coastal flooding events and distinction often difficult to make for coastal deposits (Gabriel et al., 2008; van Hengstum et al., 2008; White, 2007). Additionally, cave sediments record deposition going back potentially much further than 2000 years depending on the system. The sedimentary records preserved within cave systems have potential to not only evaluate and confirm the pre-existing paleostorm record but extend it further into the past. 


\subsection{Recommendations for future work}

The data collected during this projected revealed that sediment input into a cave system is exceptionally complex. This is not implying that storm signatures are unidentifiable, rather this project suggests that many more data are necessary in order to identify source areas and transport mechanisms before a confident assessment of storm deposits can be made.

\subsection{Organic matter}

As previously addressed, dynamic geochemical cycling was observed in the saturated sediments from TAL This observation only hints at the complexity of the geochemical processes occurring in these sediments.

A time series study focused on organic matter transformations and degradations in the cave system would be particularly valuable. Time series studies over a long enough time period will useful for paleoclimate and paleostorm reconstructions. Interactions between sediment and water should also be studied at a smaller, more detailed resolution. In order to use organic matter as a marker of allogenic input, a complete understanding of in-situ organic matter transformations is necessary. A comparison between the organic matter transformations in saturated versus. unsaturated sediments could aid in a better understanding of organic matter degradation and recalcitrance. The lack of photosynthetic metabolism in the cave environment provides a useful comparison to similar studies performed in subaerial environments.

From the data collected in this project, distinction between in-situ microbial organic matter and allogenic organic matter is not possible. Further work on FS analysis must be done in order to confidently characterize organic matter sources (Appendix III). This project performed organic matter extractions using an alkaline solution. Improvements in instrument capabilities in recent years have allowed researchers to collect fluorescence data from solid samples. Performing FS on solid samples eliminates the inherent bias associated with alkaline organic matter exactions and decreases sample preparation times. Solid phase FS on these sediments will provide a true look at the bulk organic matter characteristics and not just those alkalineextractable organic matter characteristics. Additional analysis using nuclear magnetic resonance may provide a useful comparison to the collected fluorescence data.

More data on bulk organic matter concentrations of these clastic cave sediments will also be useful moving forward. 


\subsection{Post-depositional diagenesis and metal cycling}

Each element has a distinct chemical behavior within the sedimentary environment. This behavior is dependent on several factors. The fate and behavior of an element is determined by the oxidation state of that element, the oxidation state of the surrounding solution and solid phases, acid-base controls, and thermodynamic properties. Data collected in this study did not focus on understanding these factors. As such, predications about elemental fate and transport are gathered from bulk elemental concentrations. Many more data are needed in order to provide a more detailed understanding of geochemical behavior in this sedimentary environment.

The fate and behavior of elements are certain to differ between saturated and unsaturated sediments. Exploring the differences between these two sedimentary environments is needed to better understand post-depositional diagenesis. This could be done by focusing on solid-solution interfaces at a smaller scale. Exploring the microbial ecosystem in the cave is also necessary. Metabolic pathways can control most of the chemical fate and behavior by facilitating speciation, complexation, etc. General characterization of the metabolic pathways present in TAL through DNA sequencing or polymerase chain reaction analysis will be informative.

In order to understand the TAL system, flux calculations from input to output should also be performed. Changes in groundwater chemistry from input to output will provide insight into retention and mobility of certain chemical species in these sedimentary deposits.

A more detailed petrographic investigation coupled with X-ray diffraction analysis is recommended. It is speculated that $\mathrm{Fe}$ and $\mathrm{Al}$ oxide coatings precipitate in-situ. This may contribute to the cohesiveness of these sediments despite the low proportions of clay sized particles. The presence of $\mathrm{Fe}$ and $\mathrm{Al}$ oxides will have a strong influence on the sorption and complexation of many chemical species and organic matter.

Once more XRF data are obtained and quantified, re-evaluating the relationship between grain size and elemental concentrations is needed.

\subsection{Source area investigation}

Identifying the exact source area of the TAL sediments will be exceptionally informative. This question is two-fold. The groundwater flow path through the karst aquifer must first be identified. Attempts to do this, as of this project, have been unsuccessful. Once identified, surface waters entering the sink connected to TAL must be traced back to a headwater source in 
the central highlands. The approach to this answer is not exactly known though isotopic investigations may prove to be useful. 


\subsection{Conclusion}

This project concludes that there exists a complex relationship between surface derived input and post-depositional in-situ chemical transformations. Chemical differences between saturated and unsaturated sediments in TAL was observed. Interactions between solids and the sediment solution must be considered when using geochemical parameters as a tool for paleoclimate or paleo-storm reconstructions.

Fluorescent spectroscopy and PARAFAC modeling on alkaline organic matter exactions from these sediments conclude that bulk organic matter is humic acid-like (region 5; Figure 4). FI values from saturated sediments were $<1.4$ indicating organic matter of terrestrial origin. Proportion of PARAFAC component three increased with depth in core TAL-16-01, TAL-16-02, and TAL-16-03. Saturated sediments had lower proportions of component three. No obvious trend in PARAFAC components and FOC, organic C/N, of TN concentration.

X-ray fluorescence data concludes that $\mathrm{Si}$ and $\mathrm{Al}$ are strongly negatively correlated, suggesting that clay minerals and quartz occur together resulting in Si to dominant in those sediments, though X-ray diffraction is needed to confirm this. Titanium is correlated with several trace elements. More data are needed to better understand the mechanism controlling those trends. Correlation between certain trace elements and Fe, Al, or Mn was observed suggesting that sorption and complexation to oxides facilitates retention of these elements in the sediment. Again, more data are needed to confirm this. Preliminary comparison with bedrock and soil chemistry from the central highlands show enrichment and depletion of various elements, hinting at the mobility and retention during sediment transport.

Sediments collected from both TAL and CAM demonstrate extreme heterogeneity present spatially in the cave. Geochemical parameters collected from TAL also demonstrate the importance of microenvironments within sedimentary environments.

Information regarding the chemical makeup of clastic cave sediment is limited. A frame of reference for the elemental data reported here does not exist. The creation of a matrix-specific XRF calibration and high-resolution elemental (inorganic ad organic) data collected for this project provides such a reference. As this project illustrates, cave sedimentation is a function of local climate, geomorphology, and groundwater flow dynamics. Further work on physical and chemical characteristic of cave sediments will provide a broader frame of reference for 
paleoclimate reconstructions. Exploring clastic cave deposits as paleoclimate archives, as of this project, is in its infancy. 


\subsection{References}

Acosta-Colon, A., 2016, Cueva Clara Cartography: Cave and Karst Research and Education Group.

Biau, D. J., Jolles, B. M., and Porcher, R., 2010, P Value and the Theory of Hypothesis Testing: An Explanation for New Researchers: Clinical Orthopaedics and Related Research ${ }^{\circledR}$, v. 468 , no. 3, p. 885-892.

Birdwell, J. E., and Engel, A. S., 2010, Characterization of Dissolved Organic Matter in Cave and Spring Waters Using Uv-Vis Absorbance and Fluorescence Spectroscopy: Organic Geochemistry, v. 41, no. 3, p. 270-280.

Blott, S. J., and Pye, K., 2001, Gradistat: A Grain Size Distribution and Statistics Package for the Analysis of Unconsolidated Sediments: Earth Surface Processes and Landforms, v. 26, no. 11, p. 1237-1248.

Bosch, R., and White, W. B., 2007, Lithofacies and Transport of Clastic Sediments in Karstic Aquifers, in Sasowsky, I. D., and Mylroie, J., eds., Studies of Cave Sediments: Physical and Chemical Records of Paleoclimate, p. 1-22.

Bro, R., and Smilde, A. K., 2014, Principal Component Analysis: Anal. Methods, v. 6, no. 9, p. 2812-2831.

Brown, T. L., and McKay, L., 2009, Fluorescence Characterization of Karst Aquifers, 15th International Congress of Speleology, p. 1429-1434.

Bull, P. A., 1981, Some Fine-Grained Sedimentation Phenomena in Caves: Earth Surface Processes and Landforms, v. 6, p. 11-22.

Buss, H. L., Chapela Lara, M., Moore, O. W., Kurtz, A. C., Schulz, M. S., and White, A. F., 2017, Lithological Influences on Contemporary and Long-Term Regolith Weathering at the Luquillo Critical Zone Observatory: Geochimica et Cosmochimica Acta, v. 196, p. 224-251.

Cerqueira, B., Covelo, E. F., Andrade, M. L., and Vega, F. A., 2011, Retention and Mobility of Copper and Lead in Soils as Influenced by Soil Horizon Properties: Pedosphere, v. 21, no. 5, p. 603-614.

Chen, M., and Hur, J., 2015, Pre-Treatments, Characteristics, and Biogeochemical Dynamics of Dissolved Organic Matter in Sediments: A Review: Water Res, v. 79, p. 10-25. 
Chen, W., Westerhoff, P., Leenheer, J. A., and Booksh, K., 2003, Fluorescence ExcitationEmission Matrix Regional Integration to Quantify Spectra for Dissolved Organic Matter: Envronmental Science Technology, v. 37, p. 5701-5710.

Chess, D. L., Chess, C. A., Sasowsky, I. D., Schmidt, V. A., and White, W. B., 2010, Clastic Sediments in the Butler Cave - Sinking Creek System, Virginia, USA: Acta Carsologica, v. 39 , no. 1 .

Coble, P. G., 1996, Characterization of Marine and Terrestrial Dom in Seawater Using Excitation-Emission Matrix Spectroscopy: Marine Chemistry, v. 51, p. 325-346.

Collins, S. V., Reinhardt, E. G., Rissolo, D., Chatters, J. C., Nava Blank, A., and Luna Erreguerena, P., 2015a, Reconstructing Water Level in Hoyo Negro, Quintana Roo, Mexico, Implications for Early Paleoamerican and Faunal Access: Quaternary Science Reviews, v. 124, p. 68-83.

Collins, S. V., Reinhardt, E. G., Werner, C. L., Le Maillot, C., Devos, F., and Rissolo, D., 2015b, Late Holocene Mangrove Development and Onset of Sedimentation in the Yax Chen Cave System (Ox Bel Ha) Yucatan, Mexico: Implications for Using Cave Sediments as a Sea-Level Indicator: Palaeogeography, Palaeoclimatology, Palaeoecology, v. 438, p. 124134.

Cox, D. P., 1985, Geology of the Tanama and Helecho Porphyry Copper Deposits and Vicinity, Puerto Rico, Volume Professional Paper 1327, U.S. Geological Survery.

Dixon, J. B., Golden, D. C., Uzochukwu, G. A., and Chen, C. C., 1990, Soil Manganese Oxides, in De Boodt, M. F., Hayes, M. H. B., Herbillon, A., De Strooper, E. B. A., and Tuck, J. J., eds., Soil Colloids and Their Associations in Aggregates: Boston, MA, Springer US, p. 141-163.

Doehring, D. O., and Vierbuchen, R. C., 1971, Cave Development During a Catastrophic Storm in the Great Valley of Virginia: Science, v. 174, p. 1327-1329.

Donnelly, J. P., 2005, Evidence of Past Intense Tropical Cyclones from Backbarrier Salt Pond Sediments: A Case Study from Isla De Culebrita, Puerto Rico, USA: Journal of Coastal Research, no. 42, p. 201-210.

Essington, M. E., 2015, Soil and Water Chemistry: An Integrative Approach Taylor and Francis Group. 
Farrant, A. R., and Smart, P. L., 2011, Role of Sediment in Speleogenesis; Sedimentation and Paragenesis: Geomorphology, v. 134, no. 1-2, p. 79-93.

Folk, R. L., and Ward, W. C., 1957, A Study in the Significance of Grain-Size Parameters: Journal of Sedimentary Petrology, v. 27, p. 3-26.

Ford, D., and Williams, P., 2007, Karst Hydrogeology and Geomorphology, John Wiley and Sons, Ltd.

Fornos, J. J., Gints, J., and Gracia, F., 2009, Present-Day Sedimentary Facies in the Coastal Karst Caves of Mallorca Island (Western Mediterranean): Journal of Cave and Karst Studies, v. 71, p. 86-99.

Gabor, R. S., Baker, A., McKnight, D. M., and Miller, M. P., 2014, Fluorescence Indices and Their Interpretation, Aquatic Organic Matter Fluorescence, Cambridge University Press, p. 303-338.

Gabriel, J. J., Reinhardt, E. G., Peros, M. C., Davidson, D. E., van Hengstum, P. J., and Beddows, P. A., 2008, Palaeoenvironmental Evolution of Cenote Aktun Ha (Carwash) on the Yucatan Peninsula, Mexico and Its Response to Holocene Sea-Level Rise: Journal of Paleolimnology, v. 42, no. 2, p. 199-213.

Gale, S. J., 1984, The Hydraulics of Conduit Flow in Carbonate Aquifers: Journal of Hydrology, v. 70, p. 309-327.

Gillieson, D., 1986, Cave Sedimentation in the New Guinea Highlands: Earth Surface Processes and Landforms, v. 11, p. 533-543.

Giusti, E., 1978, Hydrogeology of the Karst in Puerto Rico, Volume Professional Paper 1012, U.S. Geological Survery

Gomez-Gomez, F., Rodriguez-Martinez, J., and Santiago, M., 2014, Hydrogeology of Puerto Rico and the Outlying Islands of Vieques, Culebra, and Mona, in USGS, and USDOI, eds.: Scientific Investigations

Greenfield, L. M., Hill, P. W., Paterson, E., Baggs, E. M., and Jones, D. L., 2018, Methodological Bias Associated with Soluble Protein Recovery from Soil: Science, v. 8, no. 1, p. 11186 .

Harrell, F., and Dupont, C., 2020, Hmisc: Harrell Miscellaneous, v. Vesion: 4.4-0.

Hart, E. A., and Schurger, S. G., 2005, Sediment Storage and Yield in an Urbanized Karst Watershed: Geomorphology, v. 70, no. 1-2, p. 85-96. 
Hartland, A., Fairchild, I. J., Lead, J. R., Borsato, A., Baker, A., Frisia, S., and Baalousha, M., 2012, From Soil to Cave: Transport of Trace Metals by Natural Organic Matter in Karst Dripwaters: Chemical Geology, v. 304-305, p. 68-82.

Hearty, P. J., Olson, S. L., Kaufman, D. S., Edwards, R. L., and Cheng, H., 2004, Stratigraphy and Geochronology of Pitfall Accumulations in Caves and Fissures, Bermuda: Quaternary Science Reviews, v. 23, no. 9-10, p. 1151-1171.

Herman, E. K., Tancredi, J. H., Toran, L., and White, W. B., 2006, Mineralogy of Suspended Sediment in Three Karst Springs: Hydrogeology Journal, v. 15, no. 2, p. 255-266.

Herman, E. K., Toran, L., and White, W. B., 2008, Threshold Events in Spring Discharge: Evidence from Sediment and Continuous Water Level Measurement: Journal of Hydrology, v. 351, no. 1-2, p. 98-106.

Hur, J., Lee, B. M., and Shin, K. H., 2014, Spectroscopic Characterization of Dissolved Organic Matter Isolates from Sediments and the Association with Phenanthrene Binding Affinity: Chemosphere, v. 111, p. 450-457.

Husic, A., Fox, J., Agouridis, C., Currens, J., Ford, W., and Taylor, C., 2017, Sediment Carbon Fate in Phreatic Karst (Part 1): Conceptual Model Development: Journal of Hydrology, v. 549, p. 179-193.

Insam, H., 1996, Microorganisms and Humus in Soils, Humic Substances in Terrestrial Ecosystems: Elsevier Science.

Jolly, W., Lidiak, E. G., Dickin, A. P., and Wu, T.-W., 2001, Secular Geochemistry of Centeral Puerto Rican Island Arc Lavas: Constraints on Mesozoic Tectonism in the Eastern Greater Antilles: Journal of Petrology, v. 42, no. 12, p. 2197-2214.

Kipnis, E., Bowen, B., Hutchings, S. J., Hynek, S. A., and Benison, K. C., 2019, Analysis of Major Ions in Dense Brines Using Portable X-Ray Fluorescence Spectrometry, Geologocal Society of America Annual Meeting, Volume 51: Phoenix, AZ.

Lace, M., 2006, Unpublished Map of El Tallonal Cave.

Lin, M., Lucas, H. C., and Shmueli, G., 2013, Research Commentary-Too Big to Fail: Large Samples and the P-Value Problem: Information Systems Research, v. 24, no. 4, p. 906917. 
Lukawska-Matuszewska, K., Grzybowski, W., Szewczun, A., and Tarasiewicz, P., 2018, Constituents of Organic Alkalinity in Pore Water of Marine Sediments: Marine Chemistry, v. 200, p. 22-32.

Ma, Y., and Hooda, P., 2010, Chromium, Nickel and Cobalt, Trace Elements in Soils, p. 461479.

MacLachlan, S. E., Hunt, J. E., and Croudace, I. W., 2015, An Empirical Assessment of Variable Water Content and Grain-Size on X-Ray Fluorescence Core-Scanning Measurements of Deep Sea Sediments, Micro-Xrf Studies of Sediment Cores, p. 173-185.

Madigan, M. T., Bender, K. S., Buckley, D. H., Sattley, W. M., and Stahl, D. A., 2018, Brock Biology of Microorganisms.

Massicotte, P., 2019, Eemr: Tools for Pre-Processing Emission-Excitation-Matrix (Eem) Fluorescence Data, Volume Version 1.0.1

McCloskey, T. A., and Keller, G., 2009, 5000 Year Sedimentary Record of Hurricane Strikes on the Central Coast of Belize: Quaternary International, v. 195, no. 1-2, p. 53-68.

McKenzie, R., 1980, The Adsorption of Lead and Other Heavy Metals on Oxides of Manganese and Iron: Soil Research, v. 18, no. 1, p. 61-73.

McNeill-Jewer, C. A., Reinhardt, E. G., Collins, S., Kovacs, S., Chan, W. M., Devos, F., and LeMaillot, C., 2019, The Effect of Seasonal Rainfall on Nutrient Input and Biological Productivity in the Yax Chen Cave System (Ox Bel Ha), Mexico, and Implications for Mxrf Core Studies of Paleohydrology: Palaeogeography, Palaeoclimatology, Palaeoecology, v. 534, p. 109-120.

Miller, T., 2018, Karst Notes from the Stricken Land: Hurricane Maria and the Camuy Caverns, National Speleological Society News, Volume 76, National Speleological Society, p. 4-8.

Miller, T., Brocard, G., and Willenbring, J. K., 2017, A Chronology of Karstification in Puerto Rico Using Cosmogenic Dating of Cave Sediments, International Congress of Speleology, Volume 17: Sydney, Austrailia.

Morelock, J., Capella, J., García-Sais, J., and Barreto, M., 2016, Puerto Rico -Seas at the Millennium.

Mudarra, M., Andreo, B., and Baker, A., 2011, Characterisation of Dissolved Organic Matter in Karst Spring Waters Using Intrinsic Fluorescence: Relationship with Infiltration Processes: Science of the Total Environment, v. 409, no. 18, p. 3448-3462. 
Muller, M., Milori, D. M., Deleris, S., Steyer, J. P., and Dudal, Y., 2011, Solid-Phase

Fluorescence Spectroscopy to Characterize Organic Wastes: Waste Managment, v. 31, no. 9-10, p. 1916-1923.

Murphy, K. R., Stedmon, C. A., Graeber, D., and Bro, R., 2013, Fluorescence Spectroscopy and Multi-Way Techniques. Parafac: Analytical Methods, v. 5, no. 23.

Murphy, S. F., Stallard, R. F., Larsen, M. C., and Gould, W. A., 2012, Physiography, Geology, and Land Cover of Four Watersheds in Eastern Puerto Rico in U.S.D.I, and U.S.G.S, eds.

Mwamburi, J., 2016, Chromium Distribution and Spatial Variations in the Finer Sediment Grain Size Fraction and Unfractioned Surficial Sediments on Nyanza Gulf, of Lake Victoria (East Africa), v. 2016, p. 1-15.

Nieves-Rivera, A., 2003, Mycological Survey of Río Camuy Caves Park, Puerto Rico: Journal of Cave and Karst Studies, v. 65, p. 23-28.

Panno, S. V., Curry, B. B., Wang, H., Hackley, K. C., Liu, C.-L., Lundstrom, C., and Zhou, J., 2004, Climate Change in Southern Illinois, USA, Based on the Age and $\Delta 13 \mathrm{c}$ of Organic Matter in Cave Sediments: Quaternary Research, v. 61, no. 3, p. 301-313.

Pasch, R. J., Penny, A. B., and Berg, R., 2017, National Hurricane Center Tropical Cyclone Report: Hurricane Maria, in NOAA, ed., Volume AL 152017.

pers. comm. Padilla, I. Y., 2019, Dye Tracing at El Tallonal Cave, in Downey, A., ed.

pers. comm. Pantoja-Agred, F., 2016, Water Quality from El Tallonal Cave, Pr, Unpublished Chemical Data.

Pinti, D., 2011, Redox Zonation, p. 1441-1442.

Pipan, T., and Culver, D. C., 2013, Organic Carbon in Shallow Subterranean Habitats: Acta Carsologica, v. 42, no. 2-3, p. 291-300.

Polk, J. S., Van Beynen, P., Asmerom, Y., and Polyak, V. J., 2013, Reconstructing Past Climates Using Carbon Isotopes from Fulvic Acids in Cave Sediments, v. 360-361, p. 1-9.

Polk, J. S., Van Beynen, P. E., and Reeder, P. P., 2007, Late Holocene Environmental Reconstruction Using Cave Sediments from Belize: Quaternary Research, v. 68, no. 1, p. $53-63$.

Pucher, M., Graeber, D., Preiner, S., and Pinto, R., 2020, Stardom: Parafac Anlaysis of Eems from Dom: Version 1.1.11. 
Ringnér, M., 2008, What Is Principal Component Analysis?: Nature Biotechnology, v. 26, no. 3, p. 303-304.

Rowe, H., Hughes, N., and Robinson, K., 2012, The Quantification and Application of Handheld Energy-Dispersive X-Ray Fluorescence (Ed-Xrf) in Mudrock Chemostratigraphy and Geochemistry: Chemical Geology, v. 324-325, p. 122-131.

Schulz, M. S., and White, A. F., 1999, Chemical Weathering in a Tropical Watershed, Luquillo Mountains, Puerto Rico Iii: Quartz Dissolution Rates: Geochimica et Cosmochimica Acta, v. 63, no. 3-4, p. 337-350.

Simon, K. S., Pipan, T., and Culver, D. C., 2007, A Conceptual Model of the Flow and Distribution of Organic Carbon in Caves: Journal of Cave and Karst Studies, v. 69, p. 000-000.

Simon, K. S., Pipan, T., Ohno, T., and Culver, D. C., 2010, Spatial and Temporal Patterns in Abundance and Character of Dissolved Organic Matter in Two Karst Aquifers: Fundamental and Applied Limnology / Archiv für Hydrobiologie, v. 177, no. 2, p. 81-92.

Sobczak, W. V., Hedin, L. O., and Klug, M. J., 1998, Relationships between Bacterial Productivity and Organic Carbon at a Soil-Stream Interface: Hydrobiologia, v. 386, p. $45-53$.

Tamalavage, A. E., van Hengstum, P. J., Louchouarn, P., Molodtsov, S., Kaiser, K., Donnelly, J. P., Albury, N. A., and Fall, P. L., 2018, Organic Matter Sources and Lateral Sedimentation in a Bahamian Karst Basin (Sinkhole) over the Late Holocene: Influence of Local Vegetation and Climate: Palaeogeography, Palaeoclimatology, Palaeoecology, v. 506, p. $70-83$.

van Hengstum, P. J., Reinhardt, E. G., Beddows, P. A., and Gabriel, J. J., 2010, Linkages between Holocene Paleoclimate and Paleohydrogeology Preserved in a Yucatan Underwater Cave: Quaternary Science Reviews, v. 29, no. 19-20, p. 2788-2798. van Hengstum, P. J., Reinhardt, E. G., Beddows, P. A., Huang, R. J., and Gabriel, J. J., 2008, Thecamoebians (Testate Amoebae) and Foraminifera from Three Anchialine Cenotes in Mexico: Low Salinity (1.5-4.5 Psu) Faunal Transitions: Journal of Foraminiferal Research v. 38, p. 305-317.

Von Wandruszka, R., 2006, Phosphorus Retention in Calcareous Soils and the Effect of Organic Matter on Its Mobility: Geochemical Transactions, v. 7, no. 1, p. 6. 
Wanzek, T., Keiluweit, M., Varga, T., Lindsley, A., Nico, P. S., Fendorf, S., and Kleber, M., 2018, The Ability of Soil Pore Network Metrics to Predict Redox Dynamics Is Scale Dependent: Soil Systems, v. 2, no. 4.

White, A. F., Blum, A. E., Schulz, M. S., Vivit, D. V., Stonestrom, D. A., Larsen, M., Murphy, S. F., and Eberl, D., 1998, Chemical Weathering in a Tropical Watershed, Luquillo Mountains, Puerto Rico: I. Long-Term Versus Short-Term Weathering Fluxes: Geochimica et Cosmochimica Acta, v. 62, no. 2, p. 209-226.

White, W., 2007, Cave Sediments and Paleoclimate: Journal of Cave and Karst Studies, v. 69, p. 76-93.

White, W. B., 1988, Geomorphology and Hydrogeology of Karst Terrains, Oxford University Press. 


\section{Appendix I: Naming convention for samples collected from El Tallonal Cave and Cueva Clara, PR}

All samples collected from El Tallonal Cave or Cueva Clara begin with TAL or CAM, respectively, followed by a hyphen and number (or letter) referring to sample location followed

by a number referring to the sample number with depth at that location followed by a hyphen and number indicating the depth within that sample at which it was subsampled. (TAL-sample location-sample number at that location-depth $(\mathrm{cm})$ from the top of that sample number)

- $\quad$ Samples taken with depth and core samples are given a sample location number followed by a hyphen and number corresponding to the sample number taken at that location. This is followed by an additional hyphen and two digits indicating the depth at which the sub-sample was collected from that sample number.

O Example 1: TAL-15-02-05 refers to a sample taken from location 15 at $5 \mathrm{~cm}$ below the top of the second sample collected at location 15 .

○ Example 2: TAL-17-07-18 refers to sediment collected from sample location 17 at $18 \mathrm{~cm}$ below the top of the $7^{\text {th }}$ sample taken at location 17.

○ Example 3: TAL-11-01-00 refers to the sediment bank surface at location 11.

○ Example 4: TAL-12-04-00 refers to the $4^{\text {th }}$ sample with taken at location 12.

- Surface sediment samples are given letters referring to sample location followed by a number referring to meters away from active cave stream

○ Example 1: TAL-A1-01-00 refers to a grab sample collected at location A at 1 meter away from the stream

○ Example 2: TAL-D3-01-00 refers to a grab sample collected at location D at 3 meters away from the stream 


\section{Appendix II: Organic matter extraction method comparison}

There many ways to extract organic matter from a solid medium with results dependent on the method. Two extraction solutions were compared: (1) $0.1 \mathrm{M}$ sodium hydroxide and; (2) 0.1 M sodium pyrophosphate $\left(\mathrm{Na}_{4} \mathrm{P}_{2} \mathrm{O}_{7}\right)$ (Chen and Hur, 2015; Greenfield et al., 2018). The extraction solutions were mixed from a $1 \mathrm{~N} \mathrm{NaOH}$ stock solution and solid $\mathrm{Na}_{4} \mathrm{P}_{2} \mathrm{O}_{7}$. All extractions were completed by following a modified version of the method outlined in Hur et al. (2014) and are further described in section 4.2.6. The resulting solutions were different in color (Figure II-1). The $\mathrm{Na}_{4} \mathrm{P}_{2} \mathrm{O}_{7}$ extraction solutions were consistently dark, almost black, in color while the $\mathrm{NaOH}$ solutions tended to be a light brown but varied from dark brown to clear. Extractions using the two solutions were then analyzed for non-purgeable organic carbon (NPOC) on a Shimadzu TOC-V carbon analyzer (Figure II-2). Extraction completed with $\mathrm{Na}_{4} \mathrm{P}_{2} \mathrm{O}_{7}$ extracted more total non-purgeable organic carbon than when $\mathrm{NaOH}$ was used. However, the $\mathrm{Na}_{4} \mathrm{P}_{2} \mathrm{O}_{7}$ extraction solution yield almost no fluorescence response (Figure II-3). Extractions completed with $\mathrm{NaOH}$ responded with a higher intensity signal. Due to this lack of fluorescence signal when $\mathrm{Na}_{4} \mathrm{P}_{2} \mathrm{O}_{7}$ was used, extractions were completed using $\mathrm{NaOH}$ via the method modified from Hur et al. (2014). 


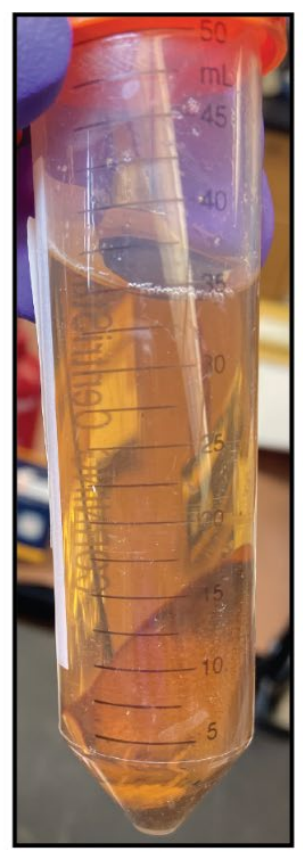

$0.1 \mathrm{~N} \mathrm{NaOH}$ $\mathrm{pH}=12$

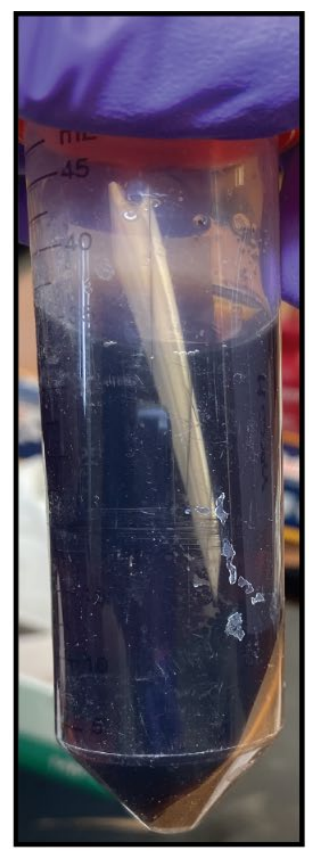

$0.1 \mathrm{~N} \mathrm{Na}_{4} \mathrm{P}_{2} \mathrm{O}_{7}$ $\mathrm{pH}=10$

Figure II-1: Photographs comparing the $\mathrm{NaOH}$ and $\mathrm{Na}_{4} \mathrm{P}_{2} \mathrm{O}_{7}$ organic matter extraction solutions. 


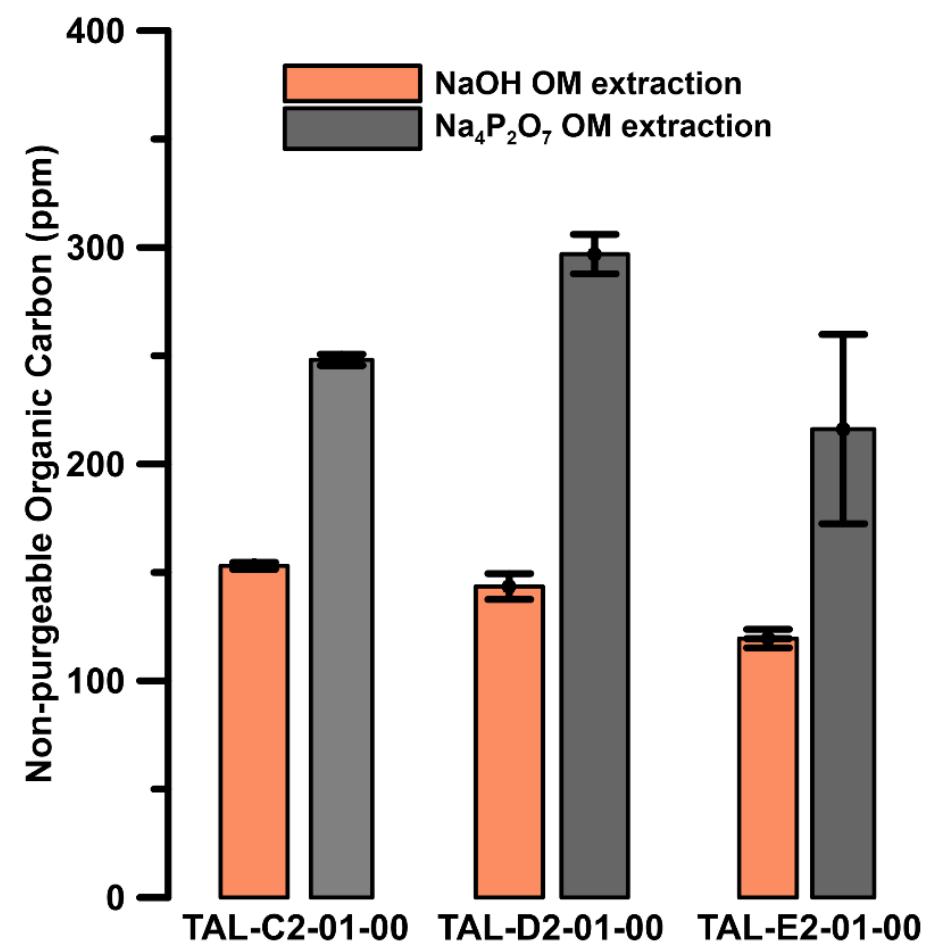

Figure II-2: Non-purgeable organic carbon values reported for the two alkaline extraction methods. Error bars represent one standard deviation total. 

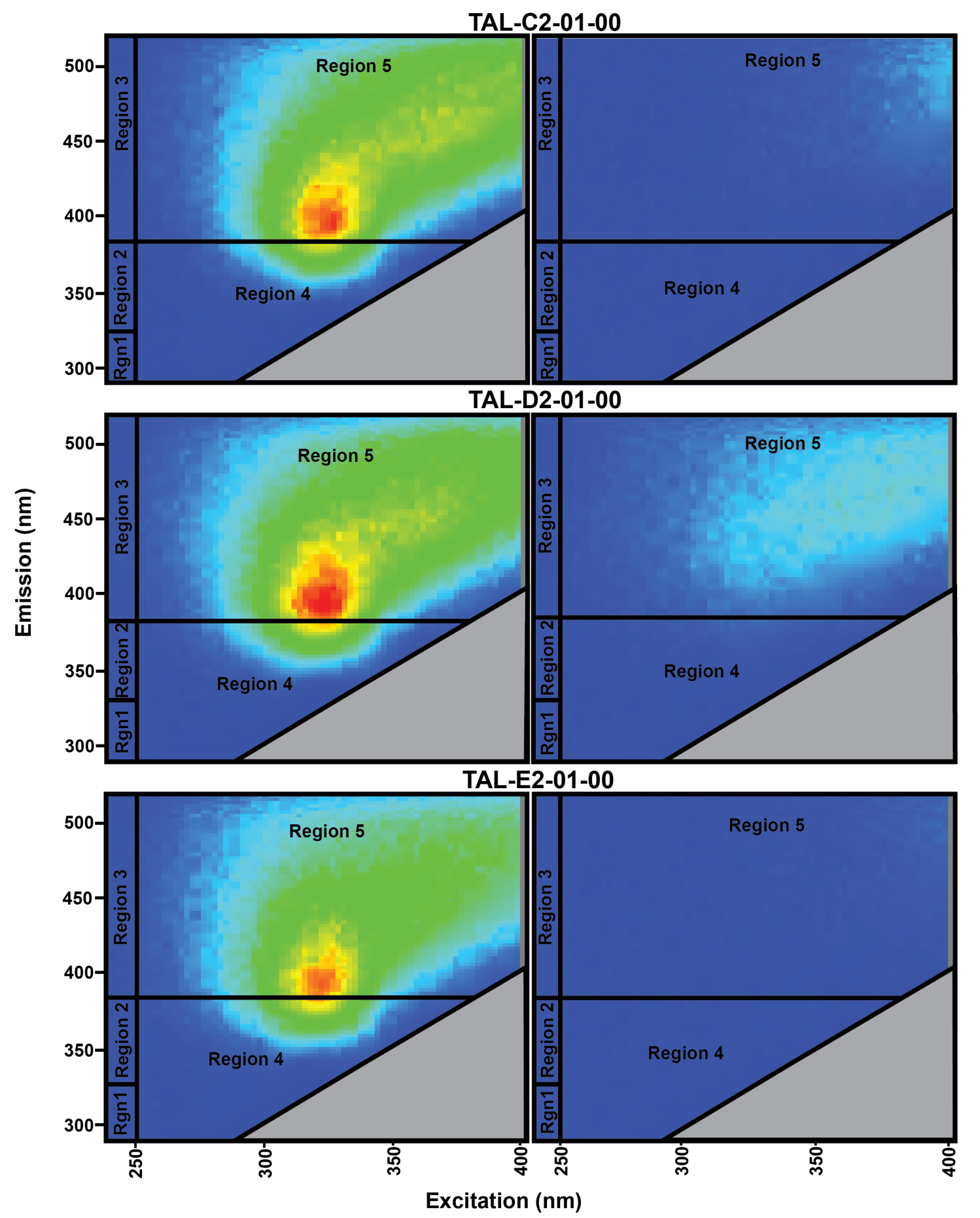

Figure II-3: Emission-excitation matrices (EEM) collected from the two organic matter extraction solutions. LEFT: $\mathrm{NaOH}$ organic matter extraction solution; RIGHT: $\mathrm{Na}_{4} \mathrm{P}_{4} \mathrm{O}_{7}$ organic matter extraction solution. 


\section{Appendix III: Solid phase FS summary}

The fluorometer is traditionally used to analyze aqueous samples; however, it was initially attempted to collect fluorescence data directly from the solid phase. Collecting fluorescence spectroscopy (FS) data from a solid sample eliminates the need to perform tedious organic matter extractions and potential bias. Solid phase fluorescence measurements were attempted on tryptophan and humic acid standards (Figure III-1). These solids were placed into the solid sample holder specifically designed for the make and model of fluorometer used. The solid sample holder was placed at an angle $30^{\circ}-40^{\circ}$ relative to the photon detector. The solid phase scans were completed ( $\lambda$ ex: $240-400 \mathrm{~nm}$; $\lambda$ em: $280-540 \mathrm{~nm}$ ) with $1^{\text {st }}$ and $2^{\text {nd }}$ Rayleigh scattering removed. A consistent fluorescence signal was collected from solid phase tryptophan at $\lambda$ ex: 270-325 nm; $\lambda \mathrm{em}$ : 320-360 $\mathrm{nm}$. However, solid phase humic acid did not yield a fluorescent response (Figure III-2). The concentration of photons supplied to the solid sample by the xenon bulb in the model of fluorometer used is not high enough to excite the medium. This issue does not exist when measuring FS on aqueous mediums as the excitation source can easily penetrate the solution. A study done by Muller et al. (2011) cites a similar issue occurring when attempting to detect a fluorescence signal from solid organic waste. Humic acid and other similarly dark colored sample mediums contain highly light absorbing chromophores that attenuate the fluorescence signal before it reaches the detector. The study successfully detected a solid phase fluorescence response when the xenon bulb was replaced with a laser source as it can supply higher concentrations of photons to the solid sample. Given that the Fluorolog-3 does not has a laser excitation source, organic carbon characterization was completed by extracting organic matter from the sediments into an aqueous form.

With necessary intrument upgrades solid phase FS may be possible. Collecting FS on solid phase is valuble for understanding bulk organic matter characteristics in-situ. This is not possible when extracdting organic matter into an aqueous form. Many more data and experiments are needed in order to determine the necessary intrument upgrades and method accuracy. 

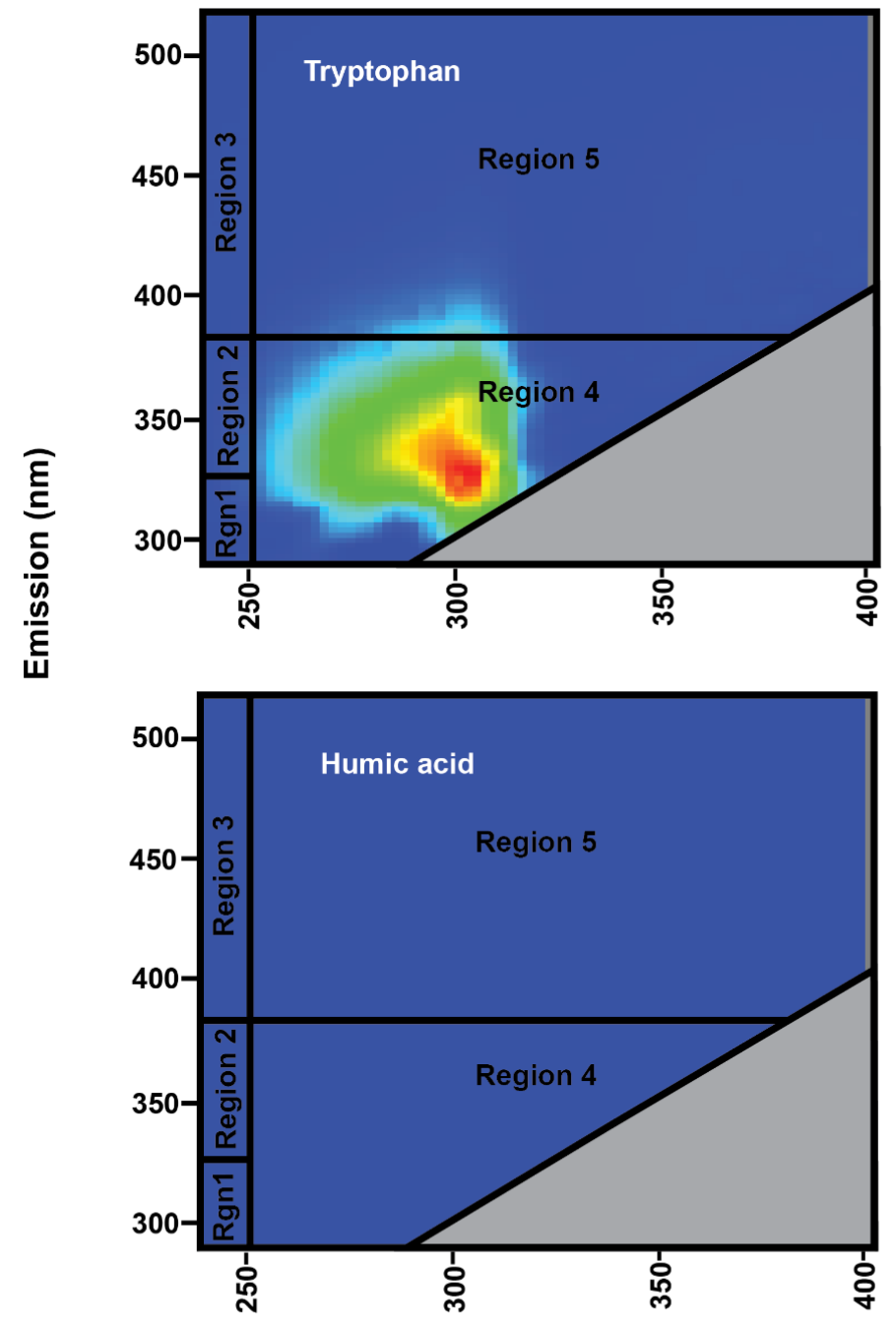

\section{Excitation (nm)}

Figure III -1: EEM collected from solid phase tryptophan and humic acid from a Horiba ${ }^{\circledR}$ Fluoro-log 3 configured with 450-Watt light source, single grated emission monochromator, and a single grated excitation monochromator 
Appendix IV: All collected subsamples with tracking ID and analysis completed.

\begin{tabular}{|c|c|c|c|c|c|c|c|c|c|c|c|c|c|c|c|}
\hline 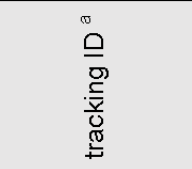 & 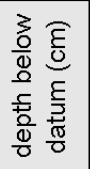 & 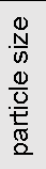 & 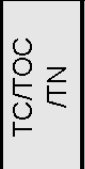 & $\underset{\amalg}{\mathscr{L}}$ & $\underline{\underline{0}}$ & $\begin{array}{l}\stackrel{0}{u} \\
\stackrel{\underline{\alpha}}{x}\end{array}$ & 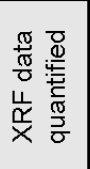 & 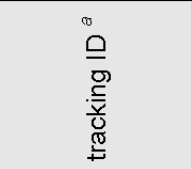 & 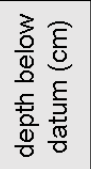 & $\begin{array}{l}0 \\
. N \\
N \\
0 \\
\frac{0}{U} \\
\frac{0}{ \pm} \\
0 \\
0\end{array}$ & 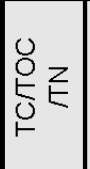 & $\stackrel{w}{4}$ & $\begin{array}{l}\stackrel{0}{0} \\
\underline{0}\end{array}$ & $\begin{array}{l}u \\
\stackrel{u}{\widetilde{r}} \\
\frac{\mathbf{\alpha}}{x}\end{array}$ & 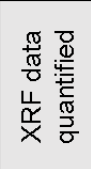 \\
\hline CAM-01-01-00 & 00 & $x$ & $x$ & & & $x$ & & CAM-08-01-07 & 07 & $x$ & $x$ & & & $x$ & \\
\hline CAM-01-01-02 & 02 & $x$ & $x$ & & & $x$ & & CAM-08-01-11 & 11 & $x$ & $x$ & & & $x$ & \\
\hline CAM-01-01-04 & 04 & $x$ & $\mathrm{x}$ & & & $\mathrm{x}$ & & CAM-08-01-15 & 15 & $\mathrm{x}$ & $x$ & & & $x$ & \\
\hline CAM-01-01-05 & 05 & $x$ & $x$ & & & $\mathrm{x}$ & & CAM-08-01-19 & 19 & $x$ & $x$ & & & $x$ & \\
\hline CAM-01-01-07 & 07 & $x$ & $x$ & & & $x$ & & CAM-09-01-01 & 01 & $x$ & $x$ & & & $x$ & \\
\hline CAM-01-01-09 & 09 & $x$ & $x$ & & & $x$ & & CAM-09-01-05 & 05 & $x$ & $x$ & & & $x$ & \\
\hline CAM-01-01-11 & 11 & $x$ & $x$ & & & $x$ & & CAM-09-01-09 & 09 & $x$ & $x$ & & & $x$ & \\
\hline CAM-01-01-12 & 12 & $x$ & $x$ & & & $x$ & & CAM-09-01-15 & 15 & $x$ & $x$ & & & $x$ & \\
\hline CAM-01-01-13 & 13 & $x$ & $x$ & & & $x$ & & CAM-09-01-17 & 17 & $x$ & $x$ & & & $x$ & \\
\hline CAM-01-01-15 & 15 & $x$ & $x$ & & & $x$ & & CAM-09-01-20 & 20 & $x$ & $x$ & & & $x$ & \\
\hline CAM-01-01-16 & 16 & $x$ & $x$ & & & $x$ & & CAM-09-02-00 & 26 & $x$ & $x$ & & & $x$ & \\
\hline CAM-01-01-19 & 19 & $x$ & $x$ & & & $x$ & & CAM-09-02-05 & 29 & $x$ & $x$ & & & $x$ & \\
\hline CAM-02-01-02 & 02 & $x$ & $x$ & & & $x$ & & CAM-09-02-08 & 34 & $x$ & $x$ & & & $x$ & \\
\hline CAM-02-01-08 & 08 & $x$ & $x$ & & & $x$ & & CAM-09-02-11 & 37 & $x$ & $x$ & & & $x$ & \\
\hline CAM-02-01-11 & 11 & $\mathrm{x}$ & $x$ & & & $x$ & & CAM-09-02-15 & 41 & $x$ & $x$ & & & $x$ & \\
\hline CAM-02-01-13 & 13 & $\mathrm{x}$ & $x$ & & & $x$ & & CAM-09-02-18 & 44 & $\mathrm{x}$ & $x$ & & & $x$ & \\
\hline CAM-02-01-15 & 15 & $x$ & $x$ & & & $x$ & & CAM-10-01-00 & 0 & $x$ & $x$ & & & $x$ & \\
\hline CAM-02-01-17 & 17 & $x$ & $x$ & & & $x$ & & CAM-10-01-10 & 10 & $x$ & $x$ & & & $x$ & \\
\hline CAM-02-01-20 & 20 & $x$ & $x$ & & & $x$ & & CAM-10-01-15 & 15 & $x$ & $x$ & & & $x$ & \\
\hline CAM-03-01-00 & 00 & $x$ & $x$ & & & $x$ & & CAM-10-01-21 & 21 & $\mathrm{x}$ & $x$ & & & $x$ & \\
\hline CAM-03-01-03 & 03 & $x$ & $x$ & & & $\mathrm{x}$ & & CAM-10-01-14 & 14 & $x$ & $x$ & & & $x$ & \\
\hline CAM-03-01-04 & 04 & $x$ & $x$ & & & $x$ & & CAM-17-01-00 & 114 & $x$ & $x$ & & & $x$ & \\
\hline CAM-03-01-08 & 08 & $\mathrm{x}$ & $x$ & & & $x$ & & TAL-17-01-03 & 117 & $x$ & $x$ & & & $x$ & \\
\hline CAM-03-01-09 & 09 & $x$ & $x$ & & & $x$ & & TAL-17-01-07 & 121 & $x$ & $x$ & & & $x$ & \\
\hline CAM-03-01-12 & 12 & $x$ & $x$ & & & $x$ & & TAL-17-01-12 & 126 & $x$ & $x$ & & & $x$ & \\
\hline CAM-03-01-15 & 15 & $\mathrm{x}$ & $x$ & & & $x$ & & TAL-17-01-16 & 130 & $x$ & $x$ & & & $x$ & \\
\hline CAM-03-01-17 & 17 & $x$ & $x$ & & & $x$ & & TAL-17-01-24 & 138 & $x$ & $x$ & & & $x$ & \\
\hline CAM-04-01-00 & 00 & $x$ & $x$ & & & $x$ & & TAL-17-02-00 & 120 & $x$ & $x$ & & & $\mathrm{x}$ & \\
\hline CAM-04-01-05 & 05 & $x$ & $x$ & & & $x$ & & TAL-17-02-02 & 122 & $x$ & $x$ & & & $x$ & \\
\hline CAM-04-01-09 & 09 & $\mathrm{x}$ & $x$ & & & $x$ & & TAL-17-02-03 & 123 & $x$ & $x$ & & & $x$ & \\
\hline CAM-04-01-13 & 13 & $x$ & $x$ & & & $x$ & & TAL-17-02-08 & 128 & $x$ & $x$ & & & $x$ & \\
\hline CAM-04-01-16 & 16 & $x$ & $x$ & & & $x$ & & TAL-17-02-11 & 131 & $x$ & $x$ & & & $x$ & \\
\hline CAM-04-01-20 & 20 & $\mathrm{x}$ & $x$ & & & $x$ & & TAL-17-02-14 & 134 & $x$ & $x$ & & & $x$ & \\
\hline CAM-05-01-00 & 00 & $x$ & $x$ & & & $x$ & & TAL-17-02-17 & 137 & $x$ & $x$ & & & $x$ & \\
\hline CAM-05-01-05 & 05 & $x$ & $x$ & & & $x$ & & TAL-17-02-21 & 141 & $x$ & $x$ & & & $\mathrm{x}$ & \\
\hline CAM-05-01-07 & 07 & $x$ & $x$ & & & $x$ & & TAL-17-02-25 & 145 & $x$ & $x$ & & & $x$ & \\
\hline CAM-05-01-11 & 11 & $x$ & $x$ & & & $x$ & & TAL-17-02-27 & 147 & $x$ & $x$ & & & $x$ & \\
\hline CAM-05-01-14 & 14 & $x$ & $x$ & & & $x$ & & TAL-17-03-00 & 135 & $x$ & $x$ & & & $x$ & \\
\hline CAM-05-01-17 & 17 & $x$ & $x$ & & & $x$ & & TAL-17-03-04 & 139 & $x$ & $x$ & & & $x$ & \\
\hline CAM-06-01-00 & 00 & $x$ & $x$ & & & $x$ & & TAL-17-03-08 & 143 & $x$ & $x$ & & & $x$ & \\
\hline CAM-06-01-05 & 05 & $x$ & $x$ & & & $x$ & & TAL-17-03-11 & 146 & $x$ & $x$ & & & $x$ & \\
\hline CAM-06-01-07 & 07 & $x$ & $x$ & & & $x$ & & TAL-17-03-13 & 148 & $x$ & $x$ & & & $\mathrm{x}$ & \\
\hline CAM-06-01-12 & 12 & $x$ & $x$ & & & $x$ & & TAL-17-03-15 & 150 & $x$ & $x$ & & & $x$ & \\
\hline CAM-06-01-19 & 19 & $x$ & $x$ & & & $x$ & & TAL-17-03-18 & 153 & $x$ & $x$ & & & $x$ & \\
\hline CAM-06-02-00 & 20 & $x$ & $x$ & & & $x$ & & TAL-17-03-22 & 157 & $x$ & $x$ & & & $x$ & \\
\hline CAM-06-02-08 & 28 & $x$ & $x$ & & & $x$ & & TAL-17-04-00 & 147 & $x$ & $x$ & & & $x$ & \\
\hline CAM-06-02-14 & 34 & $\mathrm{x}$ & $x$ & & & $x$ & & TAL-17-04-04 & 151 & $x$ & $x$ & & & $x$ & \\
\hline CAM-06-02-17 & 37 & $x$ & $x$ & & & $x$ & & TAL-17-04-07 & 154 & $x$ & $x$ & & & $x$ & \\
\hline CAM-07-01-00 & 00 & $x$ & $x$ & & & $x$ & & TAL-17-04-11 & 158 & $x$ & $x$ & & & $x$ & \\
\hline CAM-07-01-04 & 04 & $x$ & $x$ & & & $x$ & & TAL-17-04-16 & 163 & $x$ & $x$ & & & $x$ & \\
\hline CAM-07-01-07 & 07 & $x$ & $x$ & & & $x$ & & TAL-17-05-00 & 166 & $x$ & $x$ & & & $\mathrm{x}$ & \\
\hline CAM-07-01-11 & 11 & $x$ & $x$ & & & $x$ & & TAL-17-05-03 & 169 & $x$ & $x$ & & & $x$ & \\
\hline CAM-07-01-14 & 14 & $x$ & $x$ & & & $x$ & & TAL-17-05-08 & 174 & $x$ & $x$ & & & $x$ & \\
\hline CAM-07-01-17 & 17 & $x$ & $x$ & & & $x$ & & TAL-17-05-11 & 177 & $x$ & $x$ & & & $x$ & \\
\hline CAM-07-01-19 & 19 & $x$ & $x$ & & & $x$ & & TAL-16-01-00 & 40 & $x$ & $x$ & $x$ & & $x$ & $x$ \\
\hline CAM-08-01-03 & 03 & $x$ & $x$ & & & $x$ & & TAL-16-01-07 & 47 & $x$ & $x$ & $x$ & & $x$ & $x$ \\
\hline
\end{tabular}




\begin{tabular}{|c|c|c|c|c|c|c|c|c|c|c|c|c|c|c|c|}
\hline 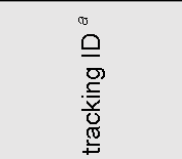 & 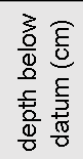 & $\begin{array}{l}\frac{0}{N} \\
\frac{N}{0} \\
\frac{0}{U} \\
\frac{U}{U} \\
\frac{1}{0}\end{array}$ & 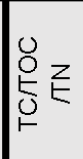 & $\stackrel{\infty}{\amalg}$ & $\underline{0}$ & $\frac{0}{\stackrel{u}{\alpha}}$ & 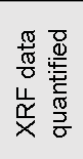 & 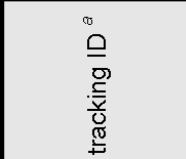 & 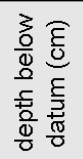 & $\begin{array}{l}0 \\
\frac{N}{0} \\
0 \\
\frac{0}{U} \\
\frac{U}{ \pm} \\
\Omega \\
\Omega\end{array}$ & 嵅 & $\underset{\amalg}{\infty}$ & $\underline{0}$ & $\begin{array}{l}\stackrel{0}{\underline{\alpha}} \\
\frac{\widetilde{x}}{x}\end{array}$ & 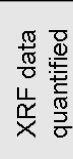 \\
\hline TAL-16-01-11 & 51 & $x$ & $\mathrm{x}$ & $x$ & & $\mathrm{x}$ & $\mathrm{x}$ & TAL-16-08-17 & 184 & $x$ & $\mathrm{x}$ & & & $x$ & \\
\hline TAL-16-01-14 & 58 & $x$ & $x$ & $x$ & & $x$ & $x$ & TAL-16-08-20 & 187 & $x$ & $x$ & & & $x$ & \\
\hline TAL-16-01-17 & 57 & $x$ & $x$ & $x$ & & $x$ & $x$ & TAL-16-08-23 & 190 & $x$ & $x$ & & & $x$ & \\
\hline TAL-16-01-19 & 59 & $x$ & $x$ & $x$ & & $x$ & $x$ & TAL-16-08-26 & 193 & $x$ & $x$ & & & $x$ & \\
\hline TAL-16-01-20 & 60 & $x$ & $x$ & $x$ & & $x$ & $x$ & TAL-A1-01-00 & 177 & $x$ & $x$ & & & $x$ & \\
\hline TAL-16-01-23 & 63 & $x$ & $x$ & $x$ & & $x$ & $x$ & TAL-A2-01-00 & 162 & $x$ & $x$ & & & $x$ & \\
\hline TAL-16-02-00 & 49 & $x$ & $x$ & $x$ & & $x$ & $x$ & TAL-A3-01-00 & 159 & $x$ & $x$ & & & $x$ & \\
\hline TAL-16-02-05 & 54 & $x$ & $x$ & $x$ & & $x$ & $x$ & TAL-B1-01-00 & 177 & $x$ & $x$ & & & $x$ & \\
\hline TAL-16-02-10 & 59 & $x$ & $x$ & $x$ & & $x$ & $x$ & TAL-B2-01-00 & 151 & $x$ & $x$ & & & $\mathrm{x}$ & \\
\hline TAL-16-02-15 & 64 & $x$ & $x$ & $x$ & & $x$ & $x$ & TAL-B3-01-00 & 152 & $x$ & $x$ & & & $x$ & \\
\hline TAL-16-02-20 & 69 & $\mathrm{x}$ & $x$ & $x$ & & $x$ & $x$ & TAL-C1-01-00 & 172 & $x$ & $x$ & & $x$ & $\mathrm{x}$ & \\
\hline TAL-16-03-00 & 61 & $x$ & $x$ & $x$ & & $x$ & $x$ & TAL-C2-01-00 & 122 & $x$ & $x$ & & $x$ & $x$ & \\
\hline TAL-16-03-05 & 66 & $x$ & $x$ & $x$ & & $x$ & $x$ & TAL-C3-01-00 & 44 & $x$ & $x$ & & $x$ & $x$ & \\
\hline TAL-16-03-09 & 70 & $x$ & $x$ & $x$ & & $x$ & $x$ & TAL-D1-01-00 & & $x$ & $x$ & & & $x$ & \\
\hline TAL-16-03-12 & 73 & $x$ & $x$ & $x$ & & $x$ & $x$ & TAL-D2-01-00 & & $x$ & $x$ & & & $x$ & \\
\hline TAL-16-03-14 & 75 & $x$ & $x$ & $x$ & & $x$ & $x$ & TAL-D3-01-00 & & $x$ & $x$ & & & $x$ & \\
\hline TAL-16-03-18 & 79 & $x$ & $x$ & $x$ & & $x$ & $x$ & TAL-E1-01-00 & 178 & $x$ & $x$ & & $x$ & $x$ & \\
\hline TAL-16-04-00 & 95 & $x$ & $x$ & $x$ & & $x$ & $x$ & TAL-E2-01-00 & 160 & $x$ & $x$ & & $x$ & $x$ & \\
\hline TAL-16-04-03 & 98 & $x$ & $\mathrm{x}$ & $x$ & & $x$ & $x$ & TAL-E3-01-00 & 158 & $x$ & $x$ & & $x$ & $x$ & \\
\hline TAL-16-04-06 & 101 & $x$ & $x$ & $x$ & & $x$ & $x$ & TAL-14-01-00 & 105 & $x$ & $x$ & & & $x$ & $x$ \\
\hline TAL-16-04-08 & 103 & $x$ & $\mathrm{x}$ & $x$ & & $\mathrm{x}$ & $x$ & TAL-14-01-03 & 123 & $x$ & $\mathrm{x}$ & & & $x$ & $x$ \\
\hline TAL-16-04-12 & 110 & $x$ & $x$ & $x$ & & $x$ & & TAL-14-01-08 & 113 & $x$ & $x$ & & & $x$ & $x$ \\
\hline TAL-16-04-18 & 116 & $x$ & $x$ & $x$ & & $x$ & & TAL-14-01-10 & 115 & $x$ & $x$ & & & $x$ & $x$ \\
\hline TAL-16-05-00 & 118 & $x$ & $x$ & $x$ & & $x$ & & TAL-14-01-12 & 117 & $x$ & $x$ & & & $x$ & $x$ \\
\hline TAL-16-05-02 & 120 & $x$ & $x$ & $x$ & & $x$ & & TAL-14-01-15 & 120 & $x$ & $x$ & & & $x$ & $x$ \\
\hline TAL-16-05-05 & 123 & $x$ & $x$ & $x$ & & $x$ & & TAL-14-02-00 & 137 & $x$ & $x$ & & & $x$ & $x$ \\
\hline TAL-16-05-07 & 125 & $x$ & $x$ & $\mathrm{x}$ & & $x$ & & TAL-14-02-06 & 143 & $x$ & $x$ & & & $x$ & $x$ \\
\hline TAL-16-05-09 & 127 & $x$ & $x$ & $x$ & & $x$ & & TAL-14-02-08 & 145 & $x$ & $x$ & & & $x$ & $x$ \\
\hline TAL-16-05-12 & 130 & $x$ & $x$ & $x$ & & $x$ & & TAL-14-02-14 & 151 & $x$ & $x$ & & & $x$ & $x$ \\
\hline TAL-16-05-15 & 133 & $x$ & $x$ & $x$ & & $x$ & & TAL-14-02-18 & 155 & $x$ & $x$ & & & $x$ & $x$ \\
\hline TAL-16-05-17 & 135 & $x$ & $x$ & $x$ & & $x$ & & TAL-14-02-23 & 160 & $x$ & $x$ & & & $x$ & $x$ \\
\hline TAL-16-05-23 & 141 & $x$ & $x$ & $x$ & & $x$ & & TAL-14-03-00 & 169 & $x$ & $x$ & & & $x$ & $x$ \\
\hline TAL-16-05-27 & 145 & $x$ & $x$ & $x$ & & $x$ & & TAL-14-03-03 & 172 & $x$ & $x$ & & & $x$ & $x$ \\
\hline TAL-16-06-00 & 131 & $x$ & $x$ & & & $x$ & & TAL-14-03-05 & 174 & $x$ & $x$ & & & $x$ & $x$ \\
\hline TAL-16-06-02 & 133 & $x$ & $x$ & & & $\mathrm{x}$ & & TAL-14-03-08 & 177 & $x$ & $x$ & & & $\mathrm{x}$ & $x$ \\
\hline TAL-16-06-03 & 134 & $x$ & $x$ & & & $x$ & & TAL-14-03-12 & 181 & $x$ & $x$ & & & $x$ & $x$ \\
\hline TAL-16-06-05 & 136 & $x$ & $x$ & & & $x$ & & TAL-15-01-00 & 104 & $x$ & $x$ & & & $x$ & \\
\hline TAL-16-06-07 & 138 & $x$ & $x$ & & & $x$ & & TAL-15-01-04 & 108 & $x$ & $x$ & & & $x$ & \\
\hline TAL-16-06-09 & 140 & $x$ & $x$ & & & $x$ & & TAL-15-01-07 & 111 & $x$ & $x$ & & & $x$ & \\
\hline TAL-16-06-12 & 143 & $\mathrm{x}$ & $x$ & & & $\mathrm{x}$ & & TAL-15-01-13 & 117 & $x$ & $x$ & & & $\mathrm{x}$ & \\
\hline TAL-16-06-15 & 146 & $x$ & $x$ & & & $x$ & & TAL-15-01-17 & 121 & $x$ & $x$ & & & $x$ & \\
\hline TAL-16-06-16 & 147 & $x$ & $x$ & & & $x$ & & TAL-15-01-20 & 124 & $x$ & $x$ & & & $x$ & \\
\hline TAL-16-06-17 & 148 & $x$ & $x$ & & & $x$ & & TAL-15-01-22 & 130 & $x$ & $x$ & & & $x$ & \\
\hline TAL-16-06-18 & 149 & $\mathrm{x}$ & $x$ & & & $x$ & & TAL-15-01-26 & 126 & $x$ & $x$ & & & $x$ & \\
\hline TAL-16-06-20 & 151 & $x$ & $\mathrm{x}$ & & & $\mathrm{x}$ & & TAL-15-02-00 & 148 & $x$ & $\mathrm{x}$ & & & $x$ & \\
\hline TAL-16-07-00 & 147 & $x$ & $x$ & & & $x$ & & TAL-15-02-04 & 152 & $x$ & $x$ & & & $\mathrm{x}$ & \\
\hline TAL-16-07-02 & 149 & $x$ & $x$ & & & $x$ & & TAL-15-02-08 & 156 & $x$ & $x$ & & & $x$ & \\
\hline TAL-16-07-04 & 151 & $x$ & $x$ & & & $x$ & & TAL-15-02-10 & 158 & $x$ & $x$ & & & $x$ & \\
\hline TAL-16-07-08 & 155 & $x$ & $x$ & & & $x$ & & TAL-15-02-13 & 161 & $x$ & $x$ & & & $x$ & \\
\hline TAL-16-07-12 & 159 & $\mathrm{x}$ & $x$ & & & $\mathrm{x}$ & & TAL-15-02-18 & 166 & $x$ & $x$ & & & $x$ & \\
\hline TAL-16-08-00 & 167 & $x$ & $x$ & & & $x$ & & TAL-13-01-00 & & $x$ & $x$ & & & $x$ & \\
\hline TAL-16-08-01 & 168 & $x$ & $x$ & & & $x$ & & TAL-13-01-03 & & $x$ & $x$ & & & $x$ & \\
\hline TAL-16-08-03 & 170 & $x$ & $x$ & & & $x$ & & TAL-13-01-05 & & $x$ & $x$ & & & $x$ & \\
\hline TAL-16-08-06 & 173 & $x$ & $x$ & & & $\mathrm{x}$ & & TAL-13-01-09 & & $x$ & $x$ & & & $x$ & \\
\hline TAL-16-08-08 & 175 & $x$ & $x$ & & & $x$ & & TAL-13-01-10 & & $x$ & $x$ & & & $x$ & \\
\hline TAL-16-08-11 & 178 & $x$ & $x$ & & & $x$ & & TAL-13-01-19 & & $x$ & $x$ & & & $x$ & \\
\hline TAL-16-08-14 & 181 & $x$ & $x$ & & & $x$ & & TAL-13-01-24 & & $x$ & $x$ & & & $x$ & \\
\hline
\end{tabular}




\begin{tabular}{|c|c|c|c|c|c|c|c|}
\hline 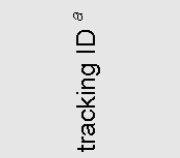 & 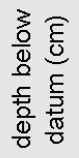 & 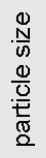 & $\stackrel{O}{O}_{\substack{0\\
}} z$ & $\underset{\square}{\mathscr{W}}$ & $\stackrel{\circ}{0}$ & $\begin{array}{l}\stackrel{0}{\underline{\alpha}} \\
\frac{\underline{\alpha}}{x}\end{array}$ & 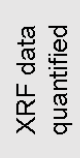 \\
\hline TAL-13-02-04 & & $x$ & $x$ & & & $\bar{x}$ & \\
\hline TAL-13-02-08 & & $x$ & $x$ & & & $\mathrm{x}$ & \\
\hline TAL-13-02-09 & & $x$ & $\mathrm{x}$ & & & $\mathrm{x}$ & \\
\hline TAL-13-02-12 & & $x$ & $x$ & & & $x$ & \\
\hline TAL-13-02-15 & & $x$ & $x$ & & & $x$ & \\
\hline TAL-13-02-21 & & $x$ & $x$ & & & $x$ & \\
\hline TAL-13-02-23 & & $x$ & $x$ & & & $x$ & \\
\hline TAL-13-02-26 & & $x$ & $x$ & & & $x$ & \\
\hline TAL-01-01-00 & 165 & $\mathrm{x}$ & $x$ & & $x$ & $x$ & \\
\hline TAL-02-01-00 & 120 & $x$ & $\hat{x}$ & & $x$ & $\hat{x}$ & \\
\hline TAL-04-01-00 & 158 & $\hat{x}$ & $\hat{x}$ & & $\hat{x}$ & $\hat{x}$ & \\
\hline TAL-05-01-00 & 168 & $x$ & $x$ & & & $x$ & \\
\hline TAL-11-01-00 & 50 & $x$ & $x$ & & $x$ & $x$ & \\
\hline TAL-11-02-00 & 79 & $x$ & $x$ & & $x$ & $x$ & \\
\hline TAL-11-03-00 & 98 & $x$ & $x$ & & & $x$ & \\
\hline TAL-11-04-00 & 108 & $x$ & $x$ & & & $x$ & \\
\hline TAL-11-05-00 & 120 & $x$ & $x$ & & $x$ & $x$ & \\
\hline TAL-11-06-00 & 129 & $x$ & $x$ & & $x$ & $\mathrm{x}$ & \\
\hline TAL-11-07-00 & 136 & $x$ & $x$ & & $x$ & $\mathrm{x}$ & \\
\hline TAL-12-01-00 & 158 & $x$ & $\hat{x}$ & & & $\hat{x}$ & \\
\hline TAL-12-02-00 & 176 & $x$ & $x$ & & $x$ & $x$ & \\
\hline TAL-12-03-00 & 182 & $x$ & $x$ & & $x$ & $x$ & \\
\hline TAL-12-04-00 & 185 & $x$ & $x$ & & & $x$ & \\
\hline
\end{tabular}




\section{Appendix V: Core photographs and particle size data collected from the remaining core not explicitly discussed in the text}

Five cores were collected from the southern bank in the middle of the cave. Like TAL-16 sample locations, cores were collected in a diagonal transect along the bank (Figure 12). Each core is treated separately as they were not collected consecutively with depth.

Core TAL-17-01 is proportionally $50 \pm 10$ percent sandy material (Figure V-1). The remaining length of the core is a consistent sedimentary texture, the proportion of sandy material decreases with depth. Some subtle redox banding is present.

Within core TAL-17-02 the proportion of sandy material transitions from 50 percent to 20 percent (Figure V-1). Subtle redox is present. Banding boundaries are consistently sub horizontal.

Redox banding is seemingly absent in core TAL-17-03 (Figure V-1). Grain size transitions from dominantly sandy ( 85 percent sand) to dominantly fine-grained (60 percent mud). No obvious sedimentary layering is present.

Core TAL-17-04 contains the highest proportion of sand at this sample location (Figure V-1). No obvious sedimentary or redox layering is present. Core TAL-17-05 contains an obvious redox zone in the bottom half of the core $(4-12 \mathrm{~cm}$ ) (Figure V-2). This redox zone contains small $(0.1 \mathrm{~cm})$ pieces of black material. The top of the core is 80 percent sandy material and deceases with depth. 

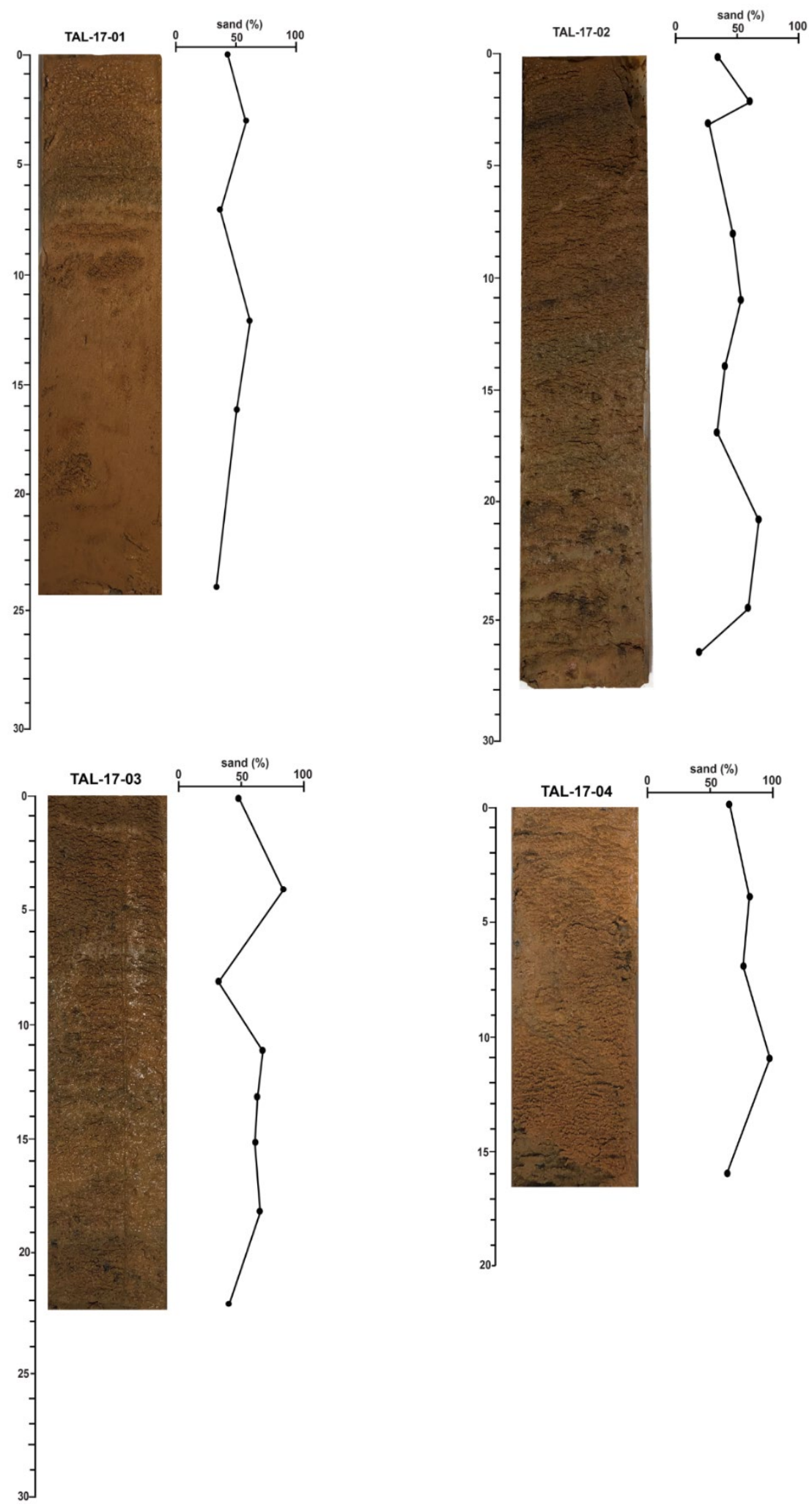

Figure V-1: Cores photographs and proportion of sand from TAL-17-01, TAL-17-02, TAL-1703, and TAL-17-04. Core are not displayed in stratigraphic order. 


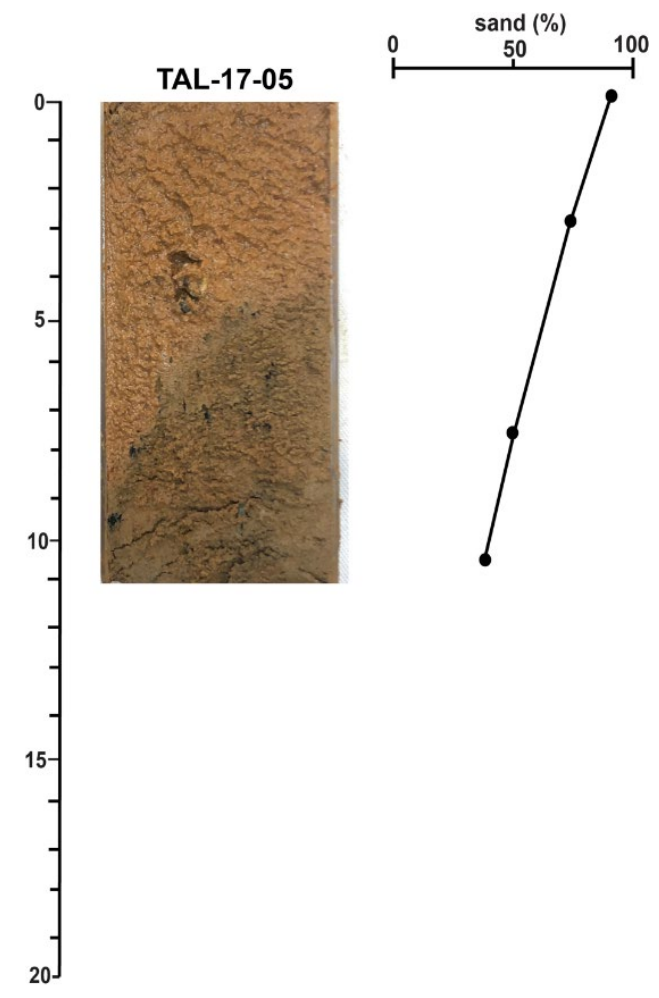

Figure V-2:Core photograph and proportion of sand from TAL-17-05. 
Appendix VI: Summary table of all collected particle size data from a Beckman Coulter single wavelength LS13-320 particle size analyzer

\begin{tabular}{|c|c|c|c|c|c|c|c|c|c|c|c|c|c|c|c|c|}
\hline 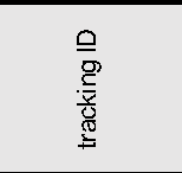 & $\frac{\widehat{E}}{\stackrel{E}{\Xi}}$ & 号 & 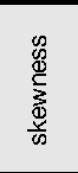 & 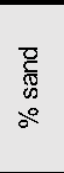 & $\begin{array}{l}\stackrel{+}{\bar{w}} \\
\stackrel{\circ}{\circ}\end{array}$ & $\begin{array}{l}\frac{\widehat{\sigma}}{0} \\
\therefore \circ\end{array}$ & 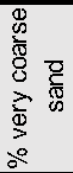 & 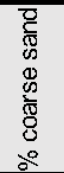 & 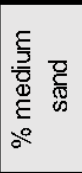 & 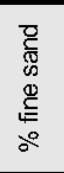 & 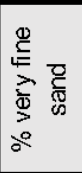 & 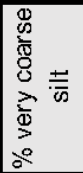 & 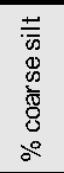 & 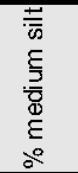 & 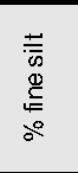 & 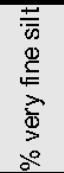 \\
\hline TAL-02-01-00 & 273 & 3.37 & -1.99 & 89.5 & 10.5 & 0 & 4.77 & 23.7 & 44.2 & 15.3 & 15.6 & 1.93 & 1.73 & 3.07 & 3.53 & 0.23 \\
\hline TAL-04-01-00 & 13.0 & 5.82 & -0.50 & 21.2 & 54.7 & 24.1 & 0 & 0 & 0 & 4.43 & 16.8 & 20.7 & 13.9 & 9.07 & 9.43 & 1.67 \\
\hline TAL-A1-01-00 & 62.5 & 8.41 & -0.61 & 50.4 & 58.7 & 10.7 & 1.97 & 16.3 & 21.4 & 6.27 & 4.77 & 13.9 & 11.1 & 6.90 & 6.17 & 0.80 \\
\hline TAL-A2-01-00 & 58.2 & 5.71 & -1.14 & 59.4 & 64.6 & 8.37 & 0 & 0.33 & 15.3 & 34.8 & 8.97 & 10.7 & 9.53 & 6.17 & 5.20 & 0.70 \\
\hline TAL-A3-01-00 & 38.8 & 6.06 & -0.84 & 46.2 & 51.9 & 11.7 & 0 & 1.17 & 9.27 & 22.9 & 12.8 & 17.2 & 11.1 & 6.87 & 6.00 & 0.93 \\
\hline TAL-B1-01-00 & 87.5 & 4.55 & -0.97 & 62.5 & 66.7 & 3.30 & 0 & 2.83 & 26.1 & 27.2 & 6.37 & 13.3 & 10.5 & 6.13 & 4.10 & 0.13 \\
\hline TAL-B2-01-00 & 18.6 & 3.55 & -0.66 & 16.6 & 19.6 & 7.40 & 0 & 0.00 & 0.00 & 3.87 & 12.6 & 20.7 & 21.9 & 18.07 & 14.63 & 0.80 \\
\hline TAL-B3-01-00 & 25.2 & 2.57 & -0.57 & 15.0 & 17.2 & 2.30 & 0 & 0.00 & 0.00 & 1.43 & 13.6 & 30.5 & 26.6 & 15.93 & 9.43 & 0.23 \\
\hline TAL-C1-01-00 & 27.4 & 4.61 & -0.74 & 32.6 & 36.8 & 9.20 & 0 & 0.33 & 0.57 & 17.3 & 14.4 & 18.0 & 18.2 & 12.77 & 8.97 & 0.23 \\
\hline TAL-C2-01-00 & 37.9 & 5.66 & -0.84 & 48.4 & 53.7 & 9.93 & 0 & 0.50 & 4.33 & 30.7 & 12.9 & 11.2 & 12.1 & 9.53 & 8.27 & 0.53 \\
\hline TAL-C3-01-00 & 35.2 & 6.65 & -0.62 & 43.5 & 50.0 & 12.7 & 0 & 1.70 & 13.8 & 15.9 & 12.2 & 14.9 & 12.0 & 8.07 & 7.57 & 1.13 \\
\hline TAL-D1-01-00 & 115.0 & 5.43 & -1.04 & 68.2 & 73.2 & 3.50 & 0.97 & 1.87 & 36.4 & 16.8 & 3.07 & 7.40 & 9.47 & 6.53 & 4.77 & 0.20 \\
\hline TAL-D2-01-00 & 19.7 & 4.74 & -0.68 & 22.6 & 26.9 & 13.1 & 0 & 0.47 & 0.47 & 8.90 & 12.8 & 21.0 & 19.6 & 13.0 & 10.2 & 0.43 \\
\hline TAL-D3-01-00 & 22.1 & 5.30 & -0.71 & 30.3 & 35.2 & 14.2 & 0 & 0.00 & 0.33 & 15.5 & 14.4 & 19.1 & 15.7 & 10.5 & 9.2 & 0.90 \\
\hline TAL-E1-01-00 & 11.8 & 2.37 & -0.60 & 0.10 & 1.88 & 4.50 & 0 & 0.00 & 0.00 & 0.00 & 0.10 & 12.8 & 25.5 & 32.2 & 24.1 & 0.90 \\
\hline TAL-E2-01-00 & 140.7 & 7.11 & -0.91 & 68.7 & 75.6 & 3.17 & 5.03 & 29.3 & 26.1 & 6.10 & 2.20 & 4.13 & 6.03 & 8.90 & 8.70 & 0.33 \\
\hline TAL-E3-01-00 & 17.8 & 3.39 & -1.44 & 4.13 & 6.13 & 9.97 & 0 & 0 & 0 & 0 & 4.13 & 37.6 & 25.0 & 13.8 & 9.10 & 0.30 \\
\hline TAL-11-01-00 & 32.2 & 3.89 & -0.42 & 26.4 & 30.1 & 5.93 & 0 & 1.33 & 4.62 & 9.60 & 11.1 & 25.0 & 21.8 & 13.2 & 7.67 & 0.08 \\
\hline TAL-11-02-00 & 227 & 4.56 & -1.43 & 79.2 & 83.1 & 1.38 & 3.84 & 35.5 & 28.5 & 7.17 & 4.09 & 7.60 & 5.39 & 3.47 & 2.86 & 0.14 \\
\hline TAL-11-03-00 & 20.53 & 4.13 & -1.20 & 20.0 & 23.1 & 12.4 & 0 & 0 & 0 & 1.00 & 19.0 & 31.1 & 17.7 & 10.8 & 7.67 & 0.38 \\
\hline TAL-11-04-00 & 237 & 4.15 & -1.12 & 77.5 & 81.3 & 0.00 & 5.33 & 34.2 & 29.9 & 5.82 & 2.23 & 7.22 & 8.27 & 5.02 & 2.02 & 0.00 \\
\hline TAL-11-05-00 & 14.7 & 4.57 & -0.90 & 13.5 & 17.3 & 17.5 & 0 & 0 & 0 & 0.37 & 13.1 & 27.8 & 18.9 & 12.2 & 9.74 & 0.38 \\
\hline TAL-11-06-00 & 20.5 & 4.39 & -0.76 & 24.0 & 27.8 & 10.5 & 0 & 0 & 0.05 & 9.68 & 14.2 & 19.4 & 19.2 & 15.4 & 11.47 & 0.18 \\
\hline TAL-11-07-00 & 86.2 & 5.12 & -0.78 & 62.9 & 67.9 & 2.61 & 0 & 5.49 & 30.2 & 21.2 & 6.04 & 7.34 & 10.5 & 9.37 & 7.03 & 0.22 \\
\hline TAL-12-01-00 & 30.3 & 4.64 & -1.12 & 36.8 & 40.7 & 10.6 & 0 & 0.30 & 0.53 & 13.4 & 22.5 & 25.1 & 13.4 & 7.97 & 5.83 & 0.33 \\
\hline TAL-12-02-00 & 144 & 4.31 & -0.50 & 65.8 & 70.3 & 0.00 & 2.57 & 2.30 & 29.2 & 6.67 & 7.07 & 13.5 & 11.5 & 7.03 & 2.13 & 0.00 \\
\hline TAL-12-03-00 & 203 & 6.64 & -1.91 & 83.8 & 89.3 & 6.53 & 4.50 & 29.5 & 39.0 & 8.97 & 1.83 & 1.90 & 1.50 & 1.57 & 3.27 & 1.47 \\
\hline TAL-12-04-00 & 168 & 7.13 & -1.41 & 75.6 & 82.1 & 6.27 & 7.13 & 29.7 & 26.4 & 9.00 & 3.97 & 5.37 & 4.80 & 3.67 & 3.70 & 0.50 \\
\hline TAL-14-01-00 & 62.8 & 3.56 & -0.41 & 52.9 & 56.5 & 0.50 & 0 & 1.67 & 11.9 & 25.1 & 14.7 & 16.2 & 14.0 & 10.2 & 6.17 & 0.07 \\
\hline TAL-14-01-03 & 70.7 & 3.55 & -0.26 & 54.2 & 58.0 & 0.00 & 0 & 2.50 & 16.0 & 22.0 & 13.7 & 16.9 & 14.3 & 9.33 & 5.27 & 0.03 \\
\hline TAL-14-01-08 & 43.0 & 4.21 & -1.31 & 49.2 & 52.6 & 6.77 & 0 & 0.00 & 0.93 & 23.3 & 25.1 & 20.5 & 11.0 & 6.83 & 5.40 & 0.27 \\
\hline TAL-14-01-10 & 89.1 & 3.64 & -1.27 & 70.6 & 73.7 & 1.80 & 0 & 1.10 & 12.5 & 43.7 & 13.4 & 9.27 & 7.77 & 5.87 & 4.47 & 0.23 \\
\hline TAL-14-01-12 & 88.2 & 3.45 & -0.54 & 64.0 & 67.5 & 0.00 & 0 & 3.70 & 16.2 & 31.6 & 12.4 & 11.2 & 13.0 & 8.07 & 3.73 & 0.00 \\
\hline TAL-14-01-15 & 48.0 & 3.36 & -0.88 & 45.0 & 48.0 & 3.00 & 0 & 0 & 1.23 & 23.8 & 20.0 & 25.0 & 14.4 & 7.93 & 4.57 & 0.07 \\
\hline TAL-14-02-00 & 49.4 & 5.36 & -1.23 & 58.9 & 63.6 & 9.27 & 0 & 0.47 & 3.93 & 36.1 & 18.4 & 12.1 & 8.07 & 5.63 & 5.30 & 0.80 \\
\hline TAL-14-02-06 & 42.0 & 4.13 & -1.14 & 44.2 & 47.6 & 6.60 & 0 & 1.10 & 2.20 & 17.1 & 23.8 & 23.1 & 12.9 & 7.67 & 5.33 & 0.17 \\
\hline TAL-14-02-08 & 118 & 4.71 & -0.61 & 66.4 & 71.2 & 0.00 & 2.03 & 12.3 & 32.0 & 16.3 & 3.73 & 5.67 & 11.5 & 10.4 & 6.00 & 0.00 \\
\hline TAL-14-02-14 & 126 & 4.86 & -0.67 & 67.2 & 72.0 & 0.00 & 2.63 & 13.0 & 36.6 & 11.5 & 3.47 & 6.03 & 9.93 & 10.4 & 6.47 & 0.00 \\
\hline TAL-14-02-18 & 178 & 5.80 & -1.24 & 75.0 & 80.3 & 1.30 & 1.50 & 31.7 & 39.3 & 2.93 & 0.27 & 1.80 & 5.10 & 8.40 & 8.37 & 0.00 \\
\hline TAL-14-02-23 & 90.2 & 5.31 & -0.63 & 62.0 & 67.3 & 2.50 & 1.27 & 11.3 & 23.4 & 17.7 & 8.30 & 8.27 & 11.2 & 9.37 & 6.47 & 0.10 \\
\hline TAL-14-03-00 & 28.9 & 1.99 & -0.63 & 9.8 & 11.3 & 0 & 0 & 0 & 0 & 0.50 & 9.30 & 43.3 & 26.3 & 14.0 & 6.57 & 0.00 \\
\hline TAL-14-03-06 & 20.1 & 2.16 & 0.32 & 6.1 & 8.67 & 0 & 0 & 0 & 1.27 & 0.83 & 4.03 & 21.1 & 33.5 & 26.9 & 12.3 & 0.03 \\
\hline TAL-14-03-09 & 77.3 & 5.68 & -0.05 & 49.1 & 55.3 & 0 & 0.40 & 18.7 & 24.6 & 3.63 & 2.33 & 8.53 & 16.4 & 16.8 & 9.10 & 0.00 \\
\hline TAL-14-03-11 & 69.5 & 4.79 & -0.14 & 51.5 & 56.6 & 0 & 0 & 7.27 & 24.8 & 15.0 & 4.33 & 8.47 & 15.9 & 15.2 & 8.87 & 0.03 \\
\hline TAL-14-03-13 & 82.0 & 5.20 & -0.80 & 63.6 & 68.6 & 3.70 & 0.37 & 7.40 & 22.6 & 21.2 & 12.0 & 8.27 & 9.77 & 8.60 & 5.97 & 0.10 \\
\hline TAL-15-01-00 & 45.2 & 3.08 & -0.97 & 44.6 & 47.2 & 2.20 & 0 & 0 & 0.25 & 17.8 & 26.6 & 24.9 & 13.6 & 8.64 & 5.94 & 0.15 \\
\hline TAL-15-01-04 & 32.0 & 4.30 & -0.98 & 37.1 & 40.8 & 7.59 & 0 & 0 & 0.21 & 18.9 & 18.0 & 20.6 & 16.5 & 10.4 & 7.52 & 0.24 \\
\hline TAL-15-01-07 & 49.5 & 2.67 & -0.52 & 46.2 & 48.8 & 0.00 & 0 & 0 & 0.15 & 20.9 & 25.1 & 23.7 & 15.2 & 9.24 & 5.60 & 0.09 \\
\hline TAL-15-01-13 & 67.8 & 3.82 & -1.02 & 61.3 & 64.8 & 2.91 & 0 & 1.39 & 6.15 & 37.6 & 16.3 & 12.1 & 12.3 & 7.51 & 3.78 & 0.04 \\
\hline TAL-15-01-17 & 24.8 & 4.89 & -0.80 & 30.0 & 34.3 & 11.6 & 0 & 0 & 0.88 & 16.0 & 13.1 & 19.7 & 19.4 & 11.7 & 7.47 & 0.22 \\
\hline TAL-15-01-20 & 69.7 & 4.87 & -1.41 & 67.1 & 71.3 & 6.37 & 0 & 1.96 & 9.98 & 38.4 & 16.8 & 9.75 & 7.32 & 4.87 & 3.93 & 0.65 \\
\hline TAL-15-01-22 & 45.5 & 5.01 & -1.19 & 54.9 & 59.3 & 8.61 & 0 & 0.82 & 2.13 & 31.1 & 20.9 & 13.8 & 10.4 & 6.50 & 5.22 & 0.57 \\
\hline TAL-15-01-26 & 55.7 & 3.73 & -0.20 & 52.2 & 56.3 & 0.00 & 0 & 3.38 & 5.42 & 27.1 & 16.4 & 11.8 & 13.6 & 13.2 & 9.08 & 0.10 \\
\hline TAL-15-02-00 & 54.8 & 4.36 & -0.62 & 48.7 & 53.0 & 3.65 & 0 & 0.92 & 12.0 & 25.6 & 10.3 & 17.7 & 14.8 & 9.01 & 5.96 & 0.16 \\
\hline TAL-15-02-04 & 174 & 4.57 & -0.92 & 79.7 & 84.1 & 0.00 & 12.4 & 14.2 & 19.9 & 23.0 & 10.2 & 7.25 & 5.11 & 4.54 & 3.36 & 0.07 \\
\hline TAL-15-02-08 & 126 & 4.21 & -0.67 & 72.8 & 77.1 & 0.00 & 4.38 & 1.35 & 22.5 & 24.8 & 10.7 & 7.45 & 6.68 & 8.05 & 5.02 & 0.01 \\
\hline
\end{tabular}




\begin{tabular}{|c|c|c|c|c|c|c|c|c|c|c|c|c|c|c|c|c|}
\hline 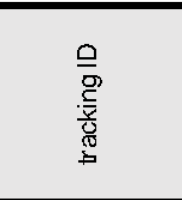 & 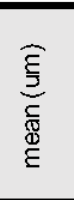 & 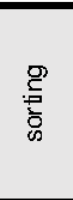 & 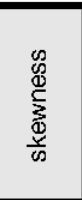 & 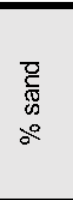 & $\begin{array}{l}+\overline{\bar{\sigma}} \\
\therefore \circ\end{array}$ & $\begin{array}{l}\frac{\vec{\sigma}}{0} \\
\therefore \\
0\end{array}$ & 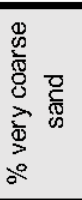 & 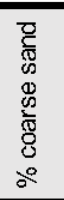 & 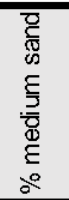 & 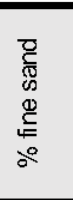 & 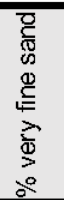 & 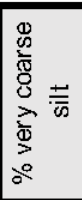 & 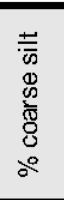 & 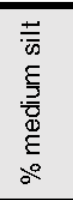 & 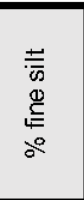 & 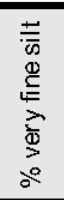 \\
\hline TAL-15-02-10 & 114 & 4.16 & -1.89 & 80.8 & 83.9 & 3.27 & 0 & 3.22 & 22.2 & 44.3 & 11.1 & 5.00 & 2.99 & 2.78 & 3.61 & 1.55 \\
\hline TAL-15-02-13 & 32.4 & 8.23 & -0.29 & 43.7 & 52.1 & 12.31 & 0 & 3.73 & 21.1 & 15.8 & 3.16 & 6.25 & 6.56 & 13.1 & 17.2 & 0.88 \\
\hline TAL-15-02-18 & 84.0 & 4.71 & -0.38 & 61.3 & 66.3 & 1.77 & 4.16 & 9.98 & 7.59 & 24.0 & 15.6 & 10.8 & 12.3 & 8.59 & 5.11 & 0.04 \\
\hline TAL-16-01-00 & 229 & 3.90 & -1.35 & 82.7 & 86.0 & 0 & 4.60 & 25.3 & 36.8 & 13.1 & 2.87 & 3.30 & 5.40 & 5.37 & 3.20 & 0.03 \\
\hline TAL-16-01-07 & 39.3 & 4.09 & 0.71 & 28.0 & 33.0 & 0 & 0.00 & 6.27 & 12.1 & 6.30 & 3.23 & 14.9 & 27.6 & 21.3 & 8.23 & 0.00 \\
\hline TAL-16-01-11 & 191 & 3.91 & -1.07 & 78.4 & 82.0 & 0 & 3.17 & 2.90 & 34.7 & 15.5 & 4.17 & 5.70 & 7.77 & 5.40 & 2.77 & 0.00 \\
\hline TAL-16-01-14 & 54.0 & 4.03 & 0.47 & 33.8 & 38.7 & 0 & 0.13 & 6.73 & 18.1 & 6.07 & 2.80 & 21.0 & 26.4 & 14.9 & 4.00 & 0.00 \\
\hline TAL-16-01-17 & 11.5 & 2.58 & -0.74 & 0.0 & 1.9 & 7.13 & 0.00 & 0.00 & 0.00 & 0.00 & 0.03 & 12.9 & 26.7 & 31.3 & 21.4 & 0.47 \\
\hline TAL-16-01-18 & 196 & 4.50 & -1.26 & 79.5 & 83.5 & 0.00 & 3.95 & 21.7 & 39.9 & 12.3 & 1.65 & 2.45 & 4.65 & 7.25 & 6.10 & 0.05 \\
\hline TAL-16-01-19 & 110 & 7.42 & -1.07 & 70.4 & 77.4 & 5.60 & 2.07 & 18.4 & 32.4 & 14.6 & 2.93 & 3.07 & 3.23 & 7.00 & 10.2 & 0.43 \\
\hline TAL-16-01-20 & 208 & 4.34 & -1.41 & 81.6 & 85.3 & 0 & 3.60 & 22.1 & 41.9 & 12.5 & 1.40 & 2.20 & 3.70 & 6.20 & 6.10 & 0.20 \\
\hline TAL-16-01-23 & 152 & 4.26 & -0.84 & 71.8 & 76.0 & 0 & 1.73 & 16.4 & 36.6 & 14.0 & 3.07 & 6.17 & 10.6 & 8.03 & 3.37 & 0.00 \\
\hline TAL-16-02-00 & 64.0 & 5.31 & -0.08 & 50.6 & 56.3 & 0 & 0.33 & 8.47 & 24.5 & 13.0 & 4.37 & 6.90 & 12.0 & 17.3 & 13.10 & 0.10 \\
\hline TAL-16-02-05 & 37.6 & 3.94 & 0.66 & 28.6 & 33.4 & 0 & 0.13 & 4.63 & 10.7 & 7.8 & 5.33 & 14.9 & 26.4 & 20.2 & 9.87 & 0.03 \\
\hline TAL-16-02-10 & 37.0 & 8.39 & -0.29 & 44.9 & 53.5 & 11.20 & 0.00 & 8.37 & 20.2 & 12.1 & 4.20 & 6.10 & 7.53 & 14.4 & 15.5 & 0.40 \\
\hline TAL-16-02-15 & 68.3 & 5.53 & -0.11 & 48.7 & 54.6 & 1.53 & 2.40 & 9.47 & 22.0 & 11.1 & 3.80 & 9.67 & 17.8 & 14.2 & 8.03 & 0.03 \\
\hline TAL-16-02-20 & 72.8 & 5.40 & 0.17 & 45.4 & 51.4 & 0 & 3.90 & 15.0 & 15.7 & 7.07 & 3.70 & 11.2 & 21.3 & 15.0 & 7.03 & 0.00 \\
\hline TAL-16-03-00 & 129 & 5.50 & -0.48 & 62.9 & 68.5 & 0 & 4.40 & 23.7 & 24.6 & 6.83 & 3.30 & 7.53 & 12.2 & 11.0 & 6.30 & 0.03 \\
\hline TAL-16-03-05 & 97.4 & 5.11 & -0.53 & 62.1 & 67.3 & 1.27 & 2.23 & 11.0 & 26.1 & 16.5 & 6.30 & 7.63 & 12.2 & 10.5 & 6.23 & 0.03 \\
\hline TAL-16-03-09 & 160 & 4.85 & -0.96 & 74.0 & 78.7 & 0.00 & 3.57 & 19.1 & 36.0 & 12.7 & 2.57 & 4.40 & 5.90 & 8.43 & 7.17 & 0.07 \\
\hline TAL-16-03-12 & 85.7 & 8.26 & -0.99 & 65.9 & 73.8 & 9.23 & 1.93 & 13.5 & 31.6 & 16.2 & 2.67 & 3.73 & 5.43 & 7.97 & 7.63 & 0.17 \\
\hline TAL-16-03-14 & 88.9 & 4.82 & -0.18 & 53.6 & 58.7 & 0 & 1.40 & 11.2 & 27.9 & 10.8 & 2.20 & 11.1 & 17.1 & 13.0 & 5.27 & 0.00 \\
\hline TAL-16-03-18 & 73.5 & 4.48 & -0.02 & 47.7 & 52.6 & 0 & 0.73 & 7.63 & 24.7 & 11.4 & 3.23 & 14.7 & 19.5 & 12.6 & 5.63 & 0.00 \\
\hline TAL-16-04-00 & 43.7 & 4.11 & -0.83 & 40.9 & 44.6 & 5.17 & 0 & 0.93 & 6.40 & 16.5 & 17.1 & 24.6 & 15.0 & 8.90 & 5.40 & 0.07 \\
\hline TAL-16-04-03 & 15.1 & 4.05 & -1.06 & 9.30 & 12.4 & 14.6 & 0 & 0 & 0 & 0.07 & 9.20 & 29.1 & 21.8 & 14.8 & 10.37 & 0.20 \\
\hline TAL-16-04-06 & 21.2 & 3.34 & -1.49 & 12.5 & 14.4 & 8.07 & 0 & 0 & 0 & 0 & 12.4 & 35.7 & 22.0 & 13.6 & 8.07 & 0.13 \\
\hline TAL-16-04-08 & 33.5 & 2.93 & -1.48 & 30.1 & 31.8 & 3.80 & 0 & 0 & 0 & 3.03 & 27.0 & 33.5 & 17.1 & 10.1 & 5.43 & 0.03 \\
\hline TAL-16-04-12 & 24.6 & 3.22 & -1.40 & 19.0 & 21.0 & 6.17 & 0 & 0 & 0 & 0.83 & 18.2 & 33.3 & 20.1 & 12.9 & 8.33 & 0.17 \\
\hline TAL-16-04-18 & 37.5 & 5.31 & -0.49 & 35.7 & 40.8 & 7.87 & 0.20 & 6.17 & 6.17 & 10.3 & 12.8 & 22.6 & 16.2 & 10.2 & 7.30 & 0.20 \\
\hline TAL-16-05-00 & 28.7 & 4.29 & -0.77 & 34.0 & 37.8 & 7.97 & 0 & 0.47 & 0.67 & 13.8 & 19.1 & 18.9 & 15.7 & 12.6 & 10.40 & 0.43 \\
\hline TAL-16-05-02 & 40.3 & 5.74 & -0.98 & 53.7 & 59.0 & 10.6 & 0 & 0.43 & 3.27 & 32.6 & 17.4 & 10.4 & 9.00 & 7.77 & 7.67 & 0.90 \\
\hline TAL-16-05-05 & 28.9 & 4.92 & -0.62 & 36.1 & 40.7 & 8.70 & 0 & 0.90 & 2.10 & 17.7 & 15.3 & 16.6 & 13.5 & 12.1 & 12.33 & 0.77 \\
\hline TAL-16-05-07 & 36.2 & 5.91 & -0.90 & 51.4 & 56.9 & 11.6 & 0 & 0.13 & 2.73 & 31.1 & 17.4 & 10.6 & 8.83 & 8.07 & 8.53 & 1.00 \\
\hline TAL-16-05-09 & 28.1 & 6.20 & -0.78 & 46.3 & 52.2 & 14.9 & 0 & 0.00 & 0.80 & 26.1 & 19.4 & 10.8 & 9.73 & 8.50 & 8.63 & 1.13 \\
\hline TAL-16-05-12 & 40.4 & 6.68 & -0.93 & 56.1 & 62.4 & 13.1 & 0 & 0.27 & 5.67 & 37.8 & 12.4 & 8.03 & 7.83 & 6.53 & 6.80 & 1.57 \\
\hline TAL-16-05-15 & 39.6 & 4.80 & -1.14 & 46.7 & 50.9 & 8.73 & 0 & 0.00 & 1.37 & 27.4 & 17.9 & 18.8 & 12.3 & 7.53 & 5.73 & 0.23 \\
\hline TAL-16-05-17 & 32.0 & 5.85 & -0.88 & 46.4 & 51.9 & 12.7 & 0 & 0.00 & 1.27 & 28.5 & 16.6 & 13.1 & 11.2 & 8.00 & 7.50 & 1.03 \\
\hline TAL-16-05-23 & 33.1 & 5.42 & -0.93 & 44.4 & 49.4 & 11.4 & 0 & 0.00 & 1.07 & 27.5 & 15.9 & 15.1 & 12.5 & 8.53 & 7.20 & 0.77 \\
\hline TAL-16-05-27 & 25.8 & 5.49 & -0.89 & 34.3 & 39.2 & 14.9 & 0 & 0.00 & 1.13 & 19.9 & 13.2 & 17.7 & 14.1 & 9.30 & 8.37 & 1.47 \\
\hline TAL-16-06-00 & 18.1 & 4.75 & -0.70 & 18.2 & 22.5 & 18.6 & 0 & 0.43 & 0.77 & 8.93 & 8.13 & 18.3 & 18.3 & 13.1 & 11.7 & 1.77 \\
\hline TAL-16-06-02 & 29.1 & 6.01 & -0.78 & 43.5 & 49.2 & 14.0 & 0 & 0.43 & 1.37 & 25.0 & 16.8 & 13.4 & 11.6 & 8.47 & 7.77 & 1.13 \\
\hline TAL-16-06-03 & 37.2 & 5.30 & -1.05 & 49.3 & 54.1 & 10.6 & 0 & 0.23 & 1.23 & 28.2 & 19.7 & 14.5 & 10.9 & 7.67 & 6.57 & 0.50 \\
\hline TAL-16-06-05 & 33.7 & 4.56 & -1.04 & 40.0 & 43.9 & 8.40 & 0 & 0.00 & 0.80 & 21.0 & 18.1 & 20.6 & 15.0 & 9.10 & 6.50 & 0.30 \\
\hline TAL-16-06-07 & 34.4 & 4.56 & -0.95 & 40.3 & 44.3 & 8.47 & 0 & 0.77 & 1.00 & 19.0 & 19.5 & 19.4 & 14.7 & 9.70 & 7.23 & 0.23 \\
\hline TAL-16-06-09 & 41.4 & 4.91 & -1.12 & 48.6 & 52.9 & 9.03 & 0 & 1.00 & 2.30 & 24.4 & 21.0 & 18.1 & 11.3 & 7.07 & 5.57 & 0.33 \\
\hline TAL-16-06-12 & 48.1 & 3.82 & 0.27 & 38.9 & 43.4 & 0.00 & 0 & 5.33 & 9.10 & 13.8 & 11.0 & 17.8 & 20.1 & 14.8 & 8.20 & 0.07 \\
\hline TAL-16-06-15 & 41.4 & 4.31 & -0.82 & 49.5 & 53.5 & 5.63 & 0 & 0.00 & 0.70 & 27.8 & 21.0 & 13.4 & 12.5 & 10.6 & 8.10 & 0.27 \\
\hline TAL-16-06-16 & 41.4 & 4.74 & -0.97 & 49.5 & 53.8 & 7.33 & 0 & 0.77 & 2.10 & 26.2 & 20.4 & 14.0 & 11.6 & 9.43 & 7.80 & 0.30 \\
\hline TAL-16-06-17 & 48.6 & 3.74 & -0.54 & 45.7 & 49.4 & 2.73 & 0 & 2.20 & 3.73 & 20.1 & 19.7 & 20.6 & 14.3 & 9.47 & 6.97 & 0.27 \\
\hline TAL-16-06-20 & 61.5 & 5.08 & -0.59 & 55.3 & 60.4 & 4.33 & 0 & 5.67 & 13.7 & 23.1 & 12.8 & 10.5 & 12.9 & 10.1 & 6.73 & 0.13 \\
\hline TAL-16-06-22 & 31.5 & 2.97 & -0.11 & 26.1 & 29.2 & 0.97 & 0 & 0.00 & 0.17 & 14.7 & 11.2 & 24.2 & 22.9 & 15.7 & 10.00 & 0.13 \\
\hline TAL-16-07-00 & 69.9 & 6.26 & -1.10 & 62.4 & 68.1 & 8.50 & 0 & 5.93 & 21.5 & 24.3 & 10.6 & 10.4 & 8.33 & 5.17 & 4.53 & 0.60 \\
\hline TAL-16-07-02 & 28.3 & 5.03 & -0.92 & 41.3 & 45.8 & 11.2 & 0 & 0 & 0 & 19.3 & 22.0 & 14.6 & 13.4 & 10.2 & 8.77 & 0.60 \\
\hline TAL-16-07-04 & 66.2 & 4.97 & -0.50 & 54.0 & 59.0 & 2.93 & 0 & 4.30 & 22.7 & 17.7 & 9.37 & 11.0 & 14.3 & 10.9 & 6.80 & 0.10 \\
\hline TAL-16-07-08 & 86.0 & 4.69 & -1.10 & 68.1 & 72.4 & 3.60 & 0 & 3.73 & 18.6 & 36.4 & 9.43 & 7.77 & 7.67 & 6.70 & 5.70 & 0.40 \\
\hline TAL-16-07-12 & 133 & 3.12 & -1.46 & 80.1 & 82.6 & 0.00 & 0 & 1.23 & 29.4 & 43.3 & 6.20 & 4.87 & 5.77 & 5.47 & 3.60 & 0.20 \\
\hline
\end{tabular}




\begin{tabular}{|c|c|c|c|c|c|c|c|c|c|c|c|c|c|c|c|c|}
\hline 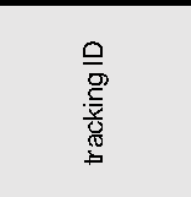 & 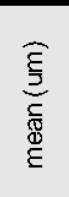 & 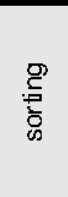 & 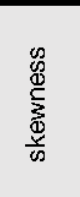 & 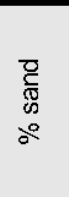 & $\begin{array}{l}+\overline{\bar{w}} \\
\therefore \\
\circ\end{array}$ & $\begin{array}{l}\frac{\mathrm{\sigma}}{0} \\
\therefore \\
\therefore\end{array}$ & 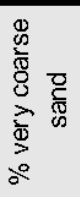 & 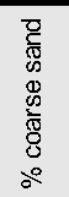 & 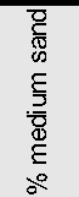 & 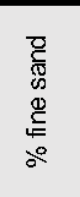 & 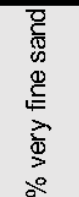 & 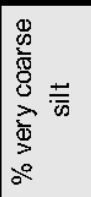 & 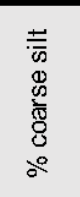 & 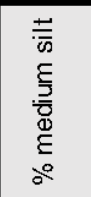 & $\begin{array}{l}\frac{+}{\bar{w}} \\
\mathbb{E} \\
\stackrel{E}{E} \\
\stackrel{\circ}{\circ}\end{array}$ & 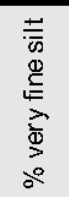 \\
\hline TAL-16-08-00 & 75.6 & 4.16 & -0.12 & 53.3 & 57.8 & 0 & 0.40 & 8.27 & 18.2 & 15.9 & 10.53 & 14.50 & 15.50 & 10.83 & 5.90 & 0.03 \\
\hline TAL-16-08-01 & 142 & 4.15 & -0.92 & 74.3 & 78.3 & 0 & 1.83 & 11.5 & 35.2 & 19.4 & 6.33 & 5.47 & 7.47 & 7.70 & 5.00 & 0.03 \\
\hline TAL-16-08-03 & 74.5 & 4.74 & -0.81 & 62.1 & 66.7 & 3.80 & 0 & 6.20 & 14.5 & 26.4 & 15.0 & 10.9 & 10.4 & 7.40 & 5.30 & 0.20 \\
\hline $\begin{array}{l}\text { TAL-16-08-06 } \\
\text { TAL-16-08-08 }\end{array}$ & $\begin{array}{l}24.3 \\
66.8\end{array}$ & $\begin{array}{l}4.37 \\
3.61\end{array}$ & $\begin{array}{l}-0.85 \\
-0.52\end{array}$ & $\begin{array}{l}32.4 \\
56.3\end{array}$ & $\begin{array}{l}36.3 \\
60.0\end{array}$ & $\begin{array}{l}9.63 \\
0.47\end{array}$ & $\begin{array}{l}0 \\
0\end{array}$ & $\begin{array}{l}0.00 \\
0.97\end{array}$ & $\begin{array}{c}0.00 \\
10.90\end{array}$ & $\begin{array}{l}9.87 \\
33.3\end{array}$ & $\begin{array}{l}22.6 \\
11.2\end{array}$ & $\begin{array}{l}17.5 \\
12.1\end{array}$ & $\begin{array}{l}15.6 \\
14.8\end{array}$ & $\begin{array}{l}13.1 \\
10.2\end{array}$ & $\begin{array}{l}11.1 \\
5.93\end{array}$ & $\begin{array}{l}0.67 \\
0.10\end{array}$ \\
\hline TAL-16-08-11 & 31.8 & 5.47 & -0.87 & 47.0 & 52.0 & 11.20 & 0 & 0.00 & 0.67 & 25.9 & 20.4 & 11.9 & 10.1 & 9.30 & 9.47 & 1.03 \\
\hline TAL-16-08-14 & 27.3 & 4.96 & -0.75 & 37.7 & 42.3 & 10.40 & 0 & 0.57 & 0.63 & 16.3 & 20.2 & 15.8 & 13.2 & 11.2 & 10.9 & 0.83 \\
\hline TAL-16-08-17 & 31.5 & 5.48 & -0.67 & 42.0 & 47.2 & 10.63 & 0.37 & 2.00 & 2.33 & 17.1 & 20.2 & 14.9 & 10.9 & 9.87 & 10.7 & 1.03 \\
\hline TAL-16-08-20 & 31.5 & 5.49 & -0.82 & 46.3 & 51.4 & 11.17 & 0 & 0.60 & 1.13 & 22.9 & 21.7 & 12.7 & 9.53 & 8.90 & 10.1 & 1.30 \\
\hline TAL-16-08-23 & 54.8 & 2.51 & -0.37 & 47.6 & 50.2 & 0 & 0 & 0.83 & 1.77 & 14.5 & 30.4 & 28.4 & 12.8 & 7.40 & 3.80 & 0.00 \\
\hline TAL-16-08-26 & 89.5 & 4.04 & -0.50 & 63.3 & 67.5 & 0 & 0 & 5.50 & 23.7 & 25.1 & 9.07 & 7.67 & 12.5 & 11.0 & 5.50 & 0.00 \\
\hline TAL-17-01-00 & 47.7 & 2.57 & -0.43 & 44.1 & 46.6 & 0 & 0 & 0 & 0.13 & 17.6 & 26.3 & 24.1 & 16.7 & 10.4 & 4.75 & 0.01 \\
\hline TAL-17-01-03 & 62.9 & 2.88 & -0.94 & 59.3 & 61.8 & 0.70 & 0 & 0 & 1.06 & 31.0 & 27.2 & 17.0 & 10.7 & 7.51 & 4.78 & 0.04 \\
\hline TAL-17-01-07 & 43.8 & 3.26 & 0.10 & 37.6 & 41.3 & 0 & 0.32 & 2.58 & 3.32 & 14.5 & 16.9 & 20.3 & 17.9 & 14.6 & 9.44 & 0.08 \\
\hline TAL-17-01-12 & 84.4 & 2.86 & -0.42 & 62.8 & 65.9 & 0 & 0 & 1.79 & 13.1 & 25.2 & 22.7 & 19.6 & 9.90 & 5.40 & 2.28 & 0.00 \\
\hline TAL-17-01-16 & 38.5 & 7.59 & -0.73 & 51.7 & 59.1 & 14.69 & 0 & 4.16 & 10.1 & 25.3 & 12.3 & 10.9 & 7.10 & 7.14 & 8.10 & 0.30 \\
\hline TAL-17-01-24 & 42.7 & 2.13 & -0.59 & 34.3 & 36.2 & 0.00 & 0 & 0 & 0 & 5.30 & 29.0 & 5.4 & 17.8 & 9.36 & 3.05 & 0.00 \\
\hline TAL-17-0 & 33.8 & 3.88 & 0.39 & 33.7 & 38.4 & 0.00 & 0 & 1.73 & 7.53 & 17.3 & 7.93 & 10.8 & 16.3 & 24.7 & 14.49 & 0.04 \\
\hline TAL-17-02-02 & 73.1 & 2.94 & -0.49 & 59.4 & 62.4 & 0.00 & 0 & 0.92 & 8.21 & 29.8 & 20.5 & 7.4 & 12.4 & 7.41 & 3.42 & 0.01 \\
\hline TAL-17-02-03 & 35.2 & 2.33 & -0.12 & 25.9 & 28.4 & 0.0 & 0 & 0 & 0.04 & 7.42 & 18.5 & 1.0 & 24.1 & 3.6 & 5.29 & 0.01 \\
\hline TAL & 52.3 & 2.82 & -0.32 & 45.6 & 48.5 & 0.00 & 0 & 0.55 & 2.23 & 21.0 & 21.8 & 4.3 & 15.1 & 9.32 & 5.65 & 0.04 \\
\hline TAL & 64.8 & 3.31 & -0.14 & 52.0 & 55.7 & 0.0 & 0 & 3 & 8.57 & 23.0 & 17.0 & 18.6 & 15.3 & 9.42 & 4.65 & 0.02 \\
\hline TAL- & 40.9 & 3.03 & -0.26 & 39.1 & 42.2 & 0.38 & 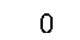 & 0.65 & 1.17 & 16.3 & 20.9 & 20.4 & 17.3 & 13.5 & 9.26 & 0.08 \\
\hline $\mathrm{TAL}$ & 38.0 & 2.57 & -0.21 & 32.8 & 35.5 & 0.00 & 0 & 0 & 0.04 & 12.1 & 20.7 & 26.4 & 21.0 & 12.8 & 6.89 & 0.05 \\
\hline TAL & 74.4 & 2.91 & -0.99 & 66.6 & 69.2 & 0.00 & 0 & 0 & 2.18 & 42.8 & 21.7 & 11.6 & 9.26 & 7.41 & 5.04 & 0.11 \\
\hline TAL & 49.4 & 4.36 & -1.12 & 57.9 & 61.7 & 5.45 & 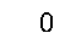 & 0.24 & 0.99 & 33.6 & 23.0 & 11.1 & 9.68 & 8.36 & 7.14 & 0.36 \\
\hline TAL & 28.6 & 2.31 & -0.18 & 18.2 & 20.5 & 0.00 & 0 & 0.00 & 0.00 & 3.2 & 15.0 & 31.0 & 25.4 & 16.1 & 9.17 & 0.08 \\
\hline TAL & 54.0 & 2.91 & -0.31 & 47.3 & 50.4 & 0.00 & 0 & 0.68 & 3.52 & 22.0 & 21.1 & 20.2 & 15.9 & 10.7 & 5.79 & 0.02 \\
\hline TAL & 134 & 3.10 & -1.65 & 83.0 & 85.3 & 0.00 & 0 & 1.56 & 26.2 & 47.4 & 7.88 & 3.91 & 3.07 & 5.11 & 4.68 & 0.24 \\
\hline TAL- & 35.0 & 2.65 & -0.13 & 31.2 & 34.1 & 0.00 & 0 & 0 & 0.13 & 11.1 & 20.0 & 23.8 & 20.6 & 15.6 & 8.68 & 0.04 \\
\hline TAL-1 & 87.5 & 3.30 & -0.78 & 66.6 & 69.8 & 0.00 & 0 & 1.36 & 13.9 & 38.4 & 12.9 & 11.1 & 9.50 & 7.98 & 4.76 & 0.04 \\
\hline TAL-1 & 73.5 & 3.44 & -0.82 & 62.6 & 65.8 & 0.56 & 0 & 1.24 & 7.28 & 38.6 & 15.5 & 12.0 & 9.89 & 8.30 & 6.61 & 0.14 \\
\hline TAL-17-03-15 & 68.4 & 3.35 & -0.68 & 60.7 & 64.0 & 0.00 & 0 & 0 & 5.37 & 42.7 & 12.7 & 10.9 & 10.7 & 11.0 & 6.63 & 0.02 \\
\hline TAL-17-03-18 & 76.3 & 3.13 & -0.82 & 64.7 & 67.6 & 0.00 & 0 & 0.46 & 5.47 & 43.3 & 15.4 & 11.1 & 10.8 & 8.14 & 5.17 & 0.10 \\
\hline TAL-17-03-22 & 37.7 & 3.51 & -0.57 & 39.6 & 42.9 & 2.76 & 0 & 0.34 & 0.68 & 18.0 & 20.5 & 19.2 & 15.9 & 12.46 & 9.82 & 0.32 \\
\hline TAL-17-04-00 & 77.7 & 2.72 & -0.76 & 63.1 & 65.7 & 0.00 & 0 & 0.34 & 4.79 & 37.0 & 21.0 & 18.1 & 9.91 & 5.78 & 3.05 & 0.01 \\
\hline TAL-17-04-04 & 122 & 3.26 & -1.38 & 79.0 & 81.7 & 0.00 & 0 & 1.19 & 24.9 & 46.5 & 6.38 & 3.76 & 5.52 & 7.24 & 4.40 & 0.08 \\
\hline TAL-17-04-07 & 105 & 3.19 & -1.10 & 74.3 & 77.1 & 0.00 & 0 & 1.52 & 16.7 & 46.3 & 9.81 & 6.50 & 8.32 & 7.02 & 3.82 & 0.08 \\
\hline TAL-17-04-11 & 239 & 2.16 & -2.96 & 95.3 & 95.4 & 0.00 & 0 & 7.51 & 47.8 & 37.8 & 2.15 & 1.09 & 0.72 & 1.21 & 1.65 & 0.07 \\
\hline TAL-17-04-16 & 65.2 & 4.46 & -0.91 & 61.4 & 65.6 & 3.25 & 0 & 1.45 & 9.51 & 38.1 & 12.4 & 8.46 & 9.28 & 9.75 & 7.63 & 0.19 \\
\hline TAL-17-05-00 & 164 & 2.75 & -2.69 & 90.4 & 91.4 & 0.99 & 0 & 1.38 & 29.7 & 52.2 & 7.12 & 2.52 & 1.57 & 1.80 & 2.58 & 0.11 \\
\hline TAL-17-05-03 & 112 & 2.97 & -1.00 & 73.5 & 76.2 & 0.00 & 0 & 1.15 & 22.1 & 37.7 & 12.5 & 10.9 & 7.89 & 5.31 & 2.43 & 0.01 \\
\hline TAL-17-05-08 & 58.0 & 3.45 & -0.18 & 49.6 & 53.4 & 0.00 & 0 & 2.99 & 7.58 & 25.6 & 14.4 & 16.3 & 16.1 & 11.1 & 6.78 & 0.06 \\
\hline TAL- & 42.4 & 2.86 & -0.02 & 37.9 & 41.2 & 0.0 & 0 & 0.24 & 1.11 & 19.4 & 17.2 & 20.6 & 21.8 & 13.8 & 5.98 & 0.01 \\
\hline CAM-01-01-00 & 34.6 & 3.05 & -0.50 & 35.0 & 37.9 & 1. & 0 & 0 & 0.03 & 12.3 & 22.7 & 22.6 & 16.9 & 13.4 & 10.3 & 0.34 \\
\hline CAN & 34.6 & 2.80 & -0.72 & 32.1 & 34.5 & 1.8 & 0 & 0 & 0. & 6.71 & 25.4 & 27.4 & 17.2 & 12.3 & 8.94 & 0.22 \\
\hline & 24.8 & 3.74 & -0.46 & & 30.1 & & 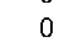 & 0 & 0.23 & 10.0 & 16.3 & 20.2 & 18.2 & 15.6 & 13.2 & 0.68 \\
\hline & 38.8 & & & & 39.0 & & 0 & 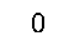 & & & 21.8 & 24.0 & 17.6 & 12.5 & 8.35 & 0.11 \\
\hline & 37.0 & & & & & & 0 & 0.62 & & & 25.6 & 23.1 & 15.9 & & 7.72 & 0.15 \\
\hline & 50.9 & 3.07 & -0.70 & 46.0 & 48.9 & & 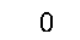 & 0 & 2.36 & 20.0 & 23.1 & 21.4 & 14.6 & 9.67 & 6.65 & 0.13 \\
\hline CAM-01-01-15 & 16.1 & 4.69 & -0.64 & 23.1 & 27.4 & 14.5 & 0 & 1.56 & 0.00 & 3.16 & 20.0 & 17.7 & 15.0 & 14.5 & 13.9 & 1.34 \\
\hline CAM-01-01-19 & 25.8 & 4.64 & -0.73 & 32.4 & 36.6 & 9.48 & 0 & 0.00 & 0.49 & 10.12 & 20.2 & 19.7 & 14.7 & 12.8 & 10.5 & 0.42 \\
\hline CAM-02-01-02 & 69.5 & 3.16 & -0.77 & 62.3 & 37.1 & 0.61 & 0 & 2.09 & 4.53 & 29.4 & 26.3 & 15.3 & 9.34 & 7.16 & 5.11 & 0.14 \\
\hline CAM-02-01-08 & 41.1 & 2.43 & -0.41 & 35.5 & 64.5 & 0.00 & 0 & 0 & 0.04 & 9.83 & 25.7 & 30.0 & 17.8 & 11.0 & 5.55 & 0.05 \\
\hline
\end{tabular}




\begin{tabular}{|c|c|c|c|c|c|c|c|c|c|c|c|c|c|c|c|c|}
\hline 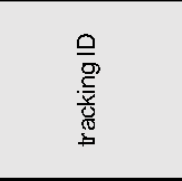 & 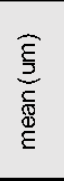 & 总 & 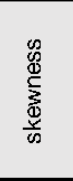 & 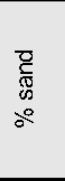 & $\begin{array}{l}+\overline{\bar{w}} \\
\text { o }\end{array}$ & $\begin{array}{l}\frac{\grave{\sigma}}{0} \\
\therefore \circ\end{array}$ & 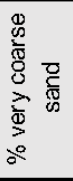 & 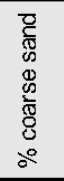 & 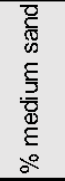 & 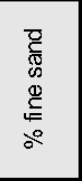 & 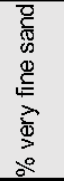 & 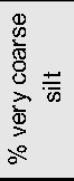 & 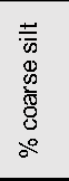 & 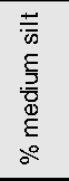 & 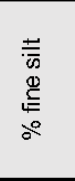 & 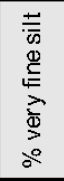 \\
\hline CAM-02-01-13 & 33.0 & 3.95 & -1.14 & 40.3 & 53.1 & 6.60 & 0 & 0 & 0.04 & 11.7 & 28.6 & 22.7 & 11.7 & 9.82 & 8.44 & 0.43 \\
\hline CAM-02-01-17 & 55.8 & 3.22 & -0.51 & 50.0 & 49.0 & 1.01 & 0 & 1.22 & 4.29 & 22.3 & 22.3 & 20.0 & 13.9 & 9.09 & 5.88 & 0.09 \\
\hline CAM-03-01-00 & 52.7 & 2.67 & -0.55 & 48.4 & 51.6 & 0.00 & 0 & 0.17 & 0.85 & 20.4 & 27.0 & 24.3 & 13.4 & 8.35 & 5.49 & 0.11 \\
\hline CAM-03-01-04 & 43.5 & 2.85 & -0.73 & 41.5 & 57.3 & 1.19 & 0 & 0 & 0.24 & 15.7 & 25.6 & 23.8 & 15.6 & 10.7 & 7.07 & 0.10 \\
\hline CAM-03-01-12 & 43.7 & 3.01 & -0.59 & 41.9 & 56.8 & 1.26 & 0 & 0.22 & 0.61 & 17.9 & 23.2 & 21.8 & 16.4 & 11.3 & 7.33 & 0.11 \\
\hline CAM-03-01-17 & 35.9 & 2.63 & -0.07 & 31.1 & 68.9 & 0 & 0 & 0 & 0.21 & 11.5 & 19.4 & 24.3 & 22.0 & 15.3 & 7.34 & 0.05 \\
\hline CAM-05-01-00 & 149 & 5.84 & -1.77 & 80.8 & 85.7 & 4.48 & 0 & 3.23 & 33.5 & 21.3 & 8.07 & 4.13 & 2.32 & 2.77 & 4.59 & 0.88 \\
\hline CAM-05-01-05 & 120 & 3.37 & -0.99 & 73.7 & 76.9 & 0 & 0 & 1.62 & 31.1 & 27.2 & 12.2 & 10.3 & 6.40 & 5.43 & 4.04 & 0.14 \\
\hline CAM-05-01-07 & 64.8 & 3.66 & -0.57 & 57.0 & 60.7 & 0.65 & 0 & 4.51 & 11.1 & 25.0 & 19.2 & 15.4 & 10.0 & 8.91 & 7.68 & 0.24 \\
\hline CAM-05-01-09 & 80.5 & 4.77 & -0.78 & 62.6 & 67.2 & 2.14 & 0 & 3.34 & 24.8 & 21.9 & 11.3 & 10.1 & 8.26 & 8.32 & 8.20 & 0.34 \\
\hline CAM-05-01-11 & 84.9 & 3.27 & -0.51 & 63.7 & 67.1 & 0 & 0 & 2.46 & 15.9 & 22.4 & 22.0 & 16.9 & 8.47 & 6.31 & 4.52 & 0.08 \\
\hline CAM-05-01-14 & 78.0 & 4.49 & -0.92 & 64.2 & 68.4 & 2.46 & 0 & 8.07 & 20.7 & 27.1 & 13.9 & 10.5 & 7.83 & 7.21 & 7.36 & 0.46 \\
\hline CAM-05-01-17 & 160 & 3.27 & -1.41 & 82.9 & 85.6 & 0 & 0 & 0 & 37.3 & 27.7 & 9.82 & 5.00 & 3.76 & 4.49 & 3.63 & 0.19 \\
\hline CAM-06-01-00 & 90.7 & 3.34 & -0.80 & 68.7 & 31.3 & 0 & 0 & 2.16 & 16.1 & 33.4 & 17.1 & 11.0 & 8.0 & 6.9 & 5.27 & 0.15 \\
\hline CAM-06-01-05 & 80.7 & 3.54 & -0.57 & 63.2 & 36.8 & 0 & 0 & 2.66 & 15.5 & 28.6 & 16.4 & 12.3 & 10.0 & 8.5 & 5.95 & 0.10 \\
\hline CAM-06-01-07 & 69.4 & 3.45 & -0.39 & 58.1 & 41.9 & 0 & 0 & 1.98 & 11.5 & 27.2 & 17.5 & 13.6 & 12.4 & 10.1 & 5.83 & 0.04 \\
\hline CAM-06-01-12 & 44.7 & 3.35 & 0.29 & 36.5 & 63.5 & 0 & 0 & 2.86 & 6.30 & 13.7 & 13.6 & 20.7 & 20.9 & 14.9 & 6.83 & 0.02 \\
\hline CAM-06-01-19 & 28.4 & 2.21 & -0.16 & 17.9 & 82.1 & 0 & 0 & 0 & 0 & 1.24 & 16.7 & 29.8 & 27.9 & 17.4 & 6.97 & 0.02 \\
\hline CAM-06-02-00 & 81.5 & 3.64 & -0.58 & 63.7 & 36.3 & 0 & 0 & 3.12 & 16.5 & 27.7 & 16.4 & 11.9 & 9.26 & 8.36 & 6.64 & 0.14 \\
\hline CAM-06-02-08 & 30.5 & 2.34 & 0.03 & 20.3 & 79.7 & 0 & 0 & 0.81 & 0.08 & 2.26 & 17.2 & 30.4 & 26.2 & 16.2 & 6.89 & 0.02 \\
\hline CAM-06-02-14 & 31.3 & 2.30 & -0.24 & 21.2 & 78.8 & 0 & 0 & 0 & 0 & 3.83 & 17.4 & 32.5 & 24.5 & 14.5 & 7.21 & 0.07 \\
\hline CAM-06-02-17 & 37.2 & 2.48 & -0.21 & 29.8 & 70.2 & 0 & 0 & 0 & 0.09 & 9.90 & 19.8 & 30.4 & 21.0 & 12.3 & 6.42 & 0.08 \\
\hline CAM-07-01-07 & 29.2 & 2.24 & -0.34 & 18.2 & 20.3 & 0 & 0 & 0 & 0 & 1.61 & 16.6 & 33.3 & 24.2 & 15.7 & 8.49 & 0.09 \\
\hline CAM-07-01-11 & 32.6 & 2.34 & -0.36 & 24.9 & 27.1 & 0 & 0 & 0.68 & 0 & 3.51 & 21.3 & 31.1 & 22.2 & 14.0 & 7.70 & 0.10 \\
\hline CAM-07-01-14 & 36.0 & 2.57 & -0.03 & 29.2 & 32.0 & 0 & 0 & 0 & 0.36 & 8.25 & 19.9 & 28.6 & 21.3 & 13.8 & 7.10 & 0.06 \\
\hline CAM-07-01-17 & 25.8 & 2.25 & -0.55 & 12.8 & 14.6 & 0.45 & 0 & 0 & 0 & 0.58 & 12.2 & 33.8 & 25.8 & 17.0 & 9.96 & 0.15 \\
\hline CAM-07-01-19 & 28.8 & 2.16 & -0.45 & 16.0 & 17.8 & 0 & 0 & 16.3 & 0 & 0.77 & 15.2 & 35.6 & 24.8 & 15.3 & 8.20 & 0.10 \\
\hline CAM-08-01-03 & 25.2 & 2.55 & -0.33 & 16.4 & 82.5 & 1.16 & 0 & 0 & 0.01 & 3.27 & 13.1 & 27.9 & 25.3 & 17.8 & 11.3 & 0.21 \\
\hline CAM-08-01-07 & 29.6 & 2.22 & -0.41 & 19.0 & 81.0 & 0 & 0 & 0 & 0 & 0.93 & 18.1 & 33.8 & 23.3 & 15.5 & 8.20 & 0.06 \\
\hline CAM-08-01-11 & 24.9 & 2.40 & -0.58 & 13.1 & 85.6 & 1.26 & 0 & 0 & 0 & 1.02 & 12.1 & 32.1 & 26.3 & 16.7 & 10.3 & 0.23 \\
\hline CAM-08-01-15 & 26.3 & 2.18 & -0.24 & 13.0 & 87.0 & 0 & 0 & 0 & 0 & 1.26 & 11.8 & 32.6 & 27.7 & 17.4 & 9.25 & 0.07 \\
\hline CAM-08-01-19 & 28.5 & 2.11 & -0.38 & 14.6 & 85.4 & 0 & 0 & 0 & 0 & 0.70 & 13.9 & 35.7 & 26.9 & 15.7 & 7.14 & 0.03 \\
\hline CAM-09-01-05 & 66.7 & 4.01 & 0.34 & 42.5 & 57.5 & 0 & 2.34 & 8.19 & 12.9 & 8.52 & 10.6 & 23.6 & 19.3 & 10.5 & 4.06 & 0.01 \\
\hline CAM-09-01-09 & 80.2 & 4.67 & 0.04 & 51.3 & 48.7 & 0 & 3.31 & 12.1 & 14.8 & 11.4 & 9.61 & 15.5 & 16.5 & 10.6 & 6.02 & 0.08 \\
\hline CAM-09-01-15 & 14.3 & 3.75 & -0.84 & 9.21 & 78.7 & 12 & 0 & 0 & 0 & 1.77 & 7.44 & 21.2 & 24.4 & 18.2 & 14.1 & 0.71 \\
\hline CAM-09-01-17 & 46.4 & 2.82 & 0.60 & 32.9 & 67.1 & 0 & 0 & 4.29 & 1.93 & 8.11 & 18.2 & 31.4 & 21.5 & 11.0 & 3.16 & 0.00 \\
\hline CAM-09-01-20 & 30.5 & 4.67 & 0.12 & 30.1 & 66.2 & 4 & 0 & 5.24 & 5.92 & 8.32 & 10.6 & 14.7 & 18.1 & 19.2 & 13.8 & 0.29 \\
\hline CAM-09-02-00 & 56.7 & 3.27 & 0.17 & 43.3 & 56.7 & 0 & 0 & 3.26 & 9.86 & 14.26 & 15.9 & 23.4 & 18.7 & 10.5 & 4.11 & 0.01 \\
\hline CAM-09-02-05 & 64.7 & 4.20 & 0.45 & 40.5 & 59.5 & 0 & 2.60 & 11.0 & 9.49 & 7.06 & 10.3 & 23.6 & 20.5 & 11.2 & 4.19 & 0.01 \\
\hline CAM-09-02-08 & 41.7 & 2.70 & 0.12 & 33.2 & 66.8 & 0 & 0 & 1.09 & 1.64 & 12.6 & 17.8 & 26.6 & 22.7 & 12.7 & 4.80 & 0.01 \\
\hline CAM-09-02-11 & 59.2 & 3.41 & 0.15 & 45.5 & 54.5 & 0 & 0.43 & 4.98 & 7.82 & 14.7 & 17.5 & 23.0 & 16.7 & 9.7 & 5.09 & 0.05 \\
\hline CAM-09-02-15 & 45.4 & 3.76 & 0.71 & 29.8 & 70.2 & 0 & 0.67 & 8.89 & 5.38 & 4.81 & 10.0 & 25.4 & 24.1 & 14.2 & 6.56 & 0.04 \\
\hline CAM-09-02-18 & 45.1 & 3.08 & 0.64 & 30.5 & 69.5 & 0 & 0.55 & 4.19 & 4.27 & 8.46 & 13.0 & 29.3 & 23.9 & 12.1 & 4.15 & 0.00 \\
\hline CAM-10-01-00 & 53.5 & 4.24 & 0.38 & 38.0 & 43.0 & 0 & 0 & 6.51 & 15.3 & 7.03 & 7.55 & 16.9 & 22.4 & 16.3 & 6.34 & 0.01 \\
\hline CAM-10-01-10 & 60.6 & 3.92 & 0.32 & 41.0 & 45.6 & 0 & 0 & 0.95 & 15.0 & 10.0 & 8.56 & 20.6 & 21.8 & 12.4 & 4.20 & 0.00 \\
\hline CAM-10-01-15 & 52.7 & 3.17 & -0.10 & 45.5 & 49.0 & 0 & 0 & 1.11 & 6.12 & 21.6 & 16.8 & 19.4 & 18.2 & 11.0 & 5.85 & 0.05 \\
\hline CAM-10-01-21 & 50.7 & 3.33 & -0.11 & 46.1 & 49.8 & 0 & 0 & 0.24 & 5.92 & 22.0 & 17.1 & 16.8 & 17.0 & 12.8 & 7.22 & 0.06 \\
\hline CAM-10-01-24 & 49.6 & 2.71 & -0.28 & 44.0 & 46.9 & 0 & 0 & 1.34 & 1.08 & 20.4 & 22.3 & 23.7 & 17.5 & 10.0 & 4.72 & 0.04 \\
\hline
\end{tabular}


Appendix VII: Summary table of all collected TC, TOC, and TN data

\begin{tabular}{|c|c|c|c|c|c|c|c|c|c|c|c|}
\hline 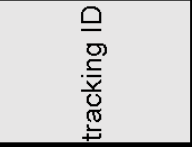 & 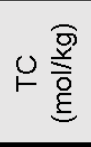 & 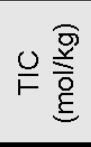 & $\begin{array}{l}\text { 응 } \\
\text { 음 }\end{array}$ & $\underset{0}{\stackrel{0}{\varrho}}$ & 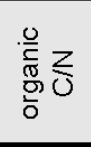 & 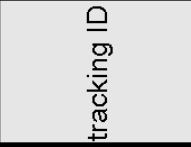 & 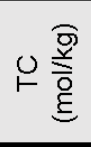 & 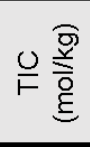 & 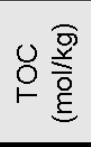 & & 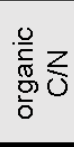 \\
\hline TAL-16-01-00 & 0.08 & 0.02 & 0.06 & 0.73 & 8.51 & TAL-16-07-12 & 0.05 & 0.00 & 0.05 & 0.55 & 9.16 \\
\hline TAL-16-01-07 & 0.03 & 0.01 & 0.03 & 0.31 & 4.52 & TAL-16-08-00 & 0.09 & 0.02 & 0.08 & 0.91 & 8.84 \\
\hline TAL-16-01-11 & 0.03 & 0.00 & 0.03 & 0.36 & 5.25 & TAL-16-08-01 & 0.07 & 0.02 & 0.06 & 0.69 & 10.1 \\
\hline TAL-16-01-14 & 0.02 & 0.00 & 0.02 & 0.28 & 4.66 & TAL-16-08-03 & 0.09 & 0.01 & 0.07 & 0.9 & 8.07 \\
\hline TAL-16-01-17 & 0.03 & 0.00 & 0.03 & 0.33 & 4.81 & TAL-16-08-06 & 0.17 & 0.01 & 0.16 & 1.95 & 12.0 \\
\hline TAL-16-01-19 & 0.03 & 0.00 & 0.03 & 0.34 & 5.66 & TAL-16-08-08 & 0.05 & 0.01 & 0.05 & 0.55 & 8.02 \\
\hline TAL-16-01-23 & 0.07 & 0.02 & 0.05 & 0.64 & 6.22 & TAL-16-08-11 & 0.15 & 0.01 & 0.13 & 1.59 & 10.9 \\
\hline TAL-16-02-00 & 0.04 & 0.00 & 0.04 & 0.48 & 6.22 & TAL-16-08-14 & 0.21 & 0.03 & 0.18 & 2.17 & 11.5 \\
\hline TAL-16-02-05 & 0.03 & 0.00 & 0.03 & 0.32 & 4.66 & TAL-16-08-17 & 0.22 & 0.02 & 0.20 & 2.35 & 11.4 \\
\hline TAL-16-02-10 & 0.03 & 0.00 & 0.02 & 0.29 & 4.83 & TAL-16-08-20 & 0.23 & 0.03 & 0.20 & 2.36 & 11.5 \\
\hline TAL-16-02-15 & 0.03 & 0.00 & 0.02 & 0.29 & 4.23 & TAL-16-08-23 & 0.03 & 0.00 & 0.03 & 0.34 & 4.96 \\
\hline TAL-16-02-20 & 0.03 & 0.01 & 0.02 & 0.30 & 5.00 & TAL-16-08-26 & 0.04 & 0.01 & 0.04 & 0.47 & 6.85 \\
\hline TAL-16-03-00 & 0.04 & 0.01 & 0.03 & 0.39 & 9.10 & TAL-A1-01-00 & 0.11 & 0.01 & 0.10 & 1.24 & 10.3 \\
\hline TAL-16-03-05 & 0.03 & 0.00 & 0.03 & 0.33 & 4.81 & TAL-A2-01-00 & 0.11 & 0.03 & 0.08 & 0.95 & 7.91 \\
\hline TAL-16-03-09 & 0.02 & 0.00 & 0.02 & 0.26 & 4.33 & TAL-A3-01-00 & 0.08 & 0.02 & 0.06 & 0.76 & 8.86 \\
\hline TAL-16-03-12 & 0.02 & 0.00 & 0.02 & 0.20 & 3.89 & TAL-B1-01-00 & 0.12 & 0.00 & 0.11 & 1.37 & 10.7 \\
\hline TAL-16-03-14 & 0.01 & 0.00 & 0.01 & 0.13 & 3.79 & TAL-B2-01-00 & 0.10 & 0.00 & 0.10 & 1.15 & 12.2 \\
\hline TAL-16-03-18 & 0.02 & 0.00 & 0.02 & 0.21 & 4.08 & TAL-B3-01-00 & 0.07 & 0.01 & 0.06 & 0.68 & 8.81 \\
\hline TAL-16-04-00 & 0.01 & 0.00 & 0.01 & 0.16 & 3.73 & TAL-C1-01-00 & 0.15 & 0.02 & 0.13 & 1.58 & 9.70 \\
\hline TAL-16-04-03 & 0.02 & 0.00 & 0.02 & 0.29 & 4.23 & TAL-C2-01-00 & 0.12 & 0.01 & 0.10 & 1.23 & 9.56 \\
\hline TAL-16-04-06 & 0.02 & 0.00 & 0.02 & 0.30 & 4.37 & TAL-C3-01-00 & 0.12 & 0.02 & 0.10 & 1.22 & 8.89 \\
\hline TAL-16-04-08 & 0.03 & 0.00 & 0.03 & 0.32 & 4.66 & TAL-D1-01-00 & 0.06 & 0.01 & 0.05 & 0.59 & 7.64 \\
\hline TAL-16-04-12 & 0.03 & 0.00 & 0.03 & 0.33 & 4.81 & TAL-D2-01-00 & 0.10 & 0.03 & 0.08 & 0.92 & 7.66 \\
\hline TAL-16-04-18 & 0.02 & 0.00 & 0.02 & 0.21 & 3.50 & TAL-D3-01-00 & 0.07 & 0.02 & 0.06 & 0.68 & 7.93 \\
\hline TAL-16-05-00 & 0.13 & 0.03 & 0.10 & 1.18 & 9.17 & TAL-E1-01-00 & 0.07 & 0.01 & 0.06 & 0.72 & 7.63 \\
\hline TAL-16-05-02 & 0.13 & 0.03 & 0.10 & 1.15 & 9.58 & TAL-E2-01-00 & 0.08 & 0.00 & 0.08 & 0.92 & 9.75 \\
\hline TAL-16-05-05 & 0.16 & 0.02 & 0.14 & 1.71 & 11.1 & TAL-E3-01-00 & 0.10 & 0.00 & 0.10 & 1.16 & 10.4 \\
\hline TAL-16-05-07 & 0.14 & 0.04 & 0.10 & 1.26 & 9.80 & TAL-01-01-00 & 0.11 & 0.02 & 0.09 & 1.12 & 8.71 \\
\hline TAL-16-05-09 & 0.16 & 0.04 & 0.12 & 1.44 & 10.5 & TAL-02-01-00 & 0.05 & 0.01 & 0.03 & 0.42 & 5.44 \\
\hline TAL-16-05-12 & 0.08 & 0.03 & 0.05 & 0.62 & 7.23 & TAL-04-01-00 & 0.06 & 0.02 & 0.04 & 0.48 & 5.60 \\
\hline TAL-16-05-15 & 0.08 & 0.02 & 0.05 & 0.63 & 8.16 & TAL-05-01-00 & 0.02 & 0.00 & 0.02 & 0.21 & 4.08 \\
\hline TAL-16-05-17 & 0.07 & 0.02 & 0.05 & 0.55 & 6.41 & & & & & & \\
\hline TAL-16-05-23 & 0.02 & 0.00 & 0.02 & 0.20 & 3.89 & & & & & & \\
\hline TAL-16-05-27 & 0.07 & 0.02 & 0.05 & 0.63 & 6.12 & & & & & & \\
\hline TAL-16-06-00 & 0.11 & 0.02 & 0.08 & 0.99 & 8.25 & & & & & & \\
\hline TAL-16-06-02 & 0.08 & 0.03 & 0.05 & 0.64 & 7.46 & & & & & & \\
\hline TAL-16-06-03 & 0.12 & 0.03 & 0.08 & 1.00 & 8.33 & & & & & & \\
\hline TAL-16-06-05 & 0.10 & 0.02 & 0.08 & 0.94 & 7.83 & & & & & & \\
\hline TAL-16-06-07 & 0.13 & 0.03 & 0.10 & 1.18 & 9.17 & & & & & & \\
\hline TAL-16-06-09 & 0.09 & 0.02 & 0.06 & 0.76 & 8.06 & & & & & & \\
\hline TAL-16-06-12 & 0.11 & 0.03 & 0.09 & 1.04 & 8.66 & & & & & & \\
\hline TAL-16-06-15 & 0.16 & 0.02 & 0.14 & 1.67 & 10.25 & & & & & & \\
\hline TAL-16-06-16 & 0.12 & 0.01 & 0.10 & 1.22 & 8.89 & & & & & & \\
\hline TAL-16-06-17 & 0.12 & 0.01 & 0.11 & 1.34 & 9.19 & & & & & & \\
\hline TAL-16-06-18 & 0.06 & 0.01 & 0.05 & 0.57 & 6.65 & & & & & & \\
\hline TAL-16-06-20 & 0.04 & 0.01 & 0.04 & 0.43 & 6.27 & & & & & & \\
\hline TAL-16-07-00 & 0.08 & 0.02 & 0.06 & 0.69 & 8.05 & & & & & & \\
\hline TAL-16-07-02 & 0.11 & 0.03 & 0.08 & 0.93 & 8.34 & & & & & & \\
\hline TAL-16-07-04 & 0.04 & 0.01 & 0.03 & 0.36 & 6.00 & & & & & & \\
\hline TAL-16-07-08 & 0.10 & 0.01 & 0.09 & 1.12 & 9.33 & & & & & & \\
\hline
\end{tabular}


Appendix VIII: Summary table of all quantified XRF data

\begin{tabular}{|c|c|c|c|c|c|c|c|c|c|c|c|c|c|c|c|c|c|c|c|c|c|c|c|c|c|c|}
\hline ¿ัँ & 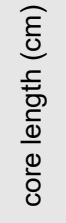 & 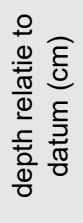 & $\underbrace{\frac{\sigma}{2}}_{z}$ & $\frac{\widehat{d}}{\frac{0}{3}}$ & $\frac{\widehat{o}}{\frac{0}{3}}$ & $\frac{\widehat{a}}{\stackrel{0}{a}}$ & \begin{tabular}{l}
$\widehat{o}$ \\
$\frac{0}{3}$ \\
\cline { 1 - 1 }
\end{tabular} & 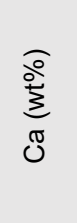 & $\begin{array}{l}\widehat{\varepsilon} \\
\stackrel{0}{0} \\
\stackrel{\mathbb{D}}{\infty}\end{array}$ & 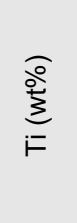 & 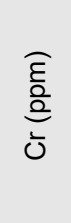 & $\begin{array}{l}\widehat{\hat{\varepsilon}} \\
\text { ôㅇ } \\
\hat{\Sigma}\end{array}$ & 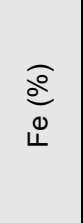 & $\begin{array}{l}\widehat{\varepsilon} \\
\text { 을 } \\
\dot{0}\end{array}$ & $\begin{array}{l}\widehat{\hat{\varepsilon}} \\
\stackrel{\circ}{0} \\
\bar{z}\end{array}$ & $\begin{array}{l}\widehat{\varepsilon} \\
\text { 을 } \\
\text { J }\end{array}$ & $\begin{array}{l}\widehat{\varepsilon} \\
\text { 을 } \\
\stackrel{ᄃ}{N}\end{array}$ & $\begin{array}{l}\widehat{\hat{\varepsilon}} \\
\frac{0}{2} \\
\frac{\infty}{4}\end{array}$ & $\begin{array}{l}\widehat{\hat{\varepsilon}} \\
\text { 을 } \\
\text { 음 }\end{array}$ & $\begin{array}{l}\widehat{\varepsilon} \\
\text { 을 } \\
\infty \\
\infty\end{array}$ & $\begin{array}{l}\widehat{\varepsilon} \\
\overline{\frac{0}{0}} \\
\text { 요 }\end{array}$ & $\begin{array}{l}\widehat{\bar{\varepsilon}} \\
\frac{\overline{0}}{2} \\
\bar{\omega}\end{array}$ & $\begin{array}{l}\widehat{\hat{\varepsilon}} \\
\hat{0} \\
>\end{array}$ & $\begin{array}{l}\widehat{\hat{\varepsilon}} \\
\stackrel{\circ}{0} \\
\grave{N}\end{array}$ & $\begin{array}{l}\text { है } \\
\text { 을 } \\
\text { 른 }\end{array}$ & $\begin{array}{l}\widehat{\varepsilon} \\
\text { 을 } \\
\stackrel{\circ}{\Sigma}\end{array}$ \\
\hline $16-01$ & 0 & 40 & 0.03 & 0 & 22.7 & 0.09 & 0.20 & 0.80 & 513 & 0.47 & 245 & 219 & 1.10 & 6.86 & 15.4 & 32.0 & 58.5 & 41.3 & 29.4 & 8.38 & 13.7 & 12.6 & 20.7 & 379 & 3.50 & 11.9 \\
\hline $16-01$ & 0.2 & 40.2 & 0.05 & 0 & 19.0 & 0.10 & 0.14 & 0.69 & 287 & 0.45 & 232 & 223 & 0.99 & 6.80 & 15.4 & 30.9 & 57.6 & 38.1 & 28.7 & 7.93 & 10.4 & 7.70 & 20.2 & 271 & 2.52 & 6.13 \\
\hline $16-01$ & 0.4 & 40.4 & 0.01 & 0 & 20.6 & 0.09 & 0.14 & 0.65 & 0.0 & 0.44 & 221 & 226 & 1.17 & 7.34 & 15.4 & 31.6 & 61.6 & 44.0 & 29.7 & 8.09 & 11.0 & 6.64 & 20.7 & 219 & 2.93 & 4.40 \\
\hline $16-01$ & 0.6 & 40.6 & 0.03 & 0 & 19.6 & 0.11 & 0.14 & 0.65 & 383 & 0.47 & 242 & 223 & 1.27 & 7.89 & 16.7 & 30.9 & 60.2 & 43.8 & 31.3 & 7.75 & 10.4 & 6.97 & 19.3 & 229 & 1.65 & 4.97 \\
\hline $16-01$ & 0.8 & 40.8 & 0.04 & 0 & 18.6 & 0.11 & 0.12 & 0.67 & 76.1 & 0.47 & 242 & 224 & 1.32 & 7.78 & 15.7 & 31.0 & 61.4 & 44.9 & 30.6 & 8.05 & 11.4 & 8.00 & 21.0 & 189 & 2.33 & 0.96 \\
\hline $16-01$ & 1 & 41 & 0.05 & 0 & 18.8 & 0.11 & 0.13 & 0.62 & 343 & 0.45 & 232 & 211 & 1.30 & 7.69 & 16.5 & 32.3 & 58.4 & 45.9 & 30.8 & 8.12 & 9.60 & 6.34 & 21.4 & 202 & 2.89 & 3.17 \\
\hline $16-01$ & 1.2 & 41.2 & 0 & 0 & 20.8 & 0.10 & 0.13 & 0.59 & 476 & 0.44 & 223 & 225 & 1.50 & 7.79 & 15.0 & 34.6 & 59.0 & 42.3 & $3 E+12$ & 7.91 & 9.74 & 7.71 & 18.8 & 226 & 2.53 & 3.19 \\
\hline $16-01$ & 1.4 & 41.4 & 0.01 & 0 & 21.7 & 0.09 & 0.15 & 0.57 & 461 & 0.44 & 216 & 232 & 1.43 & 7.63 & 14.8 & 31.3 & 52.3 & 41.0 & 28.4 & 8.13 & 9.42 & 8.64 & 18.6 & 250 & 1.66 & 3.76 \\
\hline $16-01$ & 1.6 & 41.6 & 0 & 0 & 21.1 & 0.10 & 0.14 & 0.56 & 0.0 & 0.43 & 214 & 229 & 1.13 & 7.37 & 16.3 & 30.6 & 58.1 & 42.3 & 29.9 & 8.32 & 9.62 & 6.82 & 18.5 & 238 & 1.91 & 6.22 \\
\hline $16-01$ & 1.8 & 41.8 & 0 & 0 & 20.6 & 0.11 & 0.12 & 0.54 & 562 & 0.43 & 220 & 211 & 1.28 & 7.45 & 14.1 & 29.7 & 53.1 & 37.7 & 27.9 & 8.21 & 9.29 & 5.53 & 17.5 & 244 & 1.93 & 5.09 \\
\hline $16-01$ & 2 & 42 & 0.04 & 0 & 18.7 & 0.11 & 0.11 & 0.56 & 655 & 0.41 & 206 & 201 & 0.94 & 6.77 & 14.5 & 28.5 & 51.4 & 39.4 & 26.8 & 7.87 & 8.79 & 2.74 & 16.7 & 225 & 1.92 & 3.71 \\
\hline $16-01$ & 2.2 & 42.2 & 0.03 & 0 & 19.5 & 0.11 & 0.12 & 0.56 & 449 & 0.40 & 205 & 203 & 1.05 & 7.03 & 15.8 & 30.4 & 49.0 & 36.9 & 25.3 & 8.46 & 8.25 & 5.73 & 17.3 & 212 & 1.96 & 4.62 \\
\hline $16-01$ & 2.4 & 42.4 & 0.02 & 0 & 19.5 & 0.09 & 0.12 & 0.57 & 359 & 0.40 & 203 & 203 & 0.78 & 6.19 & 13.4 & 27.5 & 47.1 & 36.6 & 24.5 & 8.66 & 9.39 & 7.39 & 16.5 & 219 & 2.13 & 4.27 \\
\hline $16-01$ & 2.6 & 42.6 & 0.03 & 0 & 19.6 & 0.09 & 0.12 & 0.56 & 456 & 0.40 & 205 & 206 & 0.93 & 6.96 & 15.1 & 27.3 & 62.2 & 38.3 & 27.5 & 7.75 & 9.44 & 5.19 & 17.9 & 299 & 1.76 & 7.02 \\
\hline $16-01$ & 2.8 & 42.8 & 0.04 & 0 & 18.3 & 0.10 & 0.11 & 0.58 & 531 & 0.41 & 209 & 211 & 0.62 & 6.90 & 18.3 & 39.5 & 624 & 38.7 & 27.7 & 8.19 & 11.1 & 6.08 & 18.9 & 417 & 2.61 & 10.1 \\
\hline $16-01$ & 3 & 43 & 0.05 & 0 & 18.0 & 0.10 & 0.11 & 0.61 & 512 & 0.42 & 216 & 215 & 0.16 & 6.19 & 18.7 & 46.5 & 694 & 43.7 & 29.6 & 8.33 & 11.4 & 8.72 & 19.7 & 400 & 2.48 & 10.7 \\
\hline $16-01$ & 3.2 & 43.2 & 0.04 & 0 & 17.8 & 0.10 & 0.11 & 0.64 & 294 & 0.44 & 222 & 213 & 1.09 & 7.92 & 18.3 & 42.0 & 645 & 44.9 & 28.3 & 8.56 & 11.4 & 9.01 & 18.3 & 319 & 2.01 & 7.09 \\
\hline $16-01$ & 3.4 & 43.4 & 0.05 & 0 & 17.5 & 0.11 & 0.10 & 0.65 & 292 & 0.43 & 217 & 211 & 0.75 & 6.85 & 15.8 & 39.3 & 182 & 43.3 & 29.8 & 8.08 & 9.04 & 7.65 & 19.2 & 255 & 3.43 & 6.15 \\
\hline $16-01$ & 3.6 & 43.6 & 0.06 & 0 & 17.8 & 0.11 & 0.11 & 0.67 & 416 & 0.44 & 225 & 218 & 0.75 & 6.73 & 16.2 & 31.0 & 58.3 & 46.3 & 31.8 & 8.25 & 10.3 & 8.96 & 20.6 & 302 & 2.52 & 7.69 \\
\hline $16-01$ & 3.8 & 43.8 & 0.05 & 0 & 17.6 & 0.11 & 0.10 & 0.73 & 321 & 0.44 & 224 & 220 & 0.96 & 7.09 & 16.3 & 36.4 & 61.4 & 44.7 & 29.8 & 8.22 & 11.7 & 9.51 & 20.4 & 319 & 2.09 & 8.81 \\
\hline $16-01$ & 4 & 44 & 0.07 & 0 & 17.0 & 0.11 & 0.10 & 0.69 & 0.0 & 0.45 & 229 & 213 & 1.47 & 7.84 & 16.2 & 36.5 & 58.8 & 49.5 & 33.7 & 7.97 & 11.9 & 9.23 & 23.0 & 258 & 3.67 & 7.20 \\
\hline $16-01$ & 4.2 & 44.2 & 0.06 & 0 & 16.9 & 0.11 & 0.10 & 0.66 & 495 & 0.44 & 229 & 206 & 1.07 & 7.00 & 17.4 & 36.4 & 54.6 & 47.5 & 34.5 & 8.66 & 11.4 & 8.38 & 19.7 & 194 & 65 & 1.17 \\
\hline $16-01$ & 4.4 & 44.4 & 0.04 & 0 & 17.4 & 0.10 & 0.10 & 0.65 & 394 & 0.44 & 225 & 205 & 1.48 & 7.64 & 16.7 & 33.8 & 58.6 & 47.9 & 31.3 & 8.32 & 10.8 & 11.4 & 20.9 & 201 & 2.92 & 2.89 \\
\hline $16-01$ & 4.6 & 44.6 & 0.04 & 0 & 18.3 & 0.10 & 0.10 & 0.64 & 563 & 0.43 & 222 & 205 & 1.32 & 7.40 & 16.7 & 30.5 & 58.0 & 42.6 & 29.6 & 7.92 & 11.8 & 9.50 & 20.8 & 225 & 3.13 & 3.19 \\
\hline $16-01$ & 4.8 & 44.8 & 0.04 & 0 & 18.2 & 0.11 & 0.11 & 0.65 & 0.0 & 0.45 & 230 & 210 & 1.40 & 7.84 & 17.3 & 34.2 & 53.2 & 43.7 & 28.2 & 8.57 & 9.79 & 7.91 & 21.2 & 282 & 2.74 & 5.25 \\
\hline $16-01$ & 5 & 45 & 0.04 & 0 & 18.2 & 0.11 & 0.11 & 0.66 & 148 & 0.44 & 226 & 210 & 1.23 & 7.19 & 15.7 & 35.2 & 89.4 & 49.4 & 32.2 & 8.49 & 10.5 & 9.59 & 21.0 & 344 & 2.18 & 7.73 \\
\hline $16-01$ & 5.2 & 45.2 & 0.05 & 0 & 17.3 & 0.12 & 0.09 & 0.66 & 218 & 0.46 & 235 & 210 & 0.98 & 7.09 & 18.4 & 41.2 & 430 & 50.2 & 31.6 & 8.71 & 11.3 & 11.3 & 22.7 & 325 & 3.24 & 8.50 \\
\hline $16-01$ & 5.4 & 45.4 & 0.06 & 0 & 16.7 & 0.12 & 0.09 & 0.64 & 217 & 0.47 & 242 & 203 & 1.20 & 7.08 & 16.5 & 38.2 & 393 & 47.3 & 31.0 & 8.54 & 10.9 & 8.44 & 21.0 & 276 & 2.81 & 5.92 \\
\hline $16-01$ & 5.6 & 45.6 & 0.06 & 0 & 16.7 & 0.13 & 0.09 & 0.65 & 154 & 0.46 & 237 & 197 & 1.87 & 8.23 & 16.6 & 32.4 & 74.4 & 45.4 & 29.6 & 8.70 & 11.2 & 6.63 & 22.1 & 220 & 2.10 & 2.16 \\
\hline $16-01$ & 5.8 & 45.8 & 0.07 & 0 & 15.8 & 0.13 & 0.09 & 0.67 & 140 & 0.47 & 241 & 193 & 1.41 & 7.09 & 16.1 & 33.4 & 54.9 & 46.8 & 32.1 & 8.32 & 10.9 & 8.66 & 21.0 & 198 & 3.24 & 1.39 \\
\hline $16-01$ & 6 & 46 & 0.08 & 0 & 15.7 & 0.12 & 0.08 & 0.68 & 214 & 0.45 & 233 & 196 & 1.49 & 7.40 & 16.2 & 32.5 & 59.2 & 47.9 & 30.9 & 8.91 & 11.1 & 9.99 & 20.9 & 220 & 3.46 & 2.35 \\
\hline $16-01$ & 6.2 & 46.2 & 0.09 & 0.01 & 15.2 & 0.12 & 0.10 & 0.71 & 359 & 0.45 & 232 & 197 & 1.37 & 7.27 & 16.9 & 34.0 & 62.4 & 50.4 & 32.8 & 8.30 & 12.3 & 7.53 & 20.6 & 226 & 2.87 & 5.10 \\
\hline $16-01$ & 6.4 & 46.4 & 0.10 & 0 & 14.8 & 0.13 & 0.08 & 0.65 & 365 & 0.44 & 225 & 195 & 1.68 & 7.79 & 16.0 & 33.6 & 62.7 & 47.8 & 32.1 & 8.68 & 13.4 & 9.19 & 20.7 & 224 & 2.81 & 5.45 \\
\hline $16-01$ & 6.6 & 46.6 & 0.11 & 0.30 & 14.3 & 0.13 & 0.09 & 0.63 & 0.0 & 0.43 & 222 & 193 & 1.85 & 7.84 & 14.9 & 35.7 & 59.5 & 47.6 & 31.8 & 8.60 & 11.1 & 8.98 & 22.2 & 261 & 2.41 & 5.87 \\
\hline $16-01$ & 6.8 & 46.8 & 0.11 & 0.22 & 14.5 & 0.13 & 0.08 & 0.63 & 419 & 0.45 & 232 & 190 & 1.44 & 7.16 & 16.8 & 35.2 & 58.1 & 50.8 & 32.9 & 8.58 & 12.5 & 8.05 & 21.9 & 260 & 2.98 & 5.32 \\
\hline $16-01$ & 7 & 47 & 0.11 & 0.17 & 14.2 & 0.13 & 0.07 & 0.63 & 525 & 0.45 & 234 & 184 & 1.47 & 6.93 & 15.8 & 37.1 & 57.4 & 47.6 & 31.0 & 8.88 & 11.8 & 9.45 & 21.5 & 271 & 2.79 & 5.61 \\
\hline $16-01$ & 7.2 & 47.2 & 0.10 & 0 & 15.2 & 0.13 & 0.09 & 0.64 & 44.9 & 0.46 & 236 & 181 & 1.65 & 7.41 & 17.5 & 32.8 & 60.7 & 49.9 & 33.2 & 8.02 & 12.5 & 8.37 & 22.2 & 401 & 3.06 & 10.1 \\
\hline $16-01$ & 7.4 & 47.4 & 0.09 & 0.08 & 15.4 & 0.13 & 0.10 & 0.67 & 611 & 0.44 & 227 & 171 & 1.88 & 7.66 & 17.7 & 37.5 & 53.3 & 47.5 & 31.4 & 8.63 & 13.3 & 6.35 & 23.8 & 385 & 2.19 & 9.92 \\
\hline
\end{tabular}

Zero values are below detection limit 


\begin{tabular}{|c|c|c|c|c|c|c|c|c|c|c|c|c|c|c|c|c|c|c|c|c|c|c|c|c|c|c|}
\hline ఫัँ & 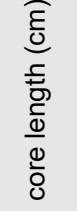 & 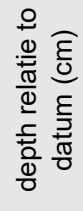 & $\frac{\widehat{0}}{\frac{0}{0}}$ & $\frac{\widehat{o}}{\frac{0}{3}}$ & $\frac{\widehat{o}}{\frac{\partial}{3}}$ & 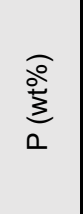 & $\frac{\widehat{o}}{\stackrel{0}{a}}$ & 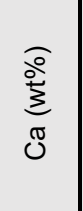 & $\begin{array}{l}\widehat{\varepsilon} \\
\text { 을 } \\
\widetilde{\infty}\end{array}$ & $\sum_{i=}^{\stackrel{o}{o}}$ & $\begin{array}{l}\widehat{\varepsilon} \\
\hat{0} \\
\bar{\varrho}\end{array}$ & $\begin{array}{l}\hat{\varepsilon} \\
\text { 을 } \\
\text { ᄃ }\end{array}$ & $\underset{\stackrel{0}{0}}{\stackrel{0}{0}}$ & $\begin{array}{l}\widehat{\hat{\varepsilon}} \\
\text { 응 } \\
\text { ᄋ }\end{array}$ & $\frac{\widehat{\bar{\varepsilon}}}{\frac{0}{0}}$ & $\begin{array}{l}\widehat{\hat{\varepsilon}} \\
\stackrel{0}{0} \\
\vec{\jmath}\end{array}$ & $\begin{array}{l}\widehat{\varepsilon} \\
\frac{0}{0} \\
\bar{N}\end{array}$ & $\begin{array}{l}\widehat{\varepsilon} \\
\stackrel{0}{0} \\
\frac{0}{<}\end{array}$ & $\begin{array}{l}\widehat{\hat{\varepsilon}} \\
\hat{\circ} \\
\stackrel{0}{0} \\
\text { م }\end{array}$ & $\begin{array}{l}\widehat{\varepsilon} \\
\text { 응 } \\
\text { ळ }\end{array}$ & $\begin{array}{l}\widehat{\varepsilon} \\
\hat{0} \\
\text { 음 }\end{array}$ & $\begin{array}{l}\widehat{\bar{\sigma}} \\
\overline{0} \\
\bar{c}\end{array}$ & $\begin{array}{l}\widehat{\hat{\varepsilon}} \\
\hat{0} \\
\succ\end{array}$ & $\begin{array}{l}\widehat{E} \\
\hat{0} \\
\overline{\mathrm{N}}\end{array}$ & $\begin{array}{l}\widehat{\hat{\varepsilon}} \\
\text { 을 } \\
\text { हo }\end{array}$ & $\begin{array}{l}\widehat{\bar{\varepsilon}} \\
\frac{0}{2} \\
\stackrel{\circ}{\Sigma}\end{array}$ \\
\hline $16-01$ & 7.6 & 47.6 & 0.07 & 0 & 16.2 & 0.12 & 0.11 & 0.66 & 349 & 0.45 & 231 & 179 & 1.57 & 7.21 & 18.0 & 34.4 & 58.1 & 48.0 & 30.4 & 8.45 & 12.5 & 8.45 & 24.4 & 391 & 2.02 & 9.45 \\
\hline $16-01$ & 7.8 & 47.8 & 0.07 & 0 & 16.2 & 0.13 & 0.11 & 0.64 & 317 & 0.45 & 233 & 187 & 1.84 & 7.92 & 16.9 & 32.0 & 58.9 & 48.0 & 29.9 & 8.57 & 13.0 & 7.66 & 23.1 & 322 & 3.17 & 8.66 \\
\hline $16-01$ & 8 & 48 & 0.07 & 0 & 17.1 & 0.12 & 0.12 & 0.61 & 173 & 0.45 & 229 & 195 & 1.65 & 8.13 & 19.2 & 34.2 & 60.0 & 48.0 & 30.6 & 8.17 & 12.0 & 11.2 & 23.8 & 201 & 3.71 & 1.68 \\
\hline $16-01$ & 8.2 & 48.2 & 0.05 & 0 & 18.4 & 0.11 & 0.14 & 0.65 & 0.0 & 0.47 & 241 & 212 & 1.32 & 7.68 & 17.9 & 36.4 & 60.3 & 53.1 & 33.6 & 8.29 & 13.1 & 10.9 & 23.4 & 219 & 3.10 & 3.59 \\
\hline $16-01$ & 8.4 & 48.4 & 0.05 & 0 & 17.8 & 0.12 & 0.12 & 0.67 & 514 & 0.46 & 237 & 220 & 1.19 & 7.79 & 16.8 & 35.8 & 59.5 & 49.8 & 32.9 & 8.45 & 11.2 & 10.1 & 23.4 & 245 & 2.76 & 5.98 \\
\hline $16-01$ & 8.6 & 48.6 & 0.11 & 0.10 & 14.9 & 0.13 & 0.08 & 0.64 & 296 & 0.43 & 219 & 224 & 0.26 & 6.45 & 15.9 & 33.5 & 50.1 & 40.9 & 26.2 & 7.67 & 9.16 & 7.98 & 20.6 & 257 & 1.65 & 3.53 \\
\hline $16-01$ & 8.8 & 48.8 & 0.21 & 1.12 & 10.7 & 0.15 & 0.04 & 0.59 & 366 & 0.40 & 206 & 219 & 0.61 & 7.23 & 12.3 & 30.8 & 46.5 & 37.1 & 28.2 & 7.73 & 8.33 & 6.84 & 20.2 & 272 & 2.62 & 6.87 \\
\hline $16-01$ & 9 & 49 & 0.33 & 2.36 & 5.97 & 0.16 & 0.00 & 0.60 & 680 & 0.40 & 205 & 217 & 0.00 & 7.14 & 15.2 & 40.8 & 50.6 & 39.0 & 28.7 & 7.77 & 7.47 & 5.18 & 19.3 & 251 & 2.52 & 9.70 \\
\hline $16-01$ & 9.2 & 49.2 & 0.46 & 3.43 & 2.23 & 0.15 & 0.00 & 0.57 & 0.0 & 0.38 & 195 & 209 & 0.00 & 5.75 & 14.3 & 67.7 & 59.7 & 37.6 & 28.2 & 10.16 & 9.20 & 4.11 & 21.9 & 254 & 3.53 & 10.37 \\
\hline $16-01$ & 9.4 & 49.4 & 0.46 & 3.48 & 1.87 & 0.16 & 0.00 & 0.68 & 908 & 0.43 & 222 & 229 & 0.00 & 6.29 & 19.2 & 82.8 & 63.3 & 37.2 & 25.1 & 8.29 & 6.92 & 1.59 & 13.9 & 220 & 2.95 & 5.56 \\
\hline $16-01$ & 9.6 & 49.6 & 0.19 & 1.16 & 10.7 & 0.14 & 0.01 & 0.64 & 0.0 & 0.45 & 228 & 239 & 0.00 & 6.98 & 16.6 & 54.1 & 64.5 & 39.8 & 29.2 & 6.83 & 4.06 & 1.89 & 18.4 & 166 & 2.87 & 0.00 \\
\hline $16-01$ & 9.8 & 49.8 & 0.04 & 0 & 17.3 & 0.11 & 0.09 & 0.62 & 637 & 0.42 & 215 & 226 & 0.84 & 6.97 & 12.1 & 39.4 & 56.6 & 43.0 & 27.8 & 7.40 & 6.68 & 4.93 & 20.4 & 201 & 1.11 & 0.68 \\
\hline $16-01$ & 10 & 50 & 0.02 & 0 & 20.1 & 0.10 & 0.13 & 0.62 & 503 & 0.42 & 214 & 216 & 0.92 & 6.96 & 13.7 & 32.8 & 50.3 & 44.0 & 28.1 & 7.86 & 10.1 & 7.27 & 21.6 & 201 & 2.21 & 0.00 \\
\hline $16-01$ & 10.2 & 50.2 & 0 & 0 & 19.9 & 0.10 & 0.13 & 0.62 & 392 & 0.42 & 215 & 220 & 1.24 & 7.45 & 13.4 & 25.1 & 50.2 & 47.6 & 28.9 & 7.87 & 9.11 & 6.56 & 21.7 & 218 & 1.75 & 2.79 \\
\hline $16-01$ & 10.4 & 50.4 & 0.02 & 0 & 19.8 & 0.11 & 0.13 & 0.60 & 333 & 0.43 & 223 & 221 & 1.26 & 7.91 & 16.7 & 31.3 & 54.3 & 47.5 & 30.9 & 7.81 & 9.04 & 8.33 & 21.2 & 218 & 1.93 & 1.02 \\
\hline $16-01$ & 10.6 & 50.6 & 0.02 & 0 & 19.3 & 0.12 & 0.13 & 0.64 & 177 & 0.45 & 232 & 221 & 0.75 & 6.92 & 15.8 & 30.4 & 56.5 & 45.7 & 30.3 & 7.85 & 10.5 & 11.0 & 23.9 & 215 & 2.15 & 2.86 \\
\hline $16-01$ & 10.8 & 50.8 & 0.05 & 0 & 17.9 & 0.12 & 0.12 & 0.62 & 245 & 0.43 & 224 & 222 & 1.03 & 7.63 & 16.8 & 28.5 & 52.8 & 46.7 & 31.3 & 8.27 & 9.56 & 8.26 & 23.0 & 194 & 3.34 & 0.00 \\
\hline $16-01$ & 11 & 51 & 0.05 & 0 & 17.3 & 0.12 & 0.11 & 0.62 & 661 & 0.43 & 218 & 214 & 0.67 & 7.01 & 17.3 & 28.3 & 55.1 & 46.0 & 30.2 & 8.06 & 10.7 & 7.03 & 20.6 & 240 & 2.48 & 4.06 \\
\hline $16-01$ & 11.2 & 51.2 & 0.05 & 0 & 17.1 & 0.12 & 0.10 & 0.62 & 413 & 0.43 & 218 & 212 & 0.68 & 6.96 & 16.4 & 30.4 & 50.9 & 45.4 & 30.1 & 7.90 & 8.81 & 5.43 & 22.4 & 300 & 2.15 & 8.39 \\
\hline $16-01$ & 11.4 & 51.4 & 0.06 & 0 & 17.1 & 0.12 & 0.11 & 0.60 & 588 & 0.43 & 221 & 216 & 0.84 & 7.56 & 17.8 & 33.9 & 50.7 & 42.9 & 27.3 & 8.10 & 9.86 & 7.28 & 19.9 & 338 & 1.61 & 8.67 \\
\hline $16-01$ & 11.6 & 51.6 & 0.06 & 0 & 17.7 & 0.12 & 0.12 & 0.63 & 0 & 0.44 & 226 & 214 & 0.62 & 6.94 & 16.9 & 28.4 & 55.1 & 43.7 & 28.7 & 8.28 & 9.98 & 6.62 & 19.2 & 310 & 2.04 & 3.47 \\
\hline $16-01$ & 11.8 & 51.8 & 0.05 & 0 & 17.9 & 0.12 & 0.12 & 0.60 & 180 & 0.44 & 221 & 210 & 0.18 & 6.37 & 19.0 & 29.3 & 56.1 & 40.3 & 28.6 & 8.01 & 9.46 & 6.76 & 19.4 & 291 & 1.93 & 6.74 \\
\hline $16-01$ & 12 & 52 & 0.05 & 0 & 18.4 & 0.11 & 0.12 & 0.58 & 486 & 0.42 & 209 & 203 & 0.38 & 6.16 & 14.6 & 28.3 & 49.2 & 37.0 & 27.7 & 7.66 & 6.87 & 2.60 & 19.0 & 317 & 1.54 & 8.46 \\
\hline $16-01$ & 12.2 & 52.2 & 0.0 & 0 & 0 & 0 & 0 & 0.56 & 229 & 0.40 & 198 & 197 & 0.35 & 5.58 & 11.2 & 24.6 & 46.3 & 30.9 & 22.4 & 8.32 & 5.55 & 3.76 & 17.8 & 312 & 1.61 & 6.96 \\
\hline $16-01$ & 12.4 & 52.4 & 0.11 & 0 & 16.1 & 0.13 & 0.09 & 0.60 & 0 & 0.41 & 203 & 201 & 0.20 & 5.73 & 14.9 & 27.4 & 47.3 & 31.1 & 22.3 & 8.03 & 7.01 & 0.83 & 17.0 & 237 & 2.00 & 2.97 \\
\hline $16-01$ & 12.6 & 52.6 & 0.16 & 0.54 & 13.8 & 0.13 & 0.06 & 0.65 & 0 & 0.42 & 209 & 200 & 0.30 & 5.91 & 14.0 & 34.2 & 51.1 & 31.3 & 25.6 & 8.55 & 7.45 & 1.27 & 17.4 & 210 & 2.25 & 4.59 \\
\hline $16-01$ & 12.8 & 52.8 & 0.21 & 1.12 & 11.6 & 0.15 & 0.04 & 0.59 & 813 & 0.40 & 204 & 203 & 0.53 & 6.19 & 13.0 & 33.3 & 47.2 & 29.2 & 21.4 & 8.03 & 6.48 & 1.52 & 16.2 & 206 & 2.03 & 4.23 \\
\hline $16-01$ & 13 & 53 & 0.22 & 1.18 & 11.1 & 0.15 & 0.03 & 0.55 & 236 & 0.42 & 210 & 207 & 0.03 & 5.67 & 15.3 & 38.1 & 51.9 & 30.9 & 21.6 & 8.22 & 7.82 & 1.04 & 18.4 & 227 & 3.26 & 6.64 \\
\hline $16-01$ & 13.2 & 53.2 & 0.16 & 0.62 & 13.5 & 0.14 & 0.06 & 0.57 & 126 & 0.39 & 198 & 206 & 0.28 & 5.61 & 12.1 & 34.8 & 50.7 & 31.1 & 24.4 & 8.47 & 6.17 & 0.25 & 17.0 & 259 & 2.82 & 6.64 \\
\hline $16-01$ & 13.4 & 53.4 & 0.09 & 0 & 17.8 & 0.12 & 0.10 & 0.58 & 611 & 0.38 & 193 & 216 & 0.00 & 5.22 & 13.9 & 33.9 & 46.3 & 33.0 & 25.0 & 7.82 & 5.46 & 0.00 & 18.9 & 337 & 1.94 & 8.89 \\
\hline $16-01$ & 13.6 & 53.6 & 0.05 & 0 & 20.1 & 0.11 & 0.13 & 0.59 & 507 & 0.40 & 204 & 194 & 0.00 & 6.83 & 23.7 & 41.3 & 56.4 & 33.9 & 26.0 & 7.73 & 6.35 & 2.41 & 17.2 & 309 & 2.31 & 7.24 \\
\hline $16-01$ & 13.8 & 53.8 & 0.02 & 0 & 22.0 & 0.11 & 0.16 & 0.56 & 506 & 0.42 & 215 & 198 & 0.00 & 6.48 & 23.2 & 38.1 & 56.3 & 32.6 & 23.5 & 7.81 & 6.41 & 3.76 & 18.3 & 244 & 1.83 & 5.30 \\
\hline $16-01$ & 14 & 54 & 0.05 & 0 & 22.3 & 0.10 & 0.18 & 0.59 & 645 & 0.42 & 208 & 228 & 0.00 & 6.94 & 22.3 & 38.1 & 56.1 & 32.3 & 25.4 & 7.43 & 4.87 & 2.88 & 15.5 & 252 & 1.04 & 3.76 \\
\hline $16-01$ & 14.2 & 54.2 & 0 & 0 & 23.3 & 0.10 & 0.18 & 0.57 & 363 & 0.38 & 194 & 210 & 0.00 & 5.85 & 14.5 & 23.1 & 42.9 & 29.8 & 23.6 & 7.31 & 3.75 & 0.08 & 13.6 & 270 & 1.43 & 3.44 \\
\hline $16-01$ & 14.4 & 54.4 & 0 & 0 & 22.8 & 0.10 & 0.19 & 0.55 & 261 & 0.37 & 190 & 196 & 0.89 & 6.24 & 13.1 & 23.4 & 42.0 & 30.4 & 24.6 & 7.68 & 5.14 & 2.70 & 15.1 & 256 & 1.70 & 2.57 \\
\hline $16-01$ & 14.6 & 54.6 & 0 & 0 & 21.8 & 0.10 & 0.15 & 0.54 & 96.2 & 0.38 & 193 & 191 & 0.99 & 6.55 & 14.4 & 24.8 & 45.0 & 33.3 & 25.9 & 7.66 & 7.20 & 2.21 & 15.1 & 225 & 1.35 & 3.04 \\
\hline $16-01$ & 14.8 & 54.8 & 0.04 & 0 & 18.0 & 0.12 & 0.10 & 0.54 & 601 & 0.39 & 194 & 191 & 1.34 & 7.21 & 13.9 & 24.9 & 46.1 & 36.6 & 26.5 & 7.92 & 8.07 & 5.47 & 19.7 & 240 & 2.11 & 2.83 \\
\hline $16-01$ & 15 & 55 & 0.18 & 0.73 & 12.3 & 0.14 & 0.03 & 0.55 & 275 & 0.37 & 183 & 185 & 0.95 & 6.10 & 12.0 & 29.8 & 41.5 & 32.2 & 24.6 & 8.35 & 7.37 & 3.57 & 17.4 & 244 & 2.16 & 7.40 \\
\hline
\end{tabular}

Zero values are below detection limit 


\begin{tabular}{|c|c|c|c|c|c|c|c|c|c|c|c|c|c|c|c|c|c|c|c|c|c|c|c|c|c|c|}
\hline ఫัँ & 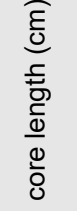 & 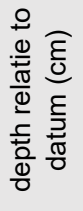 & 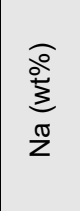 & $\frac{\widehat{o}}{\frac{0}{3}}$ & $\frac{\widehat{o}}{\frac{\partial}{3}}$ & 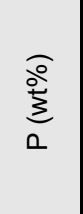 & $\frac{\substack{0 \\
\frac{0}{3}}}{x}$ & 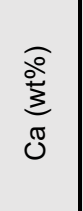 & $\begin{array}{l}\widehat{\hat{\varepsilon}} \\
\text { 을 } \\
\tilde{D} \\
\infty\end{array}$ & $\sum_{i=}^{\stackrel{o}{o}}$ & $\begin{array}{l}\widehat{\hat{\Xi}} \\
\stackrel{0}{\varrho} \\
\bar{U}\end{array}$ & 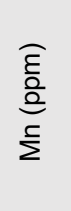 & $\underset{\stackrel{0}{0}}{\stackrel{0}{0}}$ & $\begin{array}{l}\widehat{\hat{\varepsilon}} \\
\text { 응 } \\
\text { ᄋ }\end{array}$ & $\frac{\widehat{\bar{\varepsilon}}}{\frac{0}{0}}$ & $\begin{array}{l}\widehat{\hat{\varepsilon}} \\
\text { 을 } \\
\text { o }\end{array}$ & $\begin{array}{l}\widehat{\varepsilon} \\
\text { 을 } \\
\tilde{N}\end{array}$ & $\begin{array}{l}\widehat{\varepsilon} \\
\stackrel{0}{0} \\
\frac{0}{<}\end{array}$ & $\begin{array}{l}\widehat{\hat{\varepsilon}} \\
\text { 응 } \\
\text { 음 }\end{array}$ & $\begin{array}{l}\widehat{\bar{\varepsilon}} \\
\text { 을 } \\
\infty \\
\infty\end{array}$ & $\begin{array}{l}\widehat{\hat{\varepsilon}} \\
\text { 을 } \\
\text { 음 }\end{array}$ & $\begin{array}{l}\widehat{\bar{\sigma}} \\
\overline{0} \\
\bar{c}\end{array}$ & $\begin{array}{l}\widehat{\hat{\varepsilon}} \\
\hat{0} \\
\succ\end{array}$ & $\begin{array}{l}\widehat{E} \\
\hat{0} \\
\overline{\mathrm{N}}\end{array}$ & $\begin{array}{l}\widehat{\varepsilon} \\
\text { 을 } \\
\text { है }\end{array}$ & $\begin{array}{l}\widehat{\bar{\varepsilon}} \\
\frac{0}{2} \\
\stackrel{\circ}{\Sigma}\end{array}$ \\
\hline $16-01$ & 15.2 & 55.2 & 0.31 & 2.11 & 7.20 & 0.16 & 0 & 0.57 & 616 & 0.36 & 184 & 192 & 0.84 & 6.02 & 12.3 & 38.1 & 47.2 & 31.6 & 23.3 & 7.60 & 6.66 & 2.18 & 15.5 & 242 & 1.72 & 4.92 \\
\hline $16-01$ & 15.4 & 55.4 & 0.28 & 1.76 & 9.01 & 0.16 & 0 & 0.53 & 297 & 0.34 & 174 & 190 & 0.74 & 5.98 & 12.7 & 38.1 & 41.5 & 29.8 & 22.8 & 7.83 & 5.59 & 2.51 & 16.1 & 231 & 2.30 & 6.54 \\
\hline $16-01$ & 15.6 & 55.6 & 0.19 & 0.66 & 13.2 & 0.15 & 0.02 & 0.47 & 0.0 & 0.30 & 149 & 181 & 0.60 & 5.77 & 10.4 & 26.6 & 36.9 & 24.3 & 21.5 & 7.75 & 5.45 & 1.48 & 13.3 & 254 & 1.83 & 5.81 \\
\hline $16-01$ & 15.8 & 55.8 & 0.20 & 0.90 & 12.7 & 0.15 & 0.02 & 0.43 & 271 & 0.30 & 139 & 167 & 0.99 & 5.85 & 9.31 & 24.6 & 35.9 & 22.0 & 18.6 & 7.49 & 5.57 & 0.62 & 11.9 & 251 & 1.36 & 5.11 \\
\hline $16-01$ & 16 & 56 & 0.33 & 2.23 & 7.55 & 0.16 & 0 & 0.43 & 0.0 & 0.28 & 142 & 171 & 0.30 & 4.32 & 7.56 & 30.3 & 36.9 & 21.1 & 20.1 & 7.75 & 5.75 & 0.00 & 9.63 & 241 & 2.07 & 6.02 \\
\hline $16-01$ & 16.2 & 56.2 & 0.50 & 3.70 & 1.89 & 0.17 & 0 & 0.45 & 433 & 0.28 & 149 & 179 & 0.89 & 5.93 & 11.7 & 49.9 & 47.3 & 25.2 & 21.9 & 8.35 & 4.96 & 0.00 & 12.7 & 233 & 1.28 & 9.00 \\
\hline $16-01$ & 16.4 & 56.4 & 0.56 & 4.29 & 0.16 & 0.18 & 0 & 0.46 & 0.0 & 0.27 & 146 & 176 & 0.83 & 5.42 & 9.6 & 88.6 & 48.6 & 22.3 & 17.8 & 10.8 & 4.92 & 0.00 & 14.1 & 190 & 4.07 & 3.55 \\
\hline $16-01$ & 16.6 & 56.6 & 0.60 & 4.63 & 0 & 0.18 & 0 & 0.44 & 1550 & 0.25 & 139 & 182 & 1.04 & 6.19 & 11.9 & 128.0 & 62.3 & 21.6 & 16.9 & 8.63 & 8.35 & 0.00 & 12.7 & 200 & 1.78 & 4.89 \\
\hline $16-01$ & 16.8 & 56.8 & 0.63 & 4.72 & 0 & 0.18 & 0 & 0.43 & 1286 & 0.21 & 126 & 177 & 0.61 & 6.18 & 20.1 & 132.4 & 60.9 & 26.6 & 25.3 & 9.75 & 11.67 & 0.00 & 10.7 & 159 & 5.11 & 8.17 \\
\hline $16-01$ & 17 & 57 & 0.62 & 4.70 & 0 & 0.18 & 0 & 0.42 & 0 & 0.26 & 137 & 172 & 0.74 & 6.52 & 18.7 & 159.4 & 69.4 & 22.0 & 22.4 & 10.2 & 6.24 & 0.00 & 10.3 & 236 & 2.57 & 10.34 \\
\hline $16-01$ & 17.2 & 57.2 & 0.50 & 3.74 & 2.08 & 0.17 & 0 & 0.48 & 1002 & 0.38 & 194 & 203 & 0.00 & 5.32 & 19.6 & 125.0 & 75.5 & 24.5 & 21.6 & 9.97 & 6.64 & 0.00 & 13.3 & 191 & 4.41 & 9.21 \\
\hline $16-01$ & 17.4 & 57.4 & 0.20 & 1.16 & 11.8 & 0.13 & 0 & 0.64 & 0.0 & 0.45 & 226 & 233 & 0.54 & 6.20 & 16.4 & 64.8 & 65.7 & 49.6 & 33.0 & 9.26 & 8.44 & 6.44 & 17.2 & 257 & 2.89 & 4.92 \\
\hline $16-01$ & 17.6 & 57.6 & 0.08 & 0 & 18.1 & 0.13 & 0.06 & 0.59 & 209 & 0.40 & 205 & 215 & 0.91 & 6.58 & 15.1 & 47.5 & 55.9 & 39.1 & 26.9 & 7.91 & 9.72 & 6.07 & 18.3 & 266 & 2.23 & 4.09 \\
\hline $16-01$ & 17.8 & 57.8 & 0 & 0 & 22.4 & 0.11 & 0.12 & 0.56 & 345 & 0.36 & 183 & 192 & 0.57 & 5.48 & 12.1 & 29.2 & 42.2 & 31.3 & 23.9 & 8.68 & 7.49 & 2.27 & 15.3 & 243 & 3.16 & 6.60 \\
\hline $16-01$ & 18 & 58 & 0.04 & 0 & 21.8 & 0.11 & 0.14 & 0.56 & 298 & 0.35 & 178 & 201 & 0.93 & 6.89 & 11.7 & 22.3 & 39.7 & 29.8 & 21.1 & 7.67 & 6.64 & 1.48 & 16.5 & 215 & 1.69 & 4.12 \\
\hline $16-01$ & 18.2 & 58.2 & 0.04 & 0 & 21.0 & 0.10 & 0.17 & 0.59 & 0.0 & 0.33 & 166 & 193 & 0.10 & 5.36 & 11.1 & 19.8 & 35.7 & 29.0 & 22.9 & 7.45 & 5.74 & 4.04 & 13.7 & 203 & 1.32 & 0.00 \\
\hline $16-01$ & 18.4 & 58.4 & 0.06 & 0 & 19.8 & 0.11 & 0.14 & 0.55 & 99.8 & 0.35 & 171 & 190 & 0.00 & 4.91 & 10.6 & 20.1 & 35.6 & 27.8 & 21.1 & 7.78 & 4.68 & 4.36 & 14.0 & 185 & 1.63 & 0.00 \\
\hline $16-01$ & 18.6 & 58.6 & 0.06 & 0 & 19.0 & 0.12 & 0.09 & 0.55 & 322 & 0.41 & 196 & 188 & 0.65 & 5.95 & 9.9 & 21.7 & 35.4 & 28.9 & 23.3 & 7.76 & 5.29 & 2.70 & 13.7 & 204 & 1.89 & 1.12 \\
\hline $16-01$ & 18.8 & 58.8 & 0.07 & 0 & 18.5 & 0.13 & 0.09 & 0.53 & 650 & 0.40 & 193 & 183 & 1.03 & 6.21 & 10.7 & 24.5 & 38.1 & 28.6 & 23.3 & 7.45 & 4.63 & 0.81 & 15.6 & 223 & 1.98 & 0.78 \\
\hline $16-01$ & 19 & 59 & 0.07 & 0 & 19.3 & 0.12 & 0.09 & 0.51 & 0.0 & 0.35 & 173 & 183 & 0.43 & 5.32 & 11.7 & 20.0 & 40.2 & 25.3 & 19.9 & 7.55 & 6.30 & 0.00 & 32.8 & 219 & 2.69 & 3.42 \\
\hline $16-01$ & 19.2 & 59.2 & 0.05 & 0 & 19.5 & 0.12 & 0.11 & 0.53 & 0.0 & 0.40 & 200 & 209 & 0.71 & 7.25 & 14.8 & 30.1 & 49.4 & 36.5 & 25.5 & 8.24 & 8.65 & 0.70 & 75.5 & 190 & 5.85 & 1.40 \\
\hline $16-01$ & 19.4 & 59.4 & 0.04 & 0 & 18.9 & 0.12 & 0.13 & 0.56 & 115.6 & 0.44 & 227 & 222 & 0.52 & 8.09 & 20.5 & 36.3 & 63.6 & 47.7 & 31.2 & 8.09 & 13.5 & 0.00 & 111 & 181 & 6.02 & 0.70 \\
\hline $16-01$ & 19.6 & 59.6 & 0.05 & 0 & 18.1 & 0.12 & 0.13 & 0.61 & 221 & 0.48 & 248 & 238 & 0.68 & 8.96 & 24.0 & 45.6 & 79.2 & 54.8 & 35.6 & 8.05 & 17.1 & 1.84 & 122 & 167 & 8.11 & 0.17 \\
\hline $16-01$ & 19.8 & 59.8 & 0.05 & 0 & 18.3 & 0.12 & 0.13 & 0.57 & 0.0 & 0.45 & 228 & 238 & 1.12 & 9.18 & 21.0 & 39.7 & 73.3 & 55.2 & 34.6 & 8.54 & 15.4 & 3.26 & 99.8 & 161 & 6.13 & 2.30 \\
\hline $16-01$ & 20 & 60 & 0.07 & 0 & 18.7 & 0.13 & 0.11 & 0.55 & 0.0 & 0.43 & 221 & 222 & 1.04 & 8.90 & 22.1 & 36.6 & 68.5 & 48.4 & 33.7 & 8.34 & 14.9 & 2.78 & 73.3 & 175 & 5.08 & 3.39 \\
\hline $16-01$ & 20.2 & 60.2 & 0.13 & 0.18 & 16.8 & 0.14 & 0.07 & 0.50 & 172 & 0.39 & 198 & 209 & 1.10 & 8.15 & 16.9 & 38.1 & 60.2 & 44.0 & 30.2 & 8.71 & 12.7 & 4.25 & 58.7 & 180 & 4.67 & 1.95 \\
\hline $16-01$ & 20.4 & 60.4 & 0.24 & 1.24 & 12.8 & 0.16 & 0.00 & 0.49 & 0.0 & 0.35 & 175 & 195 & 1.09 & 7.33 & 12.7 & 50.6 & 57.0 & 37.0 & 26.0 & 8.25 & 11.7 & 3.14 & 44.5 & 181 & 4.41 & 5.55 \\
\hline $16-01$ & 20.6 & 60.6 & 0.50 & 3.76 & 3.68 & 0.19 & 0 & 0.43 & 46.7 & 0.28 & 144 & 183 & 0.73 & 6.55 & 13.5 & 66.1 & 49.3 & 27.8 & 24.0 & 9.45 & 7.67 & 0.00 & 29.1 & 191 & 2.90 & 3.41 \\
\hline $16-01$ & 20.8 & 60.8 & 0.64 & 4.97 & 0 & 0.20 & 0 & 0.38 & 1452 & 0.17 & 105 & 155 & 0.04 & 3.71 & 11.1 & 188 & 57.2 & 14.9 & 14.7 & 10.3 & 4.72 & 0.00 & 2.64 & 108 & 0.92 & 7.64 \\
\hline $16-01$ & 21 & 61 & 0.66 & 5.08 & 0 & 0.19 & 0 & 0.36 & 301.0 & 0.11 & 89 & 159 & 0.29 & 5.83 & 34.3 & 455 & 141.0 & 27.2 & 22.4 & 10.5 & 4.60 & 0.00 & 2.96 & 110 & 2.10 & 0.01 \\
\hline $16-02$ & 0 & 49 & 0.24 & 1.40 & 9.8 & 0.12 & 0.04 & 0.56 & 66.0 & 0.42 & 212 & 206 & 1.44 & 7.73 & 15.9 & 40.1 & 54.4 & 41.3 & 28.0 & 9.19 & 11.6 & 5.81 & 18.3 & 190 & 2.20 & 5.66 \\
\hline $16-02$ & 0.2 & 49.2 & 0.22 & 1.24 & 10.0 & 0.12 & 0.05 & 0.54 & 213 & 0.43 & 215 & 201 & 0.55 & 5.94 & 15.6 & 35.6 & 55.4 & 43.6 & 31.8 & 9.01 & 11.2 & 9.27 & 19.1 & 189 & 2.92 & 3.92 \\
\hline $16-02$ & 0.4 & 49.4 & 0.21 & 1.03 & 10.6 & 0.12 & 0.05 & 0.54 & 139 & 0.42 & 214 & 203 & 0.97 & 6.87 & 16.0 & 35.7 & 57.3 & 43.3 & 31.2 & 8.49 & 12.2 & 7.97 & 18.0 & 187 & 3.63 & 3.77 \\
\hline $16-02$ & 0.6 & 49.6 & 0.19 & 0.80 & 11.1 & 0.13 & 0.05 & 0.54 & 195 & 0.43 & 217 & 205 & 1.29 & 7.31 & 14.3 & 34.7 & 56.8 & 41.1 & 27.2 & 8.34 & 13.5 & 3.64 & 20.2 & 217 & 2.82 & 5.62 \\
\hline $16-02$ & 0.8 & 49.8 & 0.19 & 0.92 & 11.0 & 0.12 & 0.06 & 0.54 & 403 & 0.45 & 227 & 204 & 0.74 & 6.31 & 15.3 & 36.3 & 50.0 & 42.9 & 28.8 & 8.09 & 10.1 & 7.02 & 17.7 & 249 & 2.68 & 8.23 \\
\hline $16-02$ & 1 & 50 & 0.19 & 0.85 & 11.2 & 0.12 & 0.06 & 0.55 & 0 & 0.44 & 224 & 202 & 1.19 & 7.31 & 16.5 & 35.8 & 54.0 & 39.9 & 26.1 & 8.62 & 9.89 & 4.71 & 16.0 & 242 & 3.00 & 3.87 \\
\hline $16-02$ & 1.2 & 50.2 & 0.19 & 0.96 & 10.9 & 0.12 & 0.05 & 0.57 & 102 & 0.45 & 229 & 199 & 1.27 & 6.93 & 12.8 & 37.7 & 56.2 & 41.3 & 27.7 & 8.73 & 8.90 & 5.99 & 16.6 & 231 & 2.79 & 6.68 \\
\hline $16-02$ & 1.4 & 50.4 & 0.21 & 1.02 & 10.3 & 0.13 & 0.03 & 0.61 & 0 & 0.46 & 232 & 200 & 0.94 & 6.56 & 14.9 & 35.0 & 54.9 & 44.0 & 31.3 & 7.90 & 9.96 & 7.18 & 17.5 & 233 & 2.49 & 3.43 \\
\hline
\end{tabular}

Zero values are below detection limit 


\begin{tabular}{|c|c|c|c|c|c|c|c|c|c|c|c|c|c|c|c|c|c|c|c|c|c|c|c|c|c|c|}
\hline ஹัँ & 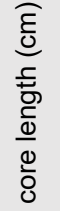 & 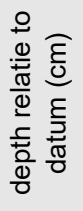 & $\frac{\widehat{o}}{\stackrel{0}{0}}$ & $\frac{\widehat{o}}{\stackrel{\frac{\rho}{3}}{\frac{\pi}{z}}}$ & $\frac{\widehat{o}}{\frac{0}{3}}$ & $\frac{\widehat{o}}{\stackrel{0}{3}}$ & 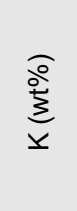 & $\frac{\widehat{o}}{\stackrel{0}{o}}$ & 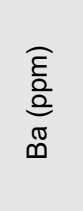 & 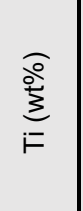 & $\begin{array}{l}\widehat{\hat{\Xi}} \\
\stackrel{0}{2} \\
\bar{u}\end{array}$ & 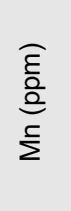 & $\underset{\stackrel{Ð}{\varrho}}{\stackrel{Ð}{\llcorner}}$ & $\begin{array}{l}\widehat{\hat{g}} \\
\text { 응 } \\
\text { ᄋ }\end{array}$ & $\frac{\widehat{\bar{\varepsilon}}}{\frac{\hat{a}}{\bar{z}}}$ & 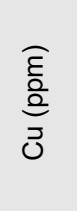 & 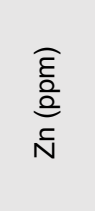 & $\begin{array}{l}\widehat{\hat{\varepsilon}} \\
\frac{0}{0} \\
\frac{0}{<}\end{array}$ & $\begin{array}{l}\widehat{\hat{\varepsilon}} \\
\text { 응 } \\
\widehat{0} 0\end{array}$ & 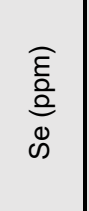 & $\begin{array}{l}\widehat{\hat{\varepsilon}} \\
\text { 을 } \\
\text { oิ }\end{array}$ & $\begin{array}{l}\widehat{\hat{\varepsilon}} \\
\frac{\text { 을 }}{\bar{\omega}}\end{array}$ & $\begin{array}{l}\widehat{\hat{\varepsilon}} \\
\stackrel{0}{0} \\
\succ\end{array}$ & $\begin{array}{l}\widehat{\hat{\varepsilon}} \\
\text { 을 } \\
\hat{N}\end{array}$ & $\begin{array}{l}\widehat{\hat{\varepsilon}} \\
\hat{0} \\
\frac{0}{z}\end{array}$ & $\begin{array}{l}\widehat{\varepsilon} \\
\text { 을 } \\
\text { 일 }\end{array}$ \\
\hline $16-02$ & 1.6 & 50.6 & 0.19 & 0.81 & 11.4 & 0.12 & 0.05 & 0.60 & 296 & 0.43 & 219 & 204 & 1.04 & 6.81 & 14.8 & 30.2 & 57.4 & 41.9 & 31.1 & 8.64 & 12.2 & 5.12 & 17.2 & 233 & 2.61 & 6.13 \\
\hline $16-02$ & 1.8 & 50.8 & 0.18 & 0.96 & 11.5 & 0.12 & 0.05 & 0.56 & 577 & 0.43 & 220 & 201 & 1.15 & 7.11 & 15.8 & 34.7 & 55.0 & 40.8 & 30.0 & 8.60 & 10.9 & 6.48 & 18.9 & 234 & 3.25 & 6.40 \\
\hline $16-02$ & 2 & 51 & 0.14 & 0.21 & 13.4 & 0.12 & 0.08 & 0.60 & 80.7 & 0.43 & 218 & 205 & 1.16 & 7.07 & 14.9 & 33.3 & 57.4 & 45.9 & 32.9 & 8.44 & 11.8 & 8.78 & 19.9 & 233 & 2.68 & 6.91 \\
\hline $16-02$ & 2.2 & 51.2 & 0.13 & 0.44 & 13.4 & 0.12 & 0.08 & 0.59 & 232 & 0.44 & 227 & 213 & 0.89 & 6.96 & 16.8 & 32.5 & 53.3 & 43.1 & 28.1 & 8.49 & 11.9 & 9.00 & 20.5 & 222 & 2.83 & 3.87 \\
\hline $16-02$ & 2.4 & 51.4 & 0.15 & 0.30 & 12.9 & 0.13 & 0.08 & 0.59 & 502 & 0.43 & 223 & 214 & 0.72 & 6.61 & 15.7 & 32.3 & 56.4 & 45.4 & 30.4 & 8.23 & 13.1 & 8.52 & 20.3 & 202 & 3.02 & 5.53 \\
\hline $16-02$ & 2.6 & 51.6 & 0.14 & 0.37 & 13.6 & 0.12 & 0.08 & 0.60 & 198 & 0.43 & 216 & 207 & 1.03 & 6.99 & 14.0 & 32.9 & 55.4 & 43.9 & 31.5 & 9.18 & 13.4 & 8.99 & 17.9 & 210 & 2.48 & 0.62 \\
\hline $16-02$ & 2.8 & 51.8 & 0.23 & 1.24 & 9.96 & 0.14 & 0.03 & 0.59 & 257 & 0.41 & 207 & 204 & 0.67 & 6.02 & 12.9 & 41.0 & 53.2 & 39.0 & 30.0 & 8.45 & 11.6 & 7.11 & 20.2 & 186 & 1.83 & 1.58 \\
\hline $16-02$ & 3 & 52 & 0.37 & 2.56 & 5.51 & 0.16 & 0 & 0.61 & 42.0 & 0.40 & 203 & 199 & 1.35 & 7.34 & 14.2 & 53.4 & 60.1 & 40.5 & 27.9 & 8.79 & 8.72 & 5.84 & 19.0 & 171 & 2.37 & 2.70 \\
\hline $16-02$ & 3.2 & 52.2 & 0.55 & 4.22 & 0.10 & 0.18 & 0 & 0.56 & 604 & 0.35 & 181 & 193 & 0.77 & 6.43 & 17.3 & 111 & 59.2 & 35.1 & 24.9 & 9.05 & 7.75 & 1.28 & 12.2 & 141 & 1.57 & 1.68 \\
\hline $16-02$ & 3.4 & 52.4 & 0.63 & 4.96 & 0 & 0.19 & 0 & 0.43 & 681 & 0.26 & 136 & 196 & 1.06 & 7.10 & 19.6 & 282 & 106.1 & 40.5 & 28.8 & 11.11 & 7.44 & 0 & 4.93 & 120 & 2.16 & 7.89 \\
\hline $16-02$ & 3.6 & 52.6 & 0.66 & 5.01 & 0 & 0.19 & 0 & 0.43 & 566 & 0.24 & 116 & 183 & 0.61 & 7.11 & 37.7 & 428 & 130.9 & 36.1 & 29.8 & 12.66 & 9.71 & 0 & 11.7 & 94 & 3.05 & 11.9 \\
\hline $16-02$ & 3.8 & 52.8 & 0.64 & 5.01 & 0 & 0.19 & 0 & 0.43 & 2121 & 0.21 & 108 & 177 & 0.69 & 6.58 & 31.6 & 389 & 152.8 & 33.1 & 22.9 & 10.99 & 6.43 & 0 & 8.49 & 103 & 2.25 & 8.19 \\
\hline $16-02$ & 4 & 53 & 0.63 & 4.83 & 0 & 0.18 & 0 & 0.50 & 949 & 0.25 & 135 & 179 & 1.35 & 7.97 & 27.9 & 324 & 144.6 & 36.6 & 30.6 & 12.98 & 16.2 & 0 & 0.00 & 98 & 4.28 & 8.25 \\
\hline $16-02$ & 4.2 & 53.2 & 0.55 & 4.33 & 0 & 0.18 & 0 & 0.48 & 0.0 & 0.30 & 158 & 188 & 1.76 & 7.68 & 14.1 & 147 & 71.1 & 28.8 & 19.6 & 7.52 & 7.41 & 0 & 12.5 & 162 & 0.07 & 5.84 \\
\hline $16-02$ & 4.4 & 53.4 & 0.44 & 3.26 & 2.95 & 0.16 & 0 & 0.51 & 115 & 0.33 & 172 & 188 & 1.13 & 6.81 & 17.0 & 72.2 & 50.4 & 28.3 & 23.6 & 9.09 & 7.21 & 0 & 13.0 & 187 & 1.39 & 3.99 \\
\hline $16-02$ & 4.6 & 53.6 & 0.26 & 1.64 & 8.27 & 0.14 & 0 & 0.58 & 436 & 0.38 & 193 & 207 & 0.86 & 6.72 & 17.9 & 48.1 & 49.0 & 39.3 & 29.2 & 8.45 & 8.87 & 4.72 & 17.0 & 189 & 2.34 & 7.91 \\
\hline $16-02$ & 4.8 & 53.8 & 0.16 & 0.71 & 12.5 & 0.12 & 0.05 & 0.56 & 127 & 0.37 & 190 & 194 & 1.15 & 6.39 & 11.8 & 30.6 & 42.4 & 39.7 & 28.5 & 7.91 & 5.81 & 4.79 & 17.2 & 190 & 2.03 & 3.06 \\
\hline $16-02$ & 5 & 54 & 0.09 & 0 & 15.8 & 0.12 & 0.09 & 0.57 & 549 & 0.40 & 204 & 196 & 1.50 & 7.40 & 13.4 & 30.4 & 45.3 & 42.8 & 29.7 & 8.08 & 9.98 & 4.13 & 20.0 & 227 & 1.63 & 3.65 \\
\hline $16-02$ & 5.2 & 54.2 & 0.09 & 0 & 15.1 & 0.13 & 0.07 & 0.60 & 10.3 & 0.42 & 214 & 200 & 1.58 & 7.74 & 14.9 & 27.5 & 50.8 & 43.3 & 29.6 & 8.21 & 10.4 & 5.43 & 21.1 & 239 & 1.87 & 4.05 \\
\hline $16-02$ & 5.4 & 54.4 & 0.07 & 0 & 16.6 & 0.12 & 0.10 & 0.61 & 0 & 0.44 & 226 & 211 & 1.28 & 7.71 & 17.2 & 27.0 & 51.8 & 44.3 & 30.7 & 8.34 & 10.6 & 9.16 & 20.9 & 221 & 2.64 & 3.29 \\
\hline $16-02$ & 5.6 & 54.6 & 0.05 & 0 & 17.5 & 0.11 & 0.13 & 0.63 & 0 & 0.43 & 219 & 217 & 1.11 & 7.39 & 15.4 & 31.9 & 54.3 & 44.6 & 32.2 & 8.23 & 10.8 & 7.76 & 20.4 & 204 & 2.09 & 0.52 \\
\hline $16-02$ & 5.8 & 54.8 & 0.05 & 0 & 17.5 & 0.11 & 0.13 & 0.63 & 157 & 0.43 & 217 & 214 & 0.94 & 7.27 & 16.9 & 26.8 & 51.0 & 46.4 & 30.1 & 8.10 & 12.7 & 9.39 & 19.7 & 191 & 3.16 & 1.72 \\
\hline $16-02$ & 6 & 55 & 0.06 & 0 & 17.1 & 0.11 & 0.11 & 0.63 & 294 & 0.41 & 210 & 209 & 1.14 & 7.39 & 15.3 & 28.8 & 50.3 & 45.9 & 32.7 & 8.47 & 11.4 & 6.95 & 21.9 & 228 & 2.58 & 4.19 \\
\hline $16-02$ & 6.2 & 55.2 & 0.08 & 0 & 16.5 & 0.11 & 0.11 & 0.61 & 0.0 & 0.42 & 210 & 199 & 1.09 & 7.02 & 16.2 & 26.4 & 48.9 & 43.5 & 30.4 & 8.17 & 10.8 & 8.58 & 21.3 & 259 & 2.56 & 3.94 \\
\hline $16-02$ & 6.4 & 55.4 & 0.07 & 0 & 16.4 & 0.12 & 0.11 & 0.60 & 171 & 0.41 & 210 & 201 & 1.21 & 6.93 & 13.8 & 25.5 & 45.3 & 44.4 & 30.5 & 8.10 & 9.75 & 7.59 & 20.6 & 329 & 2.34 & 8.26 \\
\hline $16-02$ & 6.6 & 55.6 & 0.06 & 0 & 17.2 & 0.12 & 0.11 & 0.58 & 0.0 & 0.43 & 217 & 201 & 0.93 & 6.42 & 15.1 & 29.0 & 50.7 & 42.9 & 29.3 & 8.55 & 9.28 & 4.37 & 20.5 & 330 & 1.44 & 8.97 \\
\hline $16-02$ & 6.8 & 55.8 & 0.05 & 0 & 18.1 & 0.12 & 0.11 & 0.63 & 0.0 & 0.43 & 219 & 203 & 1.09 & 6.66 & 14.9 & 29.3 & 49.4 & 41.9 & 29.8 & 8.19 & 8.75 & 7.85 & 18.4 & 286 & 3.01 & 5.28 \\
\hline $16-02$ & 7 & 56 & 0.06 & 0 & 17.0 & 0.12 & 0.09 & 0.63 & 326 & 0.44 & 227 & 207 & 1.66 & 8.01 & 15.3 & 28.1 & 50.2 & 49.9 & 34.2 & 8.34 & 10.3 & 7.20 & 19.7 & 250 & 2.45 & 3.65 \\
\hline $16-02$ & 7.2 & 56.2 & 0.06 & 0 & 16.7 & 0.12 & 0.10 & 0.64 & 11.1 & 0.44 & 225 & 215 & 1.56 & 7.95 & 15.5 & 33.4 & 55.6 & 52.0 & 32.8 & 8.16 & 10.9 & 8.22 & 25.4 & 214 & 2.42 & 1.05 \\
\hline $16-02$ & 7.4 & 56.4 & 0.06 & 0 & 16.7 & 0.12 & 0.09 & 0.68 & 360 & 0.44 & 229 & 214 & 1.64 & 8.54 & 19.0 & 33.2 & 55.3 & 51.5 & 34.3 & 7.77 & 11.7 & 11.1 & 25.3 & 192 & 1.92 & 2.45 \\
\hline $16-02$ & 7.6 & 56.6 & 0.05 & 0 & 17.6 & 0.12 & 0.09 & 0.70 & 241 & 0.43 & 223 & 207 & 1.29 & 7.55 & 17.8 & 31.3 & 53.2 & 53.6 & 33.4 & 8.64 & 9.95 & 8.69 & 24.8 & 178 & 2.64 & 0.17 \\
\hline $16-02$ & 7.8 & 56.8 & 0.08 & 0 & 16.2 & 0.12 & 0.10 & 0.70 & 0 & 0.43 & 219 & 201 & 1.86 & 8.47 & 17.0 & 29.7 & 50.8 & 46.8 & 32.9 & 7.85 & 10.0 & 9.38 & 23.0 & 184 & 3.11 & 2.16 \\
\hline $16-02$ & 8 & 57 & 0.04 & 0 & 17.7 & 0.11 & 0.11 & 0.67 & 0.0 & 0.43 & 218 & 198 & 1.34 & 6.92 & 13.4 & 24.7 & 47.0 & 50.9 & 32.2 & 8.18 & 9.35 & 6.76 & 22.4 & 206 & 2.66 & 2.12 \\
\hline $16-02$ & 8.2 & 57.2 & 0.07 & 0 & 16.2 & 0.12 & 0.10 & 0.64 & 71.3 & 0.44 & 225 & 205 & 1.62 & 7.92 & 16.4 & 32.7 & 50.5 & 53.4 & 33.2 & 8.34 & 11.8 & 7.89 & 23.7 & 214 & 2.01 & 0.97 \\
\hline $16-02$ & 8.4 & 57.4 & 0.06 & 0 & 16.6 & 0.12 & 0.10 & 0.61 & 604 & 0.45 & 230 & 211 & 1.67 & 8.24 & 17.3 & 28.9 & 55.1 & 54.2 & 33.6 & 8.35 & 11.0 & 9.57 & 23.8 & 216 & 2.66 & 3.31 \\
\hline $16-02$ & 8.6 & 57.6 & 0.07 & 0 & 16.1 & 0.12 & 0.09 & 0.59 & 289 & 0.45 & 234 & 215 & 1.49 & 7.85 & 16.2 & 31.6 & 53.9 & 55.9 & 34.7 & 8.54 & 11.8 & 11.6 & 26.3 & 207 & 2.35 & 2.79 \\
\hline $16-02$ & 8.8 & 57.8 & 0.07 & 0 & 16.5 & 0.12 & 0.09 & 0.58 & 54.2 & 0.44 & 226 & 211 & 2.02 & 9.07 & 17.6 & 28.5 & 50.3 & 52.8 & 34.3 & 7.90 & 9.79 & 10.1 & 23.1 & 191 & 2.99 & 0.77 \\
\hline $16-02$ & 9 & 58 & 0.07 & 0 & 16.6 & 0.12 & 0.09 & 0.61 & 742 & 0.42 & 216 & 208 & 1.42 & 7.75 & 16.3 & 29.3 & 52.1 & 50.4 & 32.2 & 8.29 & 10.3 & 11.3 & 22.7 & 193 & 2.91 & 0.58 \\
\hline
\end{tabular}

Zero values are below detection limit 


\begin{tabular}{|c|c|c|c|c|c|c|c|c|c|c|c|c|c|c|c|c|c|c|c|c|c|c|c|c|c|c|}
\hline ఫัँ & 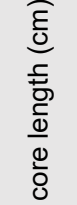 & 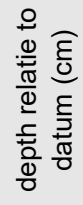 & $\frac{\widehat{0}}{\frac{0}{0}}$ & $\frac{\widehat{o}}{\frac{0}{3}}$ & $\frac{\widehat{o}}{\frac{\partial}{3}}$ & 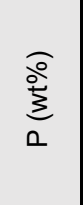 & $\frac{\widehat{o}}{\stackrel{0}{a}}$ & 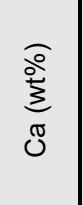 & 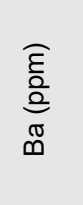 & $\sum_{i=}^{\stackrel{o}{o}}$ & $\begin{array}{l}\widehat{\hat{\Xi}} \\
\stackrel{0}{\varrho} \\
\bar{U}\end{array}$ & 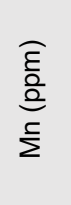 & $\underset{\stackrel{0}{0}}{\stackrel{0}{0}}$ & $\begin{array}{l}\widehat{\hat{\varepsilon}} \\
\text { 응 } \\
\text { ᄋ }\end{array}$ & $\frac{\widehat{\bar{\varepsilon}}}{\frac{0}{0}}$ & $\begin{array}{l}\widehat{\hat{\varepsilon}} \\
\stackrel{0}{0} \\
\vec{\jmath}\end{array}$ & $\begin{array}{l}\widehat{\varepsilon} \\
\frac{0}{0} \\
\bar{N}\end{array}$ & $\begin{array}{l}\widehat{\varepsilon} \\
\frac{0}{0} \\
\frac{0}{<}\end{array}$ & $\begin{array}{l}\widehat{\varepsilon} \\
\text { 을 } \\
\text { 음 }\end{array}$ & $\begin{array}{l}\widehat{\bar{\varepsilon}} \\
\text { 을 } \\
\infty \\
\infty\end{array}$ & $\begin{array}{l}\widehat{\varepsilon} \\
\hat{0} \\
\text { 음 }\end{array}$ & $\begin{array}{l}\widehat{\bar{\sigma}} \\
\overline{0} \\
\bar{c}\end{array}$ & $\begin{array}{l}\widehat{\hat{\varepsilon}} \\
\hat{0} \\
\succ\end{array}$ & $\begin{array}{l}\widehat{E} \\
\hat{0} \\
\overline{\mathrm{N}}\end{array}$ & $\begin{array}{l}\widehat{\varepsilon} \\
\text { 을 } \\
\text { है }\end{array}$ & $\begin{array}{l}\widehat{\varepsilon} \\
\hat{\frac{0}{0}} \\
\stackrel{\circ}{\Sigma}\end{array}$ \\
\hline $16-02$ & 9.2 & 58.2 & 0.06 & 0 & 17.0 & 0.13 & 0.09 & 0.63 & 0 & 0.44 & 225 & 208 & 1.28 & 7.45 & 16.1 & 33.7 & 54.2 & 55.1 & 36.2 & 8.62 & 10.3 & 10.1 & 23.1 & 213 & 3.10 & 0.50 \\
\hline $16-02$ & 9.4 & 58.4 & 0.07 & 0 & 15.9 & 0.13 & 0.07 & 0.64 & 0 & 0.47 & 241 & 215 & 1.58 & 8.41 & 18.0 & 38.0 & 58.9 & 62.4 & 39.4 & 8.10 & 11.5 & 7.86 & 27.6 & 224 & 3.60 & 3.81 \\
\hline $16-02$ & 9.6 & 58.6 & 0.07 & 0 & 15.6 & 0.13 & 0.06 & 0.66 & 32.4 & 0.47 & 246 & 226 & 1.06 & 7.42 & 17.4 & 42.1 & 60.2 & 59.7 & 37.7 & 8.17 & 11.2 & 9.59 & 26.7 & 255 & 3.41 & 5.38 \\
\hline $16-02$ & 9.8 & 58.8 & 0.08 & 0 & 15.2 & 0.12 & 0.06 & 0.62 & 67.4 & 0.44 & 228 & 218 & 1.07 & 7.50 & 18.4 & 43.3 & 60.6 & 53.8 & 34.7 & 8.12 & 10.6 & 9.87 & 24.2 & 223 & 2.77 & 3.44 \\
\hline $16-02$ & 10 & 59 & 0.07 & 0 & 16.0 & 0.12 & 0.07 & 0.61 & 229 & 0.43 & 218 & 219 & 0.73 & 6.63 & 15.2 & 37.7 & 57.5 & 51.7 & 33.2 & 8.29 & 12.0 & 10.3 & 21.3 & 228 & 3.09 & 2.82 \\
\hline $16-02$ & 10.2 & 59.2 & 0.06 & 0 & 16.4 & 0.12 & 0.09 & 0.59 & 98.8 & 0.41 & 208 & 210 & 0.82 & 6.69 & 14.7 & 28.8 & 51.9 & 49.5 & 32.8 & 8.11 & 10.3 & 6.86 & 23.4 & 250 & 2.78 & 4.36 \\
\hline $16-02$ & 10.4 & 59.4 & 0.06 & 0 & 16.6 & 0.13 & 0.09 & 0.61 & 79.3 & 0.42 & 213 & 209 & 0.73 & 6.59 & 15.9 & 32.6 & 50.9 & 46.8 & 31.6 & 8.01 & 9.96 & 7.32 & 21.5 & 266 & 1.96 & 5.22 \\
\hline $16-02$ & 10.6 & 59.6 & 0.07 & 0 & 16.4 & 0.13 & 0.09 & 0.61 & 336 & 0.41 & 211 & 208 & 1.31 & 7.81 & 17.0 & 27.4 & 49.8 & 47.0 & 31.5 & 8.44 & 10.8 & 6.71 & 21.8 & 243 & 2.44 & 3.52 \\
\hline $16-02$ & 10.8 & 59.8 & 0.07 & 0 & 16.5 & 0.13 & 0.08 & 0.59 & 244 & 0.40 & 202 & 205 & 1.35 & 7.53 & 14.9 & 26.4 & 50.2 & 46.7 & 31.1 & 8.37 & 9.17 & 5.77 & 21.1 & 217 & 1.56 & 3.07 \\
\hline $16-02$ & 11 & 60 & 0.06 & 0 & 16.8 & 0.13 & 0.09 & 0.56 & 0.0 & 0.39 & 199 & 201 & 1.34 & 7.14 & 13.5 & 25.1 & 44.8 & 39.4 & 26.7 & 8.05 & 9.49 & 6.97 & 21.1 & 192 & 1.71 & 1.83 \\
\hline $16-02$ & 11.2 & 60.2 & 0.07 & 0 & 16.6 & 0.13 & 0.09 & 0.56 & 776 & 0.39 & 195 & 192 & 1.21 & 6.94 & 14.7 & 28.4 & 48.7 & 40.4 & 28.5 & 8.08 & 9.33 & 6.26 & 18.6 & 192 & 2.51 & 1.48 \\
\hline $16-02$ & 11.4 & 60.4 & 0.08 & 0 & 16.1 & 0.13 & 0.08 & 0.56 & 286 & 0.40 & 201 & 195 & 1.17 & 6.98 & 15.4 & 25.1 & 48.9 & 39.2 & 27.1 & 7.84 & 8.13 & 7.61 & 17.0 & 224 & 2.27 & 3.75 \\
\hline $16-02$ & 11.6 & 60.6 & 0.06 & 0 & 16.7 & 0.13 & 0.08 & 0.59 & 332 & 0.40 & 203 & 196 & 1.29 & 6.71 & 11.5 & 27.0 & 46.1 & 39.5 & 27.4 & 8.36 & 8.48 & 3.93 & 15.4 & 230 & 3.46 & 3.08 \\
\hline $16-02$ & 11.8 & 60.8 & 0.08 & 0 & 16.5 & 0.13 & 0.08 & 0.62 & 0.0 & 0.43 & 214 & 190 & 1.49 & 7.18 & 12.7 & 27.0 & 44.9 & 39.8 & 28.4 & 8.26 & 8.55 & 5.54 & 16.4 & 279 & 3.00 & 6.22 \\
\hline $16-02$ & 12 & 61 & 0.09 & 0 & 15.3 & 0.13 & 0.07 & 0.62 & 482 & 0.44 & 222 & 192 & 1.15 & 6.49 & 12.6 & 28.0 & 43.9 & 42.8 & 27.4 & 8.08 & 10.3 & 7.28 & 16.7 & 267 & 2.65 & 5.27 \\
\hline $16-02$ & 12.2 & 61.2 & 0.07 & 0 & 16.3 & 0.13 & 0.08 & 0.60 & 211 & 0.44 & 224 & 200 & 1.63 & 7.70 & 14.3 & 26.6 & 47.3 & 46.9 & 32.0 & 8.20 & 9.21 & 7.92 & 18.3 & 227 & 3.18 & 0.82 \\
\hline $16-02$ & 12.4 & 61.4 & 0.08 & 0 & 16.0 & 0.12 & 0.08 & 0.59 & 81.6 & 0.43 & 217 & 205 & 1.76 & 8.26 & 15.4 & 28.7 & 50.1 & 49.5 & 32.2 & 8.00 & 8.56 & 7.04 & 22.5 & 183 & 1.92 & 0.41 \\
\hline $16-02$ & 12.6 & 61.6 & 0.07 & 0.03 & 15.7 & 0.13 & 0.08 & 0.57 & 508 & 0.45 & 233 & 216 & 1.86 & 8.73 & 16.4 & 32.7 & 56.0 & 55.8 & 35.7 & 8.03 & 10.4 & 12.0 & 26.3 & 165 & 3.30 & 0.51 \\
\hline $16-02$ & 12.8 & 61.8 & 0.07 & 0 & 15.7 & 0.13 & 0.07 & 0.59 & 493 & 0.46 & 239 & 224 & 1.85 & 9.40 & 19.9 & 36.5 & 56.6 & 60.2 & 35.5 & 8.49 & 13.4 & 10.4 & 28.4 & 182 & 2.93 & 0.94 \\
\hline $16-02$ & 13 & 62 & 0.09 & 0 & 14.9 & 0.13 & 0.07 & 0.61 & 492 & 0.46 & 239 & 224 & 1.77 & 8.88 & 17.1 & 35.6 & 58.2 & 65.3 & 40.7 & 8.66 & 12.8 & 10.5 & 29.5 & 200 & 3.16 & 2.42 \\
\hline $16-02$ & 13.2 & 62.2 & 0.09 & 0 & 15.1 & 0.13 & 0.06 & 0.61 & 15.5 & 0.46 & 237 & 218 & 1.93 & 8.99 & 16.3 & 33.1 & 55.9 & 63.0 & 37.0 & 8.26 & 14.2 & 9.62 & 28.8 & 201 & 3.01 & 2.62 \\
\hline $16-02$ & 13.4 & 62.4 & 0.11 & 0.08 & 14.3 & 0.13 & 0.06 & 0.60 & 17.3 & 0.44 & 229 & 216 & 1.32 & 8.04 & 18.9 & 35.9 & 54.4 & 58.4 & 36.4 & 8.37 & 11.7 & 9.56 & 27.5 & 221 & 2.48 & 2.12 \\
\hline $16-02$ & 13.6 & 62.6 & 0.11 & 0 & 14.2 & 0.13 & 0.06 & 0.61 & 0.0 & 0.44 & 225 & 216 & 1.20 & 7.66 & 17.8 & 37.3 & 55.6 & 59.4 & 35.6 & 9.07 & 11.7 & 11.3 & 25.2 & 215 & 2.89 & 2.63 \\
\hline $16-02$ & 13.8 & 62.8 & 0.19 & 0.95 & 10.9 & 0.14 & 0.03 & 0.60 & 142 & 0.44 & 225 & 214 & 1.33 & 7.94 & 17.4 & 42.9 & 61.0 & 56.0 & 35.6 & 8.82 & 11.6 & 10.4 & 24.9 & 210 & 3.82 & 3.86 \\
\hline $16-02$ & 14 & 63 & 0.27 & 1.70 & 7.97 & 0.15 & 0 & 0.60 & 940 & 0.43 & 222 & 217 & 1.37 & 7.92 & 17.1 & 51.0 & 57.3 & 54.8 & 34.6 & 8.84 & 12.5 & 9.15 & 25.4 & 203 & 3.79 & 4.27 \\
\hline $16-02$ & 14.2 & 63.2 & 0.34 & 2.36 & 5.73 & 0.15 & 0 & 0.59 & 915 & 0.41 & 213 & 223 & 0.85 & 7.00 & 14.6 & 54.6 & 59.3 & 43.6 & $3 E+12$ & 9.14 & 9.18 & 6.82 & 21.0 & 178 & 2.99 & 2.16 \\
\hline $16-02$ & 14.4 & 63.4 & 0.24 & 1.47 & 8.73 & 0.15 & 0.01 & 0.57 & 0.0 & 0.42 & 211 & 209 & 1.23 & 7.62 & 15.0 & 40.8 & 56.2 & 46.9 & 29.6 & 7.98 & 9.52 & 11.8 & 21.4 & 192 & 3.43 & 1.51 \\
\hline $16-02$ & 14.6 & 63.6 & 0.13 & 0.32 & 13.5 & 0.14 & 0.06 & 0.56 & 590 & 0.42 & 213 & 203 & 1.20 & 7.30 & 15.4 & 32.7 & 48.3 & 45.2 & 32.0 & 8.53 & 11.6 & 9.36 & 22.5 & 220 & 2.13 & 7.38 \\
\hline $16-02$ & 14.8 & 63.8 & 0.11 & 0 & 14.4 & 0.13 & 0.07 & 0.57 & 0.0 & 0.42 & 212 & 205 & 1.02 & 6.95 & 14.8 & 31.5 & 51.3 & 42.7 & 29.8 & 8.45 & 10.1 & 9.20 & 21.9 & 233 & 3.21 & 5.00 \\
\hline $16-02$ & 15 & 64 & 0.11 & 0.25 & 14.3 & 0.14 & 0.07 & 0.58 & 174 & 0.42 & 214 & 211 & 0.91 & 7.12 & 16.9 & 30.6 & 53.2 & 44.9 & 30.9 & 8.26 & 11.0 & 5.53 & 21.5 & 231 & 2.85 & 5.48 \\
\hline $16-02$ & 15.2 & 64.2 & 0.10 & 0 & 15.3 & 0.13 & 0.07 & 0.57 & 60.1 & 0.40 & 205 & 206 & 0.79 & 6.56 & 14.1 & 30.4 & 49.8 & 39.6 & 27.2 & 8.20 & 10.1 & 3.90 & 21.0 & 211 & 2.90 & 5.04 \\
\hline $16-02$ & 15.4 & 64.4 & 0.09 & 0.00 & 16.1 & 0.13 & 0.09 & 0.56 & 0.0 & 0.40 & 203 & 202 & 0.97 & 6.90 & 14.4 & 28.3 & 49.8 & 44.2 & 30.9 & 8.36 & 8.46 & 5.31 & 21.4 & 193 & 2.08 & 1.20 \\
\hline $16-02$ & 15.6 & 64.6 & 0.10 & 0 & 15.7 & 0.13 & 0.09 & 0.56 & 875 & 0.40 & 204 & 196 & 1.17 & 6.93 & 13.8 & 23.6 & 45.4 & 35.3 & 26.0 & 7.88 & 8.68 & 3.87 & 16.4 & 190 & 1.81 & 0 \\
\hline $16-02$ & 15.8 & 64.8 & 0.09 & 0.23 & 15.6 & 0.12 & 0.10 & 0.60 & 283 & 0.40 & 203 & 196 & 0.88 & 6.14 & 11.9 & 26.2 & 48.0 & 41.2 & 30.6 & 7.96 & 9.24 & 4.60 & 20.0 & 197 & 3.62 & 0 \\
\hline $16-02$ & 16 & 65 & 0.08 & 0 & 16.3 & 0.12 & 0.09 & 0.62 & 0 & 0.40 & 203 & 199 & 1.20 & 6.82 & 12.9 & 26.6 & 47.5 & 40.1 & 28.0 & 8.19 & 8.86 & 7.78 & 19.8 & 225 & 1.80 & 0.87 \\
\hline $16-02$ & 16.2 & 65.2 & 0.09 & 0 & 15.8 & 0.12 & 0.09 & 0.65 & 132 & 0.41 & 210 & 200 & 1.03 & 6.49 & 13.0 & 29.7 & 53.4 & 44.3 & 29.8 & 8.33 & 11.2 & 10.2 & 20.7 & 220 & 2.87 & 1.93 \\
\hline $16-02$ & 16.4 & 65.4 & 0.09 & 0.14 & 15.3 & 0.12 & 0.08 & 0.61 & 74.0 & 0.42 & 215 & 203 & 1.49 & 7.68 & 14.8 & 28.0 & 50.5 & 46.2 & 31.3 & 7.92 & 9.21 & 10.6 & 21.2 & 202 & 2.51 & 1.81 \\
\hline $16-02$ & 16.6 & 65.6 & 0.11 & 0 & 14.5 & 0.13 & 0.07 & 0.62 & 173 & 0.42 & 211 & 201 & 1.79 & 8.16 & 13.5 & 26.6 & 48.7 & 48.4 & 31.5 & 7.77 & 11.6 & 9.08 & 22.8 & 197 & 2.24 & 0.93 \\
\hline
\end{tabular}

Zero values are below detection limit 


\begin{tabular}{|c|c|c|c|c|c|c|c|c|c|c|c|c|c|c|c|c|c|c|c|c|c|c|c|c|c|c|}
\hline ஹัँ & 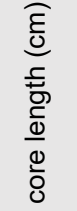 & 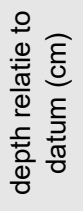 & $\frac{\widehat{o}}{\stackrel{0}{0}}$ & $\frac{\widehat{o}}{\stackrel{\frac{\rho}{3}}{\frac{\pi}{z}}}$ & $\frac{\widehat{o}}{\stackrel{0}{3}}$ & $\frac{\widehat{o}}{\stackrel{0}{3}}$ & 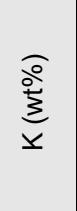 & $\frac{\widehat{o}}{\stackrel{0}{0}}$ & $\begin{array}{l}\widehat{\bar{\varepsilon}} \\
\stackrel{0}{2} \\
\stackrel{\varpi}{\infty}\end{array}$ & 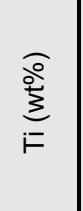 & $\begin{array}{l}\widehat{\varepsilon} \\
\stackrel{0}{0} \\
\bar{U}\end{array}$ & 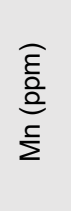 & $\underset{\stackrel{Ð}{\varrho}}{\stackrel{Ð}{\llcorner}}$ & $\begin{array}{l}\widehat{\hat{g}} \\
\text { 응 } \\
\text { ᄋ }\end{array}$ & $\frac{\widehat{\bar{\varepsilon}}}{\frac{\hat{a}}{\bar{z}}}$ & $\begin{array}{l}\widehat{\hat{\Xi}} \\
\stackrel{0}{0} \\
\vec{\jmath}\end{array}$ & $\begin{array}{l}\widehat{\hat{\varepsilon}} \\
\text { 을 } \\
\bar{N}\end{array}$ & $\begin{array}{l}\widehat{\hat{\varepsilon}} \\
\frac{0}{0} \\
\frac{0}{<}\end{array}$ & $\begin{array}{l}\widehat{\hat{\varepsilon}} \\
\text { 응 } \\
\widehat{0} 0\end{array}$ & 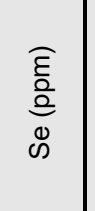 & $\begin{array}{l}\widehat{\hat{\varepsilon}} \\
\text { 을 } \\
\text { oิ }\end{array}$ & $\frac{\widehat{\varepsilon}}{\frac{0}{2}}$ & $\begin{array}{l}\widehat{\hat{\varepsilon}} \\
\hat{0} \\
>\end{array}$ & $\begin{array}{l}\widehat{\hat{\varepsilon}} \\
\text { 을 } \\
\hat{N}\end{array}$ & $\begin{array}{l}\widehat{\hat{\varepsilon}} \\
\hat{0} \\
\frac{0}{z}\end{array}$ & $\begin{array}{l}\widehat{\varepsilon} \\
\text { 을 } \\
\stackrel{0}{\Sigma}\end{array}$ \\
\hline $16-02$ & 17 & 66 & 0.15 & 0.26 & 12.8 & 0.13 & 0.05 & 0.59 & 402 & 0.41 & 208 & 206 & 1.03 & 6.84 & 14.3 & 30.3 & 49.6 & 44.9 & 31.6 & 8.11 & 7.59 & 5.55 & 21.9 & 219 & 2.11 & 2.54 \\
\hline $16-02$ & 17.2 & 66.2 & 0.17 & 0.73 & 11.7 & 0.14 & 0.04 & 0.59 & 794 & 0.43 & 220 & 212 & 1.18 & 7.36 & 16.4 & 33.7 & 48.7 & 41.5 & 28.4 & 7.30 & 7.11 & 4.48 & 22.0 & 234 & 1.86 & 4.71 \\
\hline $16-02$ & 17.4 & 66.4 & 0.17 & 0.74 & 11.7 & 0.15 & 0.05 & 0.60 & 541 & 0.44 & 226 & 217 & 1.13 & 7.60 & 18.7 & 41.5 & 57.1 & 52.5 & 33.4 & 8.49 & 12.2 & 8.26 & 23.8 & 227 & 2.76 & 4.20 \\
\hline $16-02$ & 17.6 & 66.6 & 0.16 & 0.62 & 12.0 & 0.14 & 0.05 & 0.62 & 0 & 0.47 & 245 & 225 & 1.43 & 8.47 & 20.6 & 42.8 & 68.5 & 71.0 & 41.1 & 9.03 & 14.7 & 11.4 & 31.2 & 191 & 4.60 & 1.85 \\
\hline $16-02$ & 17.8 & 66.8 & 0.13 & 0.35 & 13.4 & 0.13 & 0.06 & 0.64 & 272 & 0.48 & 250 & 229 & 1.18 & 7.58 & 17.2 & 40.0 & 68.7 & 73.5 & 41.3 & 8.70 & 15.9 & 13.6 & 31.9 & 206 & 4.02 & 4.00 \\
\hline $16-02$ & 18 & 67 & 0.14 & 0.40 & 13.0 & 0.13 & 0.06 & 0.61 & 0 & 0.46 & 236 & 222 & 1.42 & 7.90 & 16.7 & 38.6 & 58.6 & 61.9 & 38.5 & 8.50 & 16.7 & 9.76 & 29.2 & 212 & 4.07 & 2.01 \\
\hline $16-02$ & 18.2 & 67.2 & 0.12 & 0.12 & 14.1 & 0.13 & 0.07 & 0.58 & 0 & 0.44 & 223 & 207 & 1.39 & 7.52 & 15.2 & 32.2 & 53.8 & 50.6 & 32.6 & 8.12 & 15.4 & 10.03 & 24.7 & 198 & 4.36 & 1.23 \\
\hline $16-02$ & 18.4 & 67.4 & 0.12 & 0.15 & 14.2 & 0.13 & 0.07 & 0.59 & 84.2 & 0.41 & 207 & 199 & 1.30 & 7.12 & 14.1 & 25.0 & 44.8 & 41.3 & 27.8 & 8.12 & 10.9 & 9.0 & 22.0 & 211 & 3.38 & 2.96 \\
\hline $16-02$ & 18.6 & 67.6 & 0.09 & 0.21 & 15.1 & 0.12 & 0.08 & 0.62 & 224 & 0.39 & 200 & 196 & 1.13 & 6.61 & 12.8 & 25.1 & 46.9 & 42.1 & 27.9 & 8.29 & 9.36 & 6.34 & 18.1 & 215 & 2.69 & 3.60 \\
\hline $16-02$ & 18.8 & 67.8 & 0.10 & 0.00 & 15.0 & 0.12 & 0.09 & 0.64 & 276 & 0.43 & 220 & 210 & 1.33 & 7.10 & 13.5 & 31.1 & 53.0 & 53.7 & 34.9 & 8.51 & 11.2 & 9.67 & 23.5 & 231 & 2.54 & 4.20 \\
\hline $16-02$ & 19 & 68 & 0.09 & 0.16 & 15.1 & 0.12 & 0.08 & 0.61 & 575 & 0.45 & 234 & 219 & 1.55 & 8.16 & 16.9 & 36.0 & 56.2 & 57.3 & 35.5 & 8.23 & 11.6 & 9.98 & 25.1 & 239 & 3.42 & 4.04 \\
\hline $16-02$ & 19.2 & 68.2 & 0.09 & 0 & 15.5 & 0.12 & 0.08 & 0.64 & 0.0 & 0.45 & 233 & 218 & 1.70 & 8.65 & 17.8 & 33.8 & 55.3 & 59.1 & 36.3 & 8.31 & 12.9 & 11.47 & 26.4 & 241 & 3.20 & 3.68 \\
\hline $16-02$ & 19.4 & 68.4 & 0.05 & 0 & 17.5 & 0.12 & 0.09 & 0.63 & 172 & 0.44 & 227 & 219 & 1.82 & 8.89 & 17.9 & 33.7 & 55.9 & 59.3 & 34.6 & 8.48 & 12.0 & 8.92 & 27.0 & 221 & 3.14 & 3.18 \\
\hline $16-02$ & 19.6 & 68.6 & 0.04 & 0 & 18.5 & 0.12 & 0.09 & 0.58 & 0 & 0.44 & 227 & 218 & 1.04 & 7.15 & 16.4 & 34.0 & 54.3 & 59.3 & 36.4 & 8.23 & 13.4 & 9.77 & 25.8 & 212 & 2.70 & 3.32 \\
\hline $16-02$ & 19.8 & 68.8 & 0.02 & 0 & 19.5 & 0.12 & 0.10 & 0.60 & 0 & 0.43 & 221 & 214 & 1.53 & 8.30 & 18.1 & 29.6 & 52.9 & 53.8 & 35.8 & 8.28 & 12.1 & 8.22 & 24.5 & 225 & 2.53 & 3.71 \\
\hline $16-02$ & 20 & 69 & 0.09 & 0 & 15.9 & 0.13 & 0.09 & 0.56 & 130 & 0.41 & 211 & 201 & 1.83 & 8.30 & 15.5 & 25.0 & 50.4 & 49.5 & 33.9 & 8.26 & 10.6 & 7.80 & 23.6 & 213 & 2.53 & 1.99 \\
\hline $16-02$ & 20.2 & 69.2 & 0.10 & 0.10 & 15.2 & 0.13 & 0.07 & 0.53 & 226 & 0.39 & 196 & 193 & 1.33 & 6.89 & 12.8 & 23.2 & 44.2 & 42.6 & 28.8 & 8.19 & 7.36 & 6.58 & 20.3 & 194 & 2.42 & 0.00 \\
\hline $16-02$ & 20.4 & 69.4 & 0.12 & 0.11 & 15.3 & 0.14 & 0.05 & 0.50 & 351 & 0.35 & 181 & 189 & 1.66 & 7.45 & 13.6 & 16.1 & 37.3 & 37.2 & 26.5 & 8.24 & 6.49 & 3.11 & 18.6 & 193 & 1.71 & 1.89 \\
\hline $16-02$ & 20.6 & 69.6 & 0.18 & 0.76 & 13.0 & 0.15 & 0.02 & 0.48 & 0 & 0.33 & 168 & 180 & 1.48 & 6.44 & 9.0 & 24.2 & 36.5 & 35.1 & 26.6 & 8.19 & 7.88 & 2.76 & 17.3 & 192 & 2.44 & 0.00 \\
\hline $16-02$ & 20.8 & 69.8 & 0.36 & 2.45 & 7.07 & 0.17 & 0.00 & 0.46 & 0 & 0.31 & 155 & 168 & 1.33 & 5.75 & 7.2 & 42.8 & 36.0 & 29.3 & 23.7 & 8.47 & 6.62 & 0.00 & 12.1 & 198 & 1.42 & 4.32 \\
\hline $16-02$ & 21 & 70 & 0.57 & 4.36 & 0.39 & 0.18 & 0.00 & 0.46 & 554 & 0.27 & 137 & 142 & 1.01 & 4.63 & 12.6 & 102 & 44.4 & 21.1 & 15.5 & 7.85 & 0.96 & 0.00 & 4.11 & 166 & 0.00 & 0.00 \\
\hline $16-03$ & 0 & 61 & 0.28 & 1.75 & 8.38 & 0.15 & 0.02 & 0.31 & 0.0 & 0.41 & 208 & 207 & 1.62 & 7.83 & 10.4 & 76.3 & 57.9 & 42.5 & 27.1 & 10.35 & 11.2 & 7.99 & 17.4 & 171 & 4.93 & 5.53 \\
\hline $16-03$ & 0.2 & 61.2 & 0.27 & 1.65 & 9.32 & 0.14 & 0.02 & 0.32 & 0.0 & 0.39 & 200 & 206 & 1.22 & 7.42 & 14.5 & 51.5 & 54.8 & 43.3 & 28.9 & 9.14 & 12.9 & 7.94 & 20.1 & 205 & 3.65 & 3.87 \\
\hline $16-03$ & 0.4 & 61.4 & 0.24 & 1.35 & 9.51 & 0.14 & 0.02 & 0.28 & 412 & 0.40 & 203 & 212 & 0.77 & 6.32 & 12.9 & 56.1 & 56.7 & 45.6 & 28.9 & 9.46 & 13.4 & 11.21 & 21.1 & 209 & 3.44 & 12.45 \\
\hline $16-03$ & 0.6 & 61.6 & 0.21 & 1.01 & 10.8 & 0.14 & 0.03 & 0.31 & 996 & 0.39 & 201 & 209 & 1.38 & 8.16 & 17.8 & 50.4 & 53.9 & 44.3 & 29.3 & 9.24 & 10.7 & 10.2 & 20.3 & 218 & 3.62 & 4.71 \\
\hline $16-03$ & 0.8 & 61.8 & 0.16 & 0.71 & 12.8 & 0.13 & 0.06 & 0.35 & 0 & 0 & 0 & 0 & 0 & 0 & 0 & 0 & 0 & 0 & 0 & 0 & 0 & 0 & 0 & 0 & 0 & 0 \\
\hline $16-03$ & 1 & 62 & 0.12 & 0.54 & 14.6 & 0.12 & 0.08 & 0.38 & 0.0 & 0.41 & 206 & 202 & 0.58 & 6.13 & 15.8 & 40.5 & 51.5 & 40.1 & 27.5 & 8.16 & 10.1 & 6.96 & 19.2 & 317 & 2.74 & 10.2 \\
\hline $16-03$ & 1.2 & 62.2 & 0.11 & 0.18 & 15.3 & 0.12 & 0.08 & 0.39 & 430 & 0.43 & 219 & 204 & 0.69 & 6.23 & 14.0 & 34.7 & 49.8 & 38.8 & 27.9 & 8.82 & 11.5 & 5.86 & 18.6 & 297 & 2.98 & 7.42 \\
\hline $16-03$ & 1.4 & 62.4 & 0.12 & 0.21 & 14.8 & 0.13 & 0.09 & 0.39 & 0 & 0.44 & 222 & 200 & 0.85 & 6.62 & 15.7 & 28.9 & 46.9 & 40.0 & 25.8 & 8.62 & 10.6 & 5.91 & 18.3 & 272 & 2.29 & 7.85 \\
\hline $16-03$ & 1.6 & 62.6 & 0.12 & 0.15 & 14.4 & 0.13 & 0.07 & 0.39 & 210 & 0.45 & 228 & 204 & 0.59 & 6.14 & 16.3 & 28.0 & 50.0 & 40.8 & 28.1 & 7.99 & 10.1 & 4.54 & 19.3 & 227 & 3.37 & 5.45 \\
\hline $16-03$ & 1.8 & 62.8 & 0.10 & 0.00 & 15.5 & 0.13 & 0.08 & 0.42 & 369 & 0.43 & 222 & 206 & 0.63 & 5.85 & 13.1 & 33.4 & 53.2 & 41.8 & 28.7 & 8.92 & 10.6 & 5.28 & 19.1 & 174 & 3.10 & 3.08 \\
\hline $16-03$ & 2 & 63 & 0.09 & 0.00 & 15.9 & 0.13 & 0.08 & 0.45 & 552 & 0.42 & 214 & 205 & 0.53 & 5.99 & 16.0 & 31.0 & 49.3 & 40.9 & 28.2 & 8.45 & 9.77 & 7.20 & 21.1 & 172 & 3.81 & 3.20 \\
\hline $16-03$ & 2.2 & 63.2 & 0.11 & 0.21 & 15.0 & 0.13 & 0.09 & 0.46 & 201 & 0.42 & 215 & 206 & 0.77 & 6.55 & 16.7 & 30.0 & 48.9 & 41.2 & 28.7 & 8.32 & 11.0 & 5.77 & 18.5 & 189 & 3.23 & 4.24 \\
\hline $16-03$ & 2.4 & 63.4 & 0.12 & 0.02 & 14.5 & 0.13 & 0.08 & 0.46 & 1.8 & 0.41 & 210 & 202 & 0.94 & 6.83 & 15.6 & 30.1 & 51.5 & 40.8 & 26.8 & 8.25 & 12.1 & 3.73 & 20.6 & 200 & 3.45 & 3.83 \\
\hline $16-03$ & 2.6 & 63.6 & 0.11 & 0.19 & 14.8 & 0.13 & 0.09 & 0.42 & 177 & 0.43 & 220 & 211 & 0.68 & 6.40 & 14.5 & 37.3 & 55.1 & 45.3 & 30.2 & 8.33 & 8.88 & 7.81 & 20.8 & 204 & 2.30 & 5.27 \\
\hline $16-03$ & 2.8 & 63.8 & 0.12 & 0.27 & 14.3 & 0.13 & 0.08 & 0.40 & 111 & 0.44 & 228 & 216 & 0.41 & 6.25 & 15.8 & 34.6 & 53.3 & 44.5 & 29.6 & 8.18 & 10.5 & 6.61 & 21.4 & 198 & 3.03 & 2.26 \\
\hline $16-03$ & 3 & 64 & 0.23 & 1.24 & 10.1 & 0.14 & 0.02 & 0.29 & 80.1 & 0.46 & 237 & 217 & 0.90 & 7.06 & 13.9 & 37.3 & 56.6 & 48.6 & 30.0 & 8.63 & 10.2 & 6.83 & 23.0 & 169 & 2.37 & 2.24 \\
\hline $16-03$ & 3.2 & 64.2 & 0.46 & 3.31 & 3.17 & 0.17 & 0.00 & 0.13 & 433 & 0.48 & 248 & 232 & 0.32 & 6.41 & 16.6 & 58.8 & 70.4 & 51.9 & 34.7 & 8.72 & 10.5 & 9.30 & 20.8 & 178 & 1.82 & 8.21 \\
\hline
\end{tabular}

Zero values are below detection limit 


\begin{tabular}{|c|c|c|c|c|c|c|c|c|c|c|c|c|c|c|c|c|c|c|c|c|c|c|c|c|c|c|}
\hline ¿ัँ & 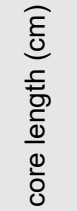 & 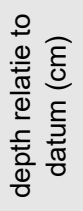 & $\underset{\frac{\pi}{20}}{\stackrel{0}{+0}}$ & $\frac{\widehat{o}}{\frac{0}{3}}$ & $\frac{\widehat{o}}{\stackrel{\circ}{3}}$ & $\frac{\widehat{o}}{\frac{0}{3}}$ & $\frac{\substack{9 \\
\frac{a}{3}}}{x}$ & $\frac{\widehat{O}}{\stackrel{0}{\infty}}$ & 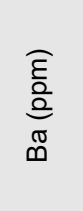 & $\frac{\widehat{o}}{\stackrel{a}{a}}$ & 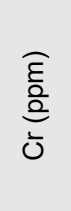 & 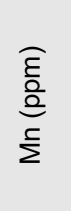 & 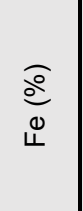 & $\begin{array}{l}\widehat{\hat{\varepsilon}} \\
\frac{0}{0} \\
0 \\
0\end{array}$ & $\begin{array}{l}\widehat{\bar{\varepsilon}} \\
\stackrel{\overline{0}}{0} \\
\bar{z}\end{array}$ & $\begin{array}{l}\widehat{\hat{\varepsilon}} \\
\frac{0}{0} \\
\vec{\jmath}\end{array}$ & $\begin{array}{l}\widehat{\varepsilon} \\
\text { 을 } \\
\bar{N}\end{array}$ & $\begin{array}{l}\widehat{\varepsilon} \\
\frac{0}{0} \\
\frac{0}{<}\end{array}$ & $\begin{array}{l}\widehat{\hat{\varepsilon}} \\
\hat{\circ} \\
\stackrel{0}{0} \\
\text { م }\end{array}$ & $\begin{array}{l}\widehat{\varepsilon} \\
\text { 응 } \\
\text { ळ }\end{array}$ & $\begin{array}{l}\widehat{\hat{\varepsilon}} \\
\text { 을 } \\
\text { 요 }\end{array}$ & $\begin{array}{l}\widehat{\varepsilon} \\
\frac{0}{0} \\
\dot{\omega}\end{array}$ & $\begin{array}{l}\widehat{\hat{\varepsilon}} \\
\frac{0}{0} \\
>\end{array}$ & $\begin{array}{l}\widehat{\bar{\varepsilon}} \\
\overline{0} \\
\overline{2}\end{array}$ & $\begin{array}{l}\widehat{\varepsilon} \\
\text { 을 } \\
\text { है }\end{array}$ & $\begin{array}{l}\widehat{\varepsilon} \\
\text { 을 } \\
\stackrel{\circ}{z}\end{array}$ \\
\hline $16-03$ & 3.4 & 64.4 & 0.65 & 4.98 & 0 & 0.18 & 0 & 0 & 442 & 0.42 & 216 & 213 & 1.13 & 7.76 & 18.9 & 89.5 & 65.9 & 46.9 & 27.6 & 9.76 & 13.7 & 6.87 & 18.4 & 149 & 5.62 & 4.20 \\
\hline $16-03$ & 3.6 & 64.6 & 0.67 & 5.04 & 0 & 0.19 & 0 & 0 & 1100 & 0.30 & 142 & 218 & 0.15 & 6.64 & 28.0 & 263 & 109 & 31.4 & 25.0 & 11.85 & 9.92 & 1.31 & 8.4 & 168 & 0.45 & 10.2 \\
\hline $16-03$ & 3.8 & 64.8 & 0.67 & 5.14 & 0 & 0.18 & 0 & 0 & 1591 & 0.16 & 89 & 178 & 0.14 & 4.80 & 20.0 & 373 & 120 & 21.1 & 18.7 & 13.72 & 11.4 & 0 & 7.5 & 80 & 1.80 & 8.12 \\
\hline $16-03$ & 4 & 65 & 0.68 & 5.01 & 0 & 0.18 & 0 & 0 & 627 & 0.10 & 78 & 157 & 0.10 & 4.89 & 31.4 & 420 & 150 & 17.0 & 10.1 & 15.60 & 17.5 & 0.14 & 2.6 & 55 & 1.66 & 0 \\
\hline $16-03$ & 4.2 & 65.2 & 0.64 & 5.01 & 0 & 0.18 & 0 & 0 & 0.0 & 0.10 & 73 & 148 & 0.48 & 4.94 & 28.7 & 442 & 164 & 21.9 & 19.4 & 13.83 & 9.8 & 0 & 13.7 & 66 & 0.38 & 0 \\
\hline $16-03$ & 4.4 & 65.4 & 0.48 & 3.46 & 2.54 & 0.17 & 0 & 0.10 & 1089 & 0.17 & 98 & 170 & 0.00 & 5.41 & 34.9 & 437 & 156 & 26.4 & 18.8 & 11.62 & 12.1 & 1.28 & 8.3 & 121 & 0.0 & 0 \\
\hline $16-03$ & 4.6 & 65.6 & 0.29 & 1.82 & 7.86 & 0.16 & 0 & 0.27 & 699 & 0.37 & 189 & 215 & 0.44 & 6.23 & 17.6 & 141 & 77.6 & 41.4 & 26.1 & 9.80 & 10.6 & 5.86 & 15.2 & 140 & 4.28 & 2.48 \\
\hline $16-03$ & 4.8 & 65.8 & 0.20 & 1.01 & 11.0 & 0.14 & 0.03 & 0.35 & 357 & 0.42 & 216 & 231 & 0.00 & 6.27 & 17.0 & 68.7 & 61.9 & 50.5 & 32.7 & 8.32 & 14.3 & 10.5 & 21.2 & 178 & 4.12 & 1.08 \\
\hline $16-03$ & 5 & 66 & 0.16 & 0.57 & 12.4 & 0.14 & 0.06 & 0.37 & 502 & 0.44 & 228 & 236 & 0.00 & 6.31 & 14.9 & 42.8 & 53.7 & 46.1 & 30.6 & 8.47 & 9.94 & 8.91 & 21.0 & 187 & 3.77 & 7.46 \\
\hline $16-03$ & 5.2 & 66.2 & 0.17 & 0.62 & 11.8 & 0.14 & 0.06 & 0.37 & 0.0 & 0.45 & 233 & 228 & 0.49 & 6.73 & 14.6 & 32.9 & 52.1 & 45.0 & 29.3 & 8.87 & 12.5 & 6.28 & 20.6 & 192 & 4.14 & 4.73 \\
\hline $16-03$ & 5.4 & 66.4 & 0.17 & 0.78 & 11.9 & 0.14 & 0.06 & 0.38 & 0.0 & 0.46 & 235 & 224 & 0.34 & 6.29 & 14.8 & 37.4 & 56.8 & 46.2 & 31.4 & 8.58 & 11.4 & 8.25 & 21.1 & 198 & 3.87 & 4.85 \\
\hline $16-03$ & 5.6 & 66.6 & 0.17 & 0.89 & 12.3 & 0.14 & 0.07 & 0.37 & 193 & 0.43 & 223 & 223 & 0.75 & 7.19 & 18.0 & 37.6 & 53.5 & 47.3 & 29.7 & 9.05 & 11.6 & 8.54 & 22.5 & 193 & 3.86 & 4.77 \\
\hline $16-03$ & 5.8 & 66.8 & 0.16 & 0.56 & 12.8 & 0.14 & 0.06 & 0.37 & 0.0 & 0.43 & 222 & 219 & 0.78 & 6.53 & 14.2 & 36.1 & 50.7 & 50.3 & 31.9 & 8.76 & 12.7 & 9.03 & 19.2 & 197 & 3.71 & 5.57 \\
\hline $16-03$ & 6 & 67 & 0.15 & 0.54 & 13.0 & 0.14 & 0.06 & 0.36 & 0.0 & 0.43 & 218 & 214 & 0.51 & 5.69 & 12.6 & 35.9 & 50.2 & 46.6 & 30.6 & 8.61 & 10.8 & 9.02 & 20.9 & 183 & 3.32 & 1.70 \\
\hline $16-03$ & 6.2 & 67.2 & 0.15 & 0.52 & 13.2 & 0.14 & 0.07 & 0.39 & 611 & 0.42 & 214 & 203 & 1.28 & 6.93 & 13.0 & 32.2 & 45.9 & 45.7 & 29.6 & 8.36 & 12.5 & 5.51 & 20.0 & 170 & 3.00 & 2.71 \\
\hline $16-03$ & 6.4 & 67.4 & 0.14 & 0.40 & 13.7 & 0.14 & 0.07 & 0.39 & 483 & 0.40 & 205 & 195 & 1.37 & 6.92 & 11.9 & 36.0 & 45.6 & 39.3 & 26.7 & 8.46 & 11.8 & 7.73 & 18.7 & 178 & 2.68 & 4.96 \\
\hline $16-03$ & 6.6 & 67.6 & 0.05 & 0 & 18.0 & 0.13 & 0.10 & 0.45 & 16.7 & 0.41 & 205 & 197 & 1.37 & 7.25 & 14.1 & 35.9 & 48.9 & 43.9 & 28.7 & 8.77 & 10.1 & 7.69 & 23.1 & 186 & 3.64 & 3.27 \\
\hline $16-03$ & 6.8 & 67.8 & 0.08 & 0 & 16.4 & 0.14 & 0.08 & 0.42 & 0.0 & 0.42 & 211 & 199 & 1.07 & 6.55 & 13.9 & 36.6 & 49.6 & 46.6 & 30.3 & 7.89 & 10.1 & 7.92 & 23.6 & 178 & 3.44 & 3.19 \\
\hline $16-03$ & 7 & 68 & 0.22 & 1.14 & 10.7 & 0.13 & 0.06 & 0.39 & 41.3 & 0.42 & 211 & 193 & 1.28 & 6.90 & 14.3 & 24.9 & 48.9 & 44.1 & 29.9 & 8.31 & 12.0 & 6.61 & 21.8 & 171 & 3.01 & 2.44 \\
\hline $16-03$ & 7.2 & 68.2 & 0.14 & 0.47 & 13.7 & 0.13 & 0.08 & 0.40 & 0.0 & 0.42 & 212 & 196 & 0.84 & 6.05 & 13.7 & 29.6 & 49.7 & 42.5 & 29.4 & 8.41 & 8.20 & 3.83 & 22.9 & 173 & 3.97 & 3.32 \\
\hline $16-03$ & 7.4 & 68.4 & 0.05 & 0 & 18.3 & 0.14 & 0.12 & 0.46 & 75.7 & 0.43 & 219 & 209 & 0.37 & 6.32 & 16.5 & 28.1 & 46.2 & 43.9 & 29.2 & 8.58 & 10.6 & 7.17 & 22.9 & 208 & 3.45 & 3.70 \\
\hline $16-03$ & 7.6 & 68.6 & 0.07 & 0 & 17.0 & 0.14 & 0.09 & 0.41 & 228 & 0.42 & 211 & 209 & 0.33 & 6.74 & 17.3 & 25.8 & 44.6 & 39.5 & 27.4 & 8.34 & 10.3 & 6.40 & 21.7 & 202 & 3.91 & 2.09 \\
\hline $16-03$ & 7.8 & 68.8 & 0.12 & 0.07 & 15.2 & 0.14 & 0.08 & 0.41 & 0.0 & 0.40 & 199 & 203 & 0.57 & 6.44 & 14.8 & 24.0 & 46.9 & 41.7 & 29.8 & 8.22 & 11.9 & 6.17 & 23.8 & 204 & 3.10 & 1.98 \\
\hline $16-03$ & 8 & 69 & 0.09 & 0.07 & 15.9 & 0.14 & 0.08 & 0.45 & 50.1 & 0.41 & 209 & 210 & 0.62 & 6.86 & 15.8 & 26.2 & 49.4 & 43.7 & 29.1 & 8.15 & 13.0 & 6.00 & 22.9 & 186 & 3.37 & 2.53 \\
\hline $16-03$ & 8.2 & 69.2 & 0.02 & 0 & 19.2 & 0.11 & 0.11 & 0.56 & 0.0 & 0.43 & 219 & 216 & 1.04 & 7.56 & 15.6 & 27.9 & 48.2 & 42.8 & 30.0 & 8.41 & 12.7 & 8.51 & 23.6 & 185 & 3.85 & 3.67 \\
\hline $16-03$ & 8.4 & 69.4 & 0.03 & 0 & 19.0 & 0.13 & 0.11 & 0.53 & 3.4 & 0.44 & 224 & 209 & 0.93 & 7.09 & 15.4 & 31.5 & 52.6 & 45.4 & 30.3 & 8.19 & 10.2 & 7.84 & 23.3 & 186 & 2.93 & 3.98 \\
\hline $16-03$ & 8.6 & 69.6 & 0.17 & 0.66 & 12.6 & 0.14 & 0.08 & 0.40 & 265 & 0.43 & 220 & 209 & 0.92 & 6.78 & 13.8 & 29.7 & 45.5 & 42.5 & 29.7 & 7.92 & 12.1 & 5.98 & 22.4 & 163 & 3.26 & 0.15 \\
\hline $16-03$ & 8.8 & 69.8 & 0.19 & 0.74 & 12.7 & 0.14 & 0.09 & 0.39 & 194 & 0.42 & 209 & 200 & 0.61 & 6.02 & 13.3 & 25.9 & 44.3 & 42.1 & 29.6 & 8.08 & 10.7 & 9.28 & 20.5 & 152 & 4.28 & 1.05 \\
\hline $16-03$ & 9 & 70 & 0.06 & 0 & 19.4 & 0.13 & 0.12 & 0.44 & 0.0 & 0.39 & 194 & 192 & 0.98 & 6.35 & 11.6 & 25.4 & 42.7 & 38.6 & 26.4 & 8.23 & 9.88 & 6.13 & 18.6 & 158 & 2.72 & 0.80 \\
\hline $16-03$ & 9.2 & 70.2 & 0.01 & 0 & 21.1 & 0.12 & 0.11 & 0.45 & 157 & 0.39 & 191 & 188 & 1.38 & 6.93 & 11.4 & 24.4 & 40.4 & 41.1 & 28.6 & 8.44 & 8.14 & 6.36 & 19.7 & 194 & 2.14 & 2.56 \\
\hline $16-03$ & 9.4 & 70.4 & 0.08 & 0 & 17.1 & 0.14 & 0.09 & 0.42 & 337 & 0.38 & 190 & 188 & 1.14 & 6.70 & 13.7 & 24.9 & 40.1 & 40.9 & 26.9 & 8.01 & 9.33 & 6.07 & 19.6 & 281 & 3.28 & 7.79 \\
\hline $16-03$ & 9.6 & 70.6 & 0.08 & 0 & 16.5 & 0.13 & 0.08 & 0.37 & 281 & 0.40 & 204 & 200 & 0.97 & 6.72 & 14.7 & 22.7 & 44.1 & 41.2 & 27.9 & 7.90 & 9.14 & 7.78 & 20.5 & 273 & 2.38 & 5.64 \\
\hline $16-03$ & 9.8 & 70.8 & 0.03 & 0 & 20.3 & 0.13 & 0.11 & 0.42 & 0.0 & 0.41 & 209 & 204 & 0.71 & 6.13 & 13.3 & 25.5 & 48.7 & 40.1 & 26.8 & 8.45 & 9.29 & 5.30 & 21.8 & 269 & 2.63 & 5.48 \\
\hline $16-03$ & 10 & 71 & 0.02 & 0 & 20.9 & 0.13 & 0.13 & 0.45 & 178 & 0.39 & 201 & 206 & 0.69 & 6.38 & 15.1 & 28.3 & 43.2 & 39.4 & 28.8 & 8.21 & 8.77 & 5.99 & 21.4 & 217 & 2.84 & 2.58 \\
\hline $16-03$ & 10.2 & 71.2 & 0.04 & 0 & 20.3 & 0.13 & 0.11 & 0.44 & 185 & 0.39 & 201 & 215 & 1.31 & 7.45 & 14.2 & 33.2 & 45.5 & 42.5 & 28.9 & 8.52 & 9.14 & 6.06 & 22.6 & 196 & 2.86 & 2.91 \\
\hline $16-03$ & 10.4 & 71.4 & 0.10 & 0 & 16.7 & 0.14 & 0.08 & 0.40 & 7.9 & 0.40 & 205 & 214 & 1.52 & 7.85 & 13.1 & 35.2 & 51.6 & 47.5 & 30.5 & 8.24 & 12.0 & 6.12 & 26.0 & 175 & 3.33 & 3.18 \\
\hline $16-03$ & 10.6 & 71.6 & 0.06 & 0 & 19.0 & 0.13 & 0.09 & 0.40 & 122 & 0.43 & 219 & 225 & 1.47 & 8.48 & 16.6 & 37.5 & 60.6 & 53.3 & 34.2 & 8.35 & 11.9 & 6.73 & 30.8 & 172 & 3.94 & 1.56 \\
\hline $16-03$ & 10.8 & 71.8 & 0.06 & 0 & 19.0 & 0.13 & 0.09 & 0.41 & 549 & 0.43 & 221 & 219 & 1.88 & 9.20 & 15.6 & 35.2 & 60.4 & 52.3 & 33.8 & 8.46 & 14.3 & 11.5 & 31.4 & 196 & 3.59 & 3.49 \\
\hline
\end{tabular}

Zero values are below detection limit 


\begin{tabular}{|c|c|c|c|c|c|c|c|c|c|c|c|c|c|c|c|c|c|c|c|c|c|c|c|c|c|c|}
\hline ๖ัँ & 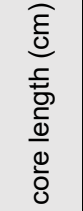 & 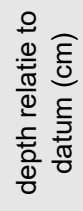 & $\frac{\substack{0 \\
\frac{0}{3}}}{\frac{\pi}{2}}$ & $\frac{\widehat{o}}{\frac{o}{3}}$ & $\frac{\widehat{o}}{\stackrel{0}{3}}$ & $\frac{\widehat{o}}{3}$ & $\frac{\widehat{o}}{\stackrel{0}{a}}$ & $\underbrace{\widehat{O}}_{0} \underset{0}{\frac{0}{3}}$ & 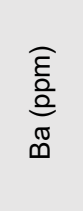 & $\frac{\widehat{o}}{\stackrel{o}{3}}$ & $\begin{array}{l}\widehat{\hat{\varepsilon}} \\
\text { قे } \\
\text { ป̀ }\end{array}$ & 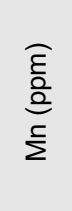 & 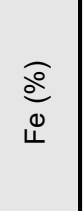 & $\begin{array}{l}\widehat{\hat{\varepsilon}} \\
\text { 을 } \\
\text { ᄋ }\end{array}$ & $\begin{array}{l}\widehat{\bar{g}} \\
\stackrel{0}{0} \\
\bar{z}\end{array}$ & $\begin{array}{l}\widehat{\hat{\varepsilon}} \\
\stackrel{\circ}{\varrho} \\
\stackrel{\jmath}{0}\end{array}$ & $\begin{array}{l}\widehat{\hat{\varepsilon}} \\
\frac{0}{0} \\
\bar{N}\end{array}$ & $\begin{array}{l}\widehat{\hat{\varepsilon}} \\
\frac{0}{0} \\
\hat{Q}\end{array}$ & $\begin{array}{l}\widehat{\hat{\varepsilon}} \\
\text { 응 } \\
\text { 응 }\end{array}$ & $\begin{array}{l}\widehat{\hat{\varepsilon}} \\
\text { 을 } \\
\text { ळ }\end{array}$ & $\begin{array}{l}\widehat{\hat{\varepsilon}} \\
\frac{0}{2} \\
\text { 옹 }\end{array}$ & $\begin{array}{l}\widehat{\bar{\varepsilon}} \\
\frac{0}{2} \\
\bar{\omega}\end{array}$ & $\begin{array}{l}\widehat{\hat{\sigma}} \\
\text { 을 } \\
>\end{array}$ & $\begin{array}{l}\widehat{E} \\
\frac{0}{0} \\
\bar{N}\end{array}$ & $\begin{array}{l}\widehat{\hat{\varepsilon}} \\
\text { 을 } \\
\text { 은 }\end{array}$ & $\begin{array}{l}\widehat{\hat{\varepsilon}} \\
\hat{0} \\
\stackrel{\circ}{\Sigma}\end{array}$ \\
\hline $16-03$ & 11 & 72 & 0.09 & 0 & 18.4 & 0.13 & 0.08 & 0.37 & 0 & 0.42 & 211 & 214 & 1.37 & 8.31 & 16.0 & 36.9 & 57.1 & 46.2 & 31.4 & 8.35 & 13.5 & 9.47 & 28.1 & 198 & 3.55 & 4.26 \\
\hline $16-03$ & 11.2 & 72.2 & 0.16 & 0.43 & 15.5 & 0.15 & 0.02 & 0.26 & 43.7 & 0.39 & 195 & 195 & 1.76 & 7.95 & 12.4 & $3 E+12$ & 48.5 & 40.3 & 27.0 & 8.93 & 12.2 & 7.87 & 23.9 & 185 & 3.58 & 2.39 \\
\hline $16-03$ & 11.4 & 72.4 & 0.39 & 2.68 & 7.79 & 0.17 & 0 & 0.15 & 3.1 & 0.30 & 147 & 164 & 0.88 & 5.19 & 9.86 & 21.7 & 36.1 & 27.4 & 21.5 & 8.26 & 8.17 & 2.61 & 15.5 & 175 & 2.68 & 4.19 \\
\hline $16-03$ & 11.6 & 72.6 & 0.43 & 3.10 & 5.29 & 0.18 & 0 & 0.09 & 282 & 0.25 & 114 & 134 & 1.20 & 4.10 & 4.77 & 27.7 & 22.8 & 17.0 & 15.7 & 7.85 & 5.50 & 0 & 9.01 & 148 & 1.70 & 5.69 \\
\hline $16-03$ & 11.8 & 72.8 & 0.36 & 2.49 & 7.45 & 0.18 & 0 & 0.11 & 0 & 0.23 & 110 & 133 & 1.02 & 4.01 & 8.00 & 49.1 & 25.2 & 15.7 & 12.7 & 8.39 & 3.40 & 0 & 9.25 & 97 & 3.38 & 2.64 \\
\hline $16-03$ & 12 & 73 & 0.31 & 1.98 & 8.96 & 0.17 & 0 & 0.16 & 124 & 0.23 & 121 & 145 & 0.73 & 4.17 & 10.4 & 55.0 & 28.3 & 20.1 & 17.9 & 8.74 & 5.71 & 0 & 8.10 & 104 & 3.15 & 5.01 \\
\hline $16-03$ & 12.2 & 73.2 & 0.33 & 2.12 & 8.94 & 0.16 & 0 & 0.19 & 0.0 & 0.23 & 123 & 146 & 0.48 & 3.24 & 5.76 & 43.6 & 26.5 & 19.3 & 15.0 & 8.06 & 4.25 & 3.22 & 8.29 & 137 & 4.23 & 3.66 \\
\hline $16-03$ & 12.4 & 73.4 & 0.40 & 2.83 & 6.27 & 0.16 & 0 & 0.17 & 30.0 & 0.23 & 112 & 139 & 0.77 & 3.48 & 4.23 & 31.3 & 22.7 & 16.8 & 15.7 & 8.56 & 7.09 & 0 & 5.77 & 133 & 3.10 & 4.12 \\
\hline $16-03$ & 12.6 & 73.6 & 0.38 & 2.58 & 8.38 & 0.17 & 0 & 0.16 & 0.0 & 0 & 107 & 135 & 0.83 & 3.38 & 3.81 & 16.5 & 21.6 & 15.6 & 14.8 & 8.38 & 4.66 & 0 & 7.69 & 114 & 2.91 & 2.77 \\
\hline $16-03$ & 12.8 & 73.8 & 0.36 & 2.41 & 9.91 & 0.18 & 0 & 0.12 & 127 & 0.18 & 99 & 130 & 0.78 & 2.92 & 2.50 & 15.9 & 15.5 & 14.2 & 12.8 & 8.52 & 3.83 & 0 & 6.71 & 89.9 & 1.65 & 4.63 \\
\hline $16-03$ & 13 & 74 & 0.36 & 2.43 & 9.80 & 0.17 & 0 & 0.10 & 178 & 0.17 & 92 & 127 & 0.88 & 2.83 & 0.47 & 16.7 & 17.3 & 13.7 & 11.4 & 8.52 & 3.37 & 0 & 8.40 & 77.7 & 3.00 & 0.00 \\
\hline $16-03$ & 13.2 & 74.2 & 0.55 & 4.10 & 1.61 & 0.19 & 0 & 0.06 & 46.6 & 0.25 & 129 & 143 & 1.31 & 5.05 & 10.3 & 54.7 & 40.2 & 24.8 & 17.6 & 9.29 & 6.57 & 0 & 11.0 & 79.5 & 5.26 & 5.72 \\
\hline $16-03$ & 13.4 & 74.4 & 0.47 & 3.59 & 2.47 & 0.19 & 0 & 0.08 & 0.0 & 0.28 & 149 & 153 & 1.62 & 6.23 & 14.6 & 55.9 & 45.7 & 25.1 & 21.4 & 8.54 & 6.87 & 0 & 12.6 & 108 & 2.94 & 1.36 \\
\hline $16-03$ & 13.6 & 74.6 & 0.37 & 2.75 & 5.11 & 0.18 & 0 & 0.13 & 165 & 0.29 & 146 & 146 & 1.63 & 5.87 & 12.3 & 42.5 & 43.2 & 29.5 & 19.3 & 7.90 & 6.65 & 0 & 11.7 & 124 & 1.44 & 0 \\
\hline $16-03$ & 13.8 & 74.8 & 0.27 & 1.73 & 9.56 & 0.16 & 0 & 0.17 & 0.0 & 0.26 & 134 & 146 & 1.63 & 5.41 & 6.96 & 26.7 & 31.7 & 27.3 & 18.4 & 7.89 & 4.97 & 0 & 9.29 & 108 & 1.57 & 0.64 \\
\hline $16-03$ & 14 & 75 & 0.17 & 0.63 & 14.8 & 0.16 & 0.03 & 0.21 & 0.0 & 0.26 & 123 & 141 & 1.62 & 5.30 & 6.13 & 16.0 & 25.1 & 20.9 & 17.1 & 7.40 & 3.66 & 0 & 7.05 & 102 & 1.15 & 0 \\
\hline $16-03$ & 14.2 & 75.2 & 0.13 & 0.28 & 16.8 & 0.16 & 0.05 & 0.21 & 97.2 & 0.24 & 120 & 140 & 1.39 & 4.69 & 5.02 & 13.5 & 22.1 & 21.3 & 18.9 & 7.81 & 3.81 & 0 & 7.90 & 111 & 0.76 & 0 \\
\hline $16-03$ & 14.4 & 75.4 & 0.11 & 0 & 18.4 & 0.15 & 0.05 & 0.24 & 0 & 0.25 & 124 & 142 & 1.60 & 5.26 & 6.61 & 15.2 & 25.2 & 23.3 & 18.0 & 7.66 & 3.46 & 0 & 8.17 & 105 & 2.09 & 0 \\
\hline $16-03$ & 14.6 & 75.6 & 0.18 & 0.69 & 14.6 & 0.15 & 0.02 & 0.21 & 0 & 0.24 & 126 & 146 & 1.53 & 5.29 & 6.91 & 25.5 & 30.3 & 23.2 & 19.9 & 7.82 & 6.12 & 0.22 & 12.1 & 119 & 1.69 & 0.25 \\
\hline $16-03$ & 14.8 & 75.8 & 0.31 & 1.95 & 9.34 & 0.16 & 0 & 0.13 & 162 & 0.26 & 133 & 144 & 1.99 & 6.07 & 7.21 & 38.1 & 35.3 & 27.1 & 20.2 & 8.27 & 7.10 & 0.12 & 10.9 & 131 & 1.49 & 2.10 \\
\hline $16-03$ & 15 & 76 & 0.43 & 3.18 & 4.72 & 0.18 & 0 & 0.08 & 649 & 0.32 & 160 & 154 & 2.06 & 7.03 & 12.7 & 57.6 & 45.8 & 37.4 & 25.3 & 8.93 & 6.78 & 0.09 & 11.9 & 143 & 1.93 & 2.05 \\
\hline $16-03$ & 15.2 & 76.2 & 0.47 & 3.47 & 4.58 & 0.17 & 0 & 0.06 & 0.0 & 0.31 & 154 & 152 & 1.76 & 6.35 & 12.1 & 55.0 & 43.9 & 35.0 & 25.6 & 9.56 & 9.76 & 3.91 & 13.0 & 125 & 3.01 & 0 \\
\hline $16-03$ & 15.4 & 76.4 & 0.42 & 2.89 & 9.31 & 0.16 & 0 & 0.06 & 473 & 0.24 & 118 & 136 & 1.32 & 4.50 & 6.74 & 46.0 & 35.2 & 27.6 & 22.3 & 8.36 & 3.54 & 0.45 & 9.48 & 103 & 1.97 & 0 \\
\hline $16-03$ & 15.6 & 76.6 & 0.30 & 1.83 & 13.8 & 0.16 & 0 & 0.09 & 0 & 0.23 & 113 & 143 & 1.53 & 5.22 & 5.50 & 34.2 & 29.8 & 22.5 & 17.8 & 8.23 & 2.07 & 0.00 & 9.40 & 106 & 1.64 & 0 \\
\hline $16-03$ & 15.8 & 76.8 & 0.21 & 0.86 & 18.3 & 0.16 & 0 & 0.14 & 0 & 0.23 & 117 & 147 & 1.12 & 4.82 & 8.06 & 25.6 & 24.8 & 22.6 & 19.1 & 7.59 & 2.95 & 0.03 & 7.55 & 133 & 1.24 & 0 \\
\hline $16-03$ & 16 & 77 & 0.19 & 0.80 & 19.8 & 0.15 & 0.03 & 0.16 & 0 & 0 & 0 & 0 & 0 & 0 & 0 & 0 & 0 & 0 & 0 & 0 & 0 & 0 & 0 & 0 & 0 & 0 \\
\hline $16-03$ & 16.2 & 77.2 & 0.14 & 0 & 24.3 & 0.15 & 0.04 & 0.19 & 0 & 0.23 & 112 & 135 & 1.41 & 4.63 & 5.69 & 16.4 & 20.6 & 20.8 & 17.7 & 7.77 & 2.85 & 0.00 & 7.97 & 130 & 1.59 & 0 \\
\hline $16-03$ & 16.4 & 77.4 & 0.09 & 0 & 26.1 & 0.14 & 0.07 & 0.24 & 0 & 0.23 & 111 & 130 & 1.52 & 4.56 & 5.65 & 13.3 & 20.1 & 22.6 & 18.0 & 7.76 & 4.75 & 2.43 & 8.96 & 124 & 1.82 & 0 \\
\hline $16-03$ & 16.6 & 77.6 & 0.09 & 0 & 26.9 & 0.13 & 0.09 & 0.29 & 0 & 0.24 & 120 & 133 & 1.74 & 5.05 & 5.24 & 7.84 & 20.3 & 23.3 & 19.6 & 7.08 & 2.07 & 1.26 & 9.72 & 141 & 0.90 & 0 \\
\hline $16-03$ & 16.8 & 77.8 & 0.09 & 0 & 28.0 & 0.12 & 0.13 & 0.33 & 0 & 0.23 & 116 & 134 & 1.88 & 5.34 & 4.89 & 7.85 & 20.8 & 21.5 & 17.8 & 6.85 & 3.27 & 0.78 & 6.89 & 151 & 0.95 & 0 \\
\hline $16-03$ & 17 & 78 & 0.14 & 0.14 & 23.7 & 0.14 & 0.08 & 0.26 & 0 & 0.23 & 115 & 135 & 1.77 & 5.18 & 5.15 & 9.77 & 15.6 & 19.7 & 16.6 & 7.40 & 0.00 & 0 & 5.23 & 155 & 1.11 & 0.49 \\
\hline $16-03$ & 17.2 & 78.2 & 0.25 & 1.27 & 16.4 & 0.14 & 0 & 0.18 & 0 & 0.21 & 108 & 139 & 1.61 & 5.03 & 4.06 & 16.5 & 20.8 & 21.0 & 17.9 & 6.99 & 1.84 & 0 & 2.86 & 161 & 0.00 & 0 \\
\hline $16-03$ & 17.4 & 78.4 & 0.33 & 2.23 & 10.8 & 0.14 & 0 & 0.13 & 167 & 0.22 & 120 & 145 & 1.32 & 5.10 & 9.41 & 26.6 & 22.1 & 22.2 & 19.0 & 8.62 & 4.76 & 0 & 7.29 & 134 & 2.06 & 2.71 \\
\hline $16-03$ & 17.6 & 78.6 & 0.42 & 3.07 & 6.38 & 0.15 & 0 & 0.10 & 1114 & 0.21 & 112 & 140 & 1.22 & 4.57 & 6.74 & 30.8 & 26.6 & 18.9 & 14.5 & 8.62 & 7.12 & 0 & 5.55 & 129 & 1.80 & 5.64 \\
\hline $16-03$ & 17.8 & 78.8 & 0.48 & 3.59 & 4.86 & 0.17 & 0 & 0.07 & 149 & 0.19 & 106 & 137 & 1.08 & 4.17 & 5.87 & 40.7 & 24.0 & 17.8 & 14.8 & 9.29 & 4.39 & 2.08 & 4.01 & 95 & 2.49 & 2.02 \\
\hline $16-03$ & 18 & 79 & 0.54 & 4.00 & 2.95 & 0.18 & 0 & 0.05 & 158 & 0.19 & 106 & 132 & 0.91 & 3.55 & 5.92 & 49.1 & 25.1 & 16.0 & 16.2 & 10.2 & 5.13 & 0 & 5.29 & 105 & 1.82 & 6.22 \\
\hline $16-03$ & 18.2 & 79.2 & 0.56 & 4.26 & 1.31 & 0.17 & 0 & 0.03 & 648 & 0.19 & 104 & 134 & 1.24 & 4.27 & 5.59 & 58.7 & 29.8 & 19.4 & 17.9 & 9.73 & 7.19 & 1.37 & 7.79 & 99.7 & 3.52 & 7.34 \\
\hline $16-03$ & 18.4 & 79.4 & 0.61 & 4.54 & 0.42 & 0.17 & 0 & 0.02 & 0 & 0.16 & 92 & 136 & 0.98 & 4.49 & 11.7 & 87.2 & 36.0 & 18.7 & 20.6 & 9.55 & 8.76 & 0 & 8.62 & 112 & 2.73 & 8.08 \\
\hline
\end{tabular}

Zero values are below detection limit 


\begin{tabular}{|c|c|c|c|c|c|c|c|c|c|c|c|c|c|c|c|c|c|c|c|c|c|c|c|c|c|c|}
\hline ఫัँ & $\begin{array}{l}\widehat{E} \\
0 \\
\overline{0} \\
\overline{0} \\
\overline{0} \\
0 \\
0 \\
0 \\
0\end{array}$ & 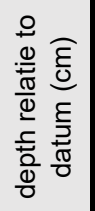 & $\frac{\substack{0 \\
\frac{0}{3}}}{z}$ & $\frac{\widehat{d}}{\frac{0}{3}}$ & $\frac{\widehat{d}}{\frac{0}{3}}$ & $\frac{a}{\stackrel{0}{a}}$ & $\frac{\widehat{0}}{\frac{0}{3}}$ & $\underbrace{\overparen{O}}_{0}$ & $\begin{array}{l}\widehat{E} \\
\stackrel{0}{0} \\
\mathbb{0} \\
\infty\end{array}$ & 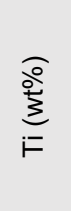 & $\begin{array}{l}\widehat{\varepsilon} \\
\stackrel{0}{0} \\
\bar{u}\end{array}$ & 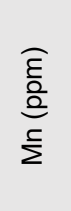 & 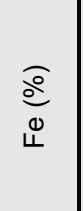 & $\begin{array}{l}\widehat{\hat{\varepsilon}} \\
\text { 응 } \\
\text { O }\end{array}$ & $\begin{array}{l}\widehat{\bar{\varepsilon}} \\
\frac{\overline{0}}{\overline{2}} \\
\bar{z}\end{array}$ & $\begin{array}{l}\widehat{\varepsilon} \\
\stackrel{0}{0} \\
\stackrel{J}{0}\end{array}$ & $\begin{array}{l}\widehat{\hat{\varepsilon}} \\
\hat{0} \\
\bar{N}\end{array}$ & $\begin{array}{l}\widehat{\varepsilon} \\
\frac{0}{0} \\
\frac{0}{4}\end{array}$ & $\begin{array}{l}\widehat{\hat{\varepsilon}} \\
\text { 응 } \\
\text { 음 }\end{array}$ & $\begin{array}{l}\widehat{\hat{\varepsilon}} \\
\text { 을 } \\
\infty \\
\infty\end{array}$ & $\begin{array}{l}\widehat{\hat{\varepsilon}} \\
\hat{0} \\
\hat{0} \\
\bar{q}\end{array}$ & $\begin{array}{l}\widehat{\hat{\sigma}} \\
\frac{\hat{0}}{\bar{\omega}}\end{array}$ & $\begin{array}{l}\widehat{\varepsilon} \\
\frac{\hat{0}}{2} \\
\succ\end{array}$ & $\begin{array}{l}\widehat{E} \\
\text { 은 } \\
\grave{N}\end{array}$ & $\begin{array}{l}\widehat{\hat{\varepsilon}} \\
\hat{0} \\
\text { ôे }\end{array}$ & $\begin{array}{l}\widehat{\varepsilon} \\
\text { 을 } \\
\text { 일 }\end{array}$ \\
\hline 16-03 & 18.6 & 79.6 & 0.62 & 4.76 & 0 & 0.18 & 0 & 0.01 & 0 & 0.16 & 103 & 141 & 0.60 & 4.10 & 15.0 & 129 & 58.3 & 18.7 & 20.2 & 11.0 & 9.25 & 0.00 & 9.26 & 105 & 3.92 & 6.56 \\
\hline $16-04$ & 0 & 95 & 0.24 & 1.42 & 8.55 & 0.14 & 0.04 & 0.28 & 343 & 0.57 & 299 & 0 & 0 & 8.40 & 24.4 & 91.0 & 103 & 92.7 & 45.3 & 9.70 & 20.6 & 17.3 & 14.7 & 258 & 4.63 & 10.4 \\
\hline $16-04$ & 0.2 & 95.2 & 0.26 & 1.62 & 8.10 & 0.15 & 0.03 & 0.26 & 465 & 0.55 & 295 & 158 & 0.80 & 10.1 & 25.5 & 84.9 & 96.7 & 86.4 & 44.3 & 9.76 & 18.7 & 15.7 & 14.8 & 274 & 3.23 & 10.2 \\
\hline $16-04$ & 0.4 & 95.4 & 0.23 & 1.33 & 9.05 & 0.15 & 0.04 & 0.27 & 590 & 0.56 & 286 & 240 & 0.75 & 9.78 & 25.8 & 84.7 & 104 & 87.9 & 43.1 & 8.87 & 20.8 & 16.4 & 14.2 & 266 & 2.87 & 13.2 \\
\hline $16-04$ & 0.6 & 95.6 & 0.22 & 1.14 & 9.19 & 0.15 & 0.04 & 0.27 & 130 & 0.58 & 301 & 272 & 1.54 & 11.1 & 26.1 & 74.3 & 98.2 & 92.2 & 46.5 & 9.49 & 21.1 & 16.8 & 14.5 & 242 & 3.70 & 9.65 \\
\hline $16-04$ & 0.8 & 95.8 & 0.23 & 1.26 & 8.97 & 0.14 & 0.03 & 0.26 & 311 & 0.57 & 300 & 286 & 0.97 & 9.56 & 25.9 & 83.4 & 103 & 88.1 & 45.9 & 10.0 & 17.7 & 18.2 & 14.0 & 272 & 3.67 & 11.9 \\
\hline $16-04$ & 1 & 96 & 0.21 & 1.08 & 9.74 & 0.15 & 0.04 & 0.27 & 28.3 & 0.56 & 279 & 302 & 1.95 & 10.7 & 23.9 & 80.2 & 102 & 80.9 & 43.6 & 9.81 & 16.1 & 15.6 & 13.1 & 290 & 4.80 & 11.0 \\
\hline $16-04$ & 1.2 & 96.2 & 0.21 & 1.11 & 9.51 & 0.15 & 0.04 & 0.26 & 0 & 0.56 & 289 & 274 & 1.15 & 9.31 & 27.6 & 75.4 & 99.4 & 78.1 & 43.8 & 9.90 & 18.6 & 13.6 & 13.2 & 330 & 3.72 & 11.1 \\
\hline $16-04$ & 1.4 & 96.4 & 0.21 & 0.97 & 9.76 & 0.15 & 0.04 & 0.25 & 0 & 0.55 & 289 & 249 & 2.06 & 10.6 & 25.9 & 72.6 & 98.3 & 77.5 & 42.5 & 9.59 & 20.3 & 14.3 & 14.3 & 329 & 3.65 & 13.7 \\
\hline $16-04$ & 1.6 & 96.6 & 0.23 & 1.23 & 9.03 & 0.15 & 0.03 & 0.23 & 391 & 0.55 & 280 & 226 & 1.36 & 8.87 & 25.7 & 74.9 & 94.1 & 74.4 & 38.5 & 9.25 & 18.0 & 13.8 & 14.0 & 313 & 5.02 & 12.2 \\
\hline $16-04$ & 1.8 & 96.8 & 0.23 & 1.29 & 9.29 & 0.15 & 0.04 & 0.24 & 358 & 0.54 & 266 & 215 & 2.34 & 10.3 & 23.2 & 81.7 & 93.2 & 69.1 & 39.3 & 9.06 & 18.0 & 14.8 & 12.8 & 336 & 4.18 & 11.9 \\
\hline $16-04$ & 2 & 97 & 0.23 & 1.27 & 9.44 & 0.15 & 0.03 & 0.23 & 46.6 & 0.55 & 271 & 210 & 2.72 & 11.0 & 22.5 & 81.0 & 97.2 & 70.6 & 39.5 & 8.96 & 18.2 & 11.9 & 14.4 & 358 & 3.90 & 13.9 \\
\hline $16-04$ & 2.2 & 97.2 & 0.23 & 1.20 & 9.17 & 0.15 & 0.03 & 0.23 & 109 & 0.54 & 261 & 205 & 1.96 & 8.83 & 18.8 & 81.3 & 98.7 & 66.6 & 37.2 & 9.33 & 19.0 & 11.9 & 12.4 & 341 & 3.44 & 11.2 \\
\hline $16-04$ & 2.4 & 97.4 & 0.24 & 1.49 & 8.54 & 0.15 & 0.02 & 0.24 & 0 & 0.56 & 259 & 214 & 1.86 & 9.67 & 25.2 & 88.0 & 94.5 & 62.9 & 37.3 & 9.07 & 18.4 & 14.8 & 10.1 & 309 & 5.01 & 10.6 \\
\hline $16-04$ & 2.6 & 97.6 & 0.26 & 1.62 & 7.82 & 0.16 & 0.02 & 0.22 & 251 & 0.54 & 246 & 209 & 2.20 & 9.78 & 21.8 & 87.6 & 102 & 71.8 & 40.8 & 9.46 & 18.5 & 11.8 & 12.8 & 287 & 3.68 & 12.4 \\
\hline $16-04$ & 2.8 & 97.8 & 0.27 & 1.81 & 7.54 & 0.16 & 0.02 & 0.23 & 0.0 & 0.55 & 259 & 203 & 1.98 & 9.68 & 24.5 & 93.2 & 104 & 77.9 & 40.5 & 9.29 & 18.9 & 13.5 & 12.6 & 270 & 5.48 & 8.82 \\
\hline $16-04$ & 3 & 98 & 0.30 & 1.99 & 6.78 & 0.16 & 0.02 & 0.22 & 0.0 & 0.55 & 254 & 200 & 2.26 & 9.95 & 23.0 & 90.5 & 99.5 & 65.3 & 35.4 & 9.34 & 21.3 & 14.7 & 15.2 & 280 & 4.39 & 10.2 \\
\hline $16-04$ & 3.2 & 98.2 & 0.29 & 2.01 & 6.45 & 0.16 & 0.02 & 0.21 & 0.0 & 0.56 & 228 & 213 & 2.12 & 10.3 & 25.6 & 102 & 106 & 70.9 & 39.0 & 9.30 & 18.9 & 18.2 & 12.6 & 315 & 2.80 & 14.1 \\
\hline $16-04$ & 3.4 & 98.4 & 0.31 & 2.20 & 5.95 & 0.16 & 0.03 & 0.22 & 592 & 0.59 & 260 & 218 & 1.79 & 10.5 & 27.7 & 109 & 118 & 83.2 & 44.2 & 9.09 & 22.6 & 19.7 & 15.4 & 310 & 4.20 & 12.6 \\
\hline $16-04$ & 3.6 & 98.6 & 0.30 & 2.04 & 6.55 & 0.16 & 0.04 & 0.23 & 55.4 & 0.62 & 284 & 225 & 1.07 & 9.83 & 29.2 & 132 & 134 & 80.1 & 41.4 & 10.2 & 23.8 & 23.4 & 17.2 & 294 & 4.35 & 12.0 \\
\hline $16-04$ & 3.8 & 98.8 & 0.32 & 2.15 & 6.81 & 0.16 & 0.04 & 0.23 & 0 & 0.64 & 317 & 227 & 0 & 7.86 & 30.4 & 154 & 146 & 84.9 & 42.1 & 9.06 & 27.7 & 26.5 & 16.7 & 295 & 3.57 & 9.06 \\
\hline $16-04$ & 4 & 99 & 0.34 & 2.28 & 6.33 & 0.17 & 0.03 & 0.21 & 339 & 0.64 & 319 & 239 & 0 & 8.98 & 36.9 & 195 & 170 & 80.7 & 41.7 & 11.2 & 31.7 & 29.8 & 21.5 & 267 & 5.98 & 8.08 \\
\hline $16-04$ & 4.2 & 99.2 & 0.38 & 2.59 & 5.74 & 0.17 & 0.03 & 0.18 & 0 & 0.63 & 279 & 238 & 0 & 8.79 & 35.9 & 277 & 215 & 90.5 & 41.6 & 13.8 & 36.2 & 33.7 & 22.3 & 225 & 5.41 & 10.9 \\
\hline $16-04$ & 4.4 & 99.4 & 0.48 & 3.41 & 3.20 & 0.18 & 0 & 0.12 & 460 & 0.43 & 153 & 198 & 2.96 & 11.7 & 33.9 & 324 & 163 & 59.3 & 35.2 & 12.5 & 20.9 & 20.9 & 2.4 & 185 & 2.45 & 11.5 \\
\hline $16-04$ & 4.6 & 99.6 & 0.46 & 3.40 & 2.52 & 0.18 & 0 & 0.10 & 530 & 0.50 & 216 & 195 & 3.70 & 12.5 & 25.2 & 199 & 123 & 46.2 & 30.5 & 9.80 & 21.5 & 15.0 & 11.7 & 209 & 4.58 & 9.83 \\
\hline $16-04$ & 4.8 & 99.8 & 0.42 & 3.10 & 3.07 & 0.16 & 0 & 0.11 & 0 & 0.52 & 229 & 205 & 2.61 & 10.7 & 24.8 & 141 & 115 & 48.6 & 33.4 & 8.92 & 23.8 & 16.5 & 16.9 & 203 & 5.94 & 4.63 \\
\hline $16-04$ & 5 & 100 & 0.30 & 2.05 & 6.40 & 0.16 & 0.04 & 0.18 & 619 & 0.54 & 245 & 213 & 2.39 & 11.1 & 28.2 & 132 & 121 & 49.8 & 33.1 & 9.98 & 25.1 & 22.7 & 15.6 & 236 & 4.27 & 14.4 \\
\hline $16-04$ & 5.2 & 100.2 & 0.27 & 1.68 & 7.69 & 0.16 & 0.07 & 0.23 & 257 & 0.55 & 265 & 207 & 2.89 & 11.1 & 21.1 & 125 & 122 & 54.1 & 31.2 & 9.23 & 24.9 & 22.5 & 18.5 & 246 & 5.04 & 7.44 \\
\hline $16-04$ & 5.4 & 100.4 & 0.26 & 1.67 & 8.11 & 0.15 & 0.08 & 0.24 & 229 & 0.57 & 276 & 215 & 2.23 & 11.2 & 28.5 & 111 & 123 & 59.6 & 36.9 & 9.13 & 24.2 & 25.5 & 19.5 & 254 & 5.24 & 10.5 \\
\hline $16-04$ & 5.6 & 100.6 & 0.28 & 1.91 & 6.98 & 0.15 & 0.07 & 0.22 & 131 & 0.56 & 266 & 213 & 2.42 & 11.2 & 26.8 & 119 & 125 & 59.1 & 33.1 & 9.77 & 25.2 & 21.5 & 16.3 & 261 & 4.90 & 13.1 \\
\hline $16-04$ & 5.8 & 100.8 & 0.31 & 2.14 & 6.23 & 0.16 & 0.04 & 0.20 & 0 & 0.54 & 241 & 213 & 2.64 & 11.8 & 28.5 & 116 & 118 & 60.3 & 34.3 & 9.67 & 25.3 & 20.8 & 17.2 & 232 & 5.58 & 8.30 \\
\hline $16-04$ & 6 & 101 & 0.33 & 2.37 & 5.46 & 0.16 & 0.02 & 0.19 & 17.6 & 0.56 & 246 & 216 & 2.25 & 11.0 & 28.3 & 115 & 124 & 70.0 & 34.9 & 9.35 & 25.9 & 17.5 & 17.0 & 228 & 5.99 & 14.2 \\
\hline $16-04$ & 6.2 & 101.2 & 0.39 & 2.93 & 3.45 & 0.17 & 0 & 0.15 & 432 & 0.55 & 249 & 212 & 2.66 & 11.1 & 25.6 & 112 & 114 & 62.8 & 36.9 & 9.69 & 21.2 & 17.9 & 15.5 & 239 & 5.25 & 15.2 \\
\hline $16-04$ & 6.4 & 101.4 & 0.40 & 3.04 & 3.12 & 0.17 & 0 & 0.14 & 806 & 0.51 & 248 & 199 & 2.85 & 11.3 & 25.5 & 115 & 113 & 65.2 & 39.1 & 9.17 & 24.8 & 15.6 & 17.3 & 237 & 5.17 & 13.6 \\
\hline $16-04$ & 6.6 & 101.6 & 0.42 & 3.10 & 2.98 & 0.17 & 0 & 0.14 & 0 & 0.53 & 252 & 214 & 3.38 & 12.5 & 25.6 & 109 & 106 & 61.3 & 33.4 & 11.2 & 18.9 & 17.9 & 13.6 & 223 & 6.40 & 9.06 \\
\hline $16-04$ & 6.8 & 101.8 & 0.39 & 3.02 & 2.98 & 0.17 & 0 & 0.14 & 701 & 0.52 & 249 & 227 & 3.63 & 13.1 & 25.2 & 117 & 118 & 71.9 & 41.2 & 10.5 & 26.6 & 15.6 & 15.0 & 223 & 6.68 & 16.9 \\
\hline $16-04$ & 7 & 102 & 0.40 & 3.12 & 2.76 & 0.17 & 0 & 0.14 & 10.3 & 0.54 & 268 & 239 & 2.24 & 10.6 & 25.4 & 119 & 121 & 73.4 & 42.1 & 9.82 & 23.1 & 18.1 & 13.6 & 218 & 5.60 & 10.8 \\
\hline $16-04$ & 7.2 & 102.2 & 0.43 & 3.33 & 2.07 & 0.17 & 0 & 0.12 & 771 & 0.53 & 268 & 256 & 2.63 & 11.6 & 25.0 & 124 & 126 & 70.9 & 33.2 & 10.6 & 21.5 & 17.7 & 16.4 & 226 & 5.94 & 8.60 \\
\hline
\end{tabular}

Zero values are below detection limit 


\begin{tabular}{|c|c|c|c|c|c|c|c|c|c|c|c|c|c|c|c|c|c|c|c|c|c|c|c|c|c|c|}
\hline ֻัँ & 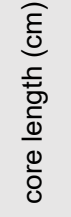 & 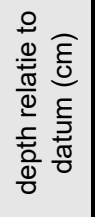 & $\frac{\widehat{\partial}}{\frac{0}{3}}$ & $\frac{\widehat{o}}{\frac{0}{3}}$ & $\frac{\widehat{o}}{\text { के }}$ & 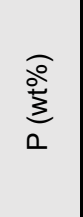 & $\frac{\substack{0 \\
\frac{0}{3}}}{x}$ & $\frac{\widehat{o}}{\stackrel{0}{\infty}}$ & 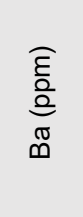 & 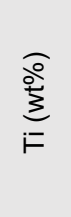 & $\begin{array}{l}\widehat{\varepsilon} \\
\stackrel{0}{0} \\
\bar{u}\end{array}$ & 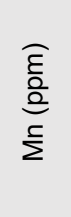 & $\frac{\widehat{\varrho}}{\stackrel{0}{\longleftarrow}}$ & $\begin{array}{l}\widehat{\varepsilon} \\
\text { 을 } \\
\text { ᄋ }\end{array}$ & $\frac{\widehat{\hat{\varepsilon}}}{\stackrel{\bar{o}}{0}}$ & $\begin{array}{l}\widehat{\hat{\varepsilon}} \\
\stackrel{0}{0} \\
\vec{\jmath}\end{array}$ & $\begin{array}{l}\widehat{\hat{\sigma}} \\
\hat{0} \\
\bar{N}\end{array}$ & $\begin{array}{l}\widehat{\hat{\varepsilon}} \\
\frac{0}{2} \\
\frac{0}{<}\end{array}$ & $\begin{array}{l}\widehat{\hat{\varepsilon}} \\
\hat{\circ} \\
\stackrel{0}{0}\end{array}$ & $\begin{array}{l}\widehat{\hat{\varepsilon}} \\
\text { 을 } \\
\infty \\
\infty\end{array}$ & $\begin{array}{l}\widehat{\hat{\varepsilon}} \\
\hat{0} \\
\hat{\alpha}\end{array}$ & $\begin{array}{l}\widehat{\bar{\varepsilon}} \\
\frac{\overline{0}}{2} \\
\bar{\omega}\end{array}$ & $\begin{array}{l}\widehat{\hat{\theta}} \\
\stackrel{0}{0}\end{array}$ & $\frac{\widehat{\varepsilon}}{\frac{0}{2}}$ & $\begin{array}{l}\widehat{\varepsilon} \\
\text { 을 } \\
\text { हo }\end{array}$ & $\begin{array}{l}\widehat{\varepsilon} \\
\text { 을 } \\
\stackrel{\circ}{\Sigma}\end{array}$ \\
\hline $16-04$ & 7.4 & 102.4 & 0.44 & 3.44 & 1.65 & 0.17 & 0 & 0.11 & 0 & 0.56 & 268 & 286 & 2.24 & 11.6 & 28.6 & 142 & 121 & 83.8 & 40.1 & 10.4 & 21.7 & 19.4 & 15.8 & 272 & 4.81 & 18.9 \\
\hline $16-04$ & 7.6 & 102.6 & 0.41 & 3.12 & 2.57 & 0.17 & 0 & 0.12 & 9.6 & 0.58 & 303 & 278 & 2.05 & 11.0 & 26.8 & 131 & 120 & 90.3 & 50.9 & 10.8 & 20.9 & 19.5 & 17.2 & 300 & 5.39 & 19.4 \\
\hline $16-04$ & 7.8 & 102.8 & 0.38 & 2.83 & 3.66 & 0.16 & 0 & 0.15 & 445 & 0.56 & 282 & 289 & 2.06 & 10.6 & 22.6 & 98.4 & 102 & 71.5 & 43.8 & 10.6 & 24.3 & 19.5 & 17.0 & 328 & 5.65 & 15.2 \\
\hline $16-04$ & 8 & 103 & 0.36 & 2.62 & 4.73 & 0.16 & 0 & 0.18 & 688 & 0.56 & 289 & 235 & 0.83 & 10.5 & 26.7 & 98.6 & 111 & 84.6 & 45.5 & 10.0 & 23.7 & 17.9 & 19.9 & 316 & 6.39 & 19.9 \\
\hline $16-04$ & 8.2 & 103.2 & 0.34 & 2.39 & 5.45 & 0.16 & 0 & 0.21 & 1492 & 0.57 & 293 & 0 & 0.00 & 8.50 & 31.2 & 98.7 & 121 & 84.9 & 43.7 & 10.8 & 20.2 & 25.8 & 22.8 & 301 & 6.13 & 16.9 \\
\hline $16-04$ & 8.4 & 103.4 & 0.33 & 2.24 & 6.08 & 0.16 & 0 & 0.23 & 229 & 0.59 & 315 & 0 & 0.00 & 8.72 & 29.6 & 95.6 & 117 & 78.3 & 41.7 & 10.1 & 21.6 & 22.5 & 18.2 & 296 & 5.77 & 13.1 \\
\hline $16-04$ & 8.6 & 103.6 & 0.30 & 1.95 & 7.50 & 0.16 & 0 & 0.24 & 843 & 0.57 & 306 & 0 & 0.00 & 6.67 & 27.5 & 100 & 103 & 88.5 & 43.6 & 8.86 & 20.8 & 19.4 & 15.3 & 282 & 5.23 & 11.7 \\
\hline $16-04$ & 8.8 & 103.8 & 0.33 & 2.14 & 7.50 & 0.17 & 0 & 0.20 & 320 & 0.54 & 284 & 200 & 0.00 & 6.61 & 22.4 & 88.8 & 102 & 70.6 & 38.8 & 9.68 & 18.2 & 15.7 & 11.6 & 265 & 3.49 & 9.81 \\
\hline $16-04$ & 9 & 104 & 0.43 & 3.06 & 4.53 & 0.18 & 0 & 0.12 & 0 & 0 & 0 & 0 & 0 & 0 & 0 & 0 & 0 & 0 & 0 & 0 & 0 & 0 & 0 & 0 & 0 & 0 \\
\hline $16-04$ & 9.2 & 104.2 & 0.61 & 4.55 & 0 & 0.20 & 0 & 0.04 & 1845 & 0.48 & 228 & 152 & 0.00 & 5.61 & 34.1 & 311 & 146 & 75.7 & 45.6 & 0 & 0 & 0 & 0 & 0 & 0 & 0 \\
\hline $14-01$ & 0 & 105 & 0.44 & 3.26 & 3.34 & 0.16 & 0 & 0.82 & 18.8 & 0.37 & 184 & 215 & 0.79 & 6.67 & 16.7 & 101 & 60.4 & 39.4 & 26.7 & 9.23 & 12.7 & 0.88 & 0 & 575 & 5.40 & 20.6 \\
\hline $14-01$ & 0.2 & 105.2 & 0.33 & 2.24 & 7.19 & 0.15 & 0 & 0.85 & 280 & 0.43 & 213 & 224 & 2.01 & 8.72 & 15.8 & 66.3 & 48.9 & 44.4 & 29.1 & 10.12 & 11.4 & 1.97 & 20.0 & 843 & 3.52 & 26.2 \\
\hline $14-01$ & 0.4 & 105.4 & 0.20 & 1.04 & 12.1 & 0.14 & 0 & 0.88 & 329 & 0.46 & 239 & 208 & 2.26 & 8.84 & 14.0 & 43.1 & 51.3 & 46.5 & 29.4 & 8.96 & 12.8 & 1.24 & 22.1 & 795 & 4.67 & 23.5 \\
\hline $14-01$ & 0.6 & 105.6 & 0.13 & 0.26 & 16.0 & 0.12 & 0.03 & 0.82 & 135 & 0.44 & 229 & 210 & 2.02 & 8.60 & 13.6 & 35.5 & 46.7 & 44.5 & 28.6 & 8.50 & 9.03 & 0 & 18.9 & 686 & 2.55 & 19.5 \\
\hline $14-01$ & 0.8 & 105.8 & 0.10 & 0.09 & 18.1 & 0.13 & 0.03 & 0.76 & 751 & 0.44 & 226 & 217 & 2.32 & 9.74 & 16.6 & 34.4 & 47.2 & 46.9 & 29.9 & 8.63 & 8.12 & 0 & 16.9 & 676 & 1.28 & 21.5 \\
\hline $14-01$ & 1 & 106 & 0.07 & 0 & 19.8 & 0.12 & 0.06 & 0 & 0 & 0 & 0 & 0 & 0 & 0 & 0 & 0 & 0 & 0 & 0 & 0 & 0 & 0 & 0 & 0 & 0 & 0 \\
\hline $14-01$ & 1.2 & 106.2 & 0.06 & 0 & 20.7 & 0.12 & 0.08 & 1.12 & 822 & 0.47 & 241 & 229 & 2.37 & 9.68 & 16.6 & 34.2 & 50.0 & 44.1 & 28.4 & 8.92 & 9.51 & 4.17 & 20.1 & 1273 & 2.76 & 24.7 \\
\hline $14-01$ & 1.4 & 106.4 & 0.07 & 0 & 21.5 & 0.11 & 0.08 & 1.13 & 719 & 0.51 & 272 & 223 & 2.26 & 9.58 & 15.8 & 36.3 & 46.9 & 37.5 & 25.4 & 9.23 & 7.41 & 1.08 & 17.8 & 1327 & 2.52 & 23.1 \\
\hline $14-01$ & 1.6 & 106.6 & 0.07 & 0 & 21.3 & 0.12 & 0.08 & 1.01 & 651 & 0.51 & 269 & 229 & 0.91 & 8.65 & 15.6 & 28.3 & 47.1 & 38.5 & 24.9 & 8.65 & 9.59 & 0.00 & 15.7 & 1022 & 1.86 & 26.5 \\
\hline $14-01$ & 1.8 & 106.8 & 0.08 & 0 & 21.5 & 0.12 & 0.07 & 0.88 & 202 & 0.48 & 248 & 221 & 0.77 & 8.27 & 14.2 & 28.9 & 45.1 & 38.4 & 26.3 & 9.22 & 8.69 & 1.56 & 17.4 & 994 & 3.22 & 23.4 \\
\hline $14-01$ & 2 & 107 & 0.08 & 0 & 20.5 & 0.11 & 0.07 & 1.02 & 1021 & 0.49 & 259 & 238 & 1.80 & 9.90 & 15.9 & 34.6 & 50.2 & 43.7 & 27.5 & 9.47 & 10.8 & 4.75 & 19.9 & 1417 & 2.69 & 21.2 \\
\hline $14-01$ & 2.2 & 107.2 & 0.09 & 0 & 18.8 & 0.11 & 0.08 & 1.15 & 821 & 0.54 & 285 & 237 & 3.17 & 11.4 & 17.7 & 37.6 & 60.4 & 47.9 & 30.1 & 9.47 & 14.5 & 6.55 & 22.8 & 1832 & 3.10 & 6.43 \\
\hline $14-01$ & 2.4 & 107.4 & 0.11 & 0.05 & 16.1 & 0.11 & 0.07 & 1.26 & 764 & 0.55 & 284 & 244 & 3.15 & 11.3 & 18.8 & 42.4 & 71.1 & 53.3 & 33.2 & 9.09 & 17.1 & 13.74 & 24.9 & 1739 & 3.18 & 10.2 \\
\hline $14-01$ & 2.6 & 107.6 & 0.11 & 0.20 & 16.7 & 0.11 & 0.10 & 1.23 & 552 & 0.50 & 258 & 216 & 3.44 & 11.2 & 16.5 & 39.2 & 64.1 & 53.5 & 33.1 & 8.57 & 12.9 & 14.35 & 21.8 & 1331 & 2.83 & 22.3 \\
\hline $14-01$ & 2.8 & 107.8 & 0.13 & 0.27 & 16.9 & 0.11 & 0.07 & 1.05 & 525 & 0.43 & 222 & 197 & 2.46 & 8.81 & 13.4 & 27.3 & 48.7 & 41.4 & 28.2 & 8.31 & 10.5 & 4.68 & 15.2 & 876 & 2.91 & 23.1 \\
\hline $14-01$ & 3 & 108 & 0.16 & 0.41 & 16.2 & 0.13 & 0.04 & 0.84 & 532 & 0.36 & 183 & 183 & 1.86 & 7.59 & 10.9 & 18.3 & 42.5 & 37.0 & 25.3 & 8.05 & 8.19 & 0 & 13.5 & 517 & 2.22 & 16.5 \\
\hline $14-01$ & 3.2 & 108.2 & 0.15 & 0.29 & 15.5 & 0.13 & 0.04 & 0.75 & 490 & 0.38 & 192 & 188 & 2.57 & 9.09 & 10.5 & 18.4 & 54.9 & 36.2 & 27.0 & 8.62 & 10.9 & 0.29 & 15.1 & 747 & 2.04 & 21.6 \\
\hline $14-01$ & 3.4 & 108.4 & 0.15 & 0.61 & 14.1 & 0.12 & 0.05 & 0.82 & 793 & 0.48 & 251 & 217 & 3.13 & 10.8 & 14.8 & 37.3 & 64.9 & 50.0 & 32.1 & 8.71 & 15.5 & 4.66 & 20.6 & 1615 & 3.00 & 15.0 \\
\hline $14-01$ & 3.6 & 108.6 & 0.13 & 0.38 & 14.9 & 0.12 & 0.07 & 0.91 & 915 & 0.55 & 294 & 224 & 3.64 & 11.9 & 16.9 & 41.2 & 67.2 & 53.1 & 32.1 & 9.44 & 17.4 & 8.98 & 23.8 & 2057 & 3.52 & 0 \\
\hline $14-01$ & 3.8 & 108.8 & 0.11 & 0.33 & 16.0 & 0.11 & 0.08 & 0.92 & 498 & 0.52 & 273 & 223 & 3.47 & 11.8 & 18.5 & 40.8 & 62.2 & 52.3 & 31.9 & 9.16 & 15.8 & 8.17 & 22.7 & 1951 & 3.27 & 0.17 \\
\hline $14-01$ & 4 & 109 & 0.11 & 0.31 & 15.8 & 0.12 & 0.08 & 0.93 & 871 & 0.49 & 254 & 204 & 3.48 & 11.2 & 15.5 & 32.3 & 60.4 & 53.8 & 33.4 & 8.79 & 16.1 & 7.17 & 23.2 & 1296 & 3.64 & 21.8 \\
\hline $14-01$ & 4.2 & 109.2 & 0.10 & 0.00 & 16.6 & 0.11 & 0.09 & 0.90 & 650 & 0.47 & 246 & 196 & 3.68 & 11.5 & 15.7 & 36.6 & 55.9 & 55.0 & 32.4 & 8.84 & 16.2 & 6.97 & 22.1 & 1107 & 2.56 & 24.1 \\
\hline $14-01$ & 4.4 & 109.4 & 0.12 & 0.52 & 15.0 & 0.12 & 0.08 & 0.94 & 1312 & 0.48 & 251 & 207 & 3.86 & 12.3 & 17.6 & 39.9 & 62.6 & 52.2 & 31.3 & 8.67 & 15.3 & 5.45 & 24.4 & 986 & 3.23 & 23.8 \\
\hline $14-01$ & 4.6 & 109.6 & 0.11 & 0.08 & 15.7 & 0.12 & 0.08 & 0.99 & 640 & 0.49 & 254 & 216 & 3.24 & 11.3 & 17.2 & 38.8 & 61.3 & 51.0 & 32.1 & 8.06 & 16.3 & 7.48 & 19.5 & 776 & 2.96 & 21.7 \\
\hline $14-01$ & 4.8 & 109.8 & 0.11 & 0.13 & 15.4 & 0.12 & 0.07 & 1.11 & 766 & 0.48 & 250 & 223 & 3.50 & 12.0 & 17.8 & 35.9 & 65.1 & 50.0 & 31.7 & 8.98 & 14.9 & 8.88 & 20.5 & 766 & 2.60 & 23.7 \\
\hline $14-01$ & 5 & 110 & 0.11 & 0 & 16.8 & 0.11 & 0.08 & 1.12 & 785 & 0.47 & 244 & 219 & 3.01 & 11.3 & 19.7 & 33.7 & 64.7 & 46.9 & 29.4 & 8.59 & 15.2 & 6.90 & 21.0 & 797 & 3.40 & 21.6 \\
\hline $14-01$ & 5.2 & 110.2 & 0.10 & 0.24 & 17.2 & 0.11 & 0.07 & 1.10 & 375 & 0.44 & 223 & 217 & 3.00 & 10.5 & 14.8 & 31.4 & 61.8 & 45.5 & 27.9 & 8.73 & 13.2 & 6.94 & 20.7 & 1000 & 3.24 & 24.2 \\
\hline $14-01$ & 5.4 & 110.4 & 0.11 & 0.20 & 16.7 & 0.11 & 0.07 & 1.07 & 218 & 0.45 & 231 & 217 & 2.86 & 10.3 & 14.4 & 30.8 & 57.8 & 44.4 & 28.3 & 8.99 & 12.4 & 8.25 & 21.3 & 1209 & 2.59 & 25.1 \\
\hline
\end{tabular}

Zero values are below detection limit 


\begin{tabular}{|c|c|c|c|c|c|c|c|c|c|c|c|c|c|c|c|c|c|c|c|c|c|c|c|c|c|c|}
\hline ๖ัँ & 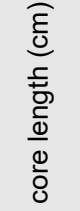 & 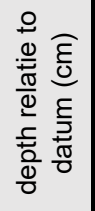 & $\frac{\substack{0 \\
\frac{0}{3}}}{\frac{\pi}{2}}$ & $\frac{\widehat{o}}{\frac{o}{3}}$ & $\frac{\widehat{o}}{\text { के }}$ & $\frac{\widehat{o}}{\stackrel{0}{3}}$ & $\frac{\widehat{o}}{\stackrel{0}{a}}$ & 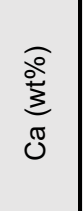 & $\begin{array}{l}\widehat{\varepsilon} \\
\stackrel{0}{0} \\
\mathbb{\infty}\end{array}$ & $\frac{\widehat{o}}{\stackrel{o}{3}}$ & 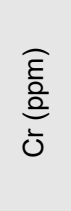 & $\begin{array}{l}\hat{\varepsilon} \\
\text { 을 } \\
\text { c }\end{array}$ & $\underset{\stackrel{0}{\varrho}}{\stackrel{0}{\varrho}}$ & $\begin{array}{l}\widehat{\hat{\varepsilon}} \\
\text { 을 } \\
\text { ᄋ }\end{array}$ & $\begin{array}{l}\widehat{\bar{\varepsilon}} \\
\stackrel{\overline{0}}{\underline{2}} \\
\bar{z}\end{array}$ & $\begin{array}{l}\widehat{\hat{\theta}} \\
\hat{0} \\
\vec{J}\end{array}$ & $\begin{array}{l}\widehat{\hat{\varepsilon}} \\
\frac{0}{0} \\
\bar{N}\end{array}$ & $\begin{array}{l}\widehat{\hat{\varepsilon}} \\
\stackrel{0}{0} \\
\stackrel{0}{<}\end{array}$ & $\begin{array}{l}\widehat{\varepsilon} \\
\text { 응 } \\
\text { 음 }\end{array}$ & $\begin{array}{l}\widehat{\varepsilon} \\
\text { 을 } \\
\text { ळ }\end{array}$ & $\begin{array}{l}\widehat{\hat{\varepsilon}} \\
\frac{0}{2} \\
\text { 옹 }\end{array}$ & 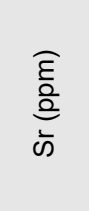 & $\begin{array}{l}\widehat{\bar{\varepsilon}} \\
\frac{0}{2} \\
\succ\end{array}$ & $\begin{array}{l}\widehat{E} \\
\frac{0}{0} \\
\bar{N}\end{array}$ & $\begin{array}{l}\widehat{\hat{\varepsilon}} \\
\hat{\circ} \\
\text { 을 }\end{array}$ & $\begin{array}{l}\widehat{\hat{\varepsilon}} \\
\text { 을 } \\
\stackrel{\circ}{\Sigma}\end{array}$ \\
\hline $14-01$ & 5.6 & 110.6 & 0.12 & 0.28 & 16.1 & 0.11 & 0.07 & 1.07 & 412 & 0.44 & 224 & 216 & 2.89 & 10.4 & 15.1 & 29.4 & 57.6 & 44.6 & 29.1 & 8.84 & 14.1 & 7.58 & 20.79 & 1139 & 2.58 & 24.4 \\
\hline $14-01$ & 5.8 & 110.8 & 0.13 & 0.39 & 15.6 & 0.11 & 0.07 & 1.00 & 668 & 0.44 & 225 & 211 & 2.88 & 10.3 & 14.6 & 29.5 & 58.4 & 47.3 & 29.1 & 8.75 & 14.2 & 7.19 & 19.61 & 1051 & 2.41 & 24.1 \\
\hline $14-01$ & 6 & 111 & 0.12 & 0.16 & 17.8 & 0.11 & 0.07 & 0.91 & 215 & 0.42 & 216 & 202 & 2.98 & 9.89 & 10.7 & 23.3 & 48.2 & 41.4 & 27.7 & 8.67 & 11.8 & 5.37 & 17.12 & 1064 & 2.91 & 24.7 \\
\hline $14-01$ & 6.2 & 111.2 & 0.13 & 0.21 & 19.2 & 0.11 & 0.06 & 0.87 & 715 & 0.45 & 233 & 205 & 2.78 & 9.69 & 12.8 & 30.3 & 46.3 & 41.1 & 28.5 & 9.09 & 13.7 & 6.22 & 19.47 & 1379 & 2.92 & 22.3 \\
\hline $14-01$ & 6.4 & 111.4 & 0.10 & 0 & 20.4 & 0.11 & 0.10 & 0.97 & 548 & 0.49 & 256 & 210 & 3.14 & 10.7 & 15.1 & 31.2 & 51.9 & 46.9 & 29.4 & 8.99 & 13.0 & 8.42 & 22.27 & 1380 & 2.79 & 22.1 \\
\hline $14-01$ & 6.6 & 111.6 & 0.10 & 0 & 19.5 & 0.11 & 0.13 & 1.14 & 198 & 0.50 & 262 & 224 & 3.25 & 11.4 & 17.3 & 38.4 & 55.1 & 55.0 & 34.1 & 8.93 & 15.0 & 9.75 & 23.55 & 1218 & 2.92 & 23.9 \\
\hline $14-01$ & 6.8 & 111.8 & 0.10 & 0 & 18.3 & 0.11 & 0.13 & 1.23 & 586 & 0.52 & 270 & 234 & 3.55 & 12.4 & 19.2 & 42.9 & 64.1 & 62.3 & 35.5 & 8.57 & 15.2 & 10.87 & 26.11 & 1193 & 3.85 & 23.0 \\
\hline $14-01$ & 7 & 112 & 0.10 & 0.12 & 18.2 & 0.11 & 0.12 & 1.27 & 662 & 0.52 & 256 & 250 & 3.55 & 12.7 & 21.2 & 44.8 & 73.2 & 62.9 & 37.4 & 8.83 & 15.2 & 13.98 & 25.51 & 1444 & 3.50 & 19.3 \\
\hline $14-01$ & 7.2 & 112.2 & 0.09 & 0.22 & 18.3 & 0.11 & 0.10 & 1.36 & 296 & 0.50 & 258 & 231 & 3.21 & 11.9 & 21.5 & 43.0 & 68.2 & 54.3 & 31.7 & 8.96 & 15.5 & 13.93 & 24.94 & 1400 & 3.12 & 21.0 \\
\hline $14-01$ & 7.4 & 112.4 & 0.10 & 0.27 & 18.4 & 0.11 & 0.10 & 1.41 & 446 & 0.48 & 251 & 215 & 3.07 & 10.9 & 17.3 & 30.1 & 54.5 & 49.0 & 31.2 & 9.03 & 13.3 & 12.03 & 21.07 & 1146 & 2.81 & 25.2 \\
\hline $14-01$ & 7.6 & 112.6 & 0.11 & 0 & 19.2 & 0.11 & 0.11 & 1.29 & 691 & 0.45 & 233 & 201 & 3.21 & 10.8 & 15.3 & 30.7 & 49.8 & 46.3 & 29.7 & 8.60 & 12.2 & 12.01 & 15.49 & 910 & 3.03 & 24.8 \\
\hline $14-01$ & 7.8 & 112.8 & 0.11 & 0 & 19.5 & 0.11 & 0.11 & 1.21 & 578 & 0.43 & 223 & 206 & 2.82 & 10.1 & 13.7 & 24.7 & 46.8 & 40.5 & 27.7 & 8.59 & 11.7 & 10.60 & 18.48 & 902 & 2.73 & 24.9 \\
\hline $14-01$ & 8 & 113 & 0.11 & 0 & 20.8 & 0.11 & 0.13 & 1.15 & 512 & 0.40 & 205 & 198 & 2.70 & 9.57 & 12.3 & 23.0 & 45.5 & 39.6 & 27.8 & 8.75 & 10.5 & 11.56 & 16.38 & 738 & 2.62 & 23.5 \\
\hline $14-01$ & 8.2 & 113.2 & 0.11 & 0.08 & 22.5 & 0.11 & 0.12 & 1.11 & 272 & 0.38 & 194 & 193 & 2.51 & 8.97 & 10.7 & 23.4 & 40.3 & 39.1 & 26.6 & 8.48 & 9.29 & 6.88 & 15.15 & 591 & 2.13 & 18.1 \\
\hline $14-01$ & 8.4 & 113.4 & 0.10 & 0.15 & 22.5 & 0.11 & 0.10 & 1.00 & 633 & 0.36 & 185 & 191 & 2.61 & 9.38 & 12.6 & 18.3 & 39.6 & 37.6 & 26.7 & 8.36 & 10.3 & 8.04 & 11.60 & 540 & 2.86 & 18.6 \\
\hline $14-01$ & 8.6 & 113.6 & 0.12 & 0.03 & 21.6 & 0.12 & 0.07 & 0.87 & 211 & 0.35 & 176 & 182 & 2.21 & 8.17 & 9.3 & 18.3 & 37.6 & 35.8 & 25.7 & 8.35 & 9.19 & 3.78 & 13.80 & 523 & 1.79 & 16.2 \\
\hline $14-01$ & 8.8 & 113.8 & 0.11 & 0 & 22.9 & 0.11 & 0.08 & 0.72 & 383 & 0.35 & 176 & 180 & 2.55 & 8.88 & 10.3 & 19.3 & 35.1 & 32.3 & 23.8 & 8.13 & 9.15 & 4.12 & 12.42 & 496 & 2.20 & 16.7 \\
\hline $14-01$ & 9 & 114 & 0.10 & 0 & 21.9 & 0.12 & 0.08 & 0.67 & 303 & 0.35 & 173 & 178 & 2.80 & 9.20 & 9.18 & 17.8 & 37.5 & 34.7 & 24.5 & 8.59 & 11.7 & 3.08 & 11.69 & 471 & 1.67 & 15.1 \\
\hline $14-01$ & 9.2 & 114.2 & 0.11 & 0 & 21.9 & 0.12 & 0.07 & 0.60 & 0.0 & 0.33 & 161 & 172 & 2.51 & 8.51 & 9.38 & 20.0 & 33.0 & 32.2 & 24.1 & 8.64 & 9.81 & 2.67 & 11.00 & 382 & 1.47 & 10.3 \\
\hline $14-01$ & 9.4 & 114.4 & 0.12 & 0.08 & 22.3 & 0.12 & 0.05 & 0.49 & 201 & 0.29 & 146 & 165 & 1.77 & 6.56 & 6.40 & 10.8 & 27.5 & 24.7 & 19.4 & 8.22 & 8.08 & 2.21 & 8.10 & 353 & 1.17 & 10.3 \\
\hline $14-01$ & 9.6 & 114.6 & 0.11 & 0 & 22.1 & 0.13 & 0.06 & 0.47 & 179 & 0.28 & 137 & 161 & 1.74 & 6.43 & 5.78 & 9.9 & 25.0 & 23.4 & 19.1 & 8.23 & 7.28 & 0.00 & 8.81 & 392 & 0.91 & 10.3 \\
\hline $14-01$ & 9.8 & 114.8 & 0.12 & 0 & 19.9 & 0.13 & 0.07 & 0.52 & 309 & 0.33 & 156 & 167 & 2.09 & 7.57 & 8.50 & 13.4 & 33.1 & 29.6 & 21.8 & 8.16 & 8.50 & 1.71 & 10.43 & 378 & 1.99 & 8.80 \\
\hline $14-01$ & 10 & 115 & 0.13 & 0.18 & 18.7 & 0.13 & 0.08 & 0.57 & 597 & 0.36 & 178 & 177 & 2.41 & 8.40 & 9.45 & 10.0 & 40.6 & 34.6 & 25.5 & 8.13 & 10.6 & 3.63 & 9.77 & 332 & 2.87 & 8.90 \\
\hline $14-01$ & 10.2 & 115.2 & 0.14 & 0.10 & 18.1 & 0.13 & 0.07 & 0.63 & 309 & 0.38 & 186 & 182 & 2.86 & 9.59 & 10.6 & 18.1 & 43.3 & 39.3 & 23.8 & 8.26 & 12.8 & 6.45 & 11.82 & 317 & 2.35 & 6.33 \\
\hline $14-01$ & 10.4 & 115.4 & 0.15 & 0.62 & 16.0 & 0.13 & 0.07 & 0.70 & 589 & 0.41 & 209 & 198 & 2.99 & 10.3 & 11.9 & 26.7 & 51.3 & 46.4 & 31.0 & 8.35 & 13.2 & 6.70 & 14.39 & 280 & 3.03 & 4.72 \\
\hline $14-01$ & 10.6 & 115.6 & 0.16 & 0.73 & 14.0 & 0.12 & 0.06 & 0.78 & 111 & 0.44 & 224 & 213 & 2.87 & 10.4 & 12.7 & 29.1 & 60.0 & 54.0 & 32.9 & 8.17 & 15.3 & 6.89 & 14.37 & 267 & 2.56 & 3.81 \\
\hline $14-01$ & 10.8 & 115.8 & 0.17 & 0.72 & 13.1 & 0.11 & 0.07 & 0.81 & 442 & 0.44 & 226 & 216 & 2.54 & 10.4 & 16.8 & 28.2 & 59.8 & 52.7 & 33.5 & 8.20 & 15.3 & 6.65 & 12.97 & 301 & 1.71 & 3.25 \\
\hline $14-01$ & 11 & 116 & 0.16 & 0.74 & 13.0 & 0.10 & 0.08 & 0.76 & 540 & 0.41 & 206 & 203 & 2.68 & 10.1 & 13.2 & 26.9 & 55.1 & 44.9 & 29.2 & 8.74 & 11.5 & 8.10 & 15.31 & 370 & 2.83 & 10.8 \\
\hline $14-01$ & 11.2 & 116.2 & 0.17 & 0.67 & 12.9 & 0.10 & 0.06 & 0.71 & 0.0 & 0.37 & 183 & 185 & 2.08 & 8.31 & 12.6 & 21.8 & 48.4 & 34.9 & 25.4 & 8.61 & 11.0 & 5.03 & 12.33 & 588 & 1.35 & 15.9 \\
\hline $14-01$ & 11.4 & 116.4 & 0.17 & 0.73 & 12.9 & 0.09 & 0.05 & 0.69 & 350 & 0.36 & 184 & 171 & 2.42 & 8.08 & 11.4 & 23.8 & 43.5 & 30.1 & 22.0 & 8.18 & 8.81 & 3.31 & 12.73 & 719 & 1.41 & 20.3 \\
\hline $14-01$ & 11.6 & 116.6 & 0.15 & 0.65 & 13.6 & 0.09 & 0.05 & 0.70 & 454 & 0.37 & 187 & 157 & 2.63 & 7.77 & 10.0 & 23.3 & 40.3 & 28.7 & 21.0 & 8.31 & 9.37 & 2.98 & 14.08 & 768 & 2.43 & 20.7 \\
\hline $14-01$ & 11.8 & 116.8 & 0.15 & 0.49 & 14.0 & 0.09 & 0.06 & 0.70 & 404 & 0.38 & 191 & 152 & 3.30 & 9.39 & 14.0 & 22.8 & 43.8 & 28.3 & 21.6 & 8.90 & 10.9 & 4.39 & 13.80 & 728 & 2.05 & 20.9 \\
\hline $14-01$ & 12 & 117 & 0.14 & 0.27 & 15.0 & 0.10 & 0.07 & 0.71 & 324 & 0.35 & 181 & 148 & 3.38 & 8.95 & 9.68 & 21.8 & 42.2 & 27.4 & 21.5 & 8.76 & 9.45 & 4.41 & 13.42 & 653 & 1.90 & 18.6 \\
\hline $14-01$ & 12.2 & 117.2 & 0.13 & 0.23 & 15.8 & 0.10 & 0.07 & 0.75 & 398 & 0.36 & 185 & 149 & 3.38 & 9.37 & 13.2 & 21.3 & 43.7 & 29.8 & 22.4 & 8.29 & 9.90 & 3.69 & 13.35 & 543 & 1.80 & 15.1 \\
\hline $14-01$ & 12.4 & 117.4 & 0.13 & 0.22 & 16.1 & 0.10 & 0.07 & 0.78 & 0.0 & 0.35 & 181 & 148 & 3.21 & 8.81 & 11.6 & 21.5 & 41.1 & 30.7 & 22.3 & 8.45 & 8.39 & 4.78 & 13.05 & 432 & 1.79 & 9.88 \\
\hline $14-01$ & 12.6 & 117.6 & 0.14 & 0.35 & 16.0 & 0.10 & 0.07 & 0.77 & 110 & 0.38 & 192 & 152 & 3.60 & 10.0 & 14.4 & 24.2 & 40.2 & 35.0 & 24.4 & 8.28 & 9.36 & 4.32 & 13.65 & 326 & 1.50 & 8.00 \\
\hline $14-01$ & 12.8 & 117.8 & 0.16 & 0.66 & 14.7 & 0.10 & 0.08 & 0.75 & 252 & 0.37 & 188 & 150 & 3.54 & 9.43 & 10.4 & 24.2 & 43.6 & 35.7 & 24.3 & 8.05 & 10.3 & 3.58 & 14.37 & 326 & 2.08 & 6.51 \\
\hline $14-01$ & 13 & 118 & 0.16 & 0.56 & 13.5 & 0.10 & 0.07 & 0.68 & 510 & 0.40 & 202 & 154 & 3.45 & 9.63 & 12.3 & 24.9 & 47.5 & 39.3 & 25.4 & 8.20 & 10.8 & 8.29 & 14.11 & 370 & 2.45 & 9.84 \\
\hline
\end{tabular}

Zero values are below detection limit 


\begin{tabular}{|c|c|c|c|c|c|c|c|c|c|c|c|c|c|c|c|c|c|c|c|c|c|c|c|c|c|c|}
\hline ๖ัँ & 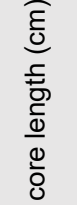 & 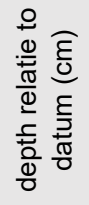 & $\frac{\widehat{o}}{\frac{0}{3}}$ & 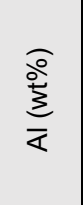 & $\frac{\widehat{o}}{\text { के }}$ & $\frac{\widehat{o}}{\frac{0}{3}}$ & $\begin{array}{l}\frac{0}{a} \\
\frac{0}{3} \\
\frac{3}{3}\end{array}$ & $\frac{\widehat{ఠ}}{\stackrel{0}{\infty}}$ & $\begin{array}{l}\widehat{\bar{\varepsilon}} \\
\stackrel{0}{0} \\
\mathbb{D}\end{array}$ & $\underbrace{\widehat{o}}_{i=}$ & $\begin{array}{l}\widehat{\varepsilon} \\
\text { 을 } \\
\bar{u}\end{array}$ & $\begin{array}{l}\hat{\varepsilon} \\
\text { 을 } \\
\text { c }\end{array}$ & 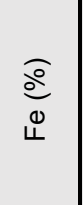 & $\begin{array}{l}\widehat{\hat{g}} \\
\text { 응 } \\
\text { ᄋ }\end{array}$ & $\begin{array}{l}\widehat{\hat{\varepsilon}} \\
\stackrel{\overline{0}}{\overline{2}} \\
\bar{z}\end{array}$ & $\begin{array}{l}\widehat{\hat{\Xi}} \\
\stackrel{0}{0} \\
\vec{\jmath}\end{array}$ & $\begin{array}{l}\widehat{\hat{\varepsilon}} \\
\text { 을 } \\
\text { N }\end{array}$ & $\begin{array}{l}\widehat{\hat{\varepsilon}} \\
\frac{0}{0} \\
\frac{0}{<}\end{array}$ & $\begin{array}{l}\widehat{\hat{\varepsilon}} \\
\text { 응 } \\
\stackrel{0}{0}\end{array}$ & 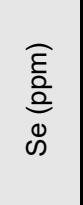 & 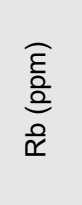 & $\begin{array}{l}\widehat{\hat{\varepsilon}} \\
\overline{0} \\
\bar{c}\end{array}$ & $\begin{array}{l}\widehat{\hat{\varepsilon}} \\
\hat{0} \\
>\end{array}$ & $\begin{array}{l}\widehat{\hat{\varepsilon}} \\
\text { 을 } \\
\hat{N}\end{array}$ & $\begin{array}{l}\widehat{\hat{\varepsilon}} \\
\hat{0} \\
\frac{0}{z}\end{array}$ & $\begin{array}{l}\widehat{\varepsilon} \\
\text { 을 } \\
\stackrel{\circ}{z}\end{array}$ \\
\hline $14-01$ & 13.2 & 118.2 & 0.16 & 0.52 & 12.7 & 0.10 & 0.07 & 0.65 & 196 & 0.41 & 211 & 157 & 3.87 & 10.8 & 14.0 & 31.1 & 49.6 & 42.2 & 29.7 & 7.90 & 11.3 & 7.91 & 17.8 & 410 & 2.31 & 10.1 \\
\hline $14-01$ & 13.4 & 118.4 & 0.17 & 0.74 & 12.1 & 0.10 & 0.06 & 0.62 & 0 & 0.40 & 207 & 158 & 3.76 & 11.1 & 17.5 & 24.1 & 50.1 & 43.4 & 26.8 & 8.33 & 10.2 & 6.53 & 16.2 & 402 & 2.20 & 10.4 \\
\hline $14-01$ & 13.6 & 118.6 & 0.17 & 0.74 & 12.3 & 0.10 & 0.07 & 0.63 & 632 & 0.42 & 218 & 161 & 3.84 & 11.2 & 16.9 & 30.0 & 56.7 & 46.7 & 29.2 & 8.17 & 11.8 & 9.58 & 13.9 & 404 & 2.03 & 9.71 \\
\hline $14-01$ & 13.8 & 118.8 & 0.16 & 0.59 & 12.6 & 0.10 & 0.07 & 0.65 & 434 & 0.43 & 224 & 165 & 4.04 & 11.4 & 15.0 & 29.5 & 52.3 & 46.2 & 28.7 & 8.84 & 13.1 & 8.73 & 13.5 & 461 & 2.28 & 12.9 \\
\hline $14-01$ & 14 & 119 & 0.15 & 0.30 & 13.3 & 0.09 & 0.07 & 0.61 & 324 & 0.44 & 228 & 164 & 3.54 & 10.5 & 15.4 & 34.5 & 52.4 & 47.5 & 28.7 & 8.00 & 10.9 & 9.20 & 17.0 & 505 & 1.55 & 16.4 \\
\hline $14-01$ & 14.2 & 119.2 & 0.13 & 0.49 & 14.0 & 0.10 & 0.09 & 0.59 & 156 & 0.42 & 213 & 157 & 3.70 & 10.9 & 17.2 & 32.1 & 52.9 & 45.8 & 31.4 & 8.78 & 14.3 & 10.3 & 15.8 & 503 & 2.37 & 14.0 \\
\hline $14-01$ & 14.4 & 119.4 & 0.11 & 0.37 & 14.9 & 0.10 & 0.10 & 0.60 & 359 & 0.42 & 214 & 155 & 3.67 & 10.9 & 18.5 & 31.7 & 54.3 & 44.6 & 29.0 & 8.52 & 12.7 & 9.37 & 14.7 & 477 & 2.70 & 11.6 \\
\hline $14-01$ & 14.6 & 119.6 & 0.12 & 0.15 & 14.8 & 0.10 & 0.11 & 0.59 & 42.1 & 0.43 & 219 & 156 & 4.20 & 11.6 & 15.2 & 30.4 & 54.7 & 43.7 & 28.7 & 8.23 & 13.9 & 11.2 & 13.6 & 443 & 2.54 & 12.8 \\
\hline $14-01$ & 14.8 & 119.8 & 0.12 & 0.14 & 14.4 & 0.09 & 0.10 & 0.60 & 524 & 0.45 & 231 & 159 & 3.85 & 11.2 & 17.0 & 32.9 & 56.1 & 45.3 & 28.3 & 8.41 & 12.9 & 13.6 & 14.7 & 468 & 2.55 & 13.2 \\
\hline $14-01$ & 15 & 120 & 0.13 & 0.25 & 13.8 & 0.09 & 0.09 & 0.61 & 507 & 0.45 & 229 & 159 & 3.99 & 11.4 & 16.1 & 33.7 & 57.3 & 49.4 & 29.5 & 8.74 & 14.4 & 11.4 & 16.9 & 477 & 2.78 & 13.5 \\
\hline $14-01$ & 15.2 & 120.2 & 0.14 & 0.51 & 13.4 & 0.10 & 0.08 & 0.63 & 13.7 & 0.44 & 223 & 159 & 3.54 & 10.6 & 16.7 & 36.9 & 55.3 & 46.1 & 29.3 & 8.51 & 12.7 & 11.0 & 14.1 & 468 & 2.55 & 13.2 \\
\hline $14-01$ & 15.4 & 120.4 & 0.15 & 0.57 & 12.9 & 0.11 & 0.07 & 0.60 & 302 & 0.43 & 220 & 158 & 3.85 & 10.8 & 13.6 & 34.5 & 53.7 & 47.0 & 30.7 & 8.61 & 11.7 & 9.55 & 16.0 & 497 & 2.09 & 12.9 \\
\hline $14-01$ & 15.6 & 120.6 & 0.16 & 0.72 & 12.5 & 0.11 & 0.07 & 0.60 & 977 & 0.42 & 215 & 157 & 4.02 & 11.3 & 15.5 & 33.2 & 51.2 & 47.0 & 30.0 & 8.44 & 14.4 & 11.3 & 13.8 & 492 & 2.58 & 14.7 \\
\hline $14-01$ & 15.8 & 120.8 & 0.15 & 0.58 & 13.1 & 0.11 & 0.07 & 0.62 & 340 & 0.42 & 215 & 162 & 3.29 & 10.2 & 17.3 & 32.0 & 53.2 & 43.1 & 28.7 & 8.65 & 14.0 & 11.4 & 14.9 & 515 & 2.13 & 15.3 \\
\hline $14-01$ & 16 & 121 & 0.14 & 0.53 & 13.7 & 0.11 & 0.07 & 0.65 & 0.0 & 0.42 & 216 & 168 & 3.07 & 9.73 & 16.6 & 31.6 & 51.5 & 44.7 & 27.5 & 8.29 & 12.5 & 11.6 & 14.9 & 483 & 1.99 & 13.7 \\
\hline $14-01$ & 16.2 & 121.2 & 0.12 & 0.35 & 14.6 & 0.09 & 0.08 & 0.65 & 325 & 0.42 & 214 & 171 & 3.20 & 9.92 & 15.5 & 33.1 & 49.3 & 42.3 & 28.0 & 8.46 & 12.0 & 14.6 & 13.7 & 496 & 2.60 & 14.5 \\
\hline $14-01$ & 16.4 & 121.4 & 0.11 & 0.07 & 15.3 & 0.08 & 0.10 & 0.62 & 890 & 0.42 & 217 & 174 & 3.28 & 10.1 & 14.8 & 31.8 & 51.0 & 43.3 & 28.7 & 8.59 & 12.9 & 13.9 & 13.2 & 527 & 2.04 & 14.3 \\
\hline $14-01$ & 16.6 & 121.6 & 0.09 & 0.12 & 16.0 & 0.07 & 0.12 & 0.61 & 123 & 0.42 & 217 & 175 & 3.38 & 10.3 & 14.6 & 25.7 & 50.9 & 44.0 & 29.2 & 8.57 & 9.88 & 10.1 & 13.7 & 569 & 2.21 & 14.5 \\
\hline $14-01$ & 16.8 & 121.8 & 0.09 & 0.32 & 16.0 & 0.07 & 0.11 & 0.58 & 625 & 0.42 & 215 & 178 & 3.38 & 10.3 & 13.8 & 32.6 & 52.3 & 42.1 & 28.1 & 8.25 & 10.7 & 16.1 & 13.0 & 558 & 2.00 & 16.5 \\
\hline $14-01$ & 17 & 122 & 0.10 & 0.05 & 16.2 & 0.07 & 0.11 & 0.59 & 116 & 0.42 & 214 & 186 & 3.26 & 10.4 & 15.2 & 28.0 & 52.9 & 47.4 & 30.0 & 8.24 & 11.7 & 18.3 & 12.9 & 552 & 1.58 & 16.2 \\
\hline $14-01$ & 17.2 & 122.2 & 0.10 & 0 & 16.2 & 0.07 & 0.11 & 0 & 0 & 0 & 0 & 0 & 0 & 0 & 0 & 0 & 0 & 0 & 0 & 0 & 0 & 0 & 0 & 0 & 0 & 0 \\
\hline $14-01$ & 17.4 & 122.4 & 0.10 & 0.29 & 15.6 & 0.08 & 0.11 & 0.59 & 685 & 0.43 & 220 & 192 & 3.10 & 10.5 & 16.8 & 31.7 & 55.5 & 46.0 & 28.7 & 8.06 & 12.6 & 23.7 & 12.1 & 430 & 1.23 & 11.2 \\
\hline $14-01$ & 17.6 & 122.6 & 0.10 & 0.33 & 15.6 & 0.08 & 0.11 & 0.62 & 430 & 0.44 & 222 & 191 & 2.88 & 10.0 & 15.7 & 35.7 & 55.6 & 45.9 & 30.4 & 8.30 & 12.0 & 27.5 & 14.3 & 455 & 2.25 & 12.5 \\
\hline $14-01$ & 17.8 & 122.8 & 0.10 & 0 & 15.7 & 0.08 & 0.11 & 0.61 & 0.0 & 0.42 & 214 & 190 & 3.27 & 10.9 & 17.2 & 31.7 & 59.6 & 48.8 & 31.2 & 7.92 & 12.2 & 21.4 & 11.4 & 422 & 2.11 & 10.2 \\
\hline $14-01$ & 18 & 123 & 0.10 & 0.07 & 15.5 & 0.08 & 0.10 & 0.58 & 0.0 & 0.42 & 215 & 192 & 3.47 & 11.1 & 15.0 & 32.0 & 60.3 & 53.3 & 33.2 & 8.35 & 13.1 & 18.8 & 10.7 & 371 & 0.81 & 8.46 \\
\hline $14-01$ & 18.2 & 123.2 & 0.10 & 0.28 & 15.4 & 0.09 & 0.09 & 0.57 & 164 & 0.41 & 212 & 193 & 3.39 & 11.3 & 17.7 & 33.1 & 60.1 & 55.9 & 34.8 & 8.22 & 13.4 & 14.4 & 9.29 & 339 & 1.22 & 9.64 \\
\hline $14-01$ & 18.4 & 123.4 & 0.10 & 0 & 15.4 & 0.09 & 0.08 & 0.59 & 176 & 0.44 & 228 & 198 & 3.02 & 10.4 & 15.9 & 36.3 & 59.6 & 59.0 & 34.8 & 8.49 & 13.9 & 11.2 & 9.10 & 258 & 2.57 & 3.65 \\
\hline $14-01$ & 18.6 & 123.6 & 0.10 & 0 & 15.7 & 0.09 & 0.09 & 0.60 & 258 & 0.42 & 217 & 197 & 3.00 & 10.7 & 18.4 & 35.7 & 58.4 & 59.0 & 35.9 & 8.42 & 13.7 & 7.96 & 11.0 & 300 & 2.37 & 3.46 \\
\hline $14-01$ & 18.8 & 123.8 & 0.08 & 0.04 & 16.0 & 0.09 & 0.09 & 0.61 & 625 & 0.42 & 216 & 196 & 3.14 & 10.8 & 17.2 & 35.2 & 57.5 & 55.2 & 33.0 & 8.33 & 15.5 & 7.75 & 9.89 & 323 & 1.71 & 7.79 \\
\hline $14-01$ & 19 & 124 & 0.09 & 0.11 & 15.6 & 0.09 & 0.10 & 0.60 & 605 & 0.44 & 226 & 204 & 2.98 & 10.5 & 16.4 & 34.5 & 61.1 & 50.9 & 31.9 & 8.58 & 14.2 & 7.92 & 9.96 & 353 & 2.22 & 6.92 \\
\hline $14-01$ & 19.2 & 124.2 & 0.11 & 0.11 & 14.9 & 0.10 & 0.09 & 0.60 & 358 & 0.45 & 229 & 205 & 2.69 & 10.1 & 17.0 & 33.3 & 60.3 & 52.9 & 32.6 & 8.53 & 13.0 & 8.21 & 9.99 & 326 & 2.52 & 7.11 \\
\hline $14-01$ & 19.4 & 124.4 & 0.11 & 0.09 & 15.2 & 0.10 & 0.09 & 0.62 & 345 & 0.44 & 228 & 207 & 2.94 & 10.5 & 16.6 & 37.8 & 64.0 & 50.1 & 31.6 & 8.11 & 13.1 & 8.18 & 11.1 & 320 & 2.53 & 8.27 \\
\hline $14-01$ & 19.6 & 124.6 & 0.13 & 0.13 & 14.3 & 0.10 & 0.08 & 0.61 & 88.9 & 0.45 & 232 & 194 & 2.85 & 9.85 & 15.8 & 38.3 & 59.7 & 46.3 & 30.3 & 8.29 & 13.2 & 7.90 & 11.8 & 342 & 1.77 & 9.88 \\
\hline $14-01$ & 19.8 & 124.8 & 0.14 & 0.45 & 13.2 & 0.10 & 0.06 & 0.60 & 126 & 0.44 & 226 & 199 & 2.99 & 10.4 & 17.0 & 34.1 & 61.3 & 49.8 & 31.2 & 8.30 & 14.5 & 5.65 & 10.2 & 406 & 2.15 & 11.7 \\
\hline $14-01$ & 20 & 125 & 0.15 & 0.49 & 12.8 & 0.10 & 0.07 & 0.57 & 95.0 & 0.45 & 232 & 194 & 2.80 & 9.90 & 16.9 & 44.6 & 62.9 & 48.9 & 32.9 & 8.76 & 12.6 & 8.11 & 11.4 & 517 & 2.58 & 14.3 \\
\hline $14-01$ & 20.2 & 125.2 & 0.16 & 0.59 & 12.4 & 0.10 & 0.07 & 0.58 & 197 & 0.47 & 241 & 192 & 3.21 & 10.6 & 16.2 & 39.2 & 63.5 & 50.3 & 31.3 & 8.65 & 13.9 & 7.35 & 9.30 & 547 & 2.82 & 16.6 \\
\hline $14-01$ & 20.4 & 125.4 & 0.16 & 0.59 & 12.7 & 0.10 & 0.06 & 0.57 & 192 & 0.47 & 246 & 208 & 2.98 & 10.9 & 19.2 & 43.6 & 71.2 & 47.1 & 28.2 & 9.34 & 14.3 & 7.73 & 12.1 & 572 & 2.75 & 19.1 \\
\hline $14-01$ & 20.6 & 125.6 & 0.18 & 0.87 & 12.3 & 0.12 & 0.05 & 0.55 & 0 & 0.46 & 237 & 220 & 2.96 & 10.4 & 14.4 & 39.9 & 68.8 & 46.4 & 30.6 & 8.57 & 13.5 & 8.35 & 11.8 & 477 & 2.33 & 17.3 \\
\hline
\end{tabular}

Zero values are below detection limit 


\begin{tabular}{|c|c|c|c|c|c|c|c|c|c|c|c|c|c|c|c|c|c|c|c|c|c|c|c|c|c|c|}
\hline ๖ัँ & 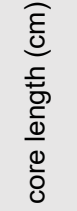 & 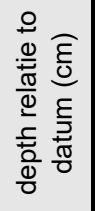 & $\frac{\substack{0 \\
\frac{0}{3}}}{\frac{\pi}{2}}$ & $\frac{\widehat{o}}{\frac{0}{c}}$ & $\frac{\widehat{o}}{\text { के }}$ & $\frac{\widehat{o}}{\stackrel{0}{3}}$ & $\frac{\widehat{o}}{\stackrel{0}{a}}$ & 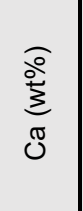 & $\begin{array}{l}\widehat{\bar{\varepsilon}} \\
\stackrel{0}{0} \\
\mathbb{D}\end{array}$ & $\frac{\widehat{o}}{\stackrel{o}{3}}$ & 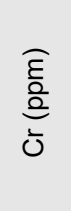 & $\begin{array}{l}\hat{\varepsilon} \\
\text { 을 } \\
\text { c }\end{array}$ & $\underset{\stackrel{0}{\varrho}}{\stackrel{0}{\varrho}}$ & $\begin{array}{l}\widehat{\hat{\varepsilon}} \\
\text { 을 } \\
\text { ᄋ }\end{array}$ & $\begin{array}{l}\widehat{\bar{\varepsilon}} \\
\frac{0}{2} \\
\bar{z}\end{array}$ & $\begin{array}{l}\widehat{\hat{g}} \\
\stackrel{0}{\varrho} \\
\mathcal{J}\end{array}$ & $\begin{array}{l}\widehat{\hat{\varepsilon}} \\
\text { 을 } \\
\text { N }\end{array}$ & $\begin{array}{l}\widehat{\hat{\varepsilon}} \\
\stackrel{0}{0} \\
\stackrel{0}{<}\end{array}$ & $\begin{array}{l}\widehat{\hat{\varepsilon}} \\
\overline{0} \\
\text { 응 }\end{array}$ & $\begin{array}{l}\widehat{\varepsilon} \\
\text { 을 } \\
\text { ळ }\end{array}$ & $\begin{array}{l}\widehat{\hat{\varepsilon}} \\
\frac{0}{2} \\
\text { 옹 }\end{array}$ & $\begin{array}{l}\widehat{\hat{\varepsilon}} \\
\stackrel{0}{0} \\
\bar{\omega}\end{array}$ & $\begin{array}{l}\widehat{\varepsilon} \\
\stackrel{0}{0} \\
>\end{array}$ & $\begin{array}{l}\widehat{E} \\
\frac{0}{0} \\
\bar{N}\end{array}$ & $\begin{array}{l}\widehat{\hat{\varepsilon}} \\
\hat{\circ} \\
\text { 을 }\end{array}$ & $\begin{array}{l}\widehat{\hat{\varepsilon}} \\
\text { 을 } \\
\stackrel{\circ}{\Sigma}\end{array}$ \\
\hline 14-01 & 20.8 & 125.8 & 0.21 & 1.11 & 12.4 & 0.12 & 0.04 & 0.51 & 331 & 0.43 & 222 & 213 & 2.26 & 9.12 & 15.0 & 36.9 & 59.5 & 41.8 & 28.4 & 8.60 & 10.9 & 8.25 & 10.9 & 465 & 2.52 & 15.2 \\
\hline $14-01$ & 21 & 126 & 0.22 & 1.20 & 12.1 & 0.12 & 0.04 & 0.49 & 0 & 0.39 & 199 & 190 & 2.16 & 8.37 & 13.8 & 34.9 & 53.7 & 35.3 & 25.2 & 8.56 & 9.60 & 4.50 & 7.88 & 412 & 2.20 & 12.5 \\
\hline $14-01$ & 21.2 & 126.2 & 0.19 & 0.98 & 12.6 & 0.12 & 0.04 & 0.50 & 0 & 0.37 & 191 & 186 & 2.22 & 8.16 & 12.4 & 34.0 & 53.6 & 33.1 & 23.6 & 8.29 & 9.69 & 4.63 & 6.87 & 444 & 2.03 & 12.8 \\
\hline $14-01$ & 21.4 & 126.4 & 0.15 & 0.41 & 14.2 & 0.11 & 0.09 & 0.46 & 0 & 0.38 & 192 & 172 & 2.16 & 7.36 & 9.56 & 27.5 & 46.9 & 26.6 & 20.7 & 7.87 & 8.92 & 0 & 4.11 & 442 & 1.19 & 14.4 \\
\hline $14-01$ & 21.6 & 126.6 & 0.12 & 0.34 & 16.4 & 0.11 & 0.15 & 0.43 & 187 & 0.34 & 166 & 153 & 1.59 & 5.63 & 7.58 & 17.0 & 35.7 & 16.4 & 15.7 & 7.67 & 3.88 & 0 & 0.60 & 340 & 0 & 10.6 \\
\hline $14-01$ & 21.8 & 126.8 & 0.13 & 0.21 & 17.2 & 0.11 & 0.13 & 0.37 & 253 & 0.28 & 140 & 140 & 1.20 & 4.05 & 3.81 & 12.8 & 24.2 & 11.2 & 11.5 & 7.69 & 0 & 0 & 1.40 & 270 & 0 & 6.69 \\
\hline $14-01$ & 22 & 127 & 0.17 & 0.67 & 15.6 & 0.11 & 0.08 & 0.39 & 86 & 0.27 & 138 & 152 & 0.93 & 4.12 & 3.96 & 16.7 & 32.1 & 12.8 & 12.4 & 7.55 & 2.65 & 0 & 8.94 & 450 & 0.32 & 12.8 \\
\hline $14-01$ & 22.2 & 127.2 & 0.22 & 1.15 & 12.3 & 0.12 & 0 & 0.46 & 156 & 0.33 & 172 & 201 & 1.39 & 7.07 & 9.28 & 30.8 & 51.5 & 26.4 & 20.5 & 8.24 & 4.44 & 0.72 & 23.6 & 703 & 1.79 & 21.0 \\
\hline $14-01$ & 22.4 & 127.4 & 0.24 & 1.36 & 9.76 & 0.11 & 0 & 0.57 & 344 & 0.47 & 245 & 228 & 2.10 & 10.7 & 18.09 & 51.3 & 86.6 & 39.9 & 26.4 & 8.91 & 9.11 & 10.4 & 36.2 & 1008 & 3.26 & 24.1 \\
\hline $14-01$ & 22.6 & 127.6 & 0.23 & 1.27 & 10.0 & 0.09 & 0.03 & 0.70 & 237 & 0.49 & 252 & 245 & 1.47 & 11.1 & 21.2 & 60.6 & 124.4 & 46.3 & 30.3 & 9.25 & 13.8 & 41.5 & 29.6 & 929 & 3.58 & 23.2 \\
\hline $14-01$ & 22.8 & 127.8 & 0.22 & 1.27 & 10.1 & 0.07 & 0.07 & 0.77 & 685 & 0.49 & 254 & 214 & 0.72 & 11.3 & 24.6 & 57.2 & 141.2 & 44.1 & 30.4 & 9.54 & 14.8 & 51.2 & 28.1 & 1020 & 3.38 & 23.6 \\
\hline $14-01$ & 23 & 128 & 0.21 & 1.05 & 10.6 & 0.06 & 0.06 & 0.75 & 702 & 0.47 & 243 & 195 & 0.00 & 10.4 & 23.2 & 61.5 & 136.3 & 42.8 & 27.9 & 8.78 & 14.1 & 58.0 & 29.9 & 973 & 4.41 & 22.9 \\
\hline $14-01$ & 23.2 & 128.2 & 0.21 & 1.15 & 10.5 & 0.05 & 0.03 & 0.73 & 137 & 0.49 & 239 & 274 & 1.31 & 10.7 & 20.4 & 62.0 & 130.3 & 46.6 & 31.0 & 9.38 & 15.3 & 56.3 & 31.5 & 973 & 3.35 & 23.6 \\
\hline $14-01$ & 23.4 & 128.4 & 0.18 & 0.69 & 11.5 & 0.03 & 0.03 & 0.71 & 430 & 0.46 & 226 & 254 & 2.42 & 10.6 & 18.4 & 52.1 & 102.2 & 48.3 & 30.8 & 9.45 & 13.2 & 57.5 & 26.8 & 780 & 3.53 & 20.4 \\
\hline $14-01$ & 23.6 & 128.6 & 0.20 & 1.00 & 10.22 & 0.04 & 0.02 & 0.71 & 140 & 0.43 & 213 & 210 & 2.47 & 9.63 & 19.0 & 39.2 & 76.4 & 42.2 & 30.5 & 9.53 & 13.3 & 57.3 & 17.6 & 520 & 3.49 & 17.2 \\
\hline $14-01$ & 23.8 & 128.8 & 0.23 & 1.39 & 9.02 & 0.05 & 0.01 & 0.72 & 0 & 0.42 & 212 & 192 & 2.50 & 8.78 & 13.7 & 45.0 & 61.9 & 41.2 & 27.0 & 9.38 & 11.1 & 49.4 & 17.4 & 425 & 3.79 & 13.1 \\
\hline $14-01$ & 24 & 129 & 0.29 & 1.97 & 6.67 & 0.07 & 0 & 0.72 & 0 & 0.38 & 194 & 180 & 1.98 & 7.14 & 9.6 & 41.0 & 59.6 & 36.6 & 25.4 & 8.60 & 10.9 & 46.9 & 14.0 & 397 & 2.40 & 11.8 \\
\hline $14-02$ & 0 & 137 & 0.54 & 4.82 & 0.00 & 0.18 & 0 & 0.05 & 0 & 0.29 & 147 & 193 & 1.35 & 8.41 & 30.8 & 239 & 101.2 & 29.8 & 24.6 & 11.9 & 11.5 & 8.48 & 15.0 & 500 & 2.61 & 19.7 \\
\hline $14-02$ & 0.2 & 137.2 & 0.62 & 4.40 & 0.11 & 0.18 & 0 & 0.13 & 85.3 & 0.43 & 215 & 225 & 0.60 & 6.75 & 20.7 & 157 & 82.2 & 48.1 & 32.0 & 11.2 & 12.0 & 10.0 & 15.0 & 892 & 3.57 & 25.1 \\
\hline $14-02$ & 0.4 & 137.4 & 0.57 & 3.39 & 2.76 & 0.16 & 0 & 0.30 & 291 & 0.47 & 235 & 240 & 1.27 & 8.06 & 19.5 & 101 & 79.1 & 50.2 & 30.6 & 10.2 & 15.5 & 8.55 & 18.4 & 888 & 3.96 & 22.9 \\
\hline $14-02$ & 0.6 & 137.6 & 0.46 & 2.10 & 6.18 & 0.15 & 0 & 0.52 & 49 & 0.47 & 240 & 241 & 1.53 & 8.41 & 18.0 & 63.2 & 72.2 & 62.5 & 37.5 & 9.71 & 15.4 & 8.17 & 23.8 & 726 & 3.81 & 22.2 \\
\hline $14-02$ & 0.8 & 137.8 & 0.31 & 1.48 & 8.23 & 0.15 & 0.01 & 0.65 & 316 & 0.49 & 253 & 238 & 2.05 & 9.49 & 18.4 & 55.9 & 74.4 & 58.1 & 35.2 & 8.80 & 18.3 & 7.77 & 23.6 & 784 & 4.66 & 22.4 \\
\hline $14-02$ & 1 & 138 & 0.25 & 1.04 & 9.87 & 0.14 & 0.03 & 0.72 & 0 & 0.52 & 272 & 241 & 1.86 & 9.70 & 22.4 & 47.7 & 79.4 & 68.3 & 38.5 & 9.81 & 18.0 & 10.2 & 26.8 & 945 & 3.36 & 23.8 \\
\hline $14-02$ & 1.2 & 138.2 & 0.20 & 0.79 & 11.1 & 0.14 & 0.04 & 0.81 & 0 & 0.52 & 273 & 242 & 2.23 & 10.8 & 24.9 & 50.4 & 75.8 & 63.8 & 35.9 & 9.31 & 16.4 & 9.95 & 25.5 & 1354 & 3.37 & 21.9 \\
\hline $14-02$ & 1.4 & 138.4 & 0.17 & 0 & 0 & 0 & 0 & 0 & 220 & 0.51 & 256 & 256 & 2.26 & 10.2 & 19.5 & 47.6 & 75.3 & 59.2 & 35.9 & 9.10 & 20.1 & 12.6 & 27.9 & 1573 & 4.44 & 14.2 \\
\hline $14-02$ & 1.6 & 138.6 & 0 & 0.73 & 12.5 & 0.13 & 0.05 & 1.05 & 555 & 0.50 & 259 & 242 & 2.50 & 10.4 & 17.7 & 43.5 & 62.6 & 57.1 & 35.0 & 9.26 & 15.2 & 10.4 & 24.2 & 1557 & 3.39 & 15.7 \\
\hline $14-02$ & 1.8 & 138.8 & 0.17 & 0.57 & 13.6 & 0.12 & 0.05 & 1.26 & 341 & 0.45 & 231 & 226 & 2.25 & 9.79 & 17.2 & 36.0 & 63.2 & 48.0 & 31.1 & 8.77 & 14.0 & 13.9 & 22.1 & 1177 & 3.51 & 24.1 \\
\hline $14-02$ & 2 & 139 & 0.17 & 0.63 & 15.0 & 0.13 & 0.06 & 1.41 & 702 & 0.41 & 210 & 211 & 2.21 & 9.36 & 15.4 & 29.5 & 53.8 & 46.6 & 29.7 & 8.56 & 14.4 & 11.6 & 20.4 & 1088 & 3.44 & 23.6 \\
\hline $14-02$ & 2.2 & 139.2 & 0.17 & 0.48 & 16.2 & 0.12 & 0.08 & 1.48 & 963 & 0.46 & 235 & 221 & 2.21 & 9.19 & 14.3 & 34.3 & 60.8 & 48.3 & 30.7 & 9.61 & 16.2 & 12.8 & 23.1 & 1411 & 3.52 & 0 \\
\hline $14-02$ & 2.4 & 139.4 & 0.15 & 0.45 & 15.9 & 0.12 & 0.10 & 1.39 & 181 & 0.51 & 263 & 238 & 2.75 & 11.0 & 19.8 & 46.0 & 71.0 & 56.3 & 34.0 & 9.35 & 16.8 & 14.1 & 27.3 & 1807 & 3.73 & 6.47 \\
\hline $14-02$ & 2.6 & 139.6 & 0.13 & 0.29 & 15.8 & 0.12 & 0.09 & 1.24 & 174 & 0.54 & 261 & 263 & 2.75 & 11.0 & 20.1 & 46.2 & 72.9 & 62.7 & 37.9 & 9.68 & 20.0 & 12.0 & 28.2 & 2005 & 3.84 & 0 \\
\hline $14-02$ & 2.8 & 139.8 & 0.13 & 0.27 & 14.8 & 0.12 & 0.08 & 1.22 & 423 & 0.53 & 270 & 247 & 2.64 & 10.4 & 18.5 & 44.6 & 69.6 & 61.3 & 34.8 & 9.56 & 16.4 & 12.5 & 27.0 & 1794 & 3.60 & 7.26 \\
\hline $14-02$ & 3 & 140 & 0.13 & 0.34 & 13.8 & 0.13 & 0.07 & 1.21 & 465 & 0.51 & 247 & 239 & 3.00 & 10.7 & 16.9 & 36.9 & 69.0 & 55.4 & 33.3 & 9.10 & 14.4 & 12.8 & 27.8 & 1686 & 3.83 & 11.3 \\
\hline $14-02$ & 3.2 & 140.2 & 0.14 & 0.46 & 13.1 & 0.13 & 0.05 & 1.11 & 422 & 0.52 & 266 & 234 & 3.17 & 11.6 & 20.6 & 42.6 & 71.1 & 57.6 & 34.5 & 9.23 & 15.3 & 13.4 & 28.1 & 1578 & 4.05 & 14.3 \\
\hline $14-02$ & 3.4 & 140.4 & 0.15 & 0.39 & 13.0 & 0.13 & 0.05 & 1.02 & 517 & 0.54 & 277 & 250 & 3.27 & 11.9 & 20.3 & 46.3 & 76.4 & 61.8 & 36.0 & 8.97 & 16.5 & 10.3 & 27.8 & 1547 & 3.96 & 15.6 \\
\hline $14-02$ & 3.6 & 140.6 & 0.15 & 0.63 & 12.7 & 0.12 & 0.05 & 0.98 & 452 & 0.56 & 289 & 250 & 3.42 & 11.9 & 17.9 & 48.4 & 74.8 & 61.5 & 36.5 & 9.69 & 17.0 & 10.8 & 26.0 & 1628 & 3.99 & 13.2 \\
\hline $14-02$ & 3.8 & 140.8 & 0.16 & 0.76 & 12.6 & 0.13 & 0.04 & 0.97 & 442 & 0.53 & 279 & 230 & 2.76 & 10.4 & 17.9 & 48.6 & 69.4 & 58.4 & 33.8 & 9.38 & 15.9 & 9.76 & 25.4 & 1628 & 2.94 & 14.5 \\
\hline $14-02$ & 4 & 141 & 0.17 & 0.63 & 12.5 & 0.13 & 0.04 & 1.04 & 427 & 0.51 & 267 & 217 & 2.84 & 10.4 & 18.3 & 45.8 & 64.0 & 52.3 & 33.1 & 9.50 & 15.2 & 8.63 & 24.7 & 1619 & 3.01 & 14.4 \\
\hline
\end{tabular}

Zero values are below detection limit 


\begin{tabular}{|c|c|c|c|c|c|c|c|c|c|c|c|c|c|c|c|c|c|c|c|c|c|c|c|c|c|c|}
\hline ๖ัँ & 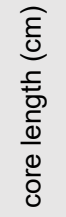 & 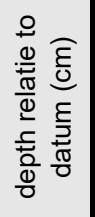 & $\frac{\widehat{0}}{\frac{0}{3}}$ & $\frac{\widehat{o}}{\frac{o}{3}}$ & $\frac{\widehat{o}}{\frac{o}{3}}$ & $\frac{\widehat{o}}{\frac{0}{3}}$ & $\frac{\widehat{o}}{\stackrel{0}{3}}$ & 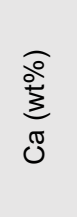 & $\begin{array}{l}\widehat{\hat{\varepsilon}} \\
\text { 을 } \\
\tilde{D}\end{array}$ & 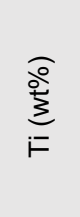 & $\begin{array}{l}\widehat{\bar{\varepsilon}} \\
\stackrel{0}{\varrho} \\
\bar{u}\end{array}$ & $\begin{array}{l}\widehat{\varepsilon} \\
\hat{\bar{o}} \\
\stackrel{c}{\Sigma}\end{array}$ & 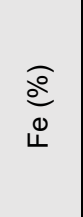 & $\begin{array}{l}\widehat{\hat{\varepsilon}} \\
\text { 을 } \\
\text { ᄋ }\end{array}$ & $\begin{array}{l}\widehat{\bar{\varepsilon}} \\
\stackrel{\overline{0}}{\bar{z}}\end{array}$ & $\begin{array}{l}\widehat{\hat{\varepsilon}} \\
\stackrel{0}{0} \\
\text { J }\end{array}$ & $\begin{array}{l}\widehat{\underline{\varepsilon}} \\
\text { 을 } \\
\text { N }\end{array}$ & $\begin{array}{l}\widehat{\varepsilon} \\
\frac{0}{0} \\
\stackrel{o}{<}\end{array}$ & $\begin{array}{l}\widehat{\hat{\varepsilon}} \\
\text { 응 } \\
\stackrel{0}{0}\end{array}$ & $\begin{array}{l}\widehat{\varepsilon} \\
\text { 을 } \\
\infty \\
\infty\end{array}$ & 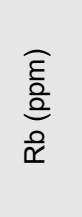 & $\begin{array}{l}\widehat{\bar{\varepsilon}} \\
\overline{\text { a }} \\
\overline{\dot{\omega}}\end{array}$ & $\begin{array}{l}\widehat{\varepsilon} \\
\text { 을 } \\
\succ\end{array}$ & $\begin{array}{l}\widehat{\varepsilon} \\
\stackrel{0}{\varrho} \\
\grave{N}\end{array}$ & $\begin{array}{l}\widehat{\hat{\varepsilon}} \\
\text { 을 } \\
\text { 을 }\end{array}$ & $\begin{array}{l}\widehat{\hat{\varepsilon}} \\
\frac{0}{0} \\
\stackrel{0}{\Sigma}\end{array}$ \\
\hline $14-02$ & 4.2 & 141.2 & 0.18 & 0.57 & 12.9 & 0.12 & 0.05 & 1.04 & 1061 & 0.46 & 233 & 212 & 2.75 & 10.1 & 17.7 & 36.9 & 62.9 & 50.9 & 31.9 & 9.00 & 13.3 & 8.61 & 23.0 & 1349 & 3.82 & 20.2 \\
\hline $14-02$ & 4.4 & 141.4 & 0.17 & 0.58 & 12.8 & 0.12 & 0.04 & 0.98 & 503 & 0.43 & 0 & 206 & 2.40 & 9.24 & 16.0 & 31.1 & 62.8 & 43.2 & 29.8 & 8.68 & 11.7 & 9.56 & 20.9 & 1019 & 2.52 & 23.2 \\
\hline $14-02$ & 4.6 & 141.6 & 0.17 & 0.80 & 12.1 & 0.13 & 0.04 & 0.76 & 513 & 0.41 & 211 & 203 & 2.39 & 9.23 & 15.7 & 30.8 & 66.7 & 43.0 & 27.5 & 8.46 & 10.5 & 6.66 & 22.7 & 706 & 3.00 & 19.2 \\
\hline $14-02$ & 4.8 & 141.8 & 0.19 & 0.79 & 11.7 & 0.12 & 0.02 & 0.62 & 0 & 0.40 & 203 & 196 & 2.00 & 8.46 & 14.6 & 28.5 & 83.7 & 38.5 & 26.2 & 8.77 & 9.76 & 4.10 & 23.0 & 566 & 2.71 & 16.7 \\
\hline $14-03$ & 0 & 169 & 0.49 & 3.78 & 1.25 & 1.25 & 0 & 0.26 & 877 & 0.39 & 193 & 210 & 1.06 & 6.80 & 16.7 & 85.7 & 63.3 & 41.1 & 31.6 & 10.28 & 11.3 & 4.29 & 18.4 & 912 & 3.17 & 24.2 \\
\hline $14-03$ & 0.2 & 169.2 & 0.46 & 3.49 & 2.24 & 2.24 & 0 & 0.35 & 853 & 0.40 & 202 & 207 & 1.13 & 7.03 & 17.0 & 70.5 & 58.1 & 37.4 & 28.3 & 9.67 & 14.3 & 4.63 & 19.5 & 701 & 4.30 & 24.5 \\
\hline $14-03$ & 0.4 & 169.4 & 0.34 & 2.45 & 6.46 & 6.46 & 0 & 0.75 & 625 & 0.50 & 262 & 221 & 1.01 & 7.02 & 15.9 & 53.4 & 62.9 & 49.2 & 33.1 & 9.51 & 14.5 & 8.85 & 22.0 & 767 & 4.52 & 24.9 \\
\hline $14-03$ & 0.6 & 169.6 & 0.23 & 1.22 & 10.9 & 10.9 & 0.04 & 1.08 & 42.7 & 0.55 & 282 & 258 & 0.84 & 6.94 & 16.7 & 54.4 & 64.1 & 54.3 & 35.5 & 9.40 & 16.5 & 16.3 & 22.0 & 971 & 4.20 & 24.5 \\
\hline $14-03$ & 0.8 & 169.8 & 0.16 & 0.48 & 13.3 & 13.3 & 0.07 & 1.15 & 32.1 & 0.59 & 302 & 277 & 0.81 & 7.31 & 19.6 & 46.2 & 77.7 & 62.3 & 38.3 & 9.76 & 16.2 & 16.7 & 25.3 & 1364 & 3.62 & 19.9 \\
\hline $14-03$ & 1 & 170 & 0.13 & 0.31 & 14.0 & 14.0 & 0.08 & 1.10 & 259 & 0.63 & 320 & 311 & 1.06 & 8.39 & 22.7 & 57.3 & 84.3 & 69.6 & 40.6 & 10.54 & 18.4 & 18.3 & 28.5 & 1837 & 4.45 & 3.84 \\
\hline $14-03$ & 1.2 & 170.2 & 0.14 & 0.42 & 13.5 & 13.5 & 0.06 & 1.02 & 109 & 0.62 & 283 & 324 & 1.13 & 8.81 & 24.4 & 58.6 & 87.5 & 78.5 & 43.7 & 10.24 & 20.8 & 16.0 & 31.0 & 2247 & 5.06 & 0.00 \\
\hline $14-03$ & 1.4 & 170.4 & 0.15 & 0.41 & 14.0 & 14.0 & 0.07 & 1.19 & 296 & 0.58 & 287 & 290 & 0.93 & 8.07 & 22.5 & 57.2 & 82.0 & 70.0 & 39.9 & 10.20 & 22.0 & 14.1 & 29.4 & 2156 & 5.22 & 0.00 \\
\hline $14-03$ & 1.6 & 170.6 & 0.16 & 0.55 & 14.8 & 14.8 & 0.08 & 1.32 & 0 & 0.51 & 262 & 246 & 1.18 & 8.08 & 20.5 & 48.2 & 72.6 & 61.5 & 37.0 & 9.64 & 19.0 & 17.8 & 28.2 & 1811 & 3.91 & 5.89 \\
\hline $14-03$ & 1.8 & 170.8 & 0.17 & 0.67 & 14.9 & 14.9 & 0.08 & 1.22 & 234 & 0.46 & 239 & 219 & 1.22 & 7.42 & 16.5 & 38.2 & 63.4 & 55.7 & 35.2 & 9.68 & 15.4 & 15.5 & 25.0 & 1285 & 4.35 & 20.8 \\
\hline $14-03$ & 2 & 171 & 0.16 & 0.55 & 14.8 & 14.8 & 0.05 & 0.90 & 0.0 & 0.43 & 219 & 203 & 1.08 & 6.60 & 13.8 & 37.6 & 56.3 & 49.7 & 33.6 & 9.10 & 14.7 & 13.4 & 19.3 & 900 & 4.44 & 21.7 \\
\hline $14-03$ & 2.2 & 171.2 & 0.20 & 0.82 & 12.3 & 12.3 & 0.02 & 0.58 & 2.3 & 0.43 & 221 & 224 & 0.92 & 7.40 & 15.7 & 37.4 & 58.5 & 44.9 & 30.2 & 8.52 & 15.6 & 11.9 & 17.8 & 761 & 3.02 & 20.5 \\
\hline $14-03$ & 2.4 & 171.4 & 0.17 & 0.52 & 12.8 & 12.8 & 0.03 & 0.52 & 222 & 0.44 & 228 & 237 & 0.35 & 6.74 & 15.3 & 38.2 & 62.5 & 46.6 & 29.8 & 9.04 & 14.9 & 9.59 & 20.5 & 848 & 3.91 & 22.9 \\
\hline $14-03$ & 2.6 & 171.6 & 0.17 & 0.69 & 12.4 & 12.4 & 0.04 & 0.54 & 426 & 0.45 & 231 & 239 & 0.68 & 7.40 & 16.7 & 48.1 & 79.3 & 46.1 & 30.5 & 9.18 & 13.7 & 11.8 & 22.3 & 881 & 4.22 & 22.0 \\
\hline $14-03$ & 2.8 & 171.8 & 0.16 & 0.53 & 12.5 & 12.5 & 0.03 & 0.62 & 0.0 & 0.45 & 233 & 238 & 0.31 & 6.71 & 19.2 & 43.0 & 74.5 & 47.7 & 30.5 & 9.19 & 14.0 & 30.1 & 23.2 & 903 & 12 & 22.9 \\
\hline $14-03$ & 3 & 172 & 0.15 & 0.49 & 13.1 & 13.1 & 0.03 & 0.64 & 0.0 & 0.46 & 230 & 238 & 0.73 & 6.81 & 19.1 & 43.1 & 74.4 & 41.7 & 30.3 & 8.83 & 12.0 & 48.1 & 24.4 & 800 & 3.46 & 22.5 \\
\hline $14-03$ & 3.2 & 172.2 & 0.14 & 0.25 & 13.6 & 13.6 & 0.03 & 0.60 & 0.0 & 0.47 & 233 & 232 & 0.64 & 6.14 & 16.5 & 37.3 & 64.5 & 44.5 & 31.0 & 8.88 & 11.5 & 43.9 & 24.4 & 584 & 3.28 & 17.6 \\
\hline $14-03$ & 3.4 & 172.4 & 0.14 & 0.33 & 13.9 & 13.9 & 0.03 & 0.47 & 395.6 & 0.45 & 225 & 221 & 1.50 & 7.23 & 12.6 & 34.0 & 51.7 & 36.9 & 25.9 & 8.60 & 12.7 & 25.1 & 19.1 & 503 & 3.39 & 14.3 \\
\hline $14-03$ & 3.6 & 172.6 & 0.13 & 0.28 & 14.4 & 14.4 & 0.03 & 0.44 & 254.8 & 0.45 & 228 & 219 & 1.45 & 7.13 & 13.0 & 34.4 & 50.4 & 35.7 & 25.4 & 8.83 & 9.05 & 1.95 & 21.0 & 397 & 3.72 & 10.1 \\
\hline $14-03$ & 3.8 & 172.8 & 0.09 & 0.00 & 17.2 & 17.2 & 0.04 & 0.51 & 22.0 & 0.40 & 203 & 189 & 1.44 & 6.94 & 12.3 & 28.4 & 45.2 & 31.7 & 24.5 & 8.26 & 6.84 & 0 & 18.2 & 370 & 2.44 & 11.5 \\
\hline $14-03$ & 4 & 173 & 0.07 & 0.00 & 18.7 & 18.7 & 0.04 & 0.55 & 287 & 0.36 & 176 & 175 & 1.22 & 6.08 & 10.1 & 17.4 & 33.8 & 26.2 & 21.1 & 7.33 & 5.38 & 0 & 14.0 & 268 & 3.07 & 5.49 \\
\hline $14-03$ & 4.2 & 173.2 & 0.07 & 0.00 & 19.4 & 19.4 & 0.02 & 0.54 & 686 & 0.32 & 154 & 174 & 0.95 & 5.73 & 8.21 & 23.1 & 30.9 & 26.5 & 21.0 & 8.02 & 4.77 & 0 & 12.9 & 213 & 2.00 & 3.97 \\
\hline $14-03$ & 4.4 & 173.4 & 0.14 & 0.38 & 17.4 & 17.4 & 0 & 0.46 & 0 & 0.26 & 126 & 167 & 0.05 & 3.92 & 5.01 & 19.3 & 23.3 & 21.5 & 18.9 & 7.27 & 1.60 & 0 & 8.50 & 186 & 0.87 & 2.45 \\
\hline $14-03$ & 4.6 & 173.6 & 0.30 & 1.86 & 11.4 & 11.4 & 0 & 0.30 & 55.7 & 0.22 & 120 & 175 & 0.04 & 4.22 & 4.25 & 22.4 & 20.0 & 20.0 & 16.5 & 8.05 & 1.06 & 0 & 7.74 & 143 & 1.32 & 0.41 \\
\hline $14-03$ & 4.8 & 173.8 & 0.33 & 2.15 & 11.2 & 11.2 & 0 & 0.28 & 0.0 & 0.20 & 110 & 160 & 0.47 & 4.25 & 5.98 & 22.9 & 18.6 & 15.4 & 12.4 & 7.75 & 2.37 & 0 & 4.09 & 92 & 1.74 & 1.31 \\
\hline $14-03$ & 5 & 174 & 0.25 & 1.45 & 13.1 & 13.1 & 0 & 0.37 & 48.9 & 0.22 & 120 & 161 & 0.64 & 4.04 & 2.03 & 20.4 & 18.3 & 18.3 & 17.6 & 8.23 & 4.88 & 0 & 7.86 & 113 & 2.88 & 1.28 \\
\hline $14-03$ & 5.2 & 174.2 & 0.20 & 1.05 & 14.1 & 14.1 & 0 & 0.46 & 411 & 0.31 & 153 & 173 & 0.73 & 4.78 & 5.19 & 24.5 & 30.8 & 25.5 & 19.6 & 7.73 & 5.34 & 0 & 13.7 & 163 & 2.93 & 3.86 \\
\hline $14-03$ & 5.4 & 174.4 & 0.18 & 0.70 & 13.4 & 13.4 & 0 & 0.53 & 56.3 & 0.37 & 186 & 193 & 1.08 & 6.53 & 11.8 & 31.6 & 39.9 & 33.8 & 27.0 & 7.84 & 4.43 & 0 & 15.3 & 255 & 1.81 & 8.61 \\
\hline $14-03$ & 5.6 & 174.6 & 0.21 & 1.17 & 11.6 & 11.6 & 0 & 0.55 & 68.7 & 0.40 & 202 & 206 & 0.80 & 6.62 & 14.8 & 31.9 & 47.0 & 40.6 & 26.9 & 8.61 & 6.11 & 0 & 14.9 & 279 & 3.02 & 7.37 \\
\hline $14-03$ & 5.8 & 174.8 & 0.24 & 1.23 & 12.2 & 12.2 & 0 & 0.53 & 230 & 0.36 & 177 & 186 & 0.99 & 6.22 & 11.2 & 32.2 & 39.6 & 31.3 & 24.7 & 8.10 & 5.12 & 0 & 13.5 & 247 & 1.51 & 4.06 \\
\hline $14-03$ & 6 & 175 & 0.26 & 1.45 & 12.7 & 12.7 & 0 & 0.43 & 43.8 & 0.33 & 166 & 174 & 1.29 & 6.01 & 8.82 & 23.1 & 31.9 & 26.9 & 21.7 & 7.99 & 4.11 & 0 & 12.1 & 229 & 1.94 & 4.99 \\
\hline $14-03$ & 6.2 & 175.2 & 0.25 & 1.34 & 13.0 & 13.0 & 0 & 0.40 & 0 & 0.31 & 157 & 166 & 0.68 & 4.43 & 7.91 & 18.5 & 24.4 & 24.5 & 20.6 & 8.25 & 4.10 & 0 & 11.2 & 222 & 3.00 & 4.44 \\
\hline $14-03$ & 6.4 & 175.4 & 0.26 & 1.55 & 11.3 & 11.3 & 0 & 0.35 & 0 & 0.34 & 175 & 175 & 0.99 & 4.96 & 6.53 & 18.5 & 28.9 & 27.0 & 21.5 & 8.60 & 4.43 & 0 & 11.1 & 235 & 3.03 & 5.84 \\
\hline $14-03$ & 6.6 & 175.6 & 0.26 & 1.64 & 10.3 & 10.3 & 0 & 0.36 & 145 & 0.34 & 175 & 184 & 1.00 & 5.57 & 8.69 & 30.5 & 34.7 & 30.7 & 22.5 & 7.78 & 4.00 & 0 & 14.0 & 245 & 2.09 & 7.86 \\
\hline
\end{tabular}

Zero values are below detection limit 


\begin{tabular}{|c|c|c|c|c|c|c|c|c|c|c|c|c|c|c|c|c|c|c|c|c|c|c|c|c|c|c|}
\hline ֻัँ & 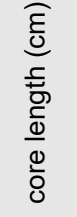 & 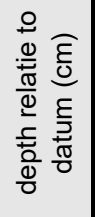 & $\frac{\widehat{\partial}}{\frac{0}{3}}$ & $\frac{\widehat{o}}{\frac{0}{3}}$ & $\frac{\widehat{o}}{\text { के }}$ & $\frac{\widehat{o}}{\substack{0 \\
0}}$ & $\frac{\substack{0 \\
\frac{0}{3}}}{x}$ & 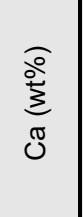 & $\begin{array}{l}\widehat{\varepsilon} \\
\stackrel{\Xi}{0} \\
\mathbb{\infty}\end{array}$ & $\sum_{i=}^{\stackrel{o}{a}}$ & $\begin{array}{l}\widehat{\varepsilon} \\
\stackrel{0}{0} \\
\bar{u}\end{array}$ & $\begin{array}{l}\widehat{\hat{\varepsilon}} \\
\text { है } \\
\hat{\Sigma}\end{array}$ & $\frac{\widehat{\varrho}}{\stackrel{0}{\longleftarrow}}$ & $\begin{array}{l}\widehat{\varepsilon} \\
\text { 을 } \\
\text { ᄋ }\end{array}$ & $\frac{\widehat{\hat{\varepsilon}}}{\stackrel{\bar{o}}{0}}$ & 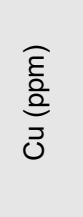 & $\begin{array}{l}\widehat{\hat{\sigma}} \\
\hat{0} \\
\bar{N}\end{array}$ & $\begin{array}{l}\widehat{\hat{\varepsilon}} \\
\frac{0}{2} \\
\frac{0}{<}\end{array}$ & $\begin{array}{l}\widehat{\hat{\varepsilon}} \\
\text { 응 } \\
\stackrel{0}{0}\end{array}$ & $\begin{array}{l}\text { है } \\
\text { 을 } \\
\infty \\
\infty\end{array}$ & 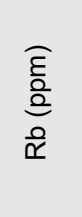 & $\begin{array}{l}\widehat{\hat{\varepsilon}} \\
\overline{0} \\
\bar{c}\end{array}$ & $\begin{array}{l}\widehat{\hat{\varepsilon}} \\
\stackrel{0}{0} \\
\succ\end{array}$ & $\begin{array}{l}\hat{\varepsilon} \\
\stackrel{\circ}{0} \\
\bar{N}\end{array}$ & $\begin{array}{l}\widehat{\varepsilon} \\
\text { 을 } \\
\text { हo }\end{array}$ & $\begin{array}{l}\widehat{\varepsilon} \\
\text { 을 } \\
\stackrel{\circ}{\Sigma}\end{array}$ \\
\hline $14-03$ & 6.8 & 175.8 & 0.27 & 1.66 & 8.55 & 8.55 & 0 & 0.35 & 0 & 0.35 & 181 & 199 & 1.01 & 6.63 & 14.5 & 33.0 & 41.0 & 30.6 & 24.2 & 7.87 & 3.57 & 0 & 15.4 & 223 & 2.12 & 5.42 \\
\hline $14-03$ & 7 & 176 & 0.27 & 1.69 & 8.35 & 8.35 & 0 & 0.36 & 0 & 0.36 & 184 & 197 & 1.11 & 7.08 & 14.4 & 34.3 & 45.3 & 41.5 & 28.6 & 8.15 & 6.34 & 0 & 17.0 & 178 & 2.41 & 3.27 \\
\hline $14-03$ & 7.2 & 176.2 & 0 & 0 & 0 & 0 & 0 & 0 & 232 & 0.38 & 195 & 207 & 1.49 & 8.00 & 15.8 & 33.5 & 55.2 & 40.4 & 26.1 & 8.41 & 6.21 & 0 & 18.8 & 181 & 3.46 & 4.21 \\
\hline $14-03$ & 7.4 & 176.4 & 0.25 & 1.52 & 9.13 & 9.13 & 0 & 0.36 & 0 & 0.37 & 192 & 203 & 1.37 & 7.13 & 12.2 & 36.0 & 49.2 & 40.0 & 28.6 & 8.69 & 8.24 & 0.55 & 19.1 & 207 & 3.20 & 3.86 \\
\hline $14-03$ & 7.6 & 176.6 & 0.26 & 1.55 & 8.83 & 8.83 & 0 & 0.36 & 391 & 0.37 & 192 & 207 & 1.18 & 7.36 & 15.1 & 33.7 & 45.8 & 40.9 & 26.1 & 8.58 & 5.75 & 0 & 16.5 & 196 & 2.01 & 4.43 \\
\hline $14-03$ & 7.8 & 176.8 & 0.24 & 1.41 & 9.44 & 9.44 & 0.01 & 0.40 & 140 & 0.38 & 192 & 200 & 1.03 & 6.95 & 13.4 & 38.5 & 47.0 & 39.5 & 29.2 & 8.39 & 8.42 & 0 & 19.7 & 174 & 3.43 & 1.46 \\
\hline $14-03$ & 8 & 177 & 0.24 & 1.38 & 9.52 & 9.52 & 0 & 0.43 & 0 & 0.40 & 204 & 223 & 1.60 & 8.52 & 16.4 & 35.3 & 52.4 & 41.3 & 29.1 & 8.48 & 8.51 & 0 & 20.5 & 181 & 3.21 & 4.94 \\
\hline $14-03$ & 8.2 & 177.2 & 0.23 & 1.16 & 9.65 & 9.65 & 0.01 & 0.43 & 164 & 0.41 & 207 & 224 & 1.75 & 8.86 & 16.9 & 37.6 & 50.1 & 40.4 & 29.1 & 8.61 & 10.2 & 1.78 & 16.6 & 190 & 2.91 & 4.96 \\
\hline $14-03$ & 8.4 & 177.4 & 0.23 & 1.23 & 9.61 & 9.61 & 0.01 & 0.42 & 267 & 0.42 & 215 & 217 & 2.10 & 9.23 & 16.8 & 39.3 & 51.6 & 44.5 & 28.5 & 8.59 & 9.61 & 4.73 & 19.1 & 191 & 3.64 & 4.79 \\
\hline $14-03$ & 8.6 & 177.6 & 0 & 0 & 0 & 0 & 0 & 0 & 171 & 0.40 & 203 & 201 & 1.61 & 7.71 & 12.5 & 38.0 & 52.0 & 41.5 & 28.2 & 8.46 & 7.40 & 0 & 18.0 & 179 & 2.87 & 4.08 \\
\hline $14-03$ & 8.8 & 177.8 & 0.23 & 1.20 & 9.72 & 9.72 & 0.01 & 0.43 & 0 & 0.39 & 194 & 191 & 1.16 & 6.80 & 13.8 & 31.9 & 43.4 & 40.1 & 26.6 & 8.23 & 6.53 & 0 & 18.5 & 168 & 2.64 & 0.71 \\
\hline $14-03$ & 9 & 178 & 0.23 & 1.36 & 9.96 & 9.96 & 0 & 0.42 & 90 & 0.36 & 175 & 181 & 1.48 & 7.10 & 12.4 & 27.8 & 40.4 & 35.0 & 22.6 & 8.27 & 7.67 & 0 & 14.8 & 175 & 2.14 & 1.56 \\
\hline $14-03$ & 9.2 & 178.2 & 0.24 & 1.38 & 9.88 & 9.88 & 0 & 0.40 & 0 & 0.35 & 173 & 183 & 1.58 & 7.25 & 11.4 & 27.8 & 40.7 & 36.6 & 26.1 & 8.01 & 5.98 & 0 & 13.7 & 211 & 2.40 & 2.44 \\
\hline $14-03$ & 9.4 & 178.4 & 0.25 & 1.45 & 10.0 & 10.0 & 0 & 0.42 & 0 & 0.33 & 168 & 182 & 1.09 & 6.42 & 12.3 & 24.0 & 36.8 & 31.8 & 24.2 & 8.23 & 3.99 & 0 & 16.3 & 261 & 1.83 & 4.87 \\
\hline $14-03$ & 9.6 & 178.6 & 0.25 & 1.43 & 10.1 & 10.1 & 0 & 0.39 & 436 & 0.33 & 168 & 189 & 0.84 & 6.01 & 9.7 & 30.6 & 38.5 & 34.6 & 27.2 & 7.67 & 5.72 & 0 & 13.3 & 245 & 2.22 & 5.54 \\
\hline $14-03$ & 9.8 & 178.8 & 0.27 & 1.61 & 11.0 & 11.0 & 0 & 0.38 & 113 & 0.33 & 161 & 182 & 0.75 & 5.91 & 10.7 & 25.3 & 37.7 & 31.9 & 24.2 & 8.01 & 5.62 & 0 & 12.4 & 256 & 1.63 & 4.78 \\
\hline $14-03$ & 10 & 179 & 0.27 & 1.65 & 12.0 & 12.0 & 0 & 0.39 & 0 & 0.33 & 166 & 184 & 0.71 & 5.76 & 10.2 & 25.3 & 31.1 & 28.6 & 21.8 & 8.12 & 6.19 & 0 & 13.4 & 299 & 2.17 & 10.8 \\
\hline $14-03$ & 10.2 & 179.2 & 0.26 & 1.53 & 14.0 & 14.0 & 0 & 0.48 & 480 & 0.34 & 169 & 180 & 0.88 & 5.70 & 9.29 & 19.3 & 29.8 & 30.5 & 22.4 & 8.09 & 6.11 & 2.34 & 12.5 & 350 & 2.74 & 9.96 \\
\hline $14-03$ & 10.4 & 179.4 & 0.24 & 1.25 & 15.2 & 15.2 & 0.01 & 0.53 & 0 & 0 & 0 & 0 & 0 & 0 & 0 & 0 & 0 & 0 & 0 & 0 & 0 & 0 & 0 & 0 & 0 & 0 \\
\hline $14-03$ & 10.6 & 179.6 & 0.24 & 1.33 & 13.5 & 13.5 & 0.02 & 0.54 & 0 & 0.37 & 190 & 191 & 1.19 & 6.29 & 9.28 & 27.2 & 41.1 & 36.3 & 24.4 & 8.72 & 11.2 & 4.10 & 12.1 & 545 & 2.87 & 19.7 \\
\hline $14-03$ & 10.8 & 179.8 & 0.23 & 1.35 & 12.6 & 12.6 & 0.03 & 0.54 & 383 & 0.39 & 199 & 195 & 0.89 & 5.72 & 8.75 & 25.5 & 41.1 & 37.7 & 26.8 & 8.39 & 11.9 & 4.09 & 12.0 & 551 & 3.29 & 17.0 \\
\hline $14-03$ & 11 & 180 & 0.23 & 1.19 & 12.7 & 12.7 & 0.02 & 0.52 & 351 & 0.36 & 186 & 195 & 0.77 & 5.90 & 11.6 & 28.2 & 38.5 & 35.7 & 24.6 & 9.08 & 11.7 & 5.27 & 11.4 & 549 & 2.86 & 16.7 \\
\hline $14-03$ & 11.2 & 180.2 & 0.24 & 1.38 & 12.8 & 12.8 & 0.01 & 0.53 & 487 & 0.33 & 166 & 179 & 0.86 & 5.36 & 7.66 & 29.9 & 39.3 & 29.8 & 22.2 & 8.69 & 8.53 & 2.79 & 11.9 & 460 & 2.45 & 17.9 \\
\hline $14-03$ & 11.4 & 180.4 & 0.24 & 1.26 & 12.4 & 12.4 & 0.02 & 0.53 & 53.6 & 0.33 & 167 & 173 & 1.20 & 5.83 & 9.52 & 27.7 & 37.6 & 29.9 & 23.1 & 8.81 & 8.56 & 3.65 & $1 \mathrm{E}+12$ & 540 & 2.83 & 16.8 \\
\hline $14-03$ & 11.6 & 180.6 & 0.21 & 1.19 & 11.7 & 11.7 & 0.03 & 0.51 & 0 & 0 & 0 & 0 & 0 & 0 & 0 & 0 & 0 & 0 & 0 & 0 & 0 & 0 & 0 & 0 & 0 & 0 \\
\hline $14-03$ & 11.8 & 180.8 & 0.19 & 0.79 & 11.3 & 11.3 & 0.03 & 0.47 & 0.0 & 0.45 & 232 & 192 & 1.33 & 6.63 & 14.1 & 31.4 & 55.4 & 43.9 & 28.3 & 8.45 & 12.3 & 29.5 & 17.8 & 672 & 4.10 & 20.5 \\
\hline $14-03$ & 12 & 181 & 0.18 & 0.66 & 11.5 & 11.5 & 0.03 & 0.46 & 5.6 & 0.46 & 235 & 201 & 1.14 & 6.44 & 14.1 & 40.8 & 53.7 & 45.1 & 30.2 & 9.44 & 11.7 & 51.3 & 16.8 & 800 & 3.20 & 22.3 \\
\hline $14-03$ & 12.2 & 181.2 & 0.19 & 0.94 & 11.3 & 11.3 & 0.03 & 0.45 & 437 & 0.45 & 233 & 206 & 0.85 & 6.07 & 13.8 & 40.7 & 54.1 & 50.5 & 30.6 & 8.96 & 11.1 & 47.2 & 18.9 & 721 & 2.37 & 20.9 \\
\hline $14-03$ & 12.4 & 181.4 & 0 & 0 & 0 & 0 & 0 & 0 & 163 & 0.45 & 234 & 210 & 1.24 & 7.08 & 15.2 & 34.9 & 53.2 & 45.4 & 30.3 & 8.30 & 12.6 & 33.8 & 16.9 & 690 & 2.50 & 19.6 \\
\hline $14-03$ & 12.6 & 181.6 & 0.15 & 0.35 & 12.9 & 12.9 & 0.04 & 0.47 & 212 & 0.46 & 236 & 202 & 0.89 & 6.24 & 14.4 & 38.1 & 51.8 & 40.8 & 28.3 & 8.65 & 14.0 & 10.1 & 17.4 & 576 & 3.41 & 18.1 \\
\hline $14-03$ & 12.8 & 181.8 & 0.15 & 0.56 & 13.2 & 13.2 & 0.05 & 0.46 & 248 & 0.44 & 226 & 193 & 1.15 & 6.38 & 13.1 & 33.1 & 45.9 & 37.7 & 25.2 & 8.45 & 13.3 & 7.29 & 13.6 & 515 & 2.99 & 16.2 \\
\hline $14-03$ & 13 & 182 & 0.14 & 0.33 & 13.9 & 13.9 & 0.04 & 0.49 & 0 & 0.44 & 222 & 190 & 1.09 & 6.17 & 12.5 & 36.0 & 46.4 & 37.6 & 27.0 & 8.78 & 14.3 & 5.16 & 14.7 & 516 & 3.47 & 14.7 \\
\hline $14-03$ & 13.2 & 182.2 & 0.15 & 0.34 & 13.6 & 13.6 & 0.04 & 0.50 & 392 & 0.43 & 219 & 192 & 1.25 & 6.63 & 13.7 & 31.9 & 48.8 & 39.0 & 26.9 & 8.66 & 11.1 & 6.52 & 15.3 & 527 & 2.79 & 16.5 \\
\hline $14-03$ & 13.4 & 182.4 & 0.20 & 1.05 & 11.3 & 11.3 & 0.00 & 0.47 & 0.0 & 0.44 & 222 & 201 & 1.16 & 6.70 & 13.6 & 38.0 & 55.8 & 44.4 & 30.6 & 9.17 & 11.2 & 8.64 & 15.7 & 585 & 3.38 & 19.4 \\
\hline
\end{tabular}

Zero values are below detection limit 
Appendix IX: All quantified XRF data displayed relative to depth of the collected cores from TAL-16-01.
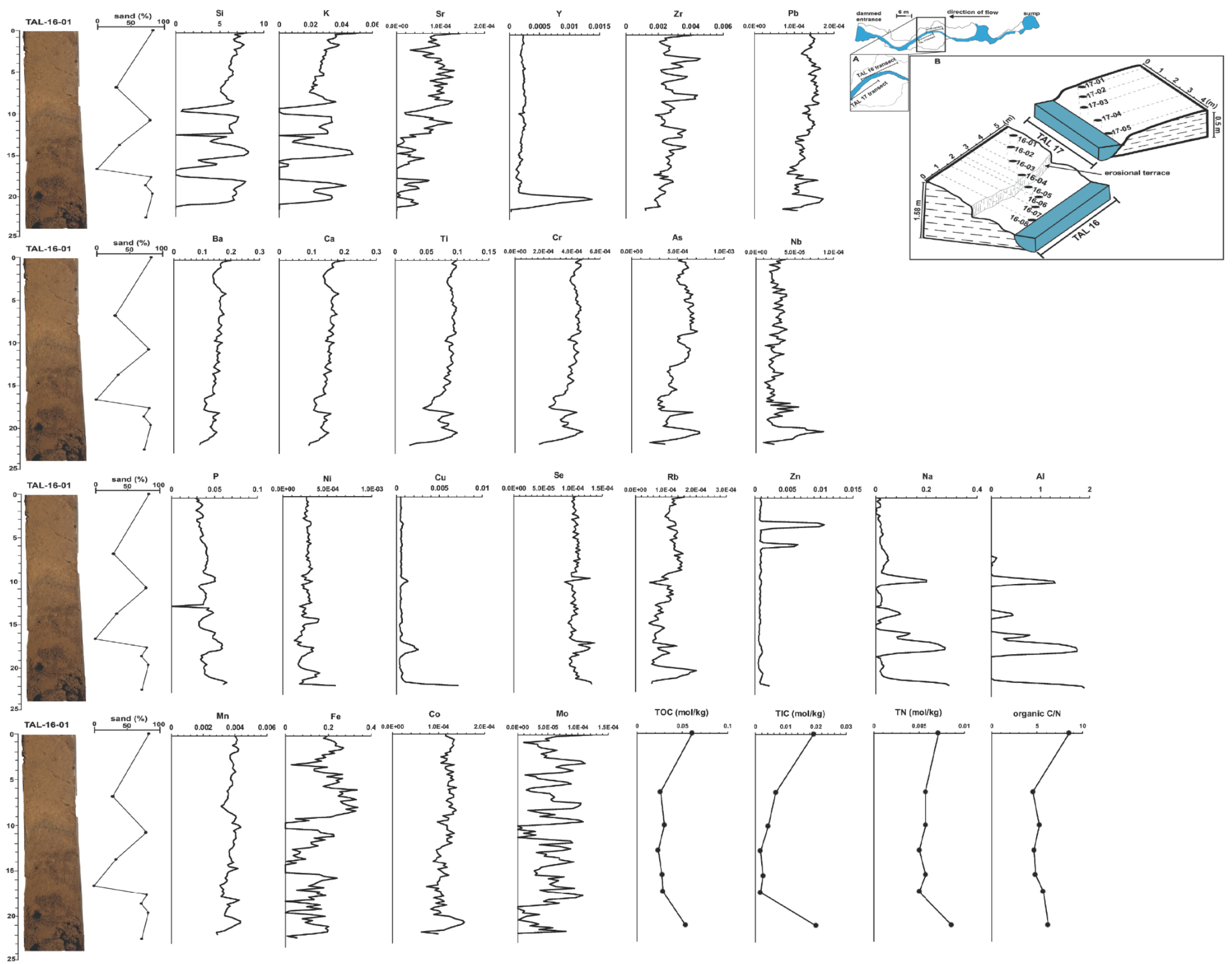
Appendix X: All quantified XRF data displayed relative to depth of the collected cores from TAL-16-02
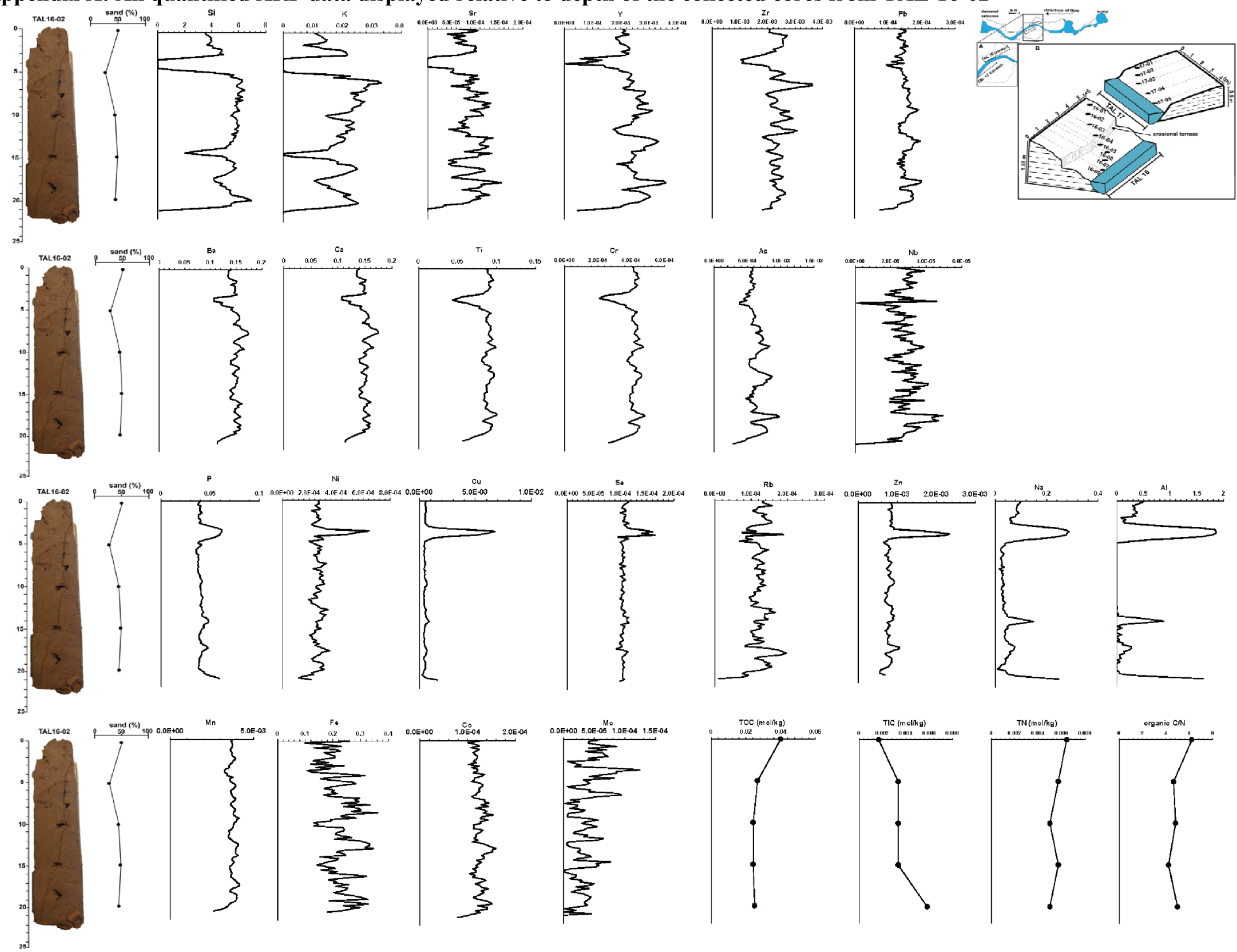
Appendix XI: All quantified XRF data displayed relative to depth of the collected cores from TAL-16-03.

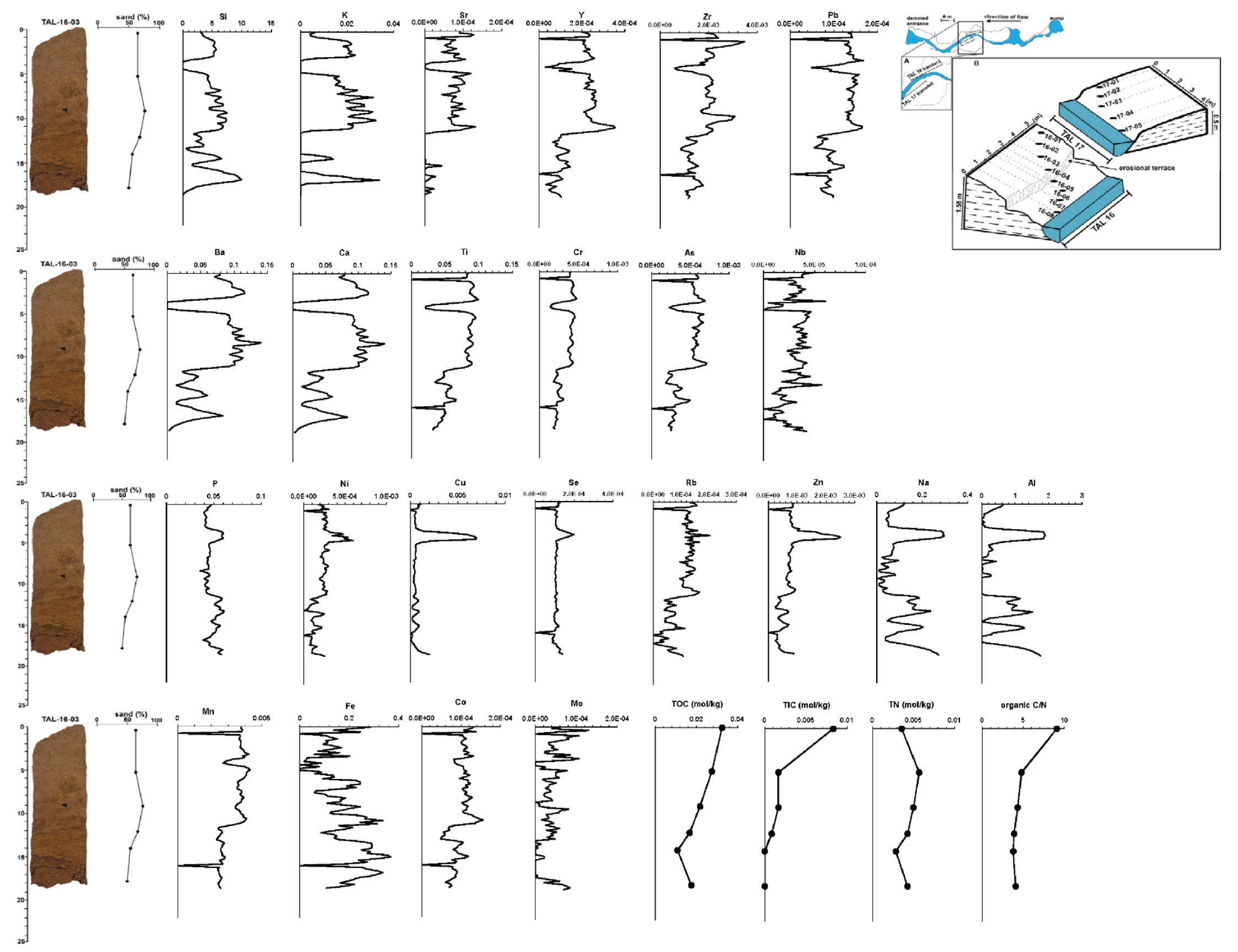


Appendix XII: All quantified XRF data displayed relative to depth of the collected cores from TAL-16-04
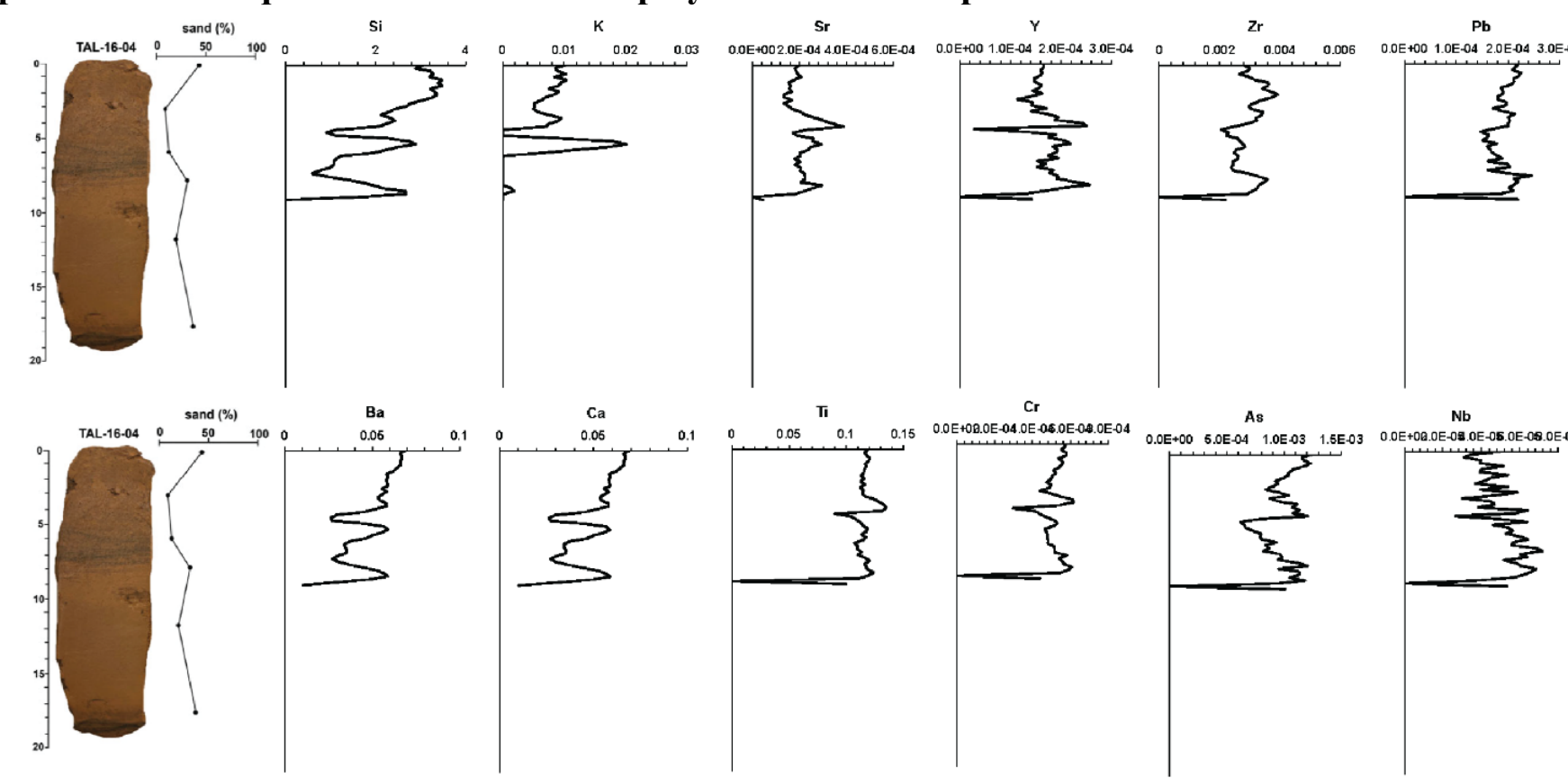

Nb
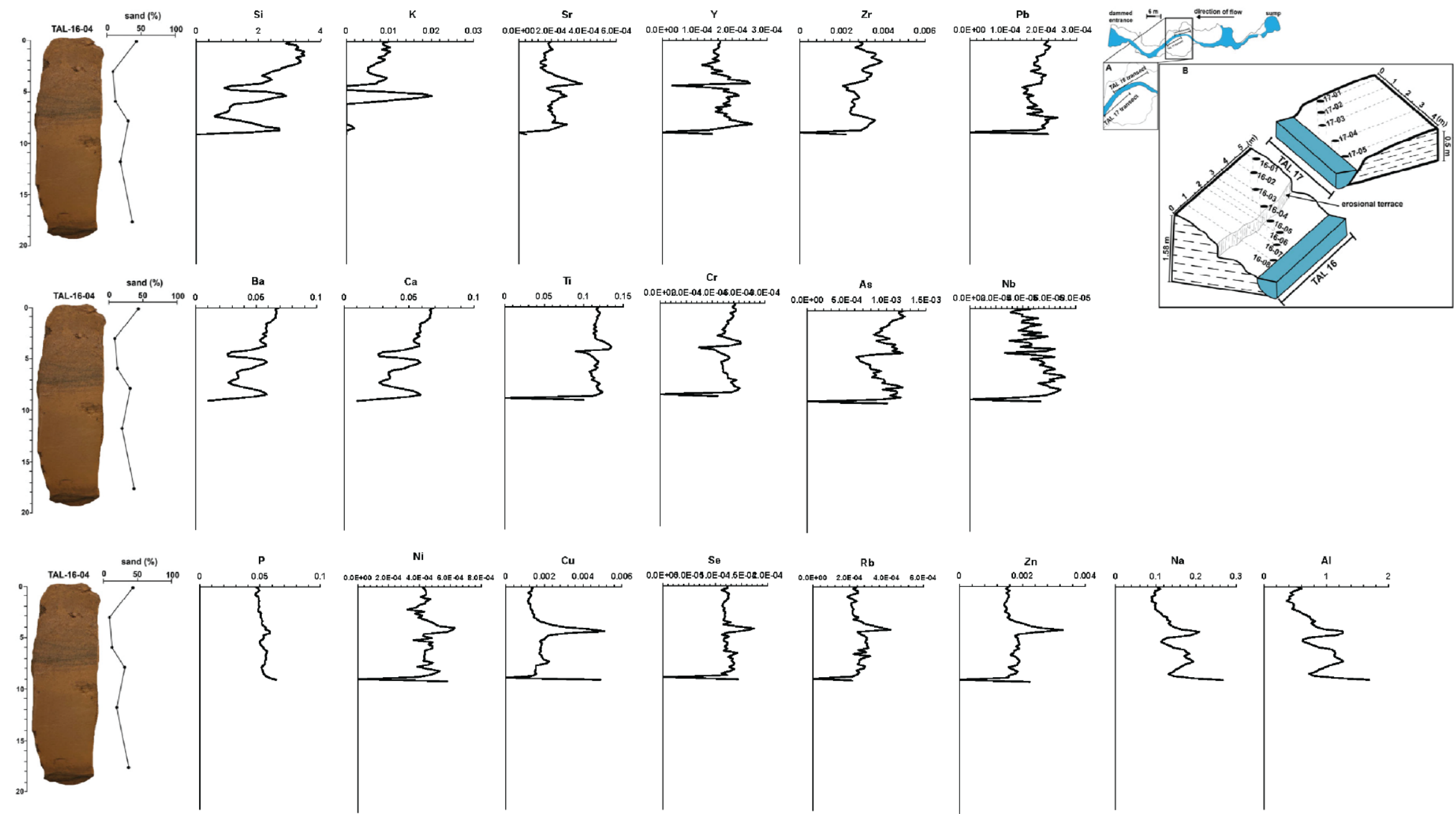

$\mathrm{Rb}$
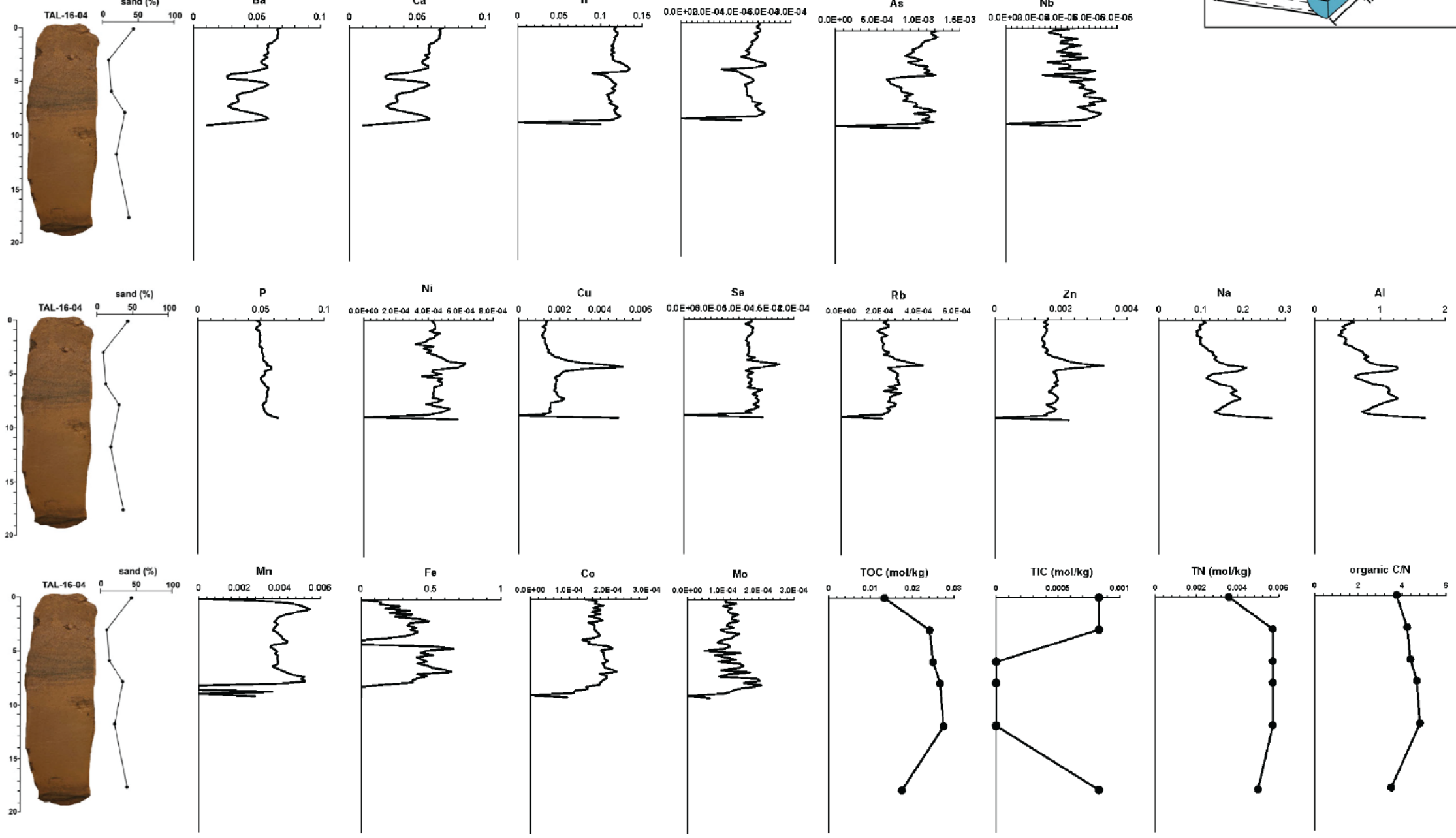


\section{Appendix XIII: README for the GitHub repository dedicated to all coding scripts used for this project}

Repository location: https://github.com/ardowney/Masters thesis

\# Physical and chemical properties of clastic cave sediment from the northern karst region of Puerto Rico

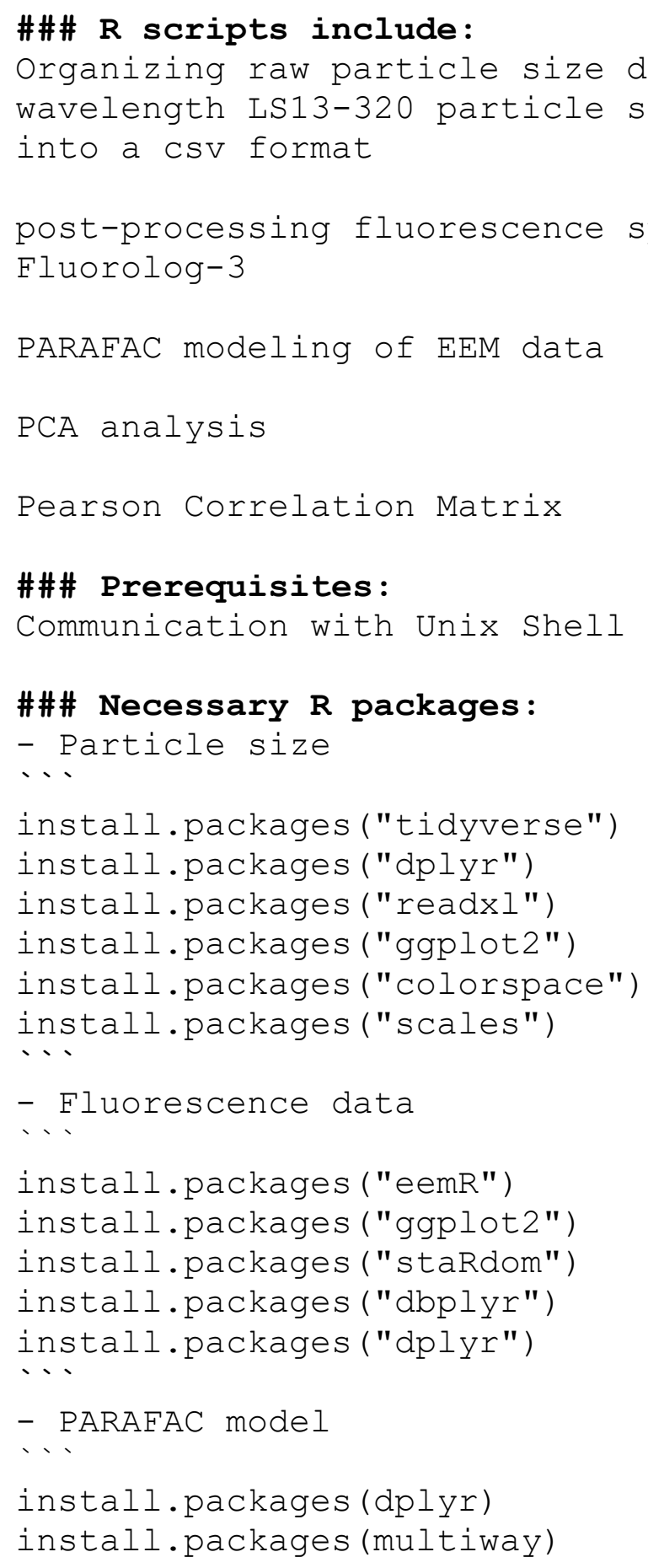




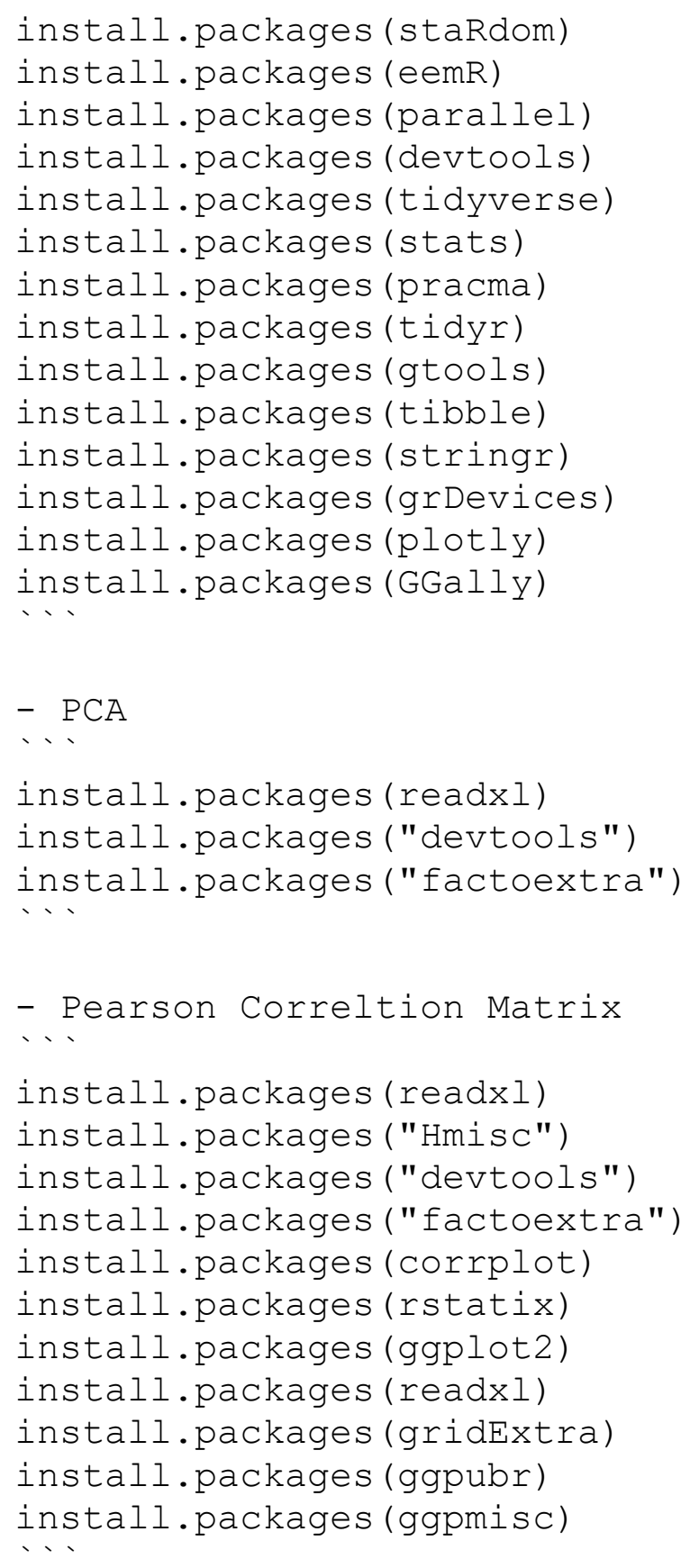

\section{\#\#\# script name and function:}

particle size:

- cut_loop.sh - Unix shell script organizing raw data from the instrument. transforms proprietary file extension to flat text file (.txt) and sends to a new organized directory.

- Particle size.R - Applies particle size bins from the instrument to the organized data created by cut_loop.sh. 
- Averaging_script.R - Takes the average of the three replicates ran for each subsample.

Fluorescence data:

- Scatter code.R - Plots EEM data stored as a CSV. Removes $15 \mathrm{~nm}$ 1st and 2nd order Rayleigh scattering. Smooths the EEM by interpreting intensity through the Rayleigh regions. Sends corrected files to a modified csv file.

- Percent_function.R - Normalizes corrected EEM to the max intensity of each scan.

PARAFAC model:

- Model functions.R - Functions needed to run the PARAFAC model

- PARAFAC_code.R - Script for creating 2-7 component models using user defined EEM data.

PCA :

- PCA.R - Creates PCA output for user defined data. Outputs include biplots, variance plots, eigenvalues, and standard PCA scatter plots.

Pearson Correlation Matrix:

- Cor matrix function.R - Creates correlation matrix with R and $p$ values exported to a csv file. $R$ values and $p$ values plots are included in the code. 